\title{
NORMAL OPERATION (NO) OF APT BLANKET SYSTEM AND ITS COMPONENTS BASED ON INITIAL CONCEPTUAL DESIGN
}

L. Larry Hamm

Si Young Lee

M:Andy Shadday.

Frank G. Smith, III

Westinghoúse Savannah River Company

Savannah River Sité

Äiken, SC 29808

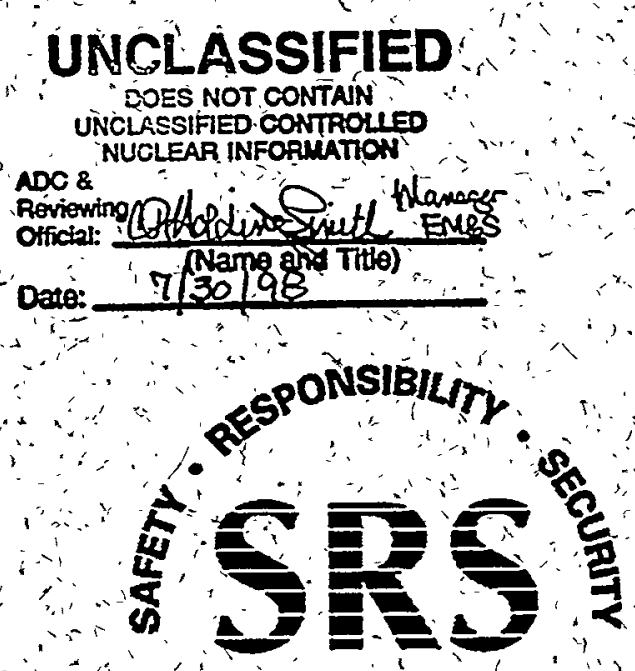

SAVANNAH RIVER SITE 


\section{DISCLAIMER}

This report was prepared as an account of work sponsored by an agency of the United States Government. Neither the United States Government nor any agency thereof, nor any of their employees, makes any warranty, express or implied, or assumes any legal liability or responsibility for the accuracy, completeness, or usefulness of any information, apparatus, product, or process disclosed, or represents that its use would not infringe privately owned rights. Reference herein to any specific commercial product, process, or service by trade name, trademark, manufacturer, or otherwise does not necessarily constitute or imply its endorsement, recommendation, or favoring by the United States Government or any agency thereof. The views and opinions of authors expressed herein do not necessarily state or reflect those of the United States Government or any agency thereof.

This report has been reproduced directly from the best available copy.

Available to DOE and DOE contractors from the Office of Scientific and Technical Information, P.O. Box 62, Oak Ridge, TN 37831; prices available from (615) 576-8401.

Available to the public from the National Technical Information Service, U.S. Department of Commerce; 5285 Port Royal Road, Springfield, VA 22161. 


\section{DISCLAIMER}

Portions of this document may be illegible in electronic image products. Images are produced from the best available original document. 


\section{WSRC-TR-98-0057}

KEYWORDS:

Accelerator Production of Tritium Blanket System

Conceptual Design

TRAC Code

FLOWTRAN-TF Code

System Model

Detailed Bin Model

Safety Analysis

RETENTION - Permanent

\section{NORMAL OPERATION (NO) OF APT BLANKET SYSTEM AND ITS COMPONENTS BASED ON INITIAL CONCEPTUAL DESIGN}

SAVANNAH RIVER TECHNOLOGY CENTER

L. Larry Hamm

Si Young Lee

M. Andy Shadday

Frank G. Smith, III

Publication Date: July, 1998

Westinghouse Savannah River Company

Savannah River Site

Aiken, SC 29808

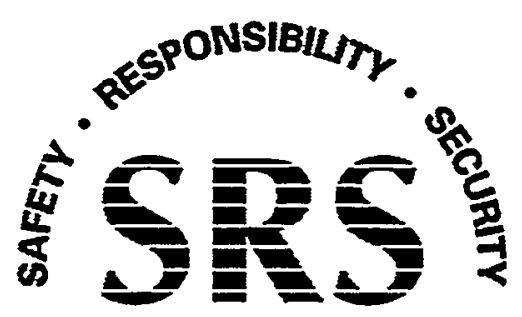

SAVANNAH RIVER SITE

Prepared for the U.S. Department of Energy under Contract No. DE-AC09-96SR18500 
DOCUMENT: WSRC-TR-98-0057

TITLE: NORMAL OPERATION (NO) OF APT BLANKET SYSTEM AND ITS COMPONENTS BASED ON INITIAL CONCEPTUAL DESIGN

\section{APPROVALS}

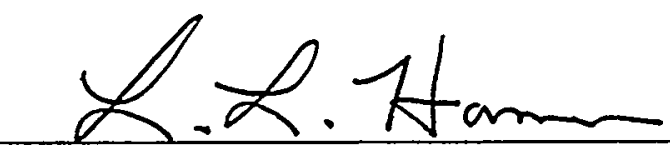

Date: $7-16-98$

L. Larry Hamm, Task Leader (EM\&S Group/SRTC)

Si Young Lee, Co-author (EM

M\&S Group/SRTC)

Date: $7-20-98$

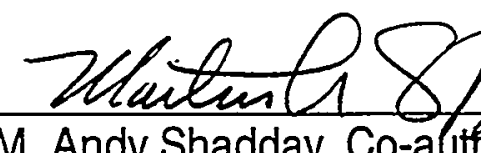

M. Andy Shadday, Co-author (EM\&S Group/SRTC)

Date: $7 / 20 / 98$

Irank $\mathrm{I}$ lmettry

Date: $2 / 20 / 98$

Frank G. Smith, III, Co-author (PC\&C Group/SRTC)
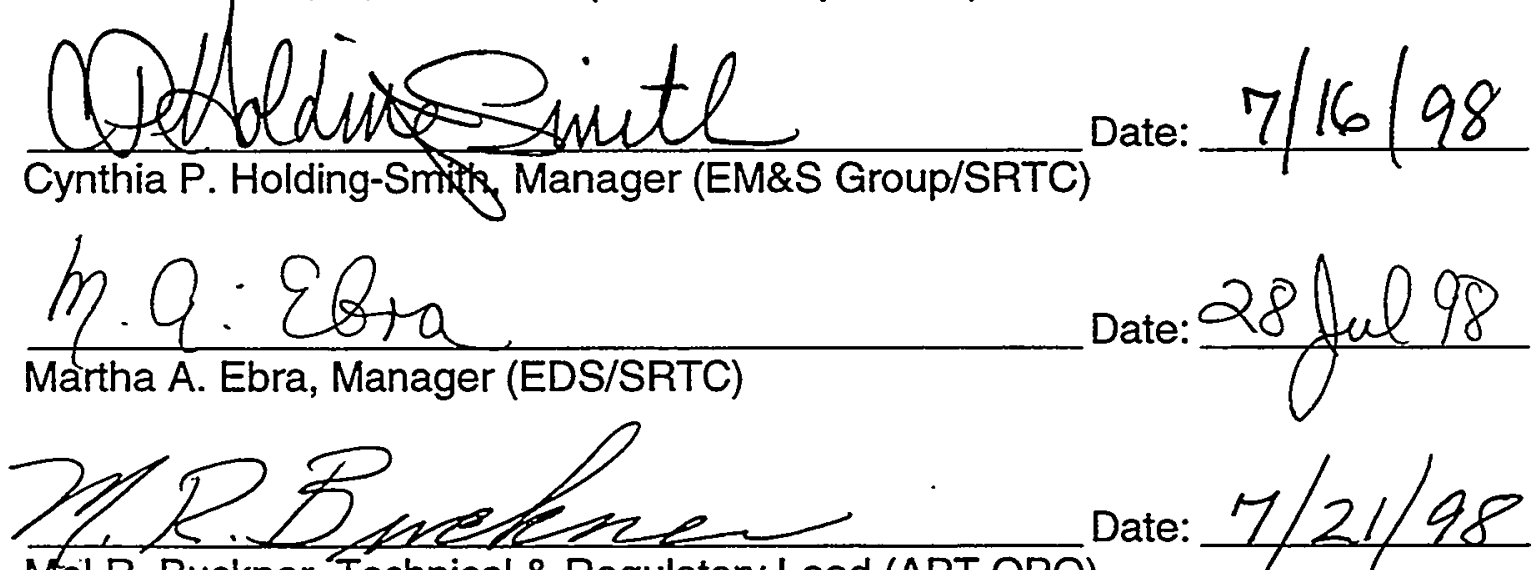

Mel R. Buckner, Technical \& Regulatory Lead (APT OPO)

Date: $7 / 21 / 98$

The internal technical review function is being performed at the APT project level and is coordinated through LANL. 


\section{Table of Contents}

1 Introduction

2 TRAC 1-D System Model $\quad 2$

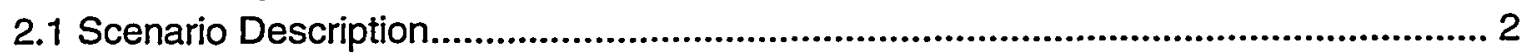

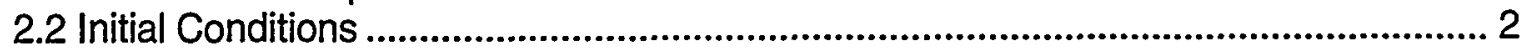

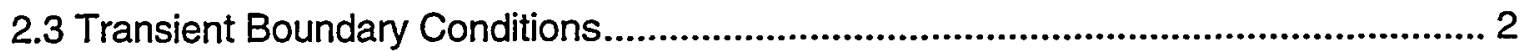

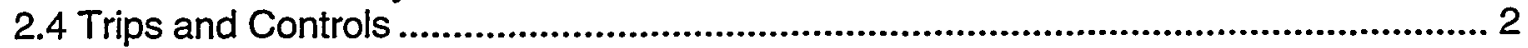

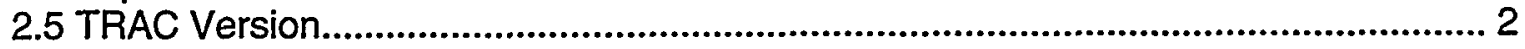

3 TRAC Results $\quad 2$

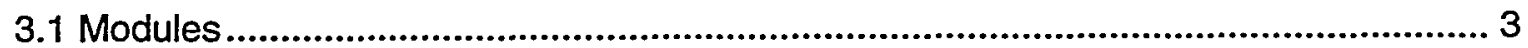

3.2 HR Loop and Pressurizer ......................................................................... 4

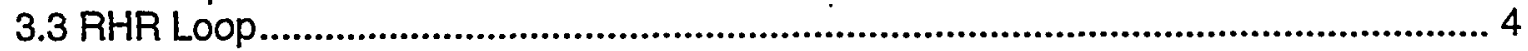

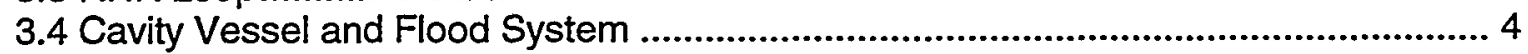

4 FLOWTRAN-TF Detailed Bin Model 5

4.1 Model Upgrades ............................................................................................. 5

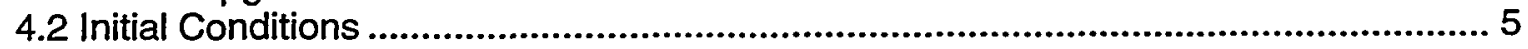

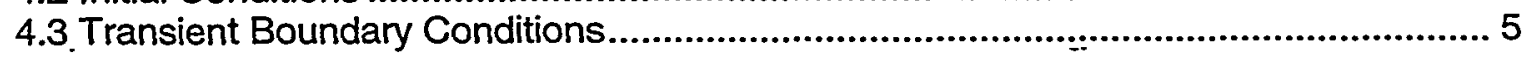

5 FLOWTRAN-TF Bin Model Results $\quad 7$

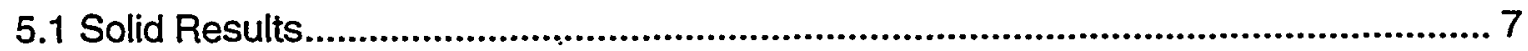

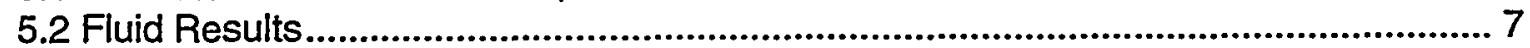

6 Conclusions $\quad 16$

6.1 Comparison to Thermal/Hydraulic Design Criteria ............................................16

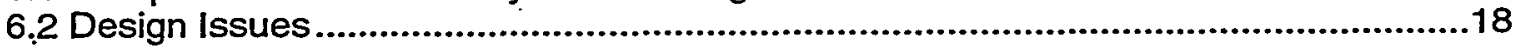

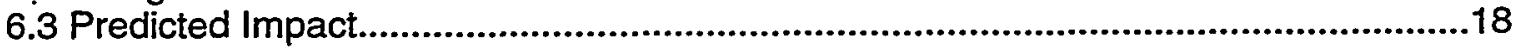

$\begin{array}{lr}7 \text { References } & 20\end{array}$

Appendix A: TRAC Model Component Nomenclature

Appendix B Normal Operation TRAC Results

Appendix C: TRAC Standard Input File for Normal Operation Case

Appendix D: TRAC Graphics Input File for Normal Operation Case

Appendix E: FLOWTRAN-TF Standard Input File for Normal Operation Case 


\section{List of Figures}

Figure 4-1 Finite element mesh of APT reference 1 blanket plate.........................6

Figure 4.1-1 Axial power shape......................................................................... 7

Figure 5.1-1 Normal operating surface temperatures...............................................8

Figure 5.1-2 Normal operating metal temperatures, cut-away view...........................9

Figure 5.2-1 Normal operating temperatures and heat fluxes in channels $1-2 \ldots \ldots . . .10$

Figure 5.2-2 Normal operating temperatures and heat fluxes in channels $3-4 \ldots \ldots . . .11$

Figure 5.2-3 Normal operating temperatures and heat fluxes in channels $5-6 \ldots \ldots . . .12$

Figure 5.2-4 Normal operating temperatures and heat fluxes in channels 7 - 8......... 13

Figure 5.2-5 Normal operating temperatures and heat fluxes in channels $9-10 \ldots \ldots . .14$

Figure 5.2-6 Normal operating temperatures and heat fluxes in channels $11-12 \ldots . .15$

\section{List of Tables}

Table 6.1-1 FLOWTRAN-TF model results under normal operating conditions for comparison to design criteria. ...................................................... 18

Table 6.1-2 TRAC fluid temperature rises across the module flow channels..............18

Table 6.1-3 TRAC peak metal temperatures in the modules..................................... 19

Table 6.1-4 Primary HR pump NPSH conditions under normal operating conditions. 


\section{Introduction}

This report is one of a series of reports documenting accident scenario simulations for the Accelerator Production of Tritium (APT) blanket heat removal systems [1-7]. The simulations were performed in support of the Preliminary Safety Analysis Report (PSAR) for the APT. This report contains the results of steady-state simulations of normal operation of the primary heat removal systems. The results for normal operation documented in this report serve as the initial conditions for the additional accident scenario simulations that are documented in the remaining reports of this series.

The accident simulations were performed, using TRAC to model transient behavior of the heat removal system, and FLOWTRAN-TF, a computer code developed at the Savannah River Technology Center, to model detailed transient behavior in a blanket module.

\section{TRAC 1-D System Model}

The TRAC model of the blanket heat removal systems is described in detail in Ref. [8]. It is an integrated one-dimensional system model that contains all necessary components, systems, and heat structures for simulation of transient system behavior for a wide range of accident conditions.

\subsection{Scenario Description}

To simulate steady-state normal operation conditions, the system model was run with the two primary heat removal system (HR) pumps operating at full speed and with full deposited beam power of $56.5 \mathrm{MW}$. A transient was run for 400 model seconds, during which steady-state conditions were achieved.

\subsection{Initial Conditions}

Reasonable estimates of steady-state values for the flow and state variables were used as initial conditions. The heat structure component initial temperatures were set at 100 C.

\subsection{Transient Boundary Conditions}

Since steady-state conditions were desired, there were no time dependent boundary conditions.

\subsection{Trips and Controls}

The primary HR pumps and check valves, deposited power in the heat structures, and secondary flow through the heat exchangers were enabled at the start of the false transient. The RHR check valve was also enabled, but it was never actuated since an adverse pressure gradient kept the check valve closed. 


\subsection{TRAC Version}

TRAC-PF1/MOD2 Version 5.28 was used for the simulations [14]. Light water properties were used. The TRAC normal operation model input file is listed in Appendix $C$ and the graphics input file is listed in Appendix D. Minor modifications were made to the TRAC source code to assist in the creation of graphical output files. Detailed discussions of the modifications to the TRAC source code are included in Ref. [9].

\section{TRAC Results}

The TRAC system model was run with time independent boundary conditions for a sufficiently long period of time for steady-state conditions to be realized. Key results are presented both graphically and in tabular form. Figures A- 1 through A-6 illustrate the TRAC model component layouts of the several sub-systems associated with the blanket heat removal system. Table A-1 provides a list of the component type, the number of cells in each component, and a brief description of each component in the TRAC model. The figures and the table provided in Appendix $A$ are used to interpret the graphical results. The figures in Appendix $B$ illustrate the transient results of the TRAC run that was used to establish steady-state. The duration of the run was 400 seconds, and this was clearly sufficient to reach steady-state. Table A-2 lists steady-state values for various parameters.

The figures in Appendix $B$ are divided into three groups: results-for the PLENUM components (Figs. B-1a through B-7d); results for the PIPE, VALVE, and PUMP components (Figs. B-8a through B-30e); and results for the HEAT STRUCTURE components (Figs. B-31 through B-49b). The legend for each figure includes the component and cell numbers for the results shown. The component numbers are the same as the TRAC system model component numbers illustrated in the component layout figures presented in Appendix $A$.

\subsection{Modules}

Figure A-1 illustrates the TRAC component layout for the six modules and the associated piping network below the two fixed headers. Figures B-1a through B-1d show the pressures, temperatures, liquid subcooling temperatures, and void fractions for the two PLENUM components 380 and 340 which, respectively, represent the fixed inlet and outlet headers. The inlet header temperature is $49.3 \mathrm{C}$ and pressure is 106.3 psia. The outlet header temperature is $57.9 \mathrm{C}$ and the pressure is $66.0 \mathrm{psia}$. Therefore, the temperature rise is approximately $9 \mathrm{C}$ and the pressure drop is approximately 40 psid in the flow through the modules.

Figures B-2a through B-2d show the pressures, temperatures, liquid subcooling temperatures, and void fractions for the three PLENUM components that represent the entrance (component 370), intermediate (component 350), and discharge (component 370 ) headers for module \#1. There is a 16.4 psid pressure drop between the entrance and discharge headers. There is downflow between the entrance and intermediate headers, and upflow between the intermediate and discharge headers. The hydrostatic pressure difference consequently opposes the irreversible pressure drop between the entrance and intermediate headers, and is additive to the irreversible pressure drop between the intermediate and discharge headers. There is a $10.4 \mathrm{C}$ temperature rise in 
fluid temperature across the module. The liquid is highly subcooled and the void fraction is zero.

Figures $\mathrm{B}-18 \mathrm{a}$ through $\mathrm{B}-18 \mathrm{e}$ show pressures, fluid temperatures, subcooling temperatures, mass flowrates, and void fractions in the first, middle, and last cells of the upflow region of module \#1 (component 300). Most of the temperature rise, $4 \mathrm{C}$ out of $4.5 \mathrm{C}$, occurs in the lower half of the component, and this is consistent with the deposited power axial profile [8] that is skewed towards the bottom of the module. Note that as shown in Fig. B-18d, the mass flowrate in cell \#1 of component 300 is less than that in the other two cells. This is due to a property donor problem in the graphics package for the first pipe cell downstream of a plenum component [8]. This problem is repeated in the mass flowrate plots for the remaining five modules.

Figures B-31 and B-37 show the maximum and surface temperatures of the HEAT STRUCTURE (component 951) associated with the upflow region of module \#1, at the bottom, middle, and top cells. Figure B-43 shows the wall and fluid temperatures at the horizontal mid-plane of the upflow region of the module. The peak metal temperature occurs near the axial mid-point, and is approximately $152 \mathrm{C}$ in module \#1. The related surface and fluid temperatures are $93 \mathrm{C}$ and $59 \mathrm{C}$, respectively. Module \#1 is the highest power module in the blanket. Similar sets of plots are provided for the remaining five modules.

\subsection{HR Loop and Pressurizer}

Figure A-4 shows the TRAC component layout for the section of the primary heat removal loop that is between the fixed headers and external to the cavity vessel. Figure A-6 is the component layout for the pressurizer and its surge line. The pressure drop in the flow through the modules, going from the inlet to outlet header, is approximately 40 psid, and the temperature rise is approximately $9 \mathrm{C}$. There is a corresponding pressure increase and temperature drop in the external portion of the loop, between the fixed headers.

Figures B-8a through B-8e show pressures, fluid temperatures, subcooling temperatures, mass flowrates, and void fractions at several locations in the HR piping between the outlet header and the dividing Tee that splits the flow for the two pumps. Figures $\mathrm{B}-9 \mathrm{a}$ through $\mathrm{B}-9 \mathrm{e}$ show the flow variables on the suction and discharge sides of pump \#1. Figures B-10a through B-10e show the flow variables on the suction and discharge sides of pump \#2. Pumps \#1 and \#2 have mass flowrates of 762 and 805 $\mathrm{kg} / \mathrm{s}$, respectively. The difference is primarily due to form losses across the pump suction asymmetric dividing Tee [8]. There are similar sets of plots for the pump discharge check valves, the heat exchanger supply and exhaust piping, and the piping between the heat exchanger discharge combining Tee and the inlet header. The mass flowrates through heat exchangers \#1 and \#2 are 811.7 and $755.0 \mathrm{~kg} / \mathrm{s}$, respectively. The exit temperatures are $49.4 \mathrm{C}$ and $49.2 \mathrm{C}$, respectively.

Figures $\mathrm{B}-15 \mathrm{a}$ through $\mathrm{B}-15 \mathrm{e}$ show pressures, fluid temperatures, subcooling temperatures, mass flowrates, and void fractions in the bottom cell of the pressurizer and in the surge line, close to the inlet header. During normal operation, the fluid in the pressurizer remains stagnant. External to the cavity vessel, the pressurizer, and its surge line, the fluid temperatures are set to $40 \mathrm{C}$. This temperature is assumed to be the maximum expected building temperature during normal operation. 


\subsection{RHR Loop}

Figure A-5 shows the TRAC component layout for the residual heat removal system. This pipe network goes from the fixed outlet header to the fixed inlet header, in parallel with the part of the primary HR system that is external to the cavity. The RHR pump is inoperative during normal operation; a check valve on the discharge side of the pump prevents back flow through the system. Figures B-16a through B-16e show the flow variables on the suction and discharge sides of the pump. Figures B-17a through B-17e show the flow variables at the heat exchanger inlet and outlet. The two pump pressures reflect the fixed outlet header pressure, with hydrostatic corrections for the elevation differences, and the heat exchanger pressures reflect the fixed inlet header pressure, again with a hydrostatic correction.

\subsection{Cavity Vessel and Flood System}

Figure A-5 shows a TRAC layout of the heat transfer connections between the cavity vessel and the module heat structures. Figure A-6 shows the TRAC layout of the cavity vessel and the cavity flood system. Figures B-26a through B-26e show the flow variables for the cavity flood system pool, and Figs. B-27a through B-27e show the flow variables in the region of the cavity vessel that is below the top shield. The cavity flood system pool is stagnant, with a temperature of $40 \mathrm{C}$. The cavity vessel has a pressure of approximately 5 psia, with no liquid present. When the void fraction is one, TRAC returns the stagnation temperature as the fluid temperature of the missing liquid phase. These are the fluid temperatures shown in Fig. B-27b.

\section{FLOWTRAN-TF Detailed Bin Model}

The FLOWTRAN-TF model of a bin contained within a plate-type module (i.e., the reference 1 lateral Row 1 module [13]) is described in detail in Ref. [10]. FLOWTRANTF is a transient two-fluid code that solves a conjugate heat transfer problem. The conduction solution is 3-D and the fluid dynamics in parallel passages is 1-D. The plate assembly model simulates the thermal/hydraulic behavior of a single plate assembly and the associated coolant flow channels. The TRAC system model provides transient boundary conditions, and the FLOWTRAN-TF model simulates the fluid behavior of the discrete coolant flow channels and the conduction behavior of the lead/aluminum composite heat structure. The areal mesh of the bin model is shown in Figure 4-1 along with the location and indexing used for the 12 discrete flow channels.

\subsection{Model Upgrades}

The model used in the normal operation simulation, and in subsequent accident simulations, has 20 axial cells for both the solid structure and the flow channels. The Dittus-Boelter correlation was used to calculate surface heat transfer coefficients under single-phase flow conditions. This correlation was found to give slightly more conservative results (metal temperatures about $2 \mathrm{C}$ greater) than were obtained using the possibly more accurate Sieder-Tate correlation. Figure 4.1-1 shows the axial power shape used in all of the calculations and its relationship to the axial mesh levels. As shown in this figure, in FLOWTRAN-TF, axial position is measured with reference to the top of the blanket module. 


\subsection{Initial Conditions}

To provide a starting point for all of the accident calculations, FLOWTRAN-TF was run until steady-state conditions were reached with normal operating boundary conditions. From the TRAC system analysis, the following pre-incident flow conditions were applied:

1. Inlet water temperature of $53.05 \mathrm{C}$.

2. Inlet pressure of $0.6860 \mathrm{Mpa}$ (99.5 psia).

3. Outlet pressure of $0.5841 \mathrm{Mpa}$ ( $48.7 \mathrm{psia}$ ).

Based on information supplied by LANL personnel, the nominal pre-incident deposited power in a single lateral Row 1 blanket plate was $61.5 \mathrm{~kW}$ (average power density 13.15 W/cc) and the total nominal pre-incident coolant flow to the 12 half channels around the plate was $1.488 \mathrm{~kg} / \mathrm{s}$.

\subsection{Transient Boundary Conditions}

Since normal operations represent steady-state conditions no transient boundary conditions are used in the calculations.

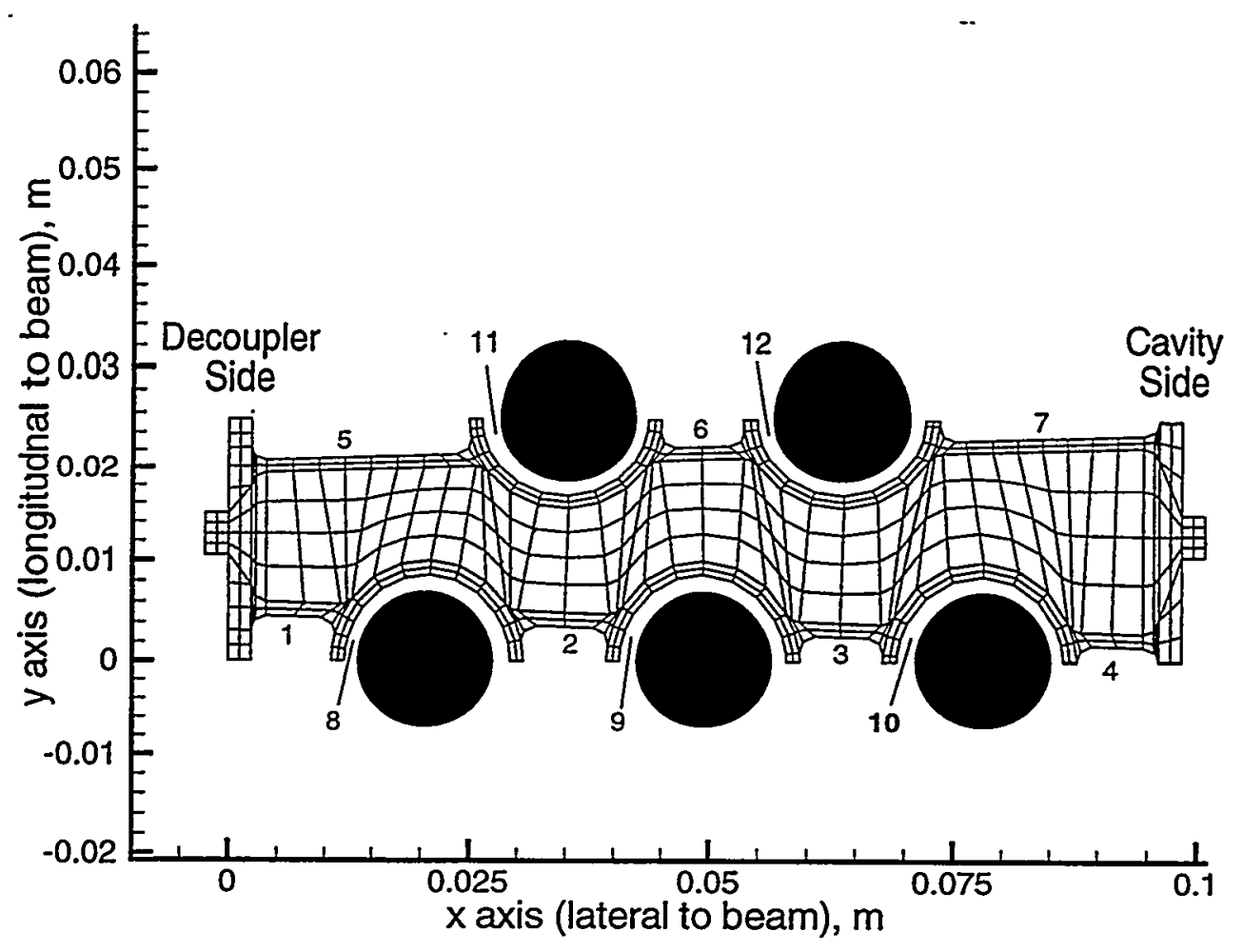

Figure 4-1 Finite element mesh of.APT reference 1 blanket plate. 


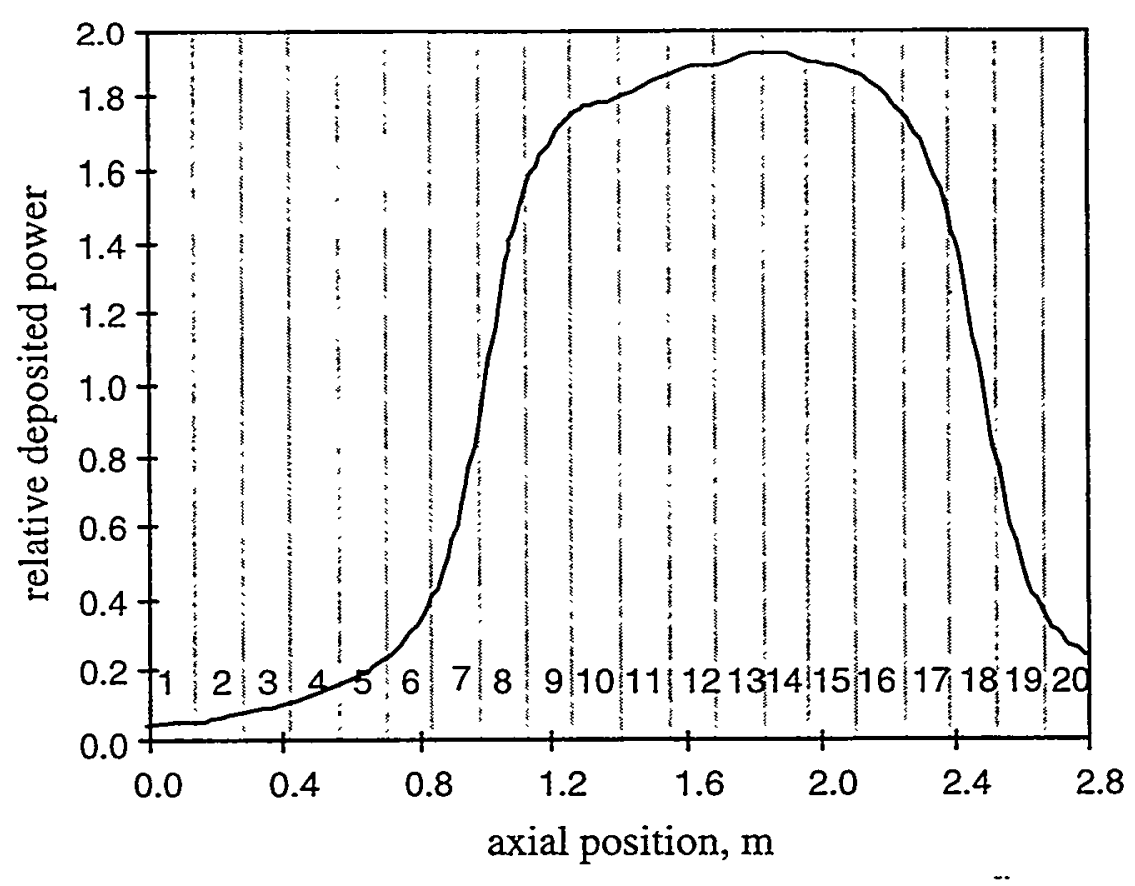

Figure 4.1-1 Axial power shape.

\section{FLOWTRAN-TF Bin Model Results}

\subsection{Solid Results}

Figure 5.1-1 shows the FLOWTRAN-TF calculated temperature distribution on the surface of the mesh at normal operating conditions. The maximum surface temperature (also the maximum aluminum temperature) is $100.0 \mathrm{C}$ on the decoupler face of the plate at the axial location where deposited power is highest. The maximum temperature in the lead is $112.8 \mathrm{C}$ at the same axial location. Figure 5.1-2 shows the solid heat conduction mesh and temperature distribution with the upper 11 cells removed. The top horizontal plane in the cut-away view is close to the axial location where the maximum metal temperatures occur.

Note that the areal dimensions shown in Figs. 5.1-1 and 5.1-2 have been greatly expanded to facilitate viewing. The actual overall dimensions of the model section shown are: $\Delta X=10 \mathrm{~cm}, \Delta Y=2.5 \mathrm{~cm}$, and $\Delta Z=278 \mathrm{~cm}$.

\subsection{Fluid Results}

Figures 5.2-1 through 5.2-6 show temperatures and heat fluxes along the axial direction for each flow channel under normal operating conditions. The first plot for each channel shows the fluid temperature $\left(T_{\text {fluid }}\right)$, maximum wall temperature along the surface at each axial level $\left(T_{\text {wall }}\right)$, and the local saturation temperature $\left(T_{\text {sat }}\right)$. The second plot for each 
channel shows the operating heat flux $\left(q_{\text {ohf }}\right)$ along with calculated values for the critical heat flux $\left(q_{\mathrm{chf}}\right)$, heat flux at the onset of subcooled nucleate boiling ( $\left.q_{\mathrm{onb}}\right)$, and heat flux at the onset of significant void formation $\left(q_{o s v}\right)$. All of the temperatures and heat fluxes are plotted on the same scale for easy comparison. At the exit of channels $4,8,9,11$, and 12, the operating heat flux becomes negative as heat is transferred from the liquid back into the solid. This reversal in the direction of heat transfer is a direct result of the long trailing edge of the axial power distribution curve shown in Fig. 4.1-1.

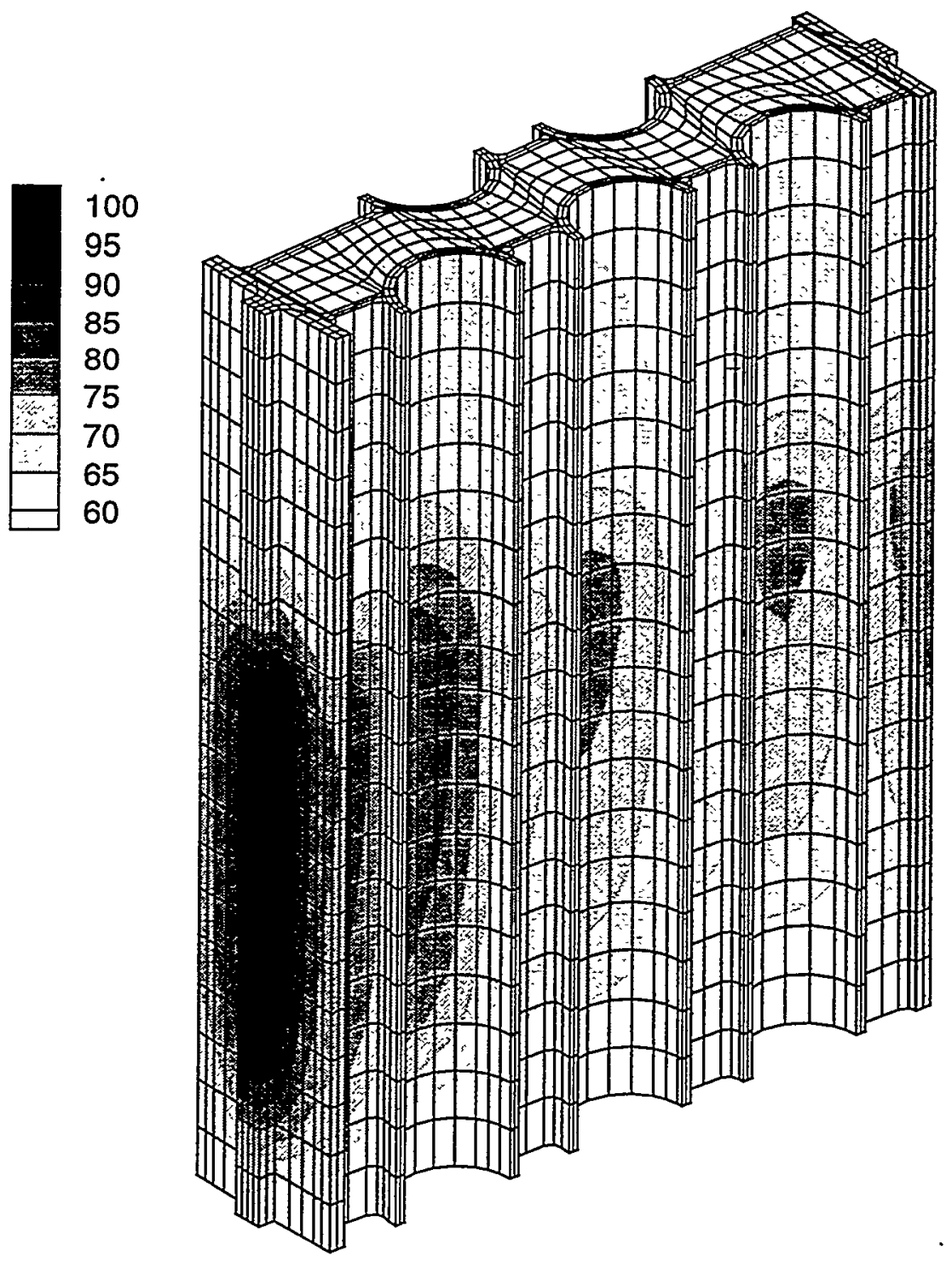

Figure 5.1-1 Normal operating surface temperatures. 
Date:

$07 / 13 / 98$
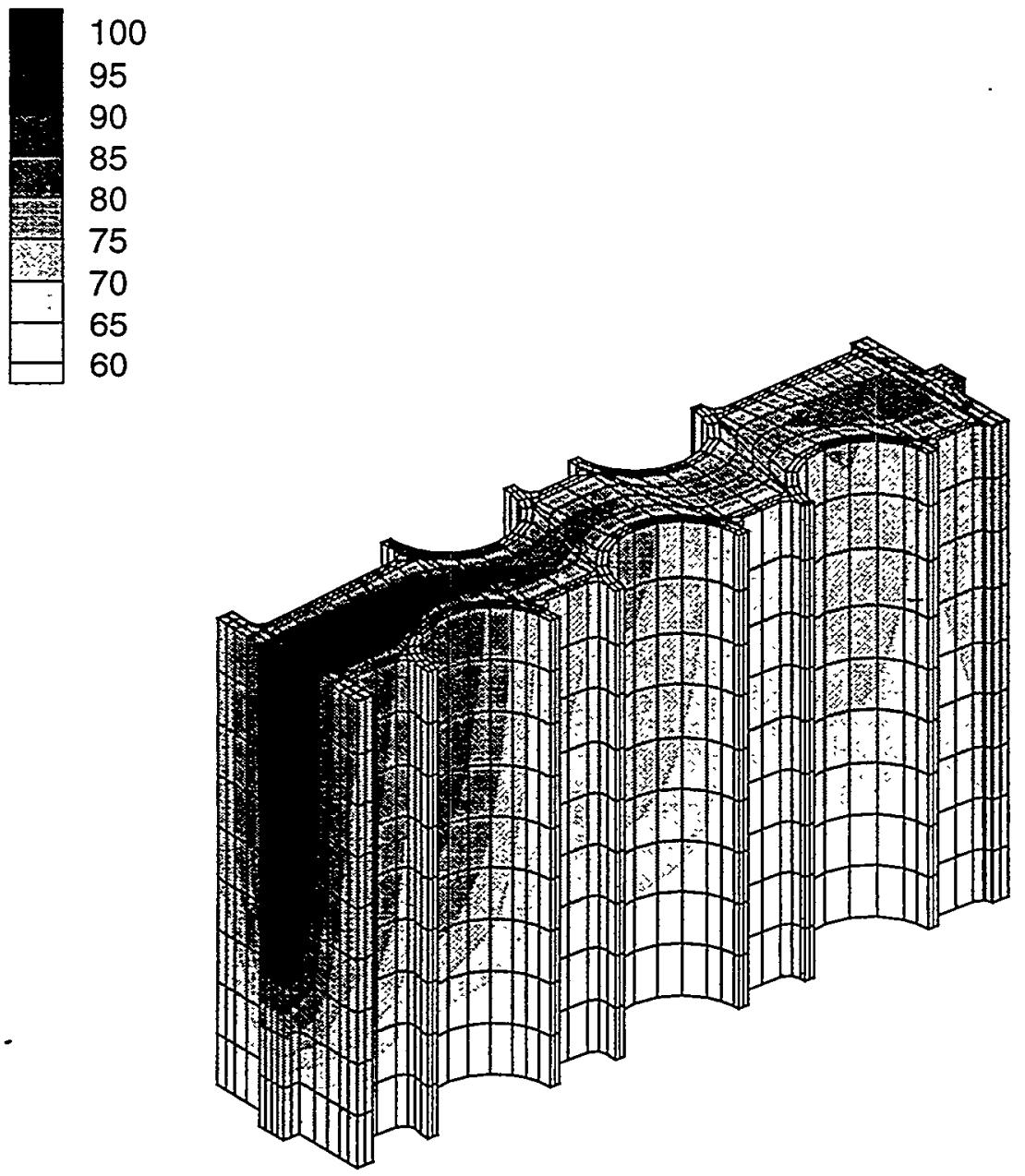

Figure 5.1-2 Normal operating metal temperatures, cut-away view. 
Channel 1

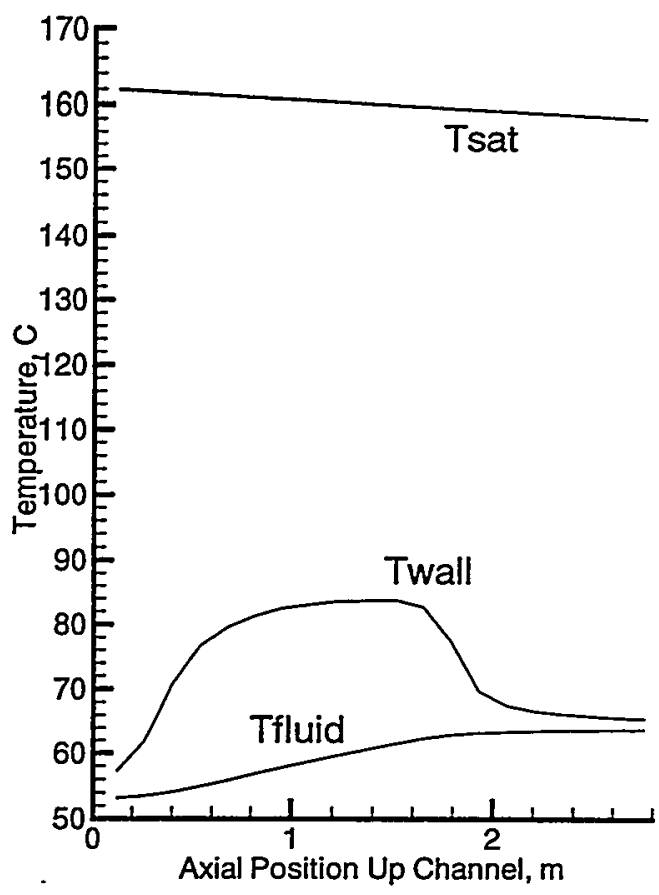

Channel 2

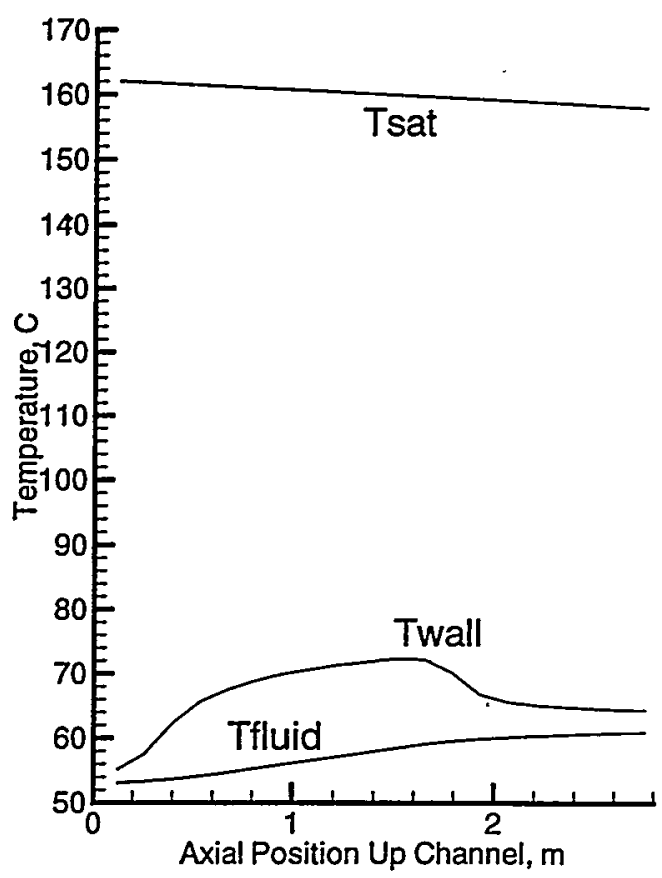

Channel 1

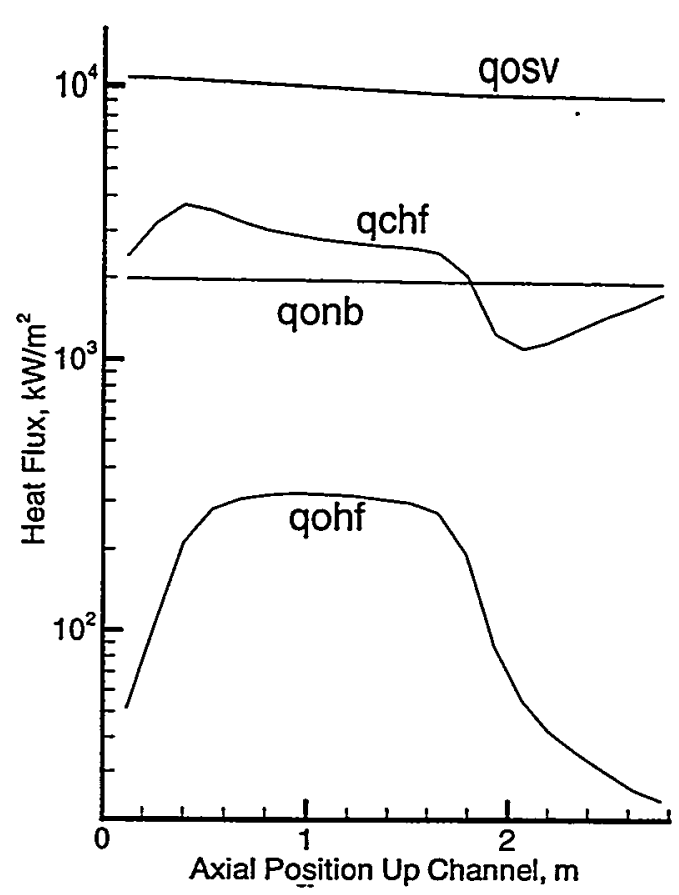

Channel 2

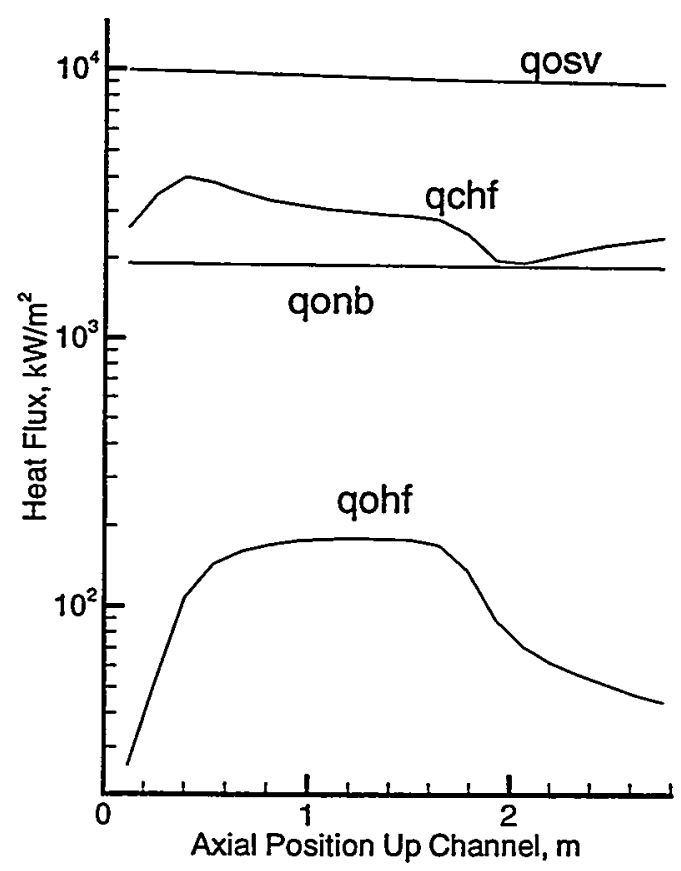

Figure 5.2-1 Normal operating temperatures and heat fluxes in channels $1-2$. 


\section{Channel 3}

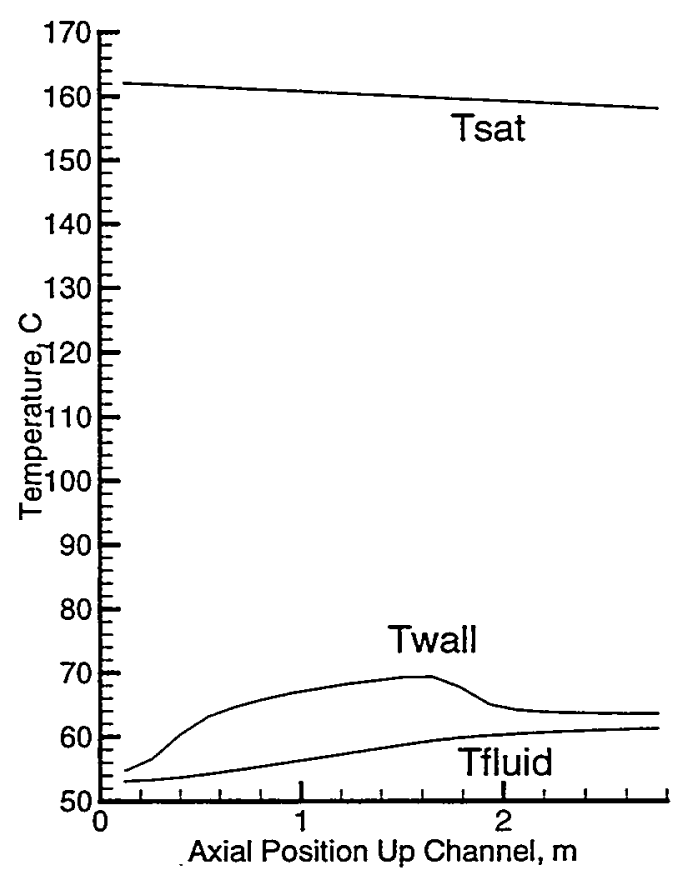

Channel 4

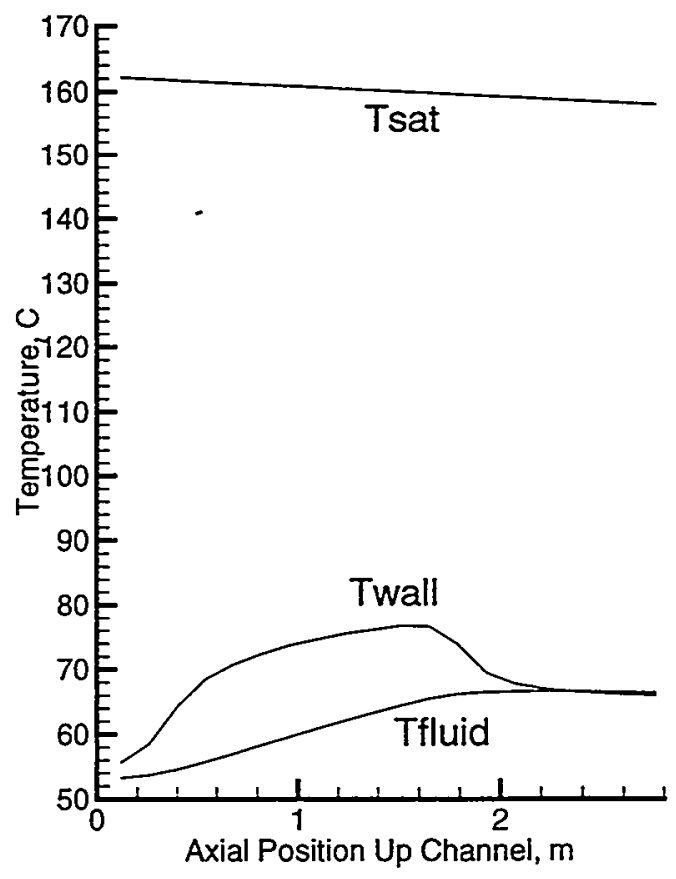

Channel 3

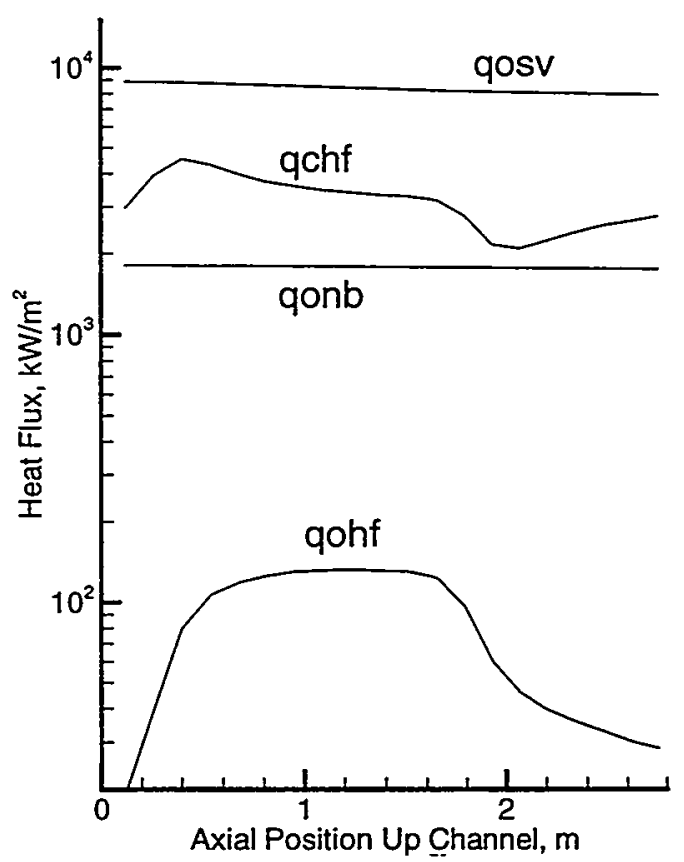

Channel 4

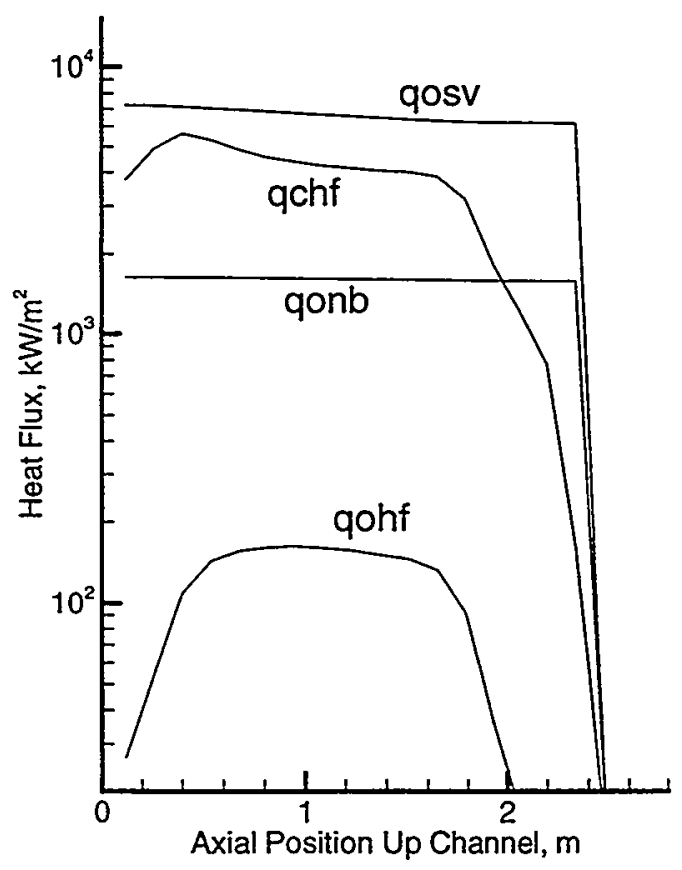

Figure 5.2-2 Normal operating temperatures and heat fluxes in channels $3-4$. 


\section{Channel 5}

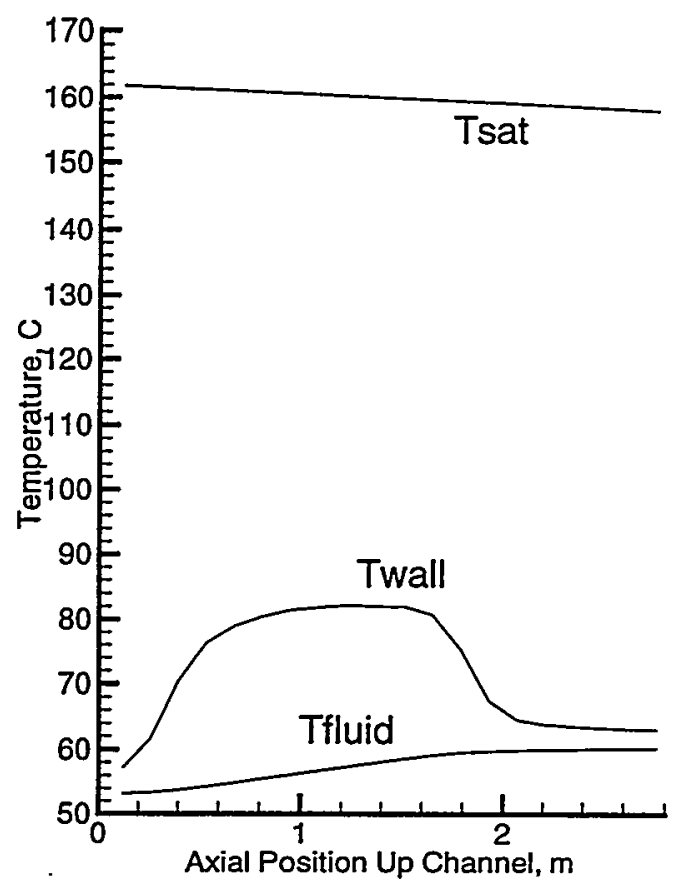

Channel 6

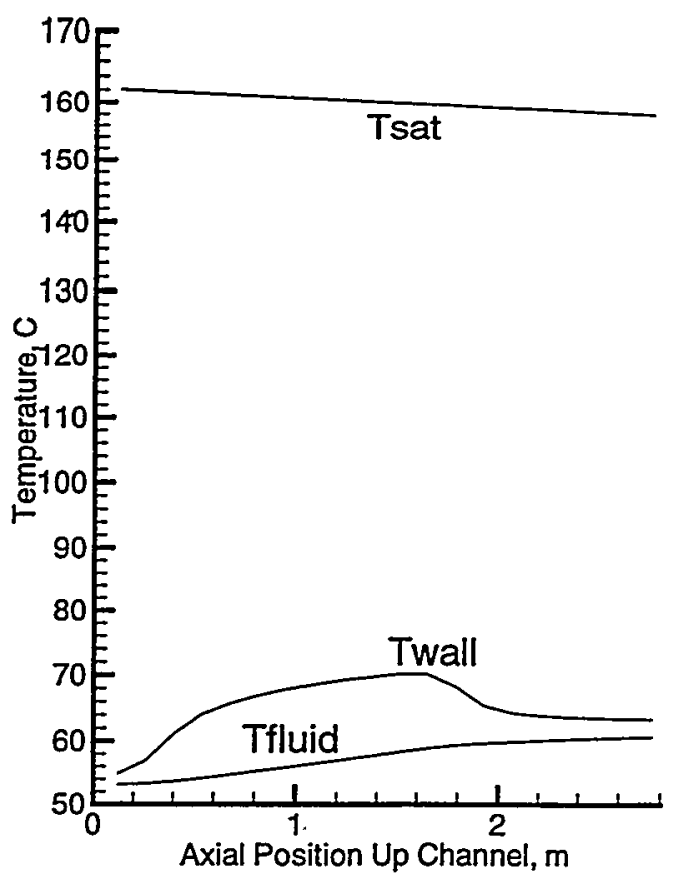

Channel 5

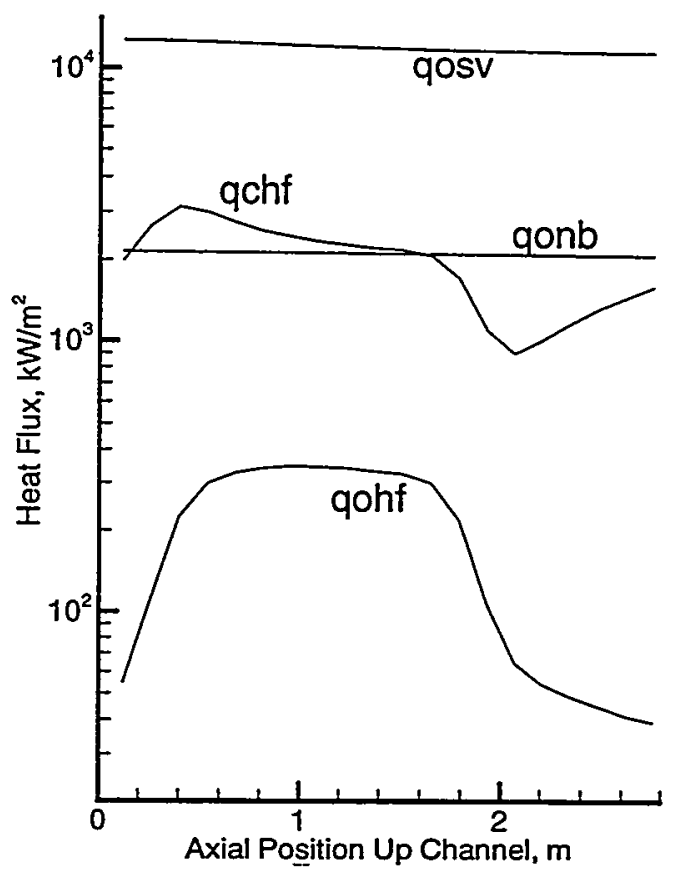

Channel 6

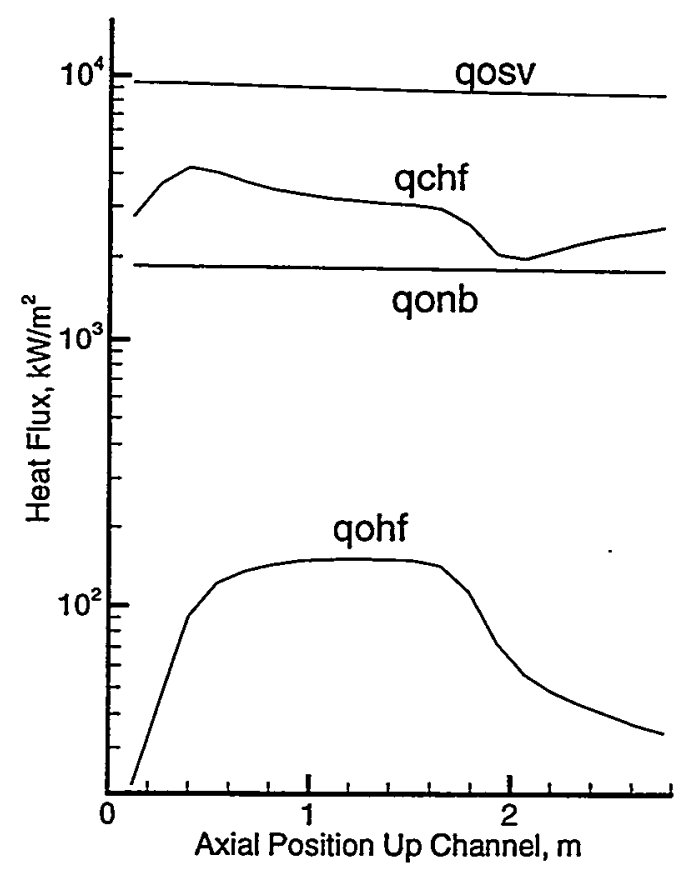

Figure 5.2-3 Normal operating temperatures and heat fluxes in channels 5 - 6 . 
Channel 7

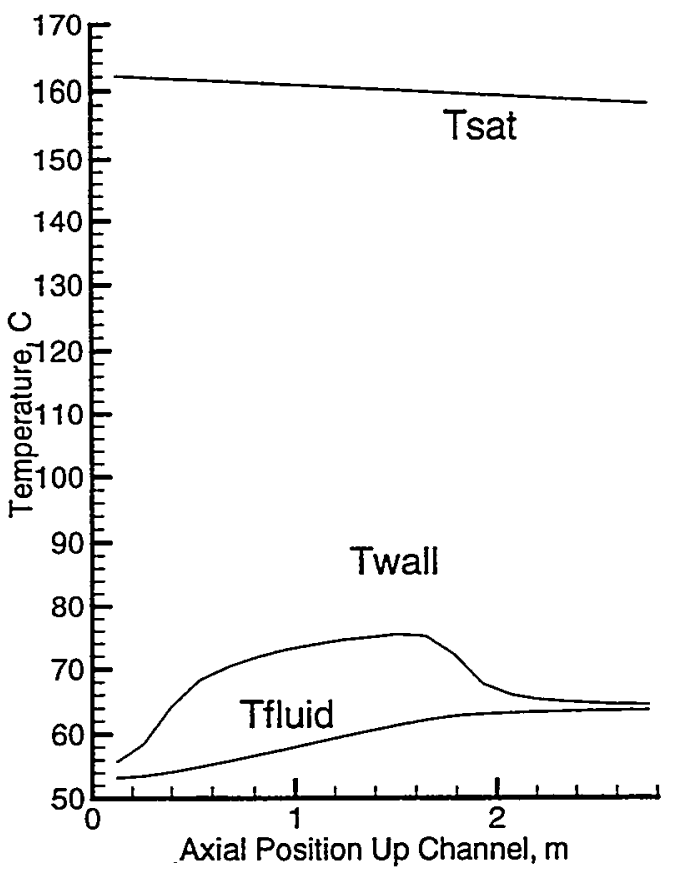

Channel 8

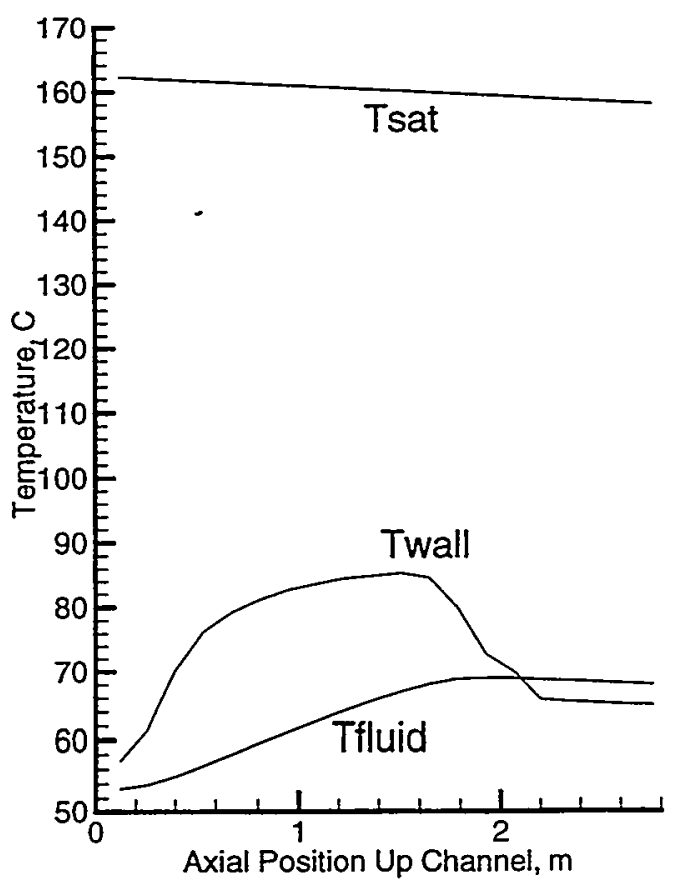

\section{Channel 7}

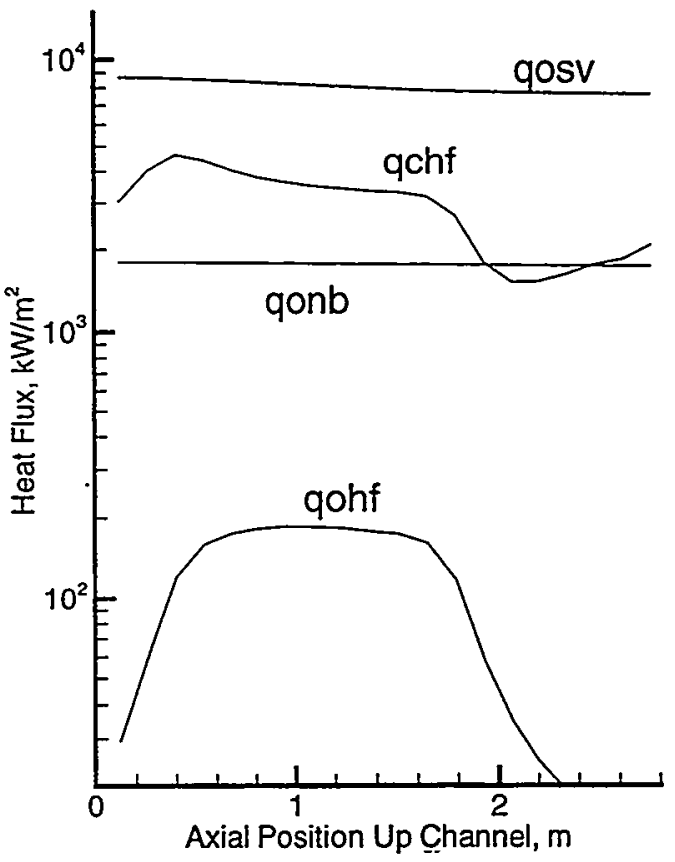

Channel 8

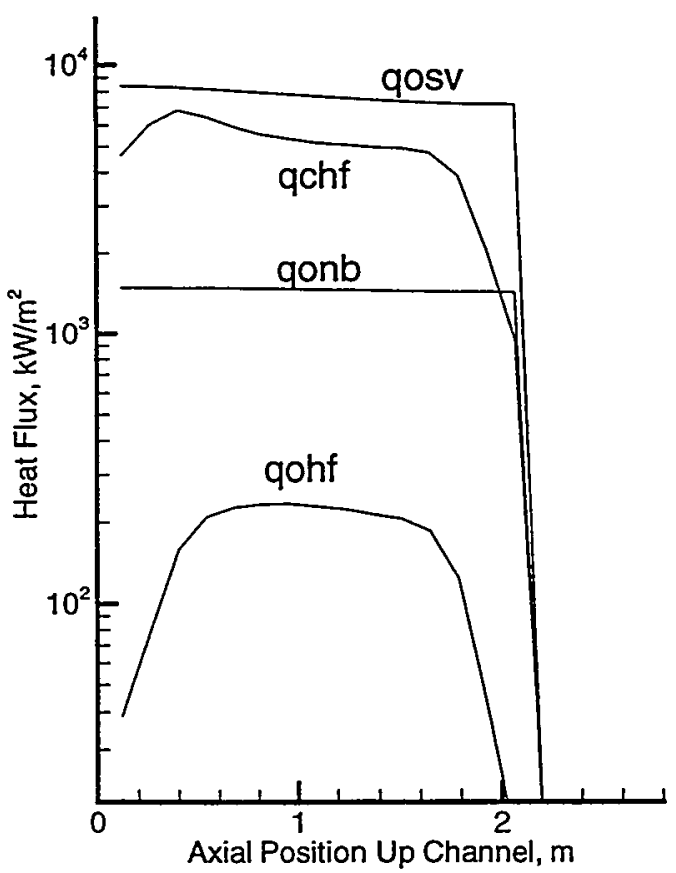

Figure 5.2-4 Normal operating temperatures and heat fluxes in channels 7 - 8 . 
Channel 9

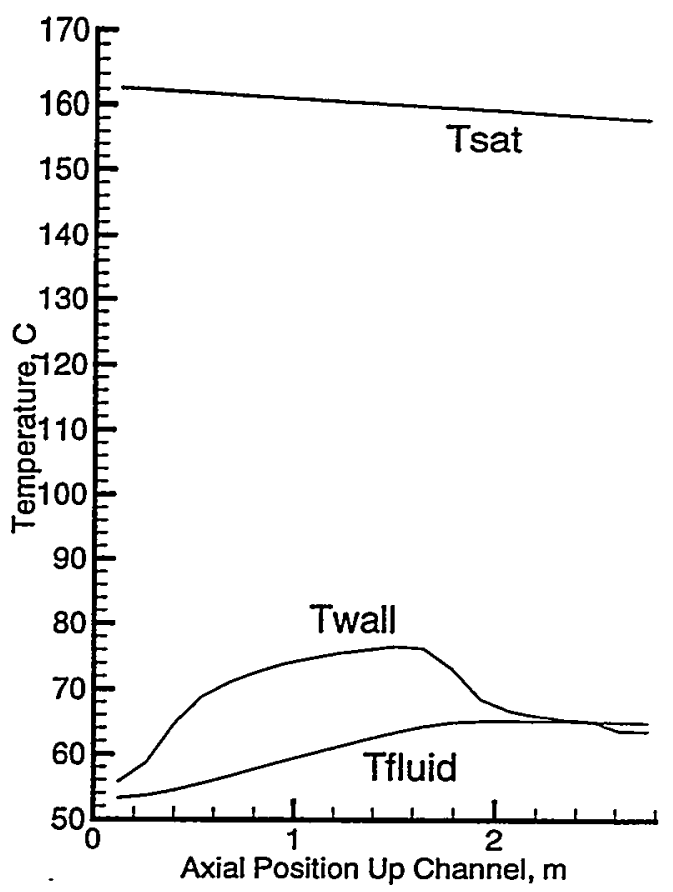

Channel 10

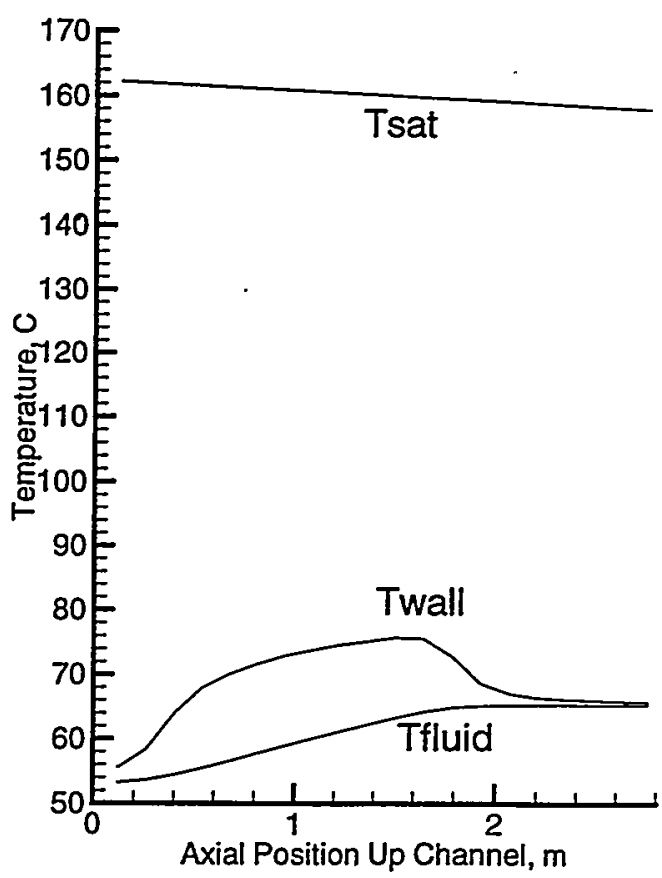

Channel 9

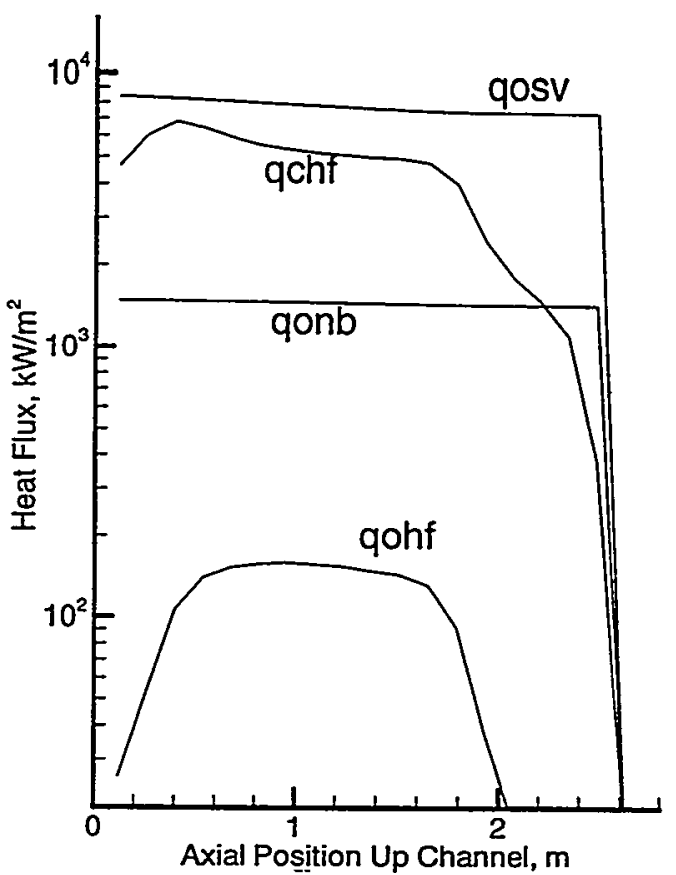

Channel 10

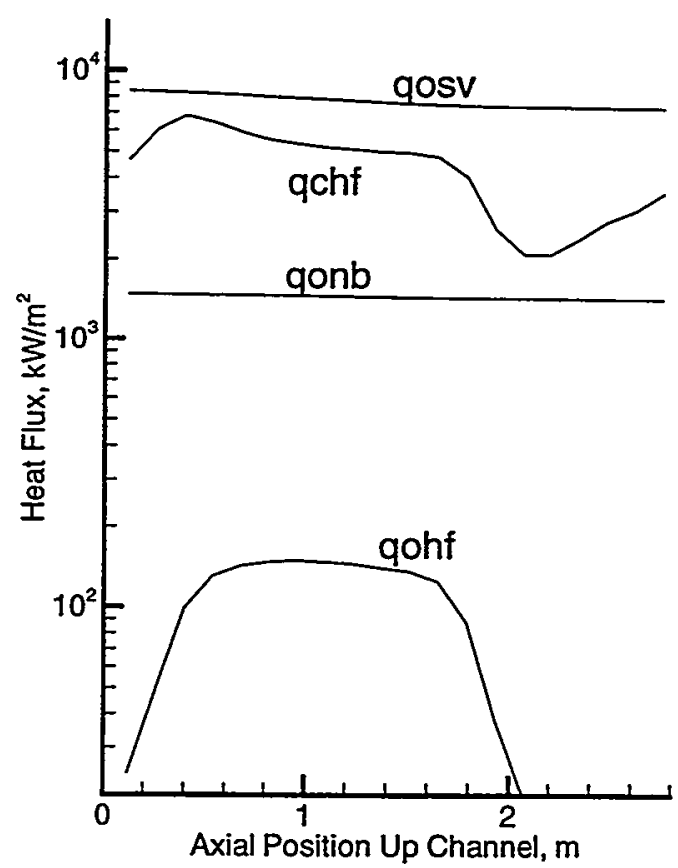

Figure 5.2-5 Normal operating temperatures and heat fluxes in channels $9-10$. 

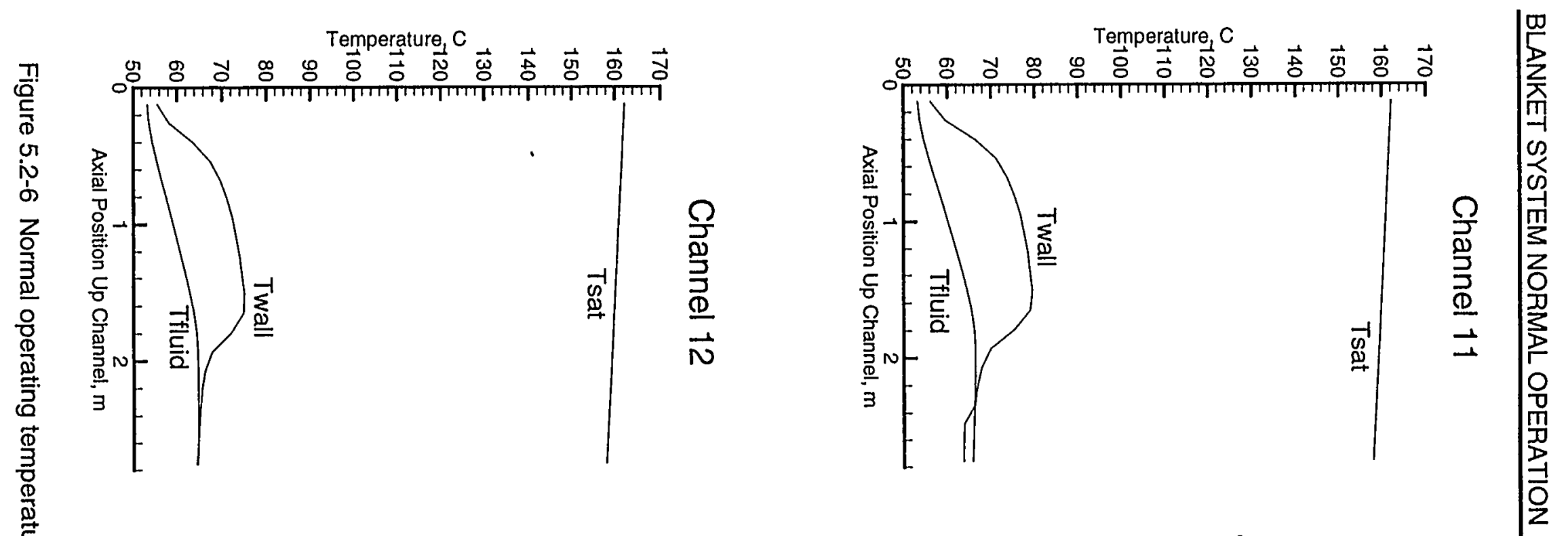

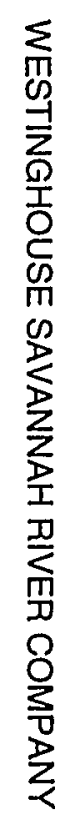
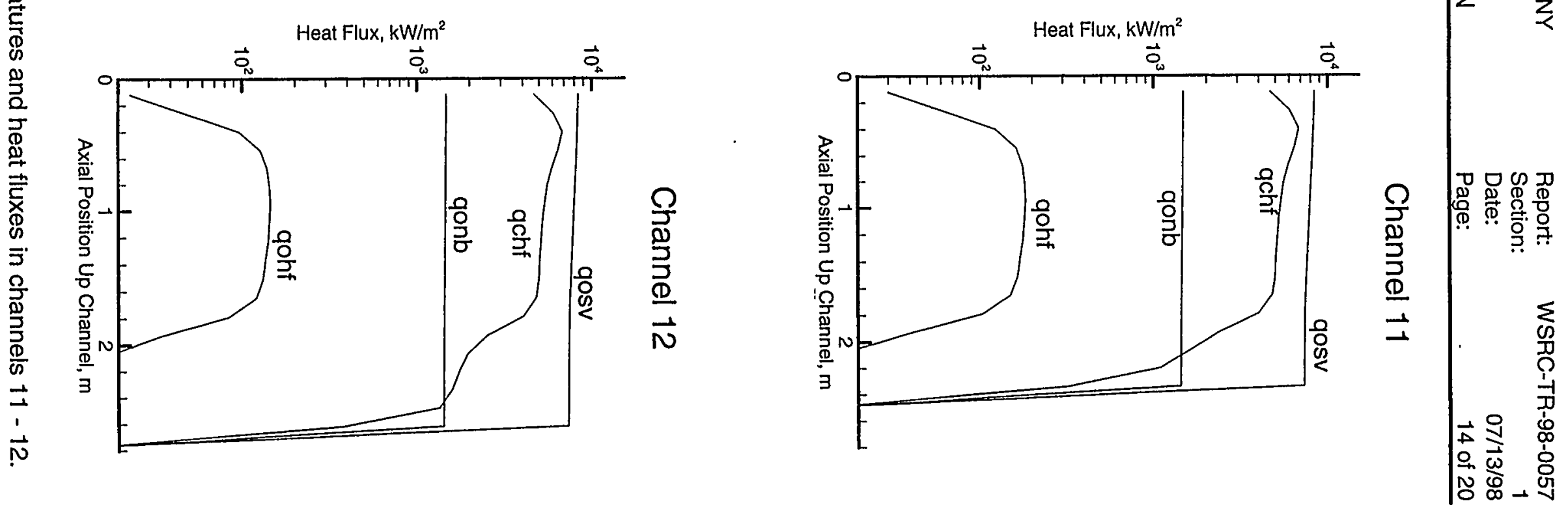


\section{Conclusions}

The detailed bin simulations performed using the TRAC system and FLOWTRAN-TF show that the primary HR system effectively cools the blanket materials during normal operation. Fluid pressures are well above the local stagnation pressures throughout the loop. There is sufficient safety margin in the design with respect to local cavitation or flashing concerns.

\subsection{Comparison to Thermal/Hydraulic Design Criteria}

The thermal/hydraulic $(T / H)$ design criteria, along with the basis for their development, is discussed in Refs. [11-12]. For normal operation (NO) the T/H onset criteria are based on meeting very strict phenomenological limits with a high degree of confidence, as follows:

- for local heated surfaces within the module components, the onset-of-significantvoids [OSV]) at a three sigma confidence level; and

- for the remaining unheated piping sections of the blanket system, the onset-of-bulkboiling $[O B B]$ ) at a three sigma confidence level.

Additional (steady-state derived) material design criteria are imposed on the maximum lead and aluminum (Series 6061 - Type T6) metal temperatures acceptable for the module components. The limiting values for these parameters are $327.5 \mathrm{C}$ and $115 \mathrm{C}$, respectively. These material design criteria ensure that a coolable geometry can be maintained throughout the expected lifetime of each module unit.

On a module-by-module basis, the above steady-state material and thermal onset criteria for NO are compared to the FLOWTRAN-TF detailed bin model results. The bin model results for the reference 1 plate-type module are tabulated in Table 6.1-1 (note that only module 1 results are currently available since the design specifications for modules 2 through 6 do not presently exist). However, module 1 should be close to the most limiting module. Additional thermal onset criteria, which are typically considered, are also provided in Table 6.1-1. Note that these are generally more stringent than the imposed design criteria chosen.

The definitions of the parameters in Table 6.1-1 are listed below, as follows:

$$
\begin{gathered}
R_{S U B}=\max \left(\frac{T_{f}-T_{i n}}{T_{s a t}-T_{i n}}\right), \text { liquid subcooling } \\
R_{S U P}=\max \left(\frac{T_{w}-T_{i n}}{T_{s a t}-T_{i n}}\right), \text { wall superheating } \\
R_{O N B}=\max \left(\frac{q_{O H F}^{\prime \prime}}{q_{O N B}^{\prime \prime}}\right), \text { ONB heat flux } \\
R_{O S V}=\max \left(\frac{q_{O H F}^{\prime \prime}}{q_{O S V}^{\prime \prime}}\right), \text { OSV heat flux }
\end{gathered}
$$




$$
R_{C H F}=\max \left(\frac{q_{O H F}^{\prime \prime}}{q_{C H F}^{\prime \prime}}\right), \mathrm{CHF} \text { heat flux }
$$

where:

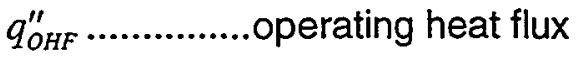

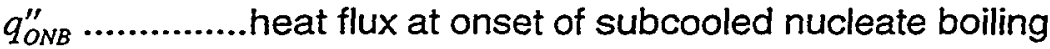

$$
\begin{aligned}
& q_{o s v}^{\prime \prime} \text {................heat flux at onset of significant void formation }
\end{aligned}
$$

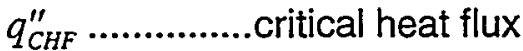

$$
\begin{aligned}
& T_{f} \text {...................fluid temperature } \\
& T_{\text {in }} \text {................... fluid temperature at inlet to flow channels, }(53.05 \mathrm{C}) \\
& T_{\text {sar }} \text {.................local fluid saturation temperature } \\
& T_{w} \text {..................wall temperature }
\end{aligned}
$$

and where the maximum value corresponds to its limit spatially, as well as over the time period of the event sequence. The ratio of OHF-to-CHF is sometimes referred to as the departure from nucleate boiling ratio (DNBR). Predicted thermal onset ratios should not exceed unity. Confidence bounds are required to establish the acceptable level of the probability of exceeding these criteria.

The results presented in Table 6.1-1 represent best estimate values (i.e., all input parameters were set to their best estimate values). Quantification of overall uncertainties and then their corresponding confidence levels (i.e., operating and modeling uncertainties) have not yet been performed. Future efforts to perform a response surface analysis are planned. At that time quantification of safety margins will be determined.

The peak blanket metal temperature occurs in module \#1, and it is $112.8 \mathrm{C}$, as predicted by the FLOWTRAN-TF model. This occurs in the lead plate, and it is well below the lead melting point, $327.5 \mathrm{C}$. The peak aluminum temperature also occurs in module $\# 1$, and it is $100 \mathrm{C}$, below the long term temperature limit of $115 \mathrm{C}$.

Table 6.1-2 shows the deposited powers, mass flowrates through, fluid temperatures across, and the exit fluid temperatures for the six modules, as predicted by the TRAC system model. The module exit temperatures vary from a low of $52.7 \mathrm{C}$ for module \#6 to $72.4 \mathrm{C}$ for module \#4. The outlet header temperature is $57.9 \mathrm{C}$. The flow splits between the modules are not optimum with respect to having similar temperature rises across all of the parallel flow channels. Table 6.1-3 lists the peak lead and aluminum temperatures in the six modules. The mean peak lead and aluminum temperatures for the six modules are $99.9 \mathrm{C}$ and $72.9 \mathrm{C}$ respectively. Module \#4, which has the highest fluid temperature rise, has peak metal temperatures close to the mean. Module \#6, which has the smallest temperature rise, has a peak lead temperature larger than the mean. Module \#1, which has the highest power and the highest peak metal temperatures, has a fluid temperature rise only slightly higher than the mean. Optimizing the flow distribution to the modules must take metal temperatures under consideration. For normal operation, the present design is adequate.

Using the deposited power and the flow channel $\Delta T$ values for the six modules in Table 6.1-2, a mixed mean exit temperature of $57.9 \mathrm{C}$ was calculated using an inlet temperature of $49.4 \mathrm{C}$. This agrees with the TRAC system model fixed outlet header temperature of $57.9 \mathrm{C}$. This agreement globally verifies energy conservation. 
Under NO conditions neither HR pump cavitation nor local flashing within the coolant piping network occurred (i.e., no OBB observed). The net positive suction head (NPSH) for both HR primary pumps is listed in Table 6.1-4.

\subsection{Design Issues}

The TRAC system model predicts a peak lead temperature in module \#1 of $152 \mathrm{C}$ and the detailed FLOWTRAN-TF bin model predicts a peak lead temperature of $112.8 \mathrm{C}$. The cruciform design was used in the TRAC system model while the plate-type design was used in the FLOWTRAN-TF model. This points out the need for consistency between the two models. For future computations, the TRAC model will be upgraded to model the plate-type blanket module in order to provide this consistency.

\subsection{Predicted Impact}

Normal operation is well within all specified thermal/hydraulic design criteria. No adverse affects beyond normal wear-and-tear of the systems and components is expected. As such, negligible onsite and offsite impact on people or the environment occur as a result of normal APT operations.

Table 6.1-1 FLOWTRAN-TF model results under normal operating conditions for comparison to design criteria.

\begin{tabular}{|c|c|c|c|c|c|c|c|}
\hline Module & $\begin{array}{l}\text { Max } \\
\text { Pb } \\
\text { Temp } \\
\text { (C) }\end{array}$ & $\begin{array}{l}\text { Max } \\
\text { Al } \\
\text { (C) }\end{array}$ & $\begin{array}{l}\text { Max } \\
\text { Subcooling } \\
\text { Ratio }\end{array}$ & $\begin{array}{l}\text { Max } \\
\text { Superheat } \\
\text { Ratio }\end{array}$ & $\begin{array}{l}\text { Max } \\
\text { ONB } \\
\text { Ratio }\end{array}$ & $\begin{array}{l}\text { Max } \\
\text { OsV } \\
\text { Ratio }\end{array}$ & $\begin{array}{l}\text { Mäx } \\
\text { CHR } \\
\text { Ratio }\end{array}$ \\
\hline 1 & 112.8 & 100.0 & 0.150 & 0.301 & 0.165 & 0.032 & 0.150 \\
\hline 2 & TBD & TBD & TBD & TBD & TBD & TBD & TBD \\
\hline 3 & TBD & TBD & TBD & TBD & TBD & TBD & TBD \\
\hline 4 & TBD & TBD & TBD & TBD & TBD & TBD & TBD \\
\hline 5 & TBD & TBD & TBD & TBD & TBD & TBD & TBD \\
\hline 6 & TBD & TBD & TBD & TBD & TBD & TBD & TBD \\
\hline
\end{tabular}

Table 6.1-2 TRAC fluid temperature rises across the module flow channels.

\begin{tabular}{|c|c|c|c|c|}
\hline $\begin{array}{r}\text { Module } \$ \\
\\
\end{array}$ & $\begin{array}{l}\text { Deposited } \\
\text { Power (MW) }\end{array}$ & $\begin{array}{l}\text { Mass } \\
\text { Flowrate } \\
\text { (kg/s) }\end{array}$ & $\begin{array}{l}\Delta \mathbf{T}\left({ }^{\circ} \mathbf{C}\right) \\
\therefore\end{array}$ & $\begin{array}{r}\text { Exit Temp } \\
(\mathrm{oc})\end{array}$ \\
\hline 1 & 23.990 & 544.5 & 10.4 & 59.8 \\
\hline 2 & 10.720 & 351.0 & 7.2 & 56.6 \\
\hline 3 & 3.556 & 55.4 & 15.3 & 64.7 \\
\hline 4 & 9.336 & 96.7 & 23.0 & 72.4 \\
\hline 5 & 3.167 & 114.6 & 6.6 & 56.0 \\
\hline 6 & 5.712 & 404.6 & 3.3 & 52.7 \\
\hline
\end{tabular}


Table 6.1-3 TRAC peak metal temperatures in the modules.

\begin{tabular}{|c|c|c|c|}
\hline Module & $\begin{array}{l}\text { Deposited Power } \\
\text { (MW) }\end{array}$ & $\begin{array}{l}\text { Maximum Lead } \\
\text { Temp }(C)\end{array}$ & $\begin{array}{l}\text { Maximum } \\
\text { Aluminum } \\
\text { Temp. (c) }\end{array}$ \\
\hline 1 & 23.990 & 152.0 & 93.0 \\
\hline 2 & 10.72 & 98.0 & 69.4 \\
\hline 3 & 3.556 & 88.3 & 72.5 \\
\hline 4 & 9.336 & 95.5 & 80.7 \\
\hline 5 & 3.167 & 63.0 & 55.4 \\
\hline 6 & 5.712 & 102.5 & 66.5 \\
\hline
\end{tabular}

Table 6.1-4 Primary HR pump NPSH conditions under normal operating conditions.

\begin{tabular}{|c|c|c|}
\hline HR primary pump & Available NPSH & Required NPSH \\
& m (ft) & m (ft) \\
\hline 1 & $23.9(78.4)$ & $6.8(22.3)$ \\
\hline 2 & $26.0(85.3)$ & $7.1(23.3)$ \\
\hline
\end{tabular}




\section{References}

1. L. L. Hamm, S. Y. Lee, M. A. Shadday, and F. G. Smith, III, "APT Blanket System Loss-of-Flow Accident (LOFA) Analyses Based on Initial Conceptual Design Case 1: with Beam Shutdown and Active RHR," Westinghouse Savannah River Company, WSRC-TR-98-0058 (July 1998).

2. L. L. Hamm, S. Y. Lee, M. A. Shadday, and F. G. Smith, III, "APT Blanket System Loss-of-Coolant Accident (LOCA) Analysis Based on Initial Conceptual Design Case 1: External HR Break Near Inlet Header," Westinghouse Savannah River Company, WSRC-TR-98-0059 (July 1998).

3. L. L. Hamm, S. Y. Lee, M. A. Shadday, and F. G. Smith, III, "APT Blanket System Loss-of-Coolant Accident (LOCA) Analysis Based on Initial Conceptual Design Case 2: External HR Break at Pump Outlet with Pump Trip," Westinghouse Savannah River Company, WSRC-TR-98-0060 (July 1998).

4. L. L. Hamm, S. Y. Lee, M. A. Shadday, and F. G. Smith, III, "APT Blanket System Loss-of-Coolant Accident (LOCA) Analysis Based on Initial Conceptual Design Case 3: External HR Break at Pump Outlet without Pump Trip," Westinghouse Savannah River Company, WSRC-TR-98-0061 (July 1998).

5. L. L. Hamm, S. Y. Lee, M. A. Shadday, and F. G. Smith, III, "APT Blanket System Loss-of-Coolant Accident (LOCA) Analysis Based on Initial Conceptual Design Case 4: External Pressurizer Surge Line Break Near Inlet Header," Westinghouse Savannah River Company, WSRC-TR-98-0062 (July 1998).

6. L. L. Hamm, S. Y. Lee, M. A. Shadday, and F. G. Smith, III, "APT Blanket System Loss-of-Coolant Accident (LOCA) Analysis Based on Initial Conceptual Design Case 5: External RHR Break Near Inlet Header," Westinghouse Savannah River Company, WSRC-TR-98-0063 (July 1998).

7. L. L. Hamm, S. Y. Lee, M. A. Shadday, and F. G. Smith, III, "APT Blanket System Internally Dry Flooded Cavity Accident (IDFCA) Based on Initial Plate-Type Design - Demonstration of Bin. Heat Conduction Capability," Westinghouse Savannah River Company, WSRC-TR-98-0064 (July 1998).

8. L. L. Hamm, S. Y. Lee, M. A. Shadday, and F. G. Smith, III, "APT Blanket System - Model Based on Initial Conceptual Design - Integrated 1-D TRAC System Model," Westinghouse Savannah River Company, WSRC-TR-98-0053 (July 1998).

9. L. L. Hamm, S. Y. Lee, M. A. Shadday, and F. G. Smith, III, "TRAC Code Modifications made for APT Blanket Safety Analysis," Westinghouse Savannah River Company, WSRC-TR-98-0054 (July 1998).

10. L. L. Hamm, S. Y. Lee, M. A. Shadday, and F. G. Smith, III, "APT Blanket Detailed Bin Model Based on Initial Plate-Type Design - 3-D FLOWTRAN-TF Model," Westinghouse Savannah River Company, WSRC-TR-98-0055 (July 1998).

11. "APT Conceptual Design Report," Los Alamos National Laboratory report, LA-UR97-1329 (April 1997).

12. L. L. Hamm, S. Y. Lee, M. A. Shadday, and F. G. Smith, III, "APT Blanket System Safety Analysis Methodology," Westinghouse Savannah River Company, WSRCTR-98-0052 (May 1998).

13. R. Kapernick, "Blanket Reference 1 Plate-Type Design for Lateral Row 1 Module", e-mail memo from Los Alamos National Laboratory, Oct. 11, 1997. 
14. Safety Code Development Group, "TRAC-PF1/MOD2: An Advanced Best Estimate Computer Program for Pressurized Water Reactor Thermal-Hydraulic Analysis," Los Alamos National Laboratory report LA-12031-M, Vol. 1 (NUREG/CR-5673), (July 21, 1993). 
Page:

\section{Appendix A: TRAC Model Component Nomenclature}

Table A-1 Blanket System Component Descriptions in TRAC Model.

\begin{tabular}{|c|c|c|c|c|}
\hline System & Component Type & Comp & $\begin{array}{l}\text { No of } \\
\text { Célls }\end{array}$ & Descriptions \\
\hline \multirow[t]{25}{*}{$\mathrm{HR}$} & Fixed Header (FH) & 380 & 1 & coolant Supply FH \\
\hline & & 340 & 1 & coolant Return FH \\
\hline & Pressurizer (Pzr) & 760 & 1 & Pzr surge line 1 connected to Supply FH 380 \\
\hline & & 761 & 2 & Pzr surge line 2 \\
\hline & & 762 & 1 & Pzr surge line 3 \\
\hline & & 763 & 1 & Pzr surge line 4 \\
\hline & & 764 & 1. & Pzr surge line 5 \\
\hline & & 765 & 13 & Pzr surge line 6 \\
\hline & & 766 & 9 & primary Pzr \\
\hline & Hot Leg Loop & 20 & 1 & pipe connected to Return $\mathrm{FH} 340$ \\
\hline & & 21 & 1 & plenum for potential break loc. \\
\hline & & 22 & 7 & pipe connection to external loop \\
\hline & & 23 & 1 & pipe connect. for potential break \\
\hline & & 24 & 13 & connection pipe \\
\hline & & 25 & 1 & connection pipe \\
\hline & & 26 & 2 & pipe connected to two pumps \\
\hline & & 27 & 1 & plenum for two pump connection \\
\hline & & 28 & 2 & pump\#1 suction pipe \\
\hline & & 29 & 7 & pump\#2 suction pipe \\
\hline & & 30 & 2 & pump located at cell face 2 \\
\hline & & 31 & 2 & pump located at cell face 2 \\
\hline & & 32 & 3 & check valve located at pump\#1 discharge \\
\hline & & 33 & 3 & check valve located at pump\#2 discharge \\
\hline & & 34 & 1 & pump outlet plenum \\
\hline & & 36 & 1 & connect. pipe between pump and pipe \\
\hline 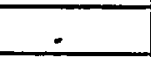 & & 37 & 1 & HX connect. pipe for potential break \\
\hline & & 38 & 1 & pipe connect. to two HX's inlet plenum \\
\hline & & 40 & 1 & plenum \\
\hline & $\mathrm{HX}$ & 48 & 3 & HX\#1 inlet pipe \\
\hline & & 50 & 4 & 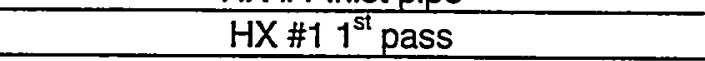 \\
\hline & & 52 & 3 & HX \#1 middle header \\
\hline & & 54 & 4 & $H X \# 12^{\text {nd }}$ pass \\
\hline & & 49 & 3 & $\mathrm{HX} \# 2$ inlet pipe \\
\hline & & 51 & 4 & $\mathrm{HX} \# 21^{\text {st }}$ pass \\
\hline & & 53 & 3 & HX \#2 middle header \\
\hline & & 55 & 4 & $H X \# 22^{\text {nd }}$ pass \\
\hline & & 710 & 1 & HX\#1 secondary side fill \\
\hline & & 711 & 4 & $\mathrm{HX} \# 12^{\text {nd }}$ pass secondary side \\
\hline & & 712 & 3 & HX \#1 middle header secondary side \\
\hline & & 713 & 4 & $H X \# 11^{\text {st }}$ pass secondary side \\
\hline & & 714 & 1 & $\mathrm{HX} \# 1$ secondary side break $\mathrm{BC}$ \\
\hline & & 730 & 1 & $\mathrm{HX} \# 2$ secondary side fill $\mathrm{BC}$ \\
\hline
\end{tabular}


Report:

Section:

Date:

Page:
WSRC-TR-98-0057

Appendix A

07/13/98

2 of 12

Table A-1 Blanket System Component Descriptions in TRAC Model (continued).

\begin{tabular}{|c|c|c|c|c|}
\hline \multirow[t]{5}{*}{\begin{tabular}{l} 
System \\
\hdashline \\
0
\end{tabular}} & \multirow[t]{2}{*}{ Component Type } & \multirow{2}{*}{$\frac{\text { Comp }}{731}$} & \multirow{2}{*}{\multicolumn{2}{|c|}{$\begin{array}{l}\text { No } \\
\text { of } \\
\text { of } \\
\text { Cells }\end{array}$}} \\
\hline & & & & \\
\hline & & 732 & 3 & HX \#2 middle header secondary side \\
\hline & & 733 & 4 & $H X \# 21^{\text {st }}$ pass secondary side \\
\hline & & 734 & 1 & $\mathrm{HX} \# 2$ secondary side break $\mathrm{BC}$ \\
\hline \multirow[t]{12}{*}{$\mathrm{HR}$} & Cold Leg Loop & 56 & 3 & HX\#1 outlet pipe \\
\hline & & 57 & 6 & HX \#2 outlet pipe \\
\hline & & 60 & 3 & HX outlet plenum merged after two HX's \\
\hline & & 62 & 1 & cold leg pipe \\
\hline & & 63 & 1 & cold leg pipe \\
\hline & & 64 & 13 & cold leg pipe located outside cavity wall \\
\hline & & 65 & 1 & pipe for cold leg pipe break \\
\hline & & 66 & 1 & horizontal cold leg pipe penetration \\
\hline & & 67 & 1 & plenum for internal break on HR loop \\
\hline & & 854 & 2 & HR isolation valve for internal break \\
\hline & & 69 & 1 & plenum for internal LOCA simulation \\
\hline & & 68 & 5 & pipe connect. to $\mathrm{FH} 340$ inside cavity \\
\hline \multirow{9}{*}{$\begin{array}{l}\text { Cavity } \\
\text { Vessel } \\
\end{array}$} & Cold Leg Loop & 850 & 2 & valve located bet. cavity vessel and HR \\
\hline & & 852 & 2 & valve located bet. cavity vessel and HR \\
\hline & & & 1 & plenum for cavity vessel connection \\
\hline & & 828 & 3 & cavity vent valve \\
\hline & & 802 & 1 & break component for cavity vent pressure BC \\
\hline & & 823 & 11 & pipe for cavity lower section simulation \\
\hline & & 824 & 1 & plenum for cavity connection \\
\hline & & 840 & 2 & valve to connect cavity line to Module 1 \\
\hline & & 825 & 4 & pipe for cavity middle section simulation \\
\hline \multirow[t]{8}{*}{$\begin{array}{l}\text { Cavity } \\
\text { Pool }\end{array}$} & Cavity Flood Line & 820 & 13 & $\begin{array}{c}\text { pipe for cavity pool connection to cavity } \\
\text { vessel }\end{array}$ \\
\hline & & 821 & 2 & cavity flood line valve \\
\hline & & 822 & 1 & flood line pipe inside cavity vessel \\
\hline & Cavity Flood Pool & 801 & 1 & break component for cavity pool BC \\
\hline & & 810 & 10 & pipe for top cavity pool section \\
\hline & & 811 & 1 & plenum for middle cavity pool section \\
\hline & & 812 & 7 & pipe for lower cavity pool section \\
\hline & & 813 & 1 & plenum for cavity pool bottom \\
\hline \multirow[t]{10}{*}{ RHR } & RHR Loop & 621 & 1 & pipe located to return $\mathrm{FH}$ \\
\hline & & 623 & 10 & pipe located inside the cavity vessel \\
\hline & & 624 & 1 & pipe located outside the cavity vessel \\
\hline & & 625 & 18 & pipe bet. RHR pump and pipe comp. \#624 \\
\hline & & 630 & 2 & RHR pump located at face 2 \\
\hline & & 640 & 3 & check valve located at pump discharge \\
\hline & & 652 & 4 & $\mathrm{HX}$ tubes \\
\hline & & 660 & 16 & pipe at the cold leg side \\
\hline & & 661 & 1 & pipe located before cavity vessel \\
\hline & & 662 & 8 & cold leg pipe inside cavity vessel \\
\hline
\end{tabular}


Table A-1 Blanket System Component Descriptions in TRAC Model (continued).

\begin{tabular}{|c|c|c|c|c|}
\hline \begin{tabular}{c} 
System \\
\hdashline \\
\hdashline
\end{tabular} & \begin{tabular}{c} 
Component Type \\
\hdashline \\
0
\end{tabular} & Comp & $\begin{array}{l}\text { No } \\
\text { of } \\
\text { Cells }\end{array}$ & Descriptions \\
\hline & & 663 & 1 & cold leg pipe connected to supply FH \\
\hline & & 672 & 1 & fill for $\mathrm{HX}$ secondary side $\mathrm{BC}$ \\
\hline & & 671 & 4 & HX secondary shell side \\
\hline & & 673 & 1 & break comp. for $\mathrm{HX}$ secondary side $\mathrm{BC}$ \\
\hline Module & Module 1 Flow & 454 & 7 & pipe connected to supply $\mathrm{FH}$ \\
\hline & & 80 & 1 & $\begin{array}{c}\text { plenum for potential internal break simulation } \\
\text { at Module } 1\end{array}$ \\
\hline & & 375 & 5 & $\begin{array}{c}\text { pipe connection bet. Suuply FH and Module } \\
1 \text { upper plenum }\end{array}$ \\
\hline & & 370 & 1 & upper plenum for Module 1 downcomer \\
\hline & & 360 & 5 & Module 1 downflow region \\
\hline & & 350 & 1 & $\begin{array}{c}\text { middle plenum bet. Module } 1 \text { downflow and } \\
\text { upflow regions }\end{array}$ \\
\hline & & 300 & 5 & Module 1 upflow region \\
\hline & & 330 & 1 & upper plenum for module 1 upflow region \\
\hline & & 335 & 5 & $\begin{array}{c}\text { connection pipe after Module } 1 \text { upper } \\
\text { plenum }\end{array}$ \\
\hline & & 429 & 4 & pipe cormected to return $\mathrm{FH}$ \\
\hline & Module 2 Flow & 173 & 7 & pipe coonected to supply FH \\
\hline & & 81 & 1 & $\begin{array}{l}\text { plenum for potential internal break simulation } \\
\text { at Module } 2\end{array}$ \\
\hline & & 82 & 3 & pipe connection \\
\hline & & 172 & 1 & upper plenum for Module 2 downcomer \\
\hline & & 158 & 6 & Module 2 downflow region \\
\hline & & 147 & 1 & $\begin{array}{c}\text { middle plenum bet. Module } 2 \text { downflow and } \\
\text { upflow regions }\end{array}$ \\
\hline & & 102 & 6 & Module 2 upflow region \\
\hline & & 133 & 1 & upper plenum for module 2 upflow region \\
\hline - & & 136 & 7 & pipe connected to return $\mathrm{FH}$ \\
\hline & Module 3 Flow & 415 & 7 & pipe connected to supply FH \\
\hline & & 85 & 1 & $\begin{array}{c}\text { plenum for potential internal break simulation } \\
\text { at Module } 3\end{array}$ \\
\hline & & 86 & 3 & pipe connection \\
\hline & & 479 & 1 & upper plenum for Module 3 downcomer \\
\hline & & 478 & 5 & Module 3 downflow region \\
\hline & & 418 & 1 & $\begin{array}{c}\text { middle plenum bet. Module } 3 \text { downflow and } \\
\text { upflow regions }\end{array}$ \\
\hline & & 409 & 5 & Module 3 upflow region \\
\hline & & 423 & 1 & upper plenum for module 3 upflow region \\
\hline & & 417 & 7 & pipe connected to return FH \\
\hline & Module 4 Flow & 485 & 7 & pipe connected to supply FH \\
\hline & & 87 & 1 & $\begin{array}{l}\text { plenum for potential internal break simulation } \\
\text { at Module } 4\end{array}$ \\
\hline & & 88 & 3 & pipe connection \\
\hline & & 489 & 1 & upper plenum for Module 4 downcomer \\
\hline
\end{tabular}


Table A-1 Blanket System Component Descriptions in TRAC Model (continued).

\begin{tabular}{|c|c|c|c|c|}
\hline System & Component Type & Comp & $\begin{array}{l}\text { No of } \\
\text { Cells }\end{array}$ & W WDescriptions \\
\hline & & 480 & 6 & Module 4 downflow region \\
\hline & & 419 & 1 & $\begin{array}{l}\text { middle plenum bet. Module } 4 \text { downflow and } \\
\text { upflow regions }\end{array}$ \\
\hline & & 412 & 6 & Module 4 upflow region \\
\hline \multirow[t]{2}{*}{$\cdot$} & & 483 & 1 & upper plenum for module 4 upflow region \\
\hline & & 484 & 7 & pipe connected to return $\mathrm{FH}$ \\
\hline \multirow[t]{31}{*}{ Module } & Module 5 Flow & 513 & 7 & pipe connected to supply FH \\
\hline & & 89 & 1 & $\begin{array}{l}\text { plenum for potential internal break } \\
\text { simulation at Module } 5\end{array}$ \\
\hline & & 90 & 3 & pipe connection \\
\hline & & 510 & 1 & upper plenum for Module 5 downcomer \\
\hline & & 507 & 6 & Module 5 downflow region \\
\hline & & 503 & 1 & $\begin{array}{c}\text { middle plenum bet. Module } 4 \text { downflow and } \\
\text { upflow regions }\end{array}$ \\
\hline & & 500 & 6 & Module 5 upflow region \\
\hline & & 508 & 1 & upper plenum for Module 5 upflow region \\
\hline & & 511 & 7 & pipe connected to return $\mathrm{FH}$ \\
\hline & Module 6 Flow & 541 & 7 & pipe connected to supply FH \\
\hline & & 83 & 1 & $\begin{array}{c}\text { plenum for potential' internal break } \\
\text { simulation at Module } 6\end{array}$ \\
\hline & & 84 & 1 & pipe connection \\
\hline & & 538 & 1 & upper plenum for Module 6 decoupler \\
\hline & & 535 & 5 & Module 6 downcomer region \\
\hline & & 531 & 1 & $\begin{array}{l}\text { middle plenum bet. Module } 6 \text { decoupler and } \\
\text { main heated regions }\end{array}$ \\
\hline & & 528 & 5 & Module 6 main heated region \\
\hline & & 536 & 1 & $\begin{array}{l}\text { upper plenum for module } 6 \text { main heated } \\
\text { region }\end{array}$ \\
\hline & & 539 & 12 & pipe connected to return $\mathrm{FH}$ \\
\hline & $\begin{array}{l}\text { Module } 1 \text { Heater } \\
\text { Structure }\end{array}$ & 901 & 5 & Al tube structure in Row 1 \\
\hline & & 951 & 5 & Lead zone with Al cladding in Row 1 \\
\hline & & 984 & 5 & Al tube structure in decoupler \\
\hline & $\begin{array}{l}\text { Module } 2 \text { Heater } \\
\text { Structure }\end{array}$ & 905 & 6 & Al tube structure in Row 2 \\
\hline & & 955 & 6 & Lead zone with Al cladding in Row 2 \\
\hline & & 916 & 6 & Al tube structure in Row 3 \\
\hline & & 966 & 6 & Lead zone with Al cladding in Row 3 \\
\hline & $\begin{array}{l}\text { Module } 3 \text { Heater } \\
\text { Structure }\end{array}$ & 911 & 5 & Al tube structure in Row 1 \\
\hline & & 961 & 5 & Lead zone with Al cladding in Row 1 \\
\hline & & 988 & 5 & Al tube structure in decoupler \\
\hline & $\begin{array}{l}\text { Module } 4 \text { Heater } \\
\text { Structure }\end{array}$ & 912 & 6 & Al tube structure in Row 1 \\
\hline & & 962 & 6 & Lead zone with Al cladding in Row 1 \\
\hline & & 931 & 6 & Al tube structure in Row 2 \\
\hline
\end{tabular}


Table A-1 Blanket System Component Descriptions in TRAC Model (continued).

\begin{tabular}{|c|c|c|c|c|c|}
\hline System & Component Type & Comp & No & \\
\hline & & & of & Descriptions \\
\hline & $\begin{array}{c}\text { Module 5 Heater } \\
\text { Structure }\end{array}$ & 913 & 6 & Cells & Al tube structure in Row 2 \\
\hline & & 963 & 6 & Lead zone with Al cladding in Row 2 \\
\hline & & 932 & 6 & Al tube structure in Row 2 \\
\hline & & 979 & 6 & Lead zone with Al cladding in Row 2 \\
\hline & $\begin{array}{c}\text { Module 6 Heater } \\
\text { Structure }\end{array}$ & 915 & 5 & Al tube structure in Row 2 \\
\hline & & 965 & 5 & Lead zone with Al cladding in Row 2 \\
\hline
\end{tabular}

Table A-2 Steady State Conditions.

\begin{tabular}{|c|c|c|}
\hline & Units & Calculated \\
& Parameter & Values \\
\hline Total power deposited in blanket modules & $\mathrm{MW}$ & 56.5 \\
\hline Total flow rate & $\mathrm{kg} / \mathrm{sec}$ & 1569 \\
& $\mathrm{gpm}$ & 25252 \\
\hline Pressure in cold-leg fixed header & $\mathrm{MPa}$ & 0.7325 \\
& $\mathrm{psia}$ & 106.24 \\
\hline Pressure in hot-leg fixed header & $\mathrm{MPa}$ & 0.4563 \\
& $\mathrm{psia}$ & 66.180 \\
\hline Pressurizer (cell \#1) pressure & $\mathrm{MPa}$ & 0.7311 \\
& $\mathrm{psia}$ & 106.03 \\
\hline Pump \#1 suction pressure & $\mathrm{MPa}$ & 0.2751 \\
& $\mathrm{psia}$ & 39.90 \\
\hline Pump \#1 discharge pressure & $\mathrm{MPa}$ & 1.0356 \\
& $\mathrm{psia}$ & 150.20 \\
\hline Pump \#2 suction pressure & $\mathrm{MPa}$ & 0.2958 \\
& $\mathrm{psia}$ & 42.91 \\
\hline Pump \#2 discharge pressure & $\mathrm{MPa}$ & 1.0409 \\
& $\mathrm{psia}$ & 150.97 \\
\hline Temperature in cold-leg fixed header & $\mathrm{C}$ & 49.43 \\
& $\mathrm{~F}$ & 121.0 \\
\hline Temperature in hot-leg fixed header & $\mathrm{C}$ & 58.03 \\
& $\mathrm{~F}$ & 136.5 \\
\hline Max. fluid temperature of the hottest & $\mathrm{C}$ & 71.95 \\
module & $\mathrm{F}$ & 161.5 \\
\hline
\end{tabular}




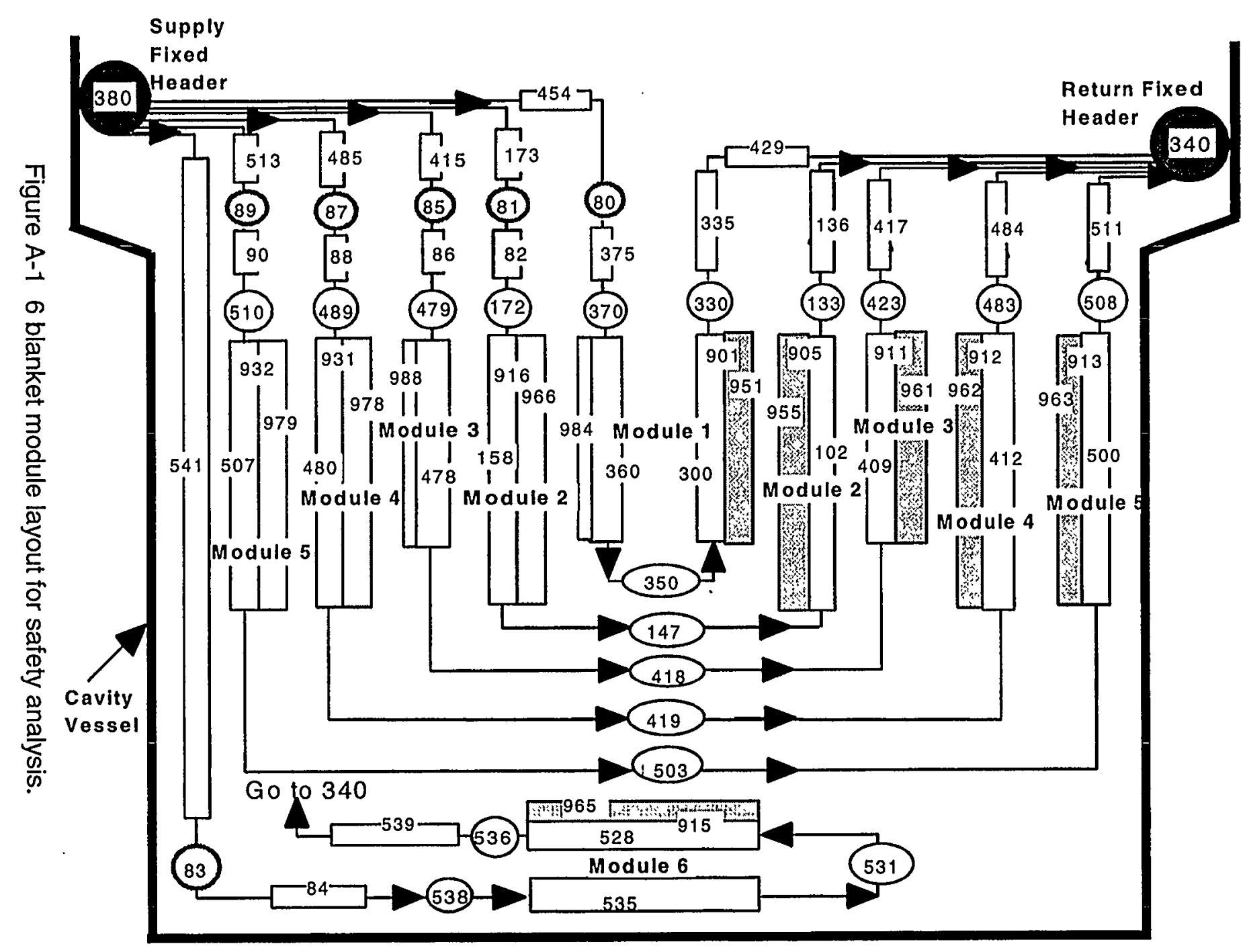

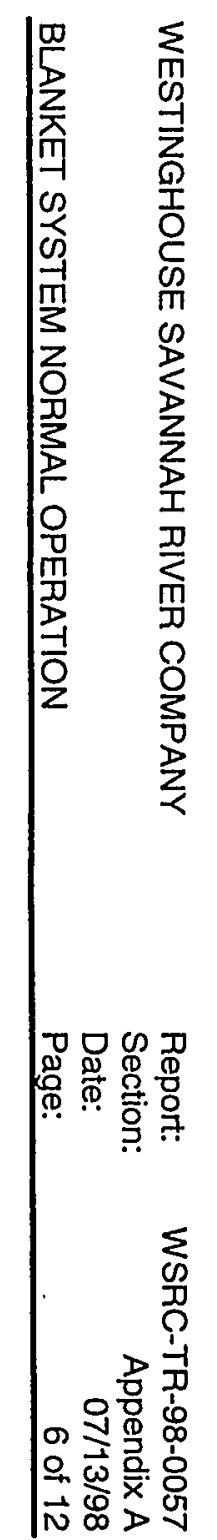




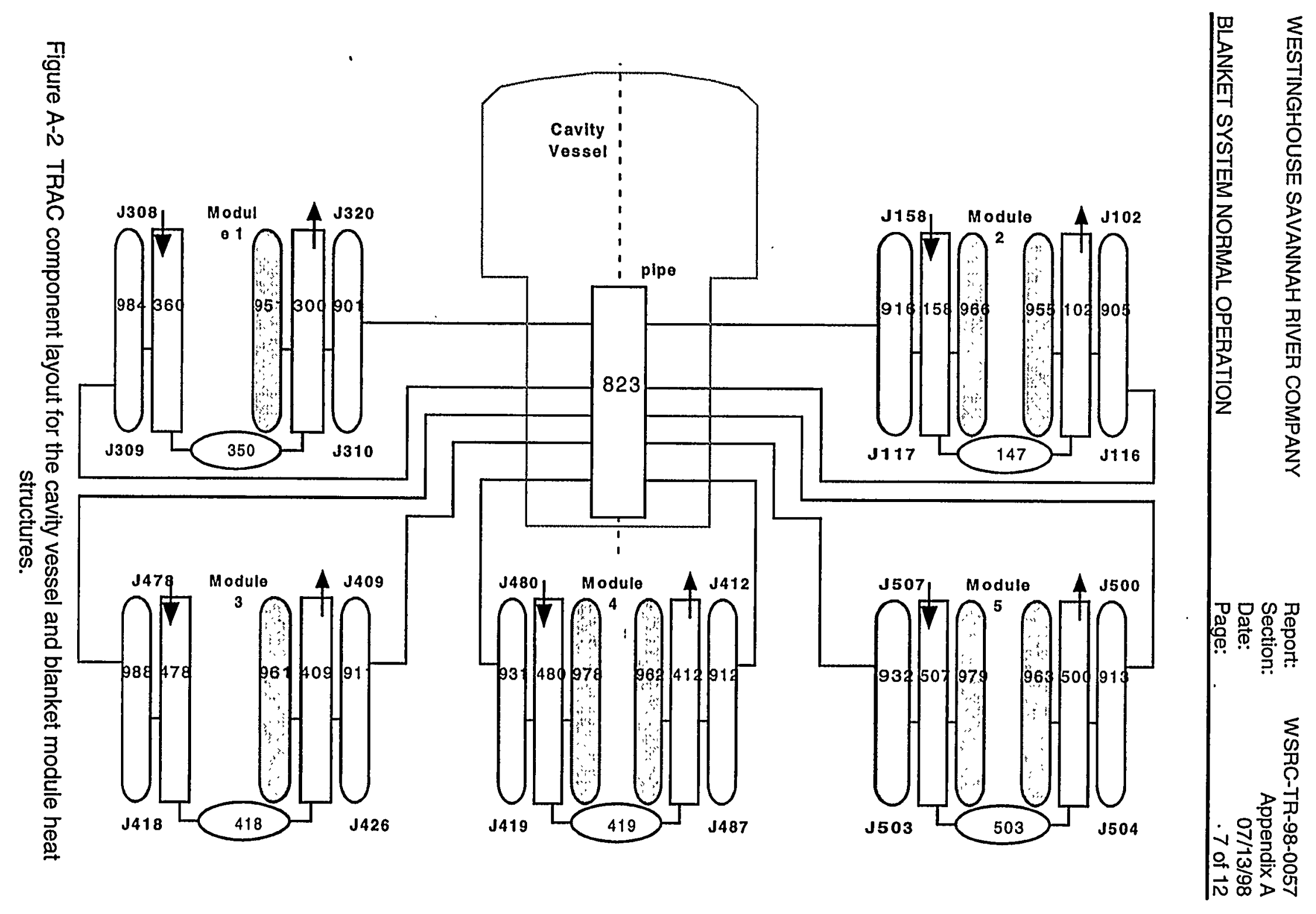


WESTINGHOUSE SAVANNAH RIVER COMPANY

BLANKET SYSTEM NORMAL OPERATION
Report: WSRC-TR-98-0057

Section: Appendix A

Date:

Page:

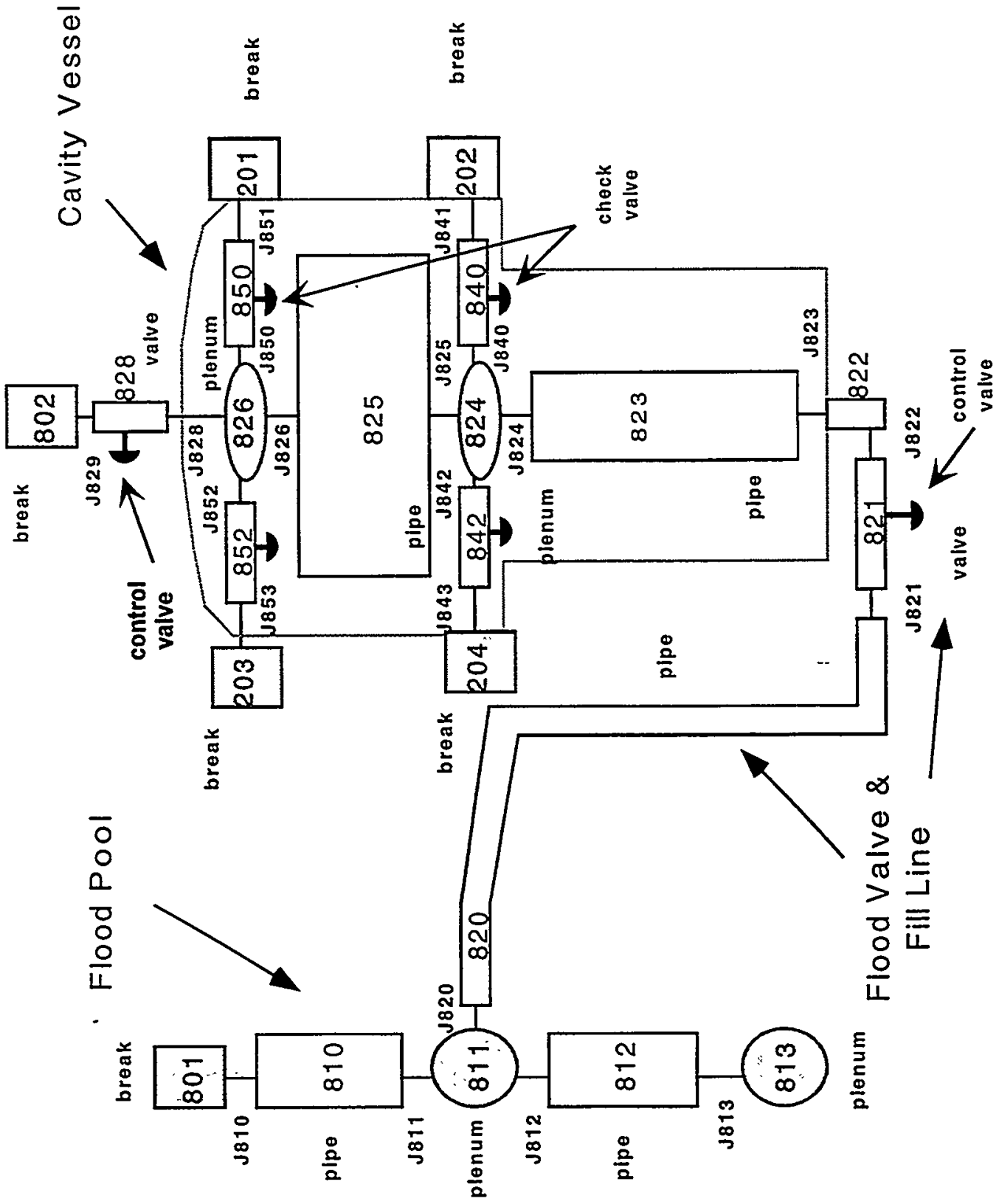

Figure A-3 TRAC component layout for the cavity vessel and cavity flood system. 

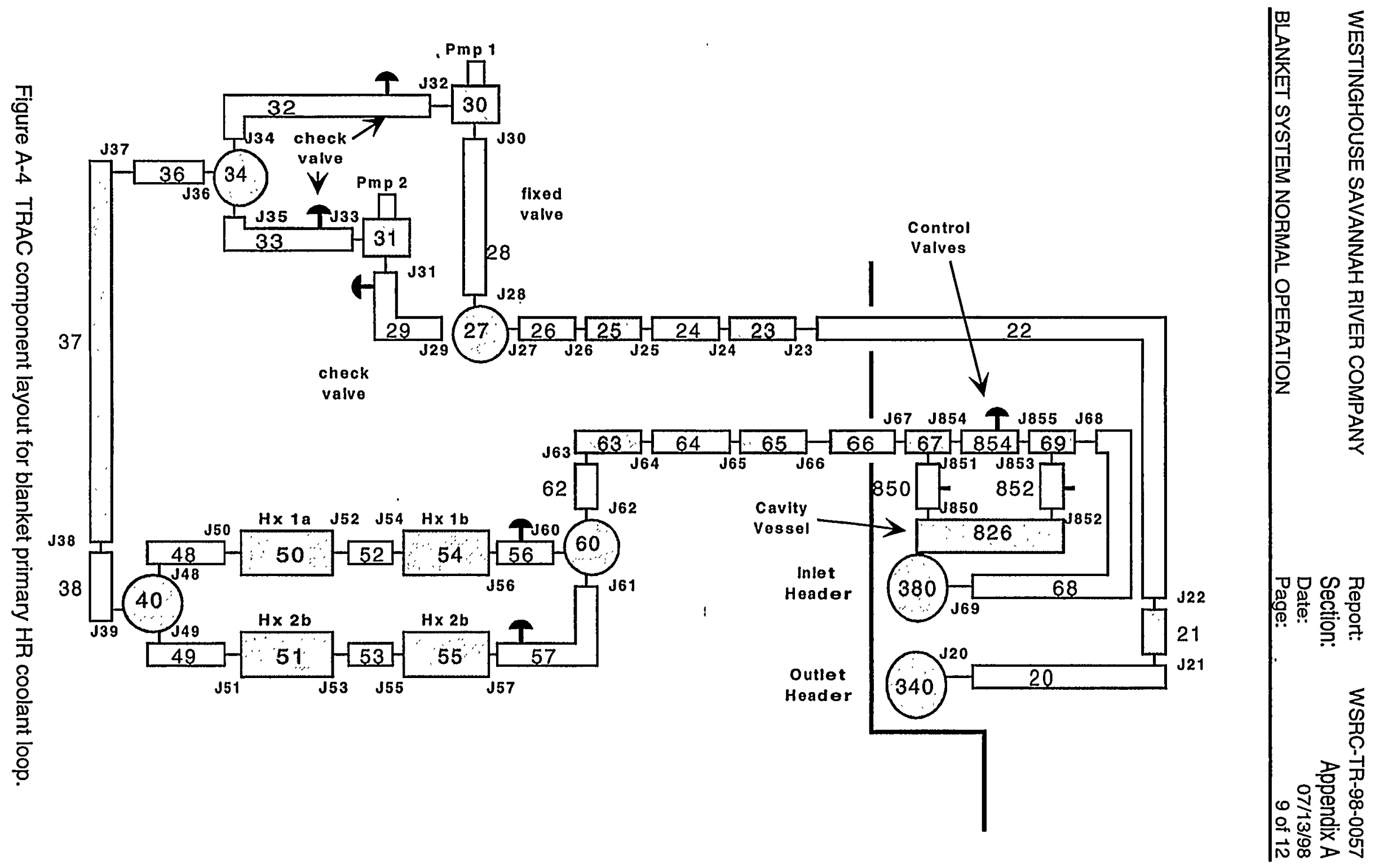


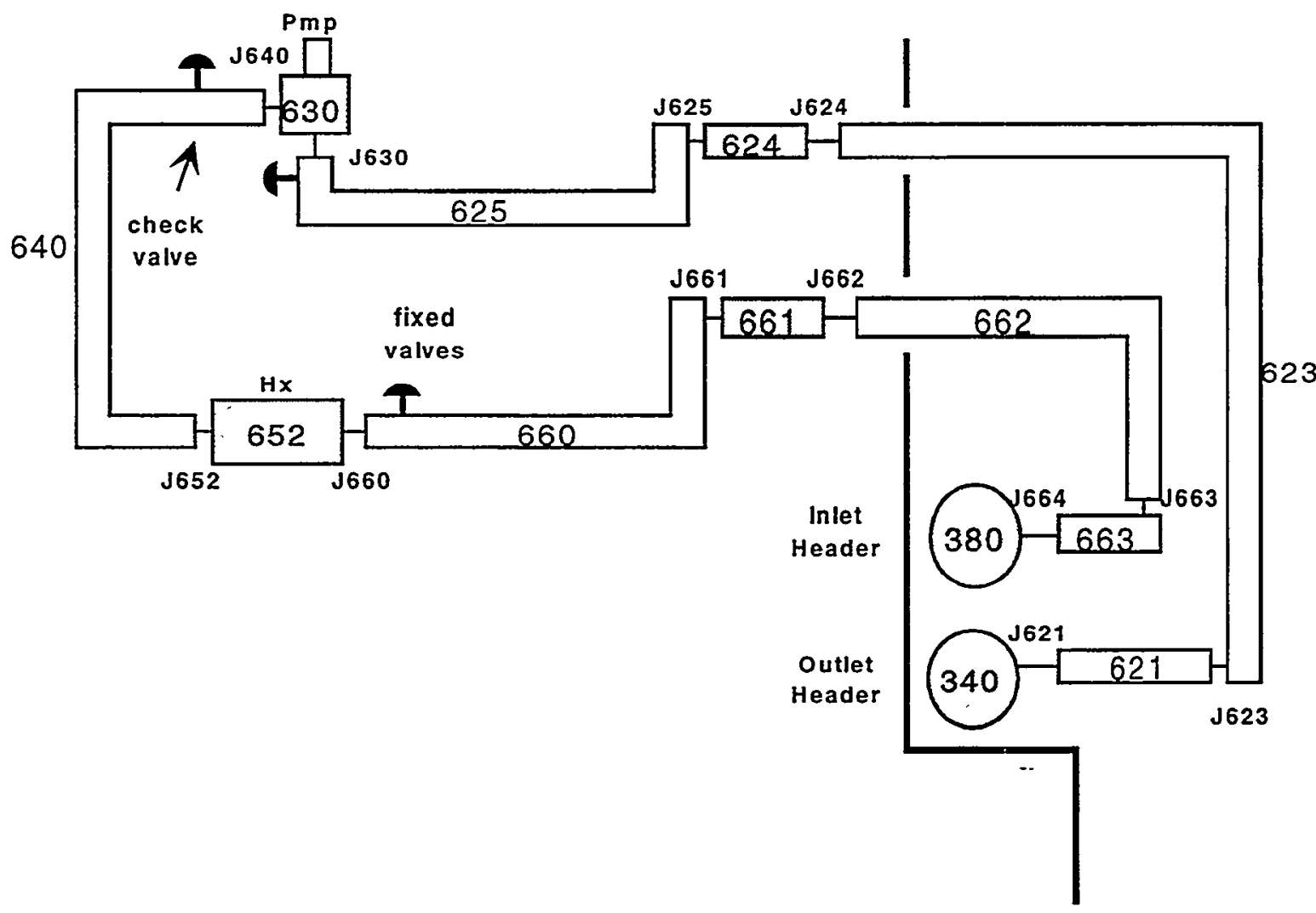

Figure A-5 TRAC component layout for blanket primary RHR coolant loop. 


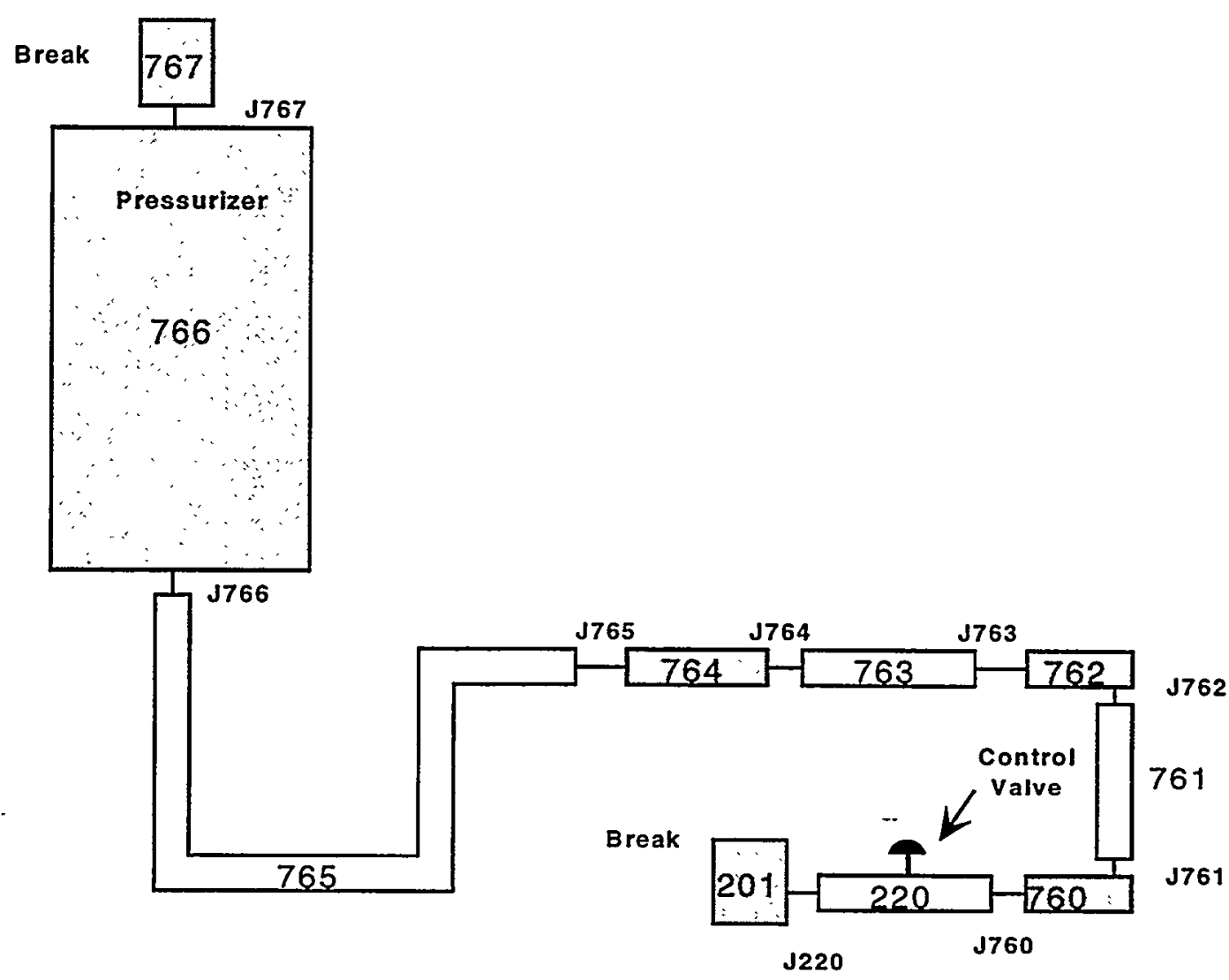

Figure A-6 TRAC component layout for blanket primary pressurizer and surge line. 
WESTINGHOUSE SAVANNAH RIVER COMPANY

BLANKET SYSTEM NORMAL OPERATION
Report: WSRC-TR-98-0057

Section: Appendix A

Date:

Page:
$07 / 13 / 98$

12 of 12

(This Page intentionally Left Blank) 


\section{Appendix B Normal Operation TRAC Results}

\section{Appendix B1 Normal Operation TRAC Plenum Component Figures}

The following figures are from a TRAC simulation for normal operation:

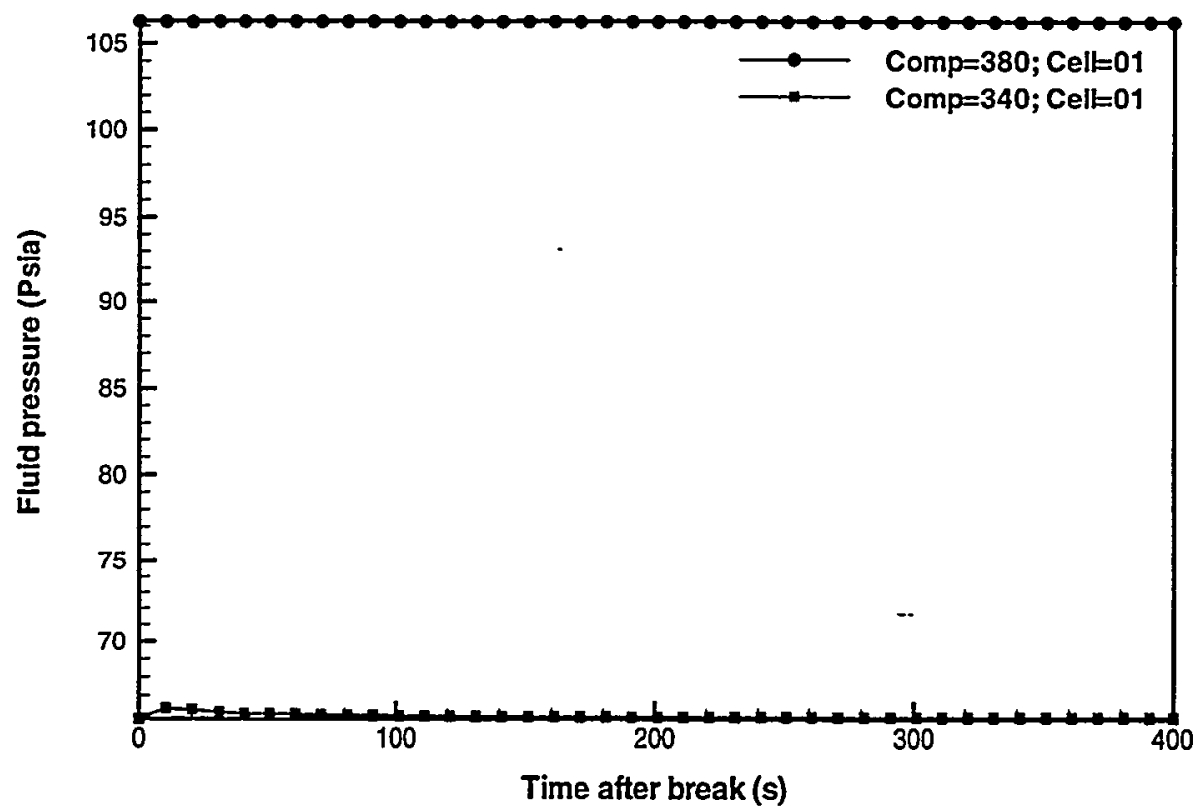

Figure B-1a Fixed header fluid pressures for NO (False transient to establish steadystate). 


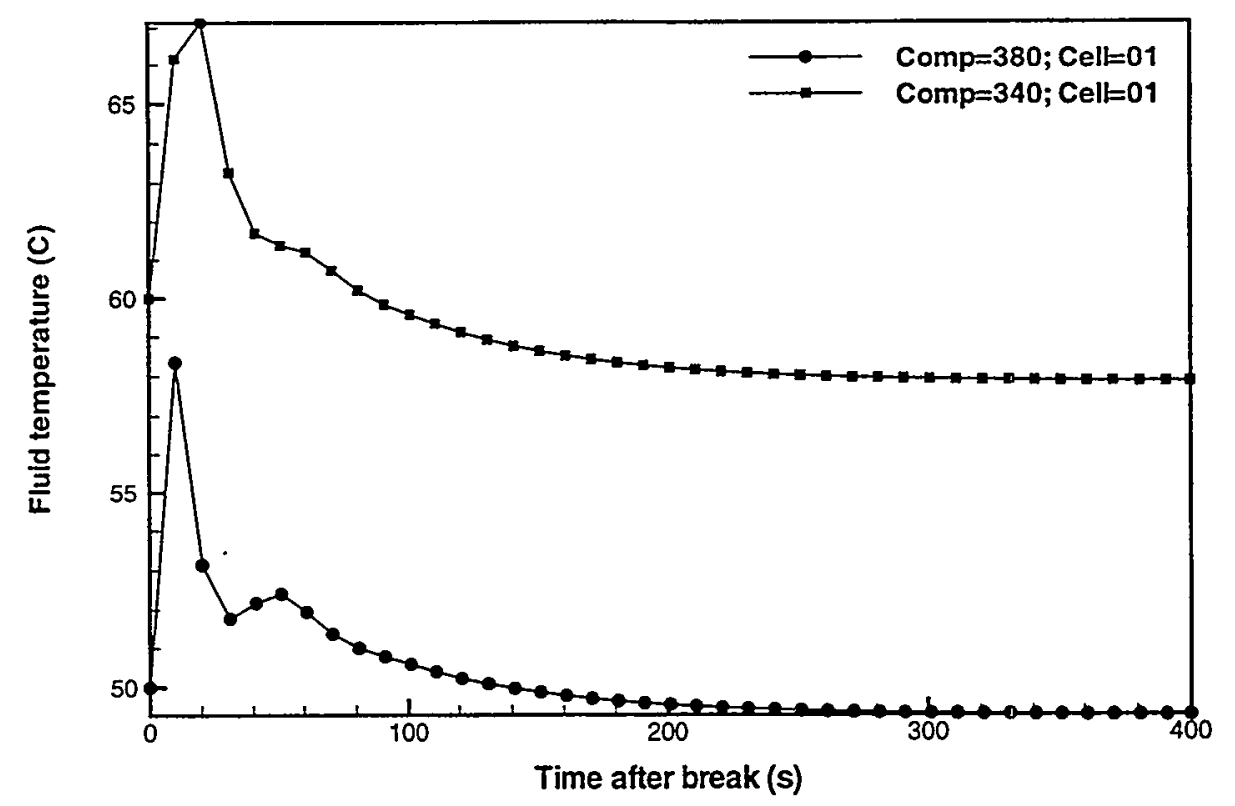

Figure B-1b Fixed header fluid temperatures for NO (False transient to establish steady-state).

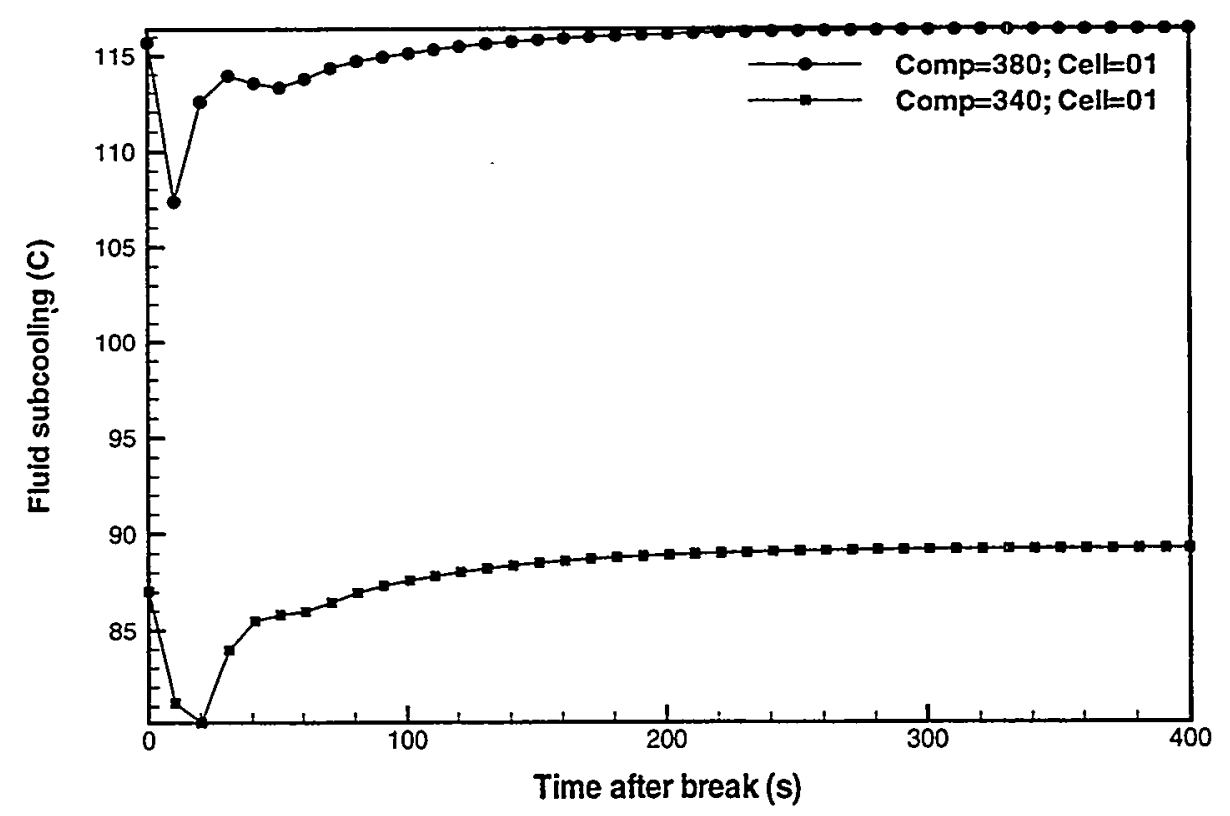

Figure B-1c Fixed header fluid subcoolings for NO (False transient to establish steadystate). 


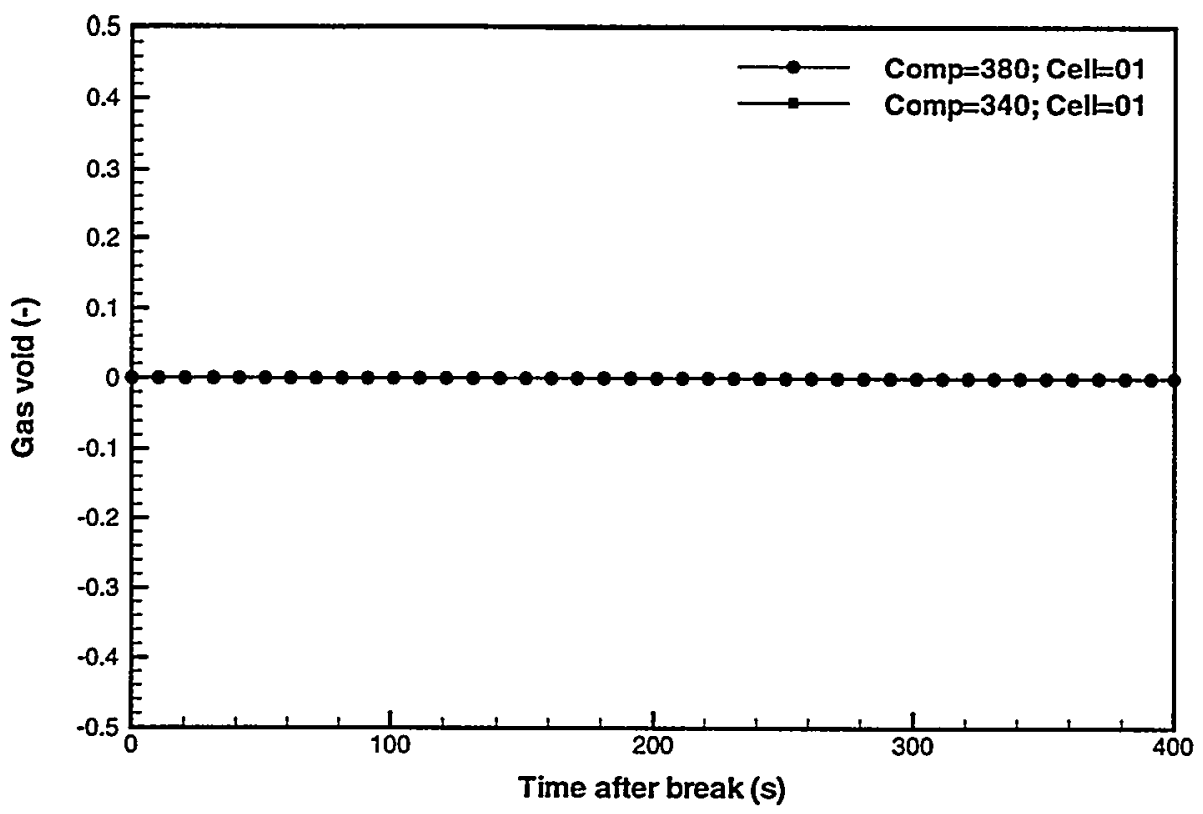

Figure B-1d Fixed header void fractions for NO (False transient to establish steadystate).

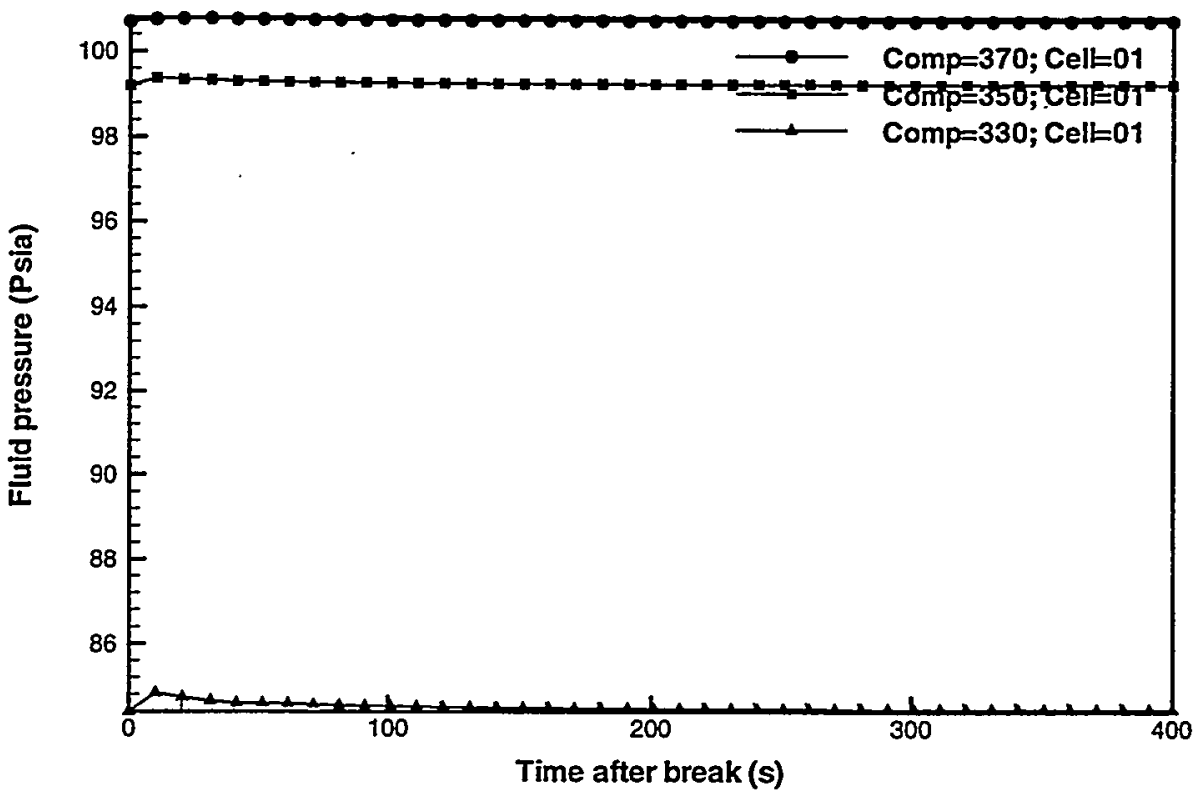

Figure B-2a Module 1 plenum fluid pressures for NO (False transient to establish steady-state). 


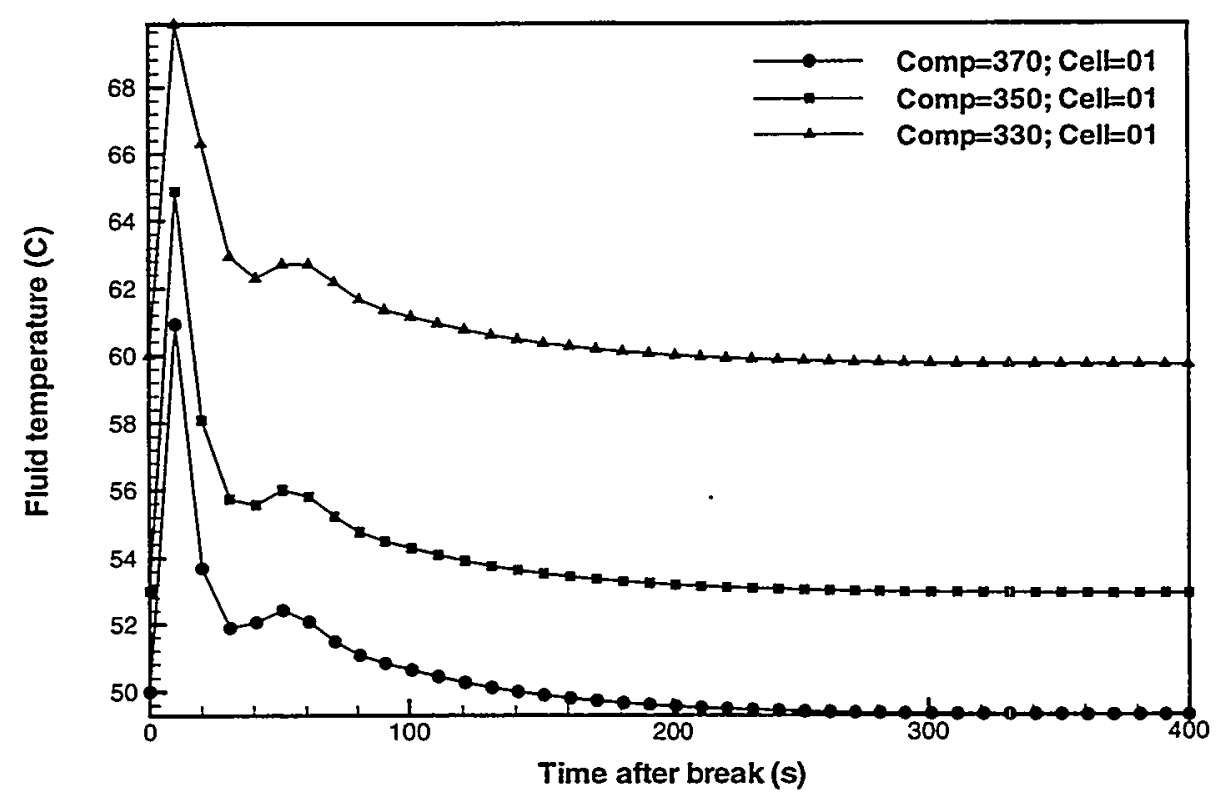

Figure B-2b Module 1 plenum fluid temperatures for NO (False transient to establish steady-state).

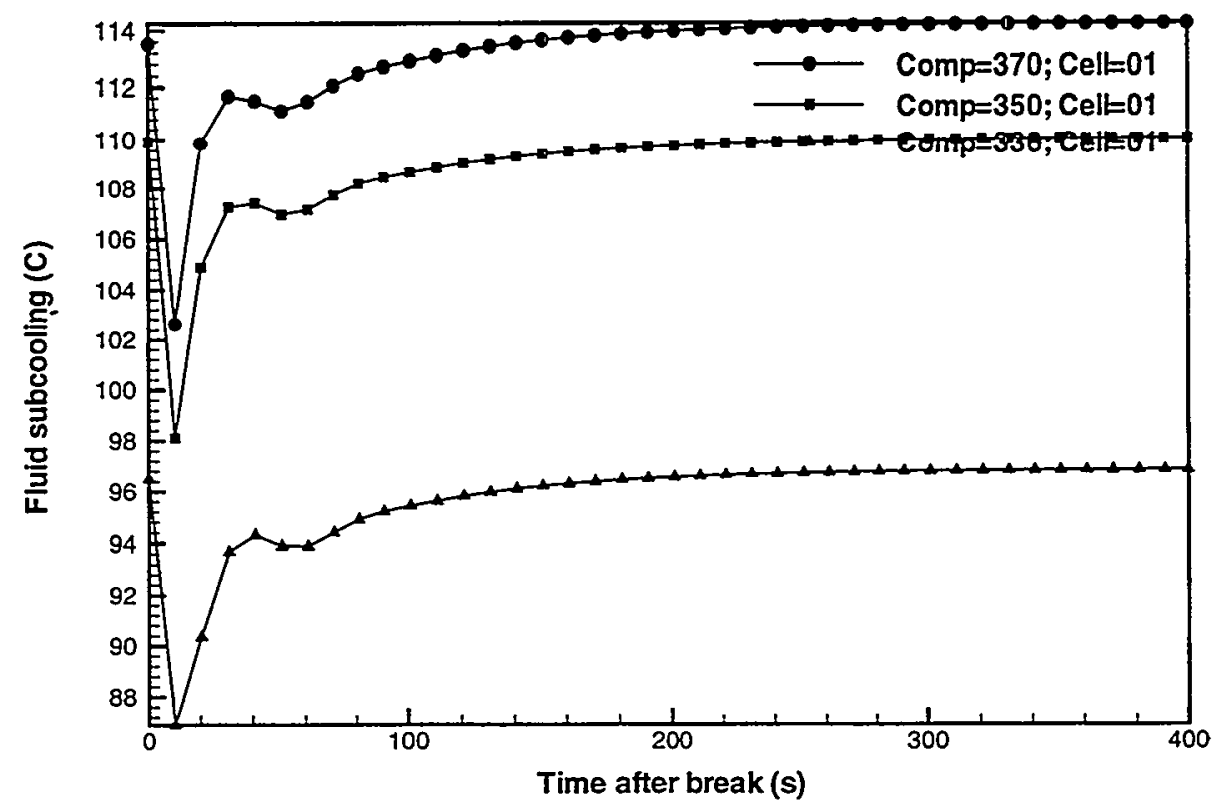

Figure B-2c Module 1 plenum fluid subcoolings for NO (False transient to establish steady-state). 


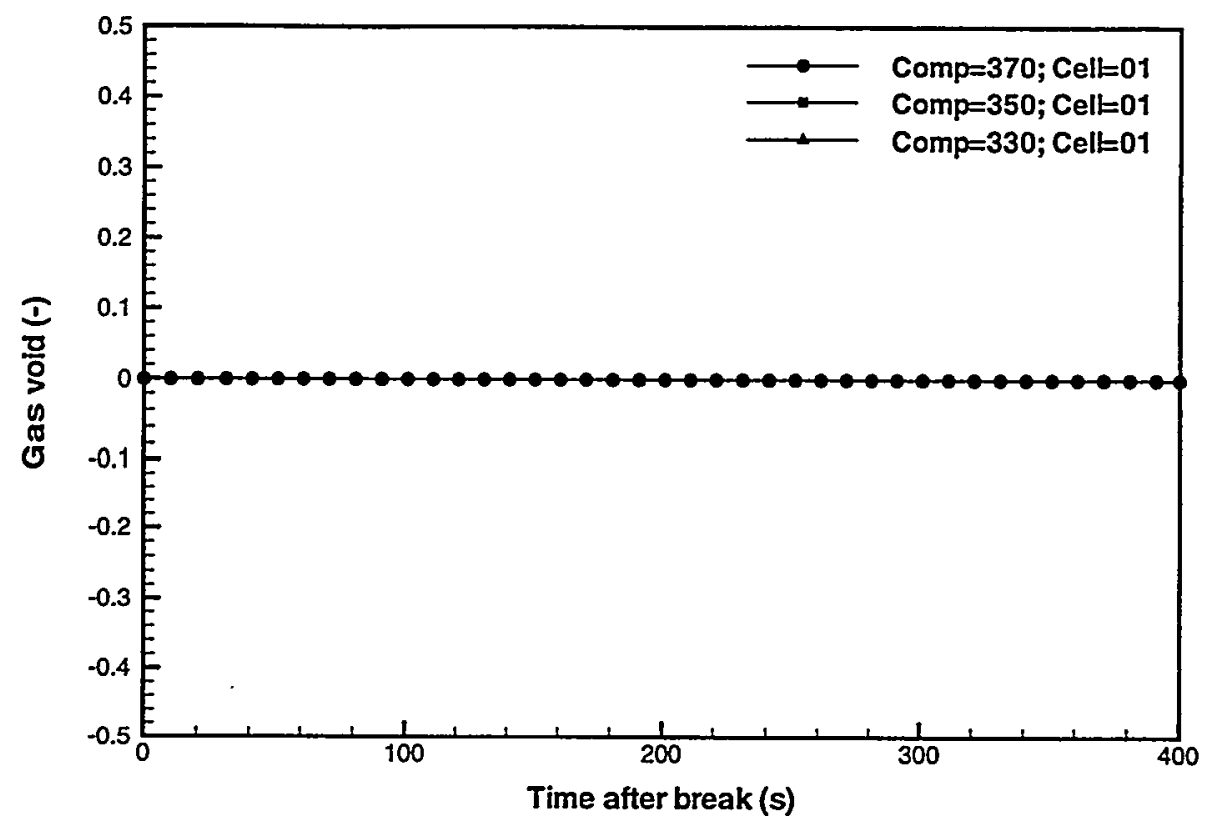

Figure B-2d Module 1 plenum void fractions for NO (False transient to establish steadystate).

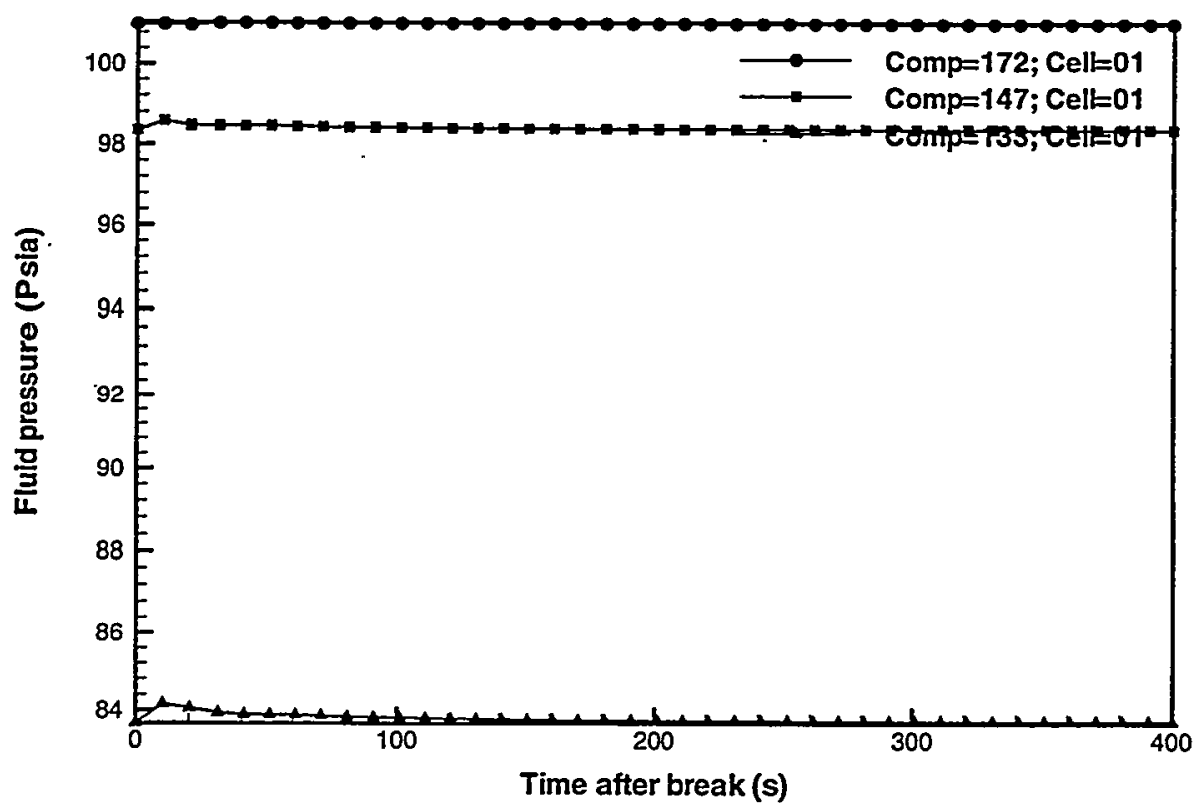

Figure B-3a Module 2 plenum fluid pressures for NO (False transient to establish steady-state). 


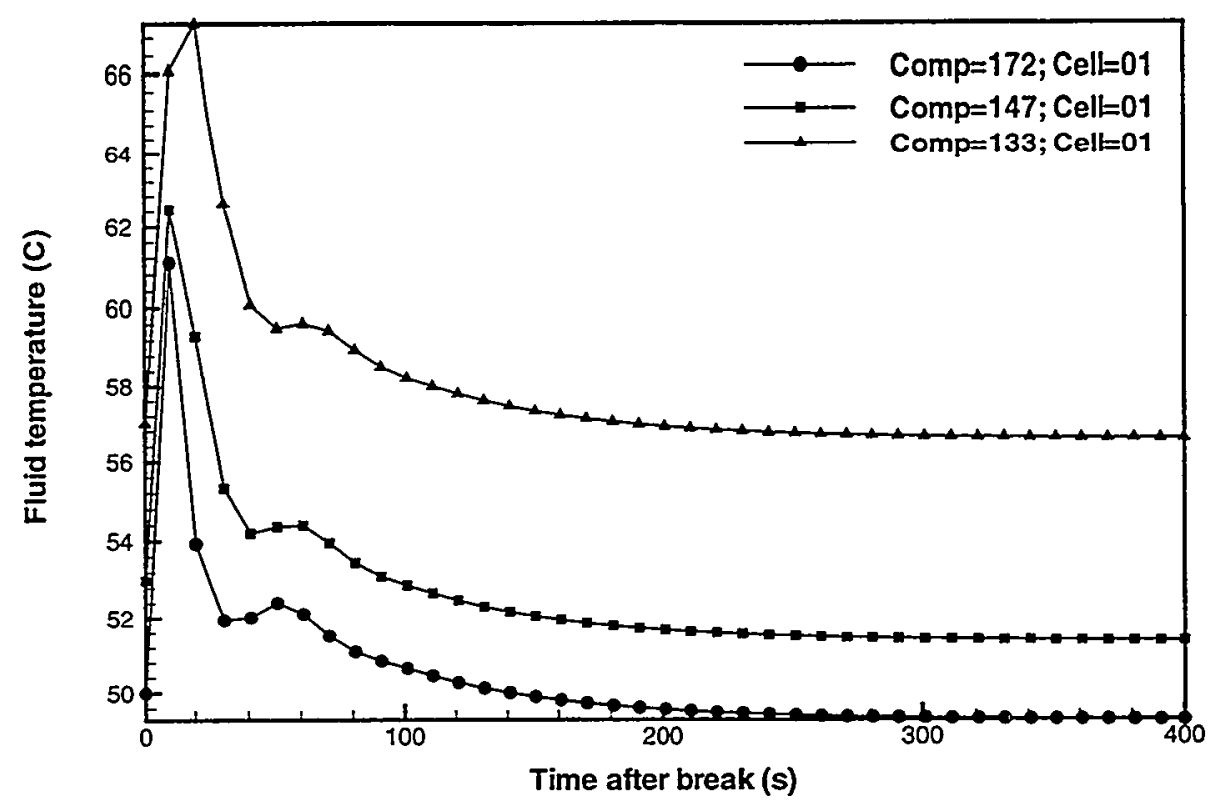

Figure B-3b Module 2 plenum fluid temperatures for NO (False transient to establish steady-state).

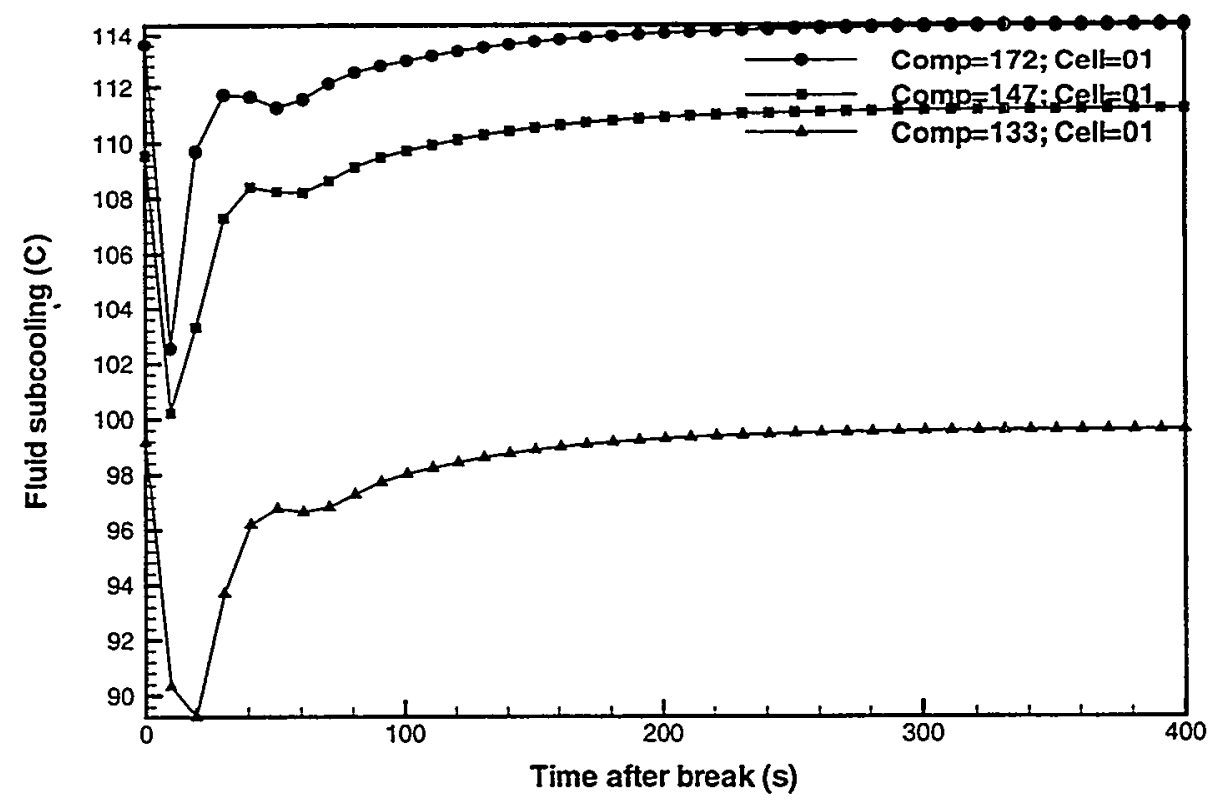

Figure B-3c Module 2 plenum fluid subcoolings for NO (False transient to establish steady-state). 


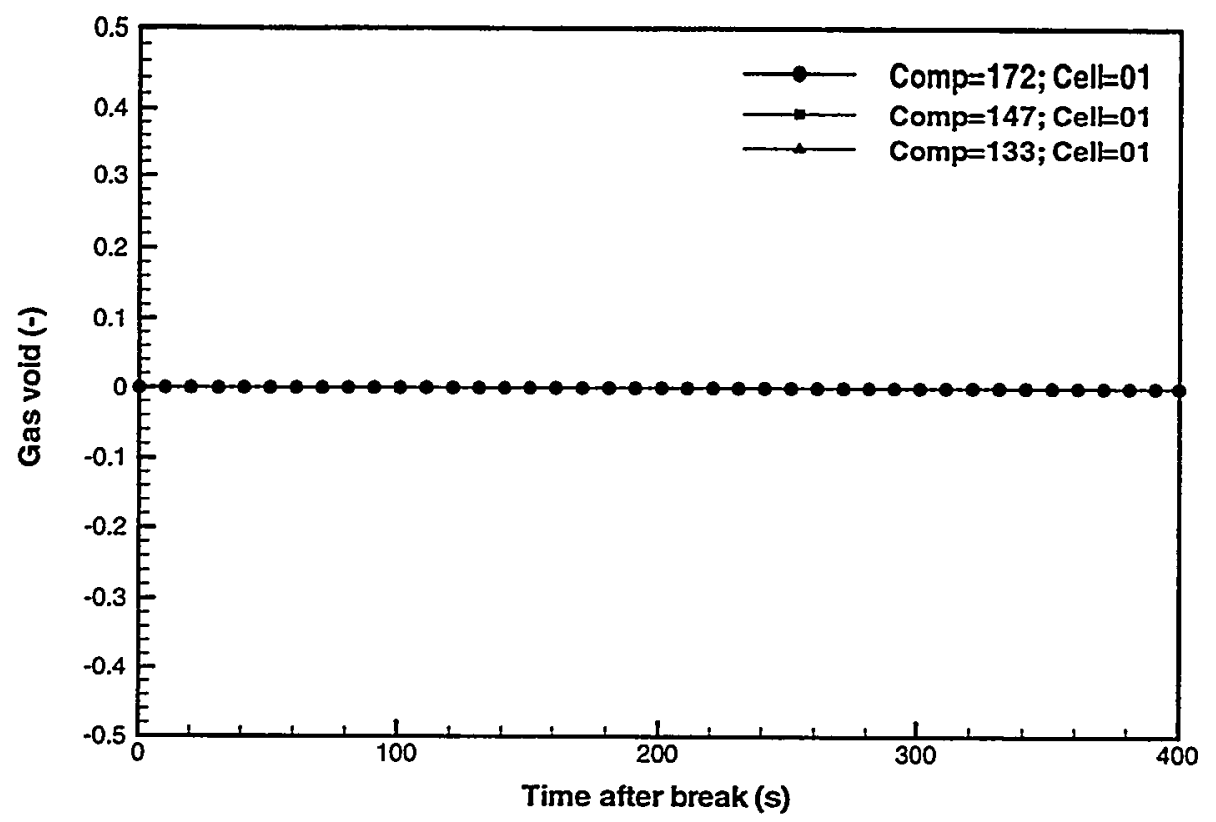

Figure B-3d Module 2 plenum void fractions for NO (False trañsient to establish steadystate).

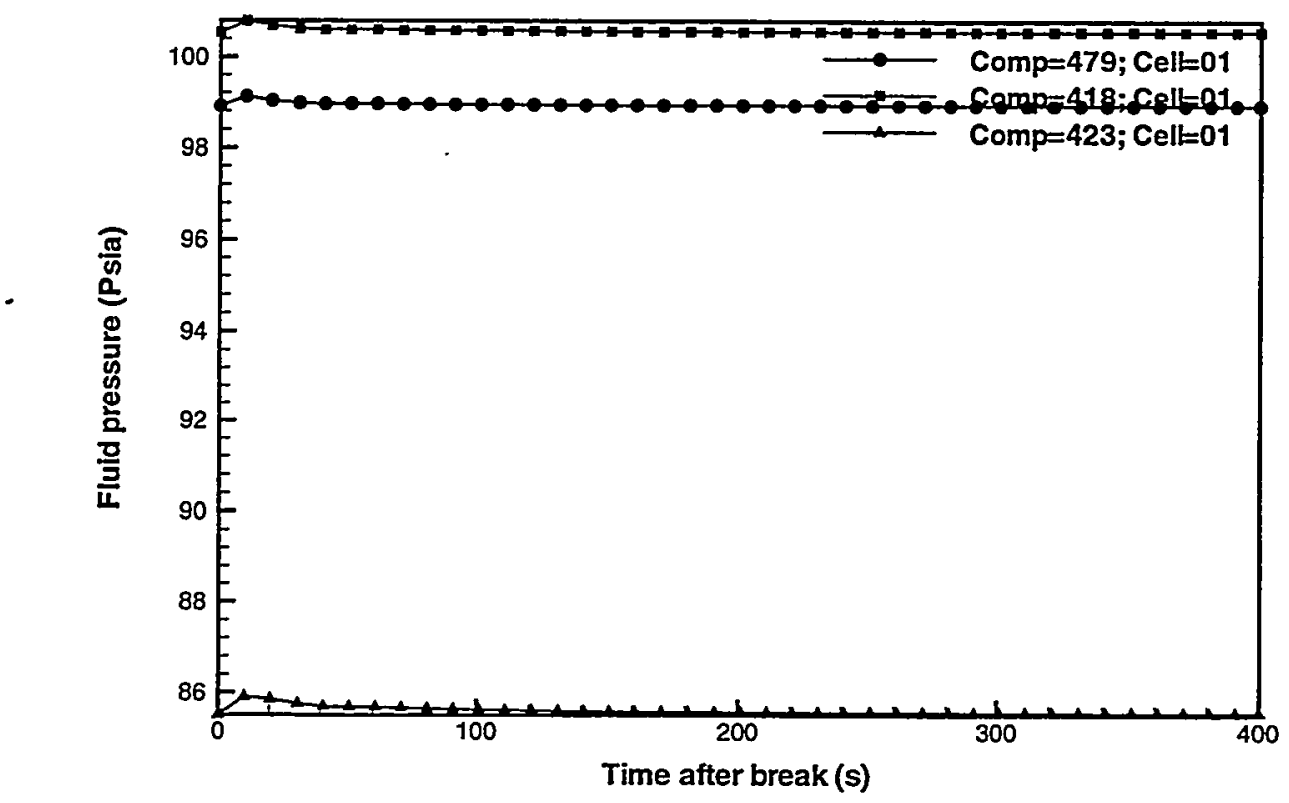

Figure B-4a Module 3 plenum fluid pressures for NO (False transient to establish steady-state). 


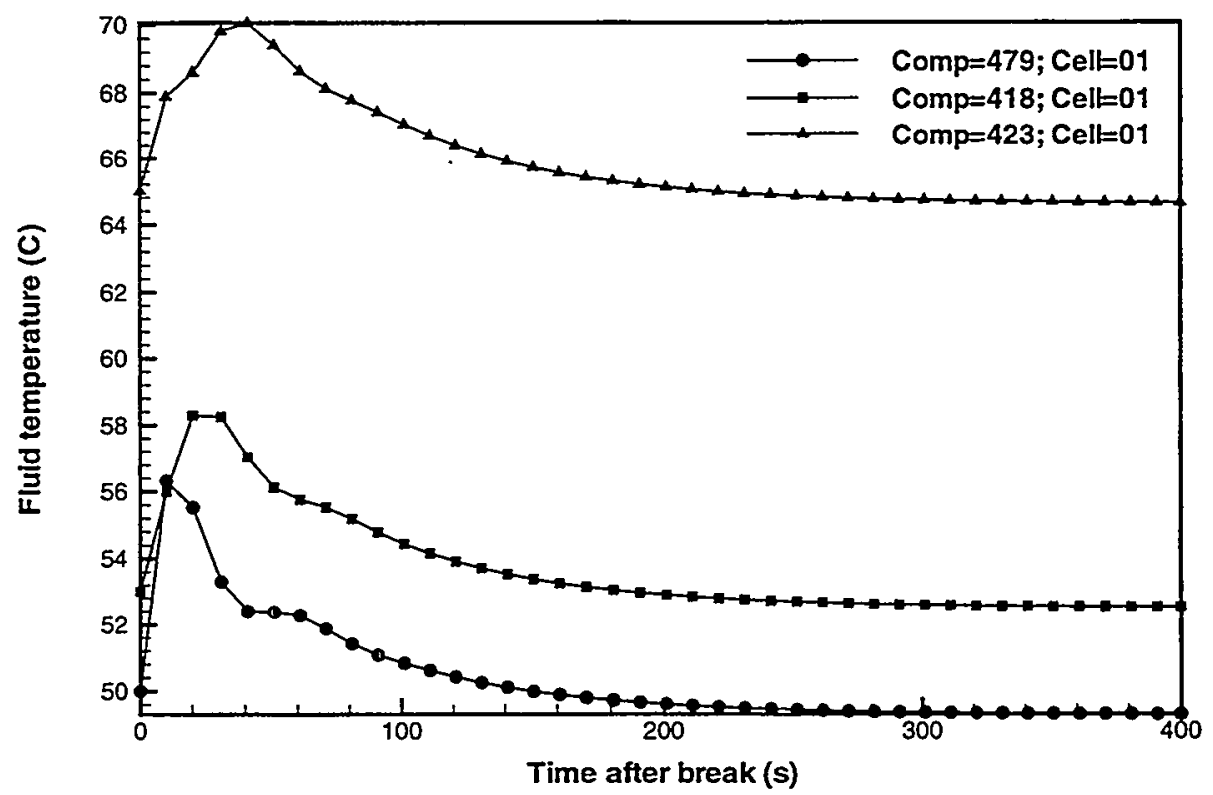

Figure B-4b Module 3 plenum fluid temperatures for NO (False tranšient to establish steady-state).

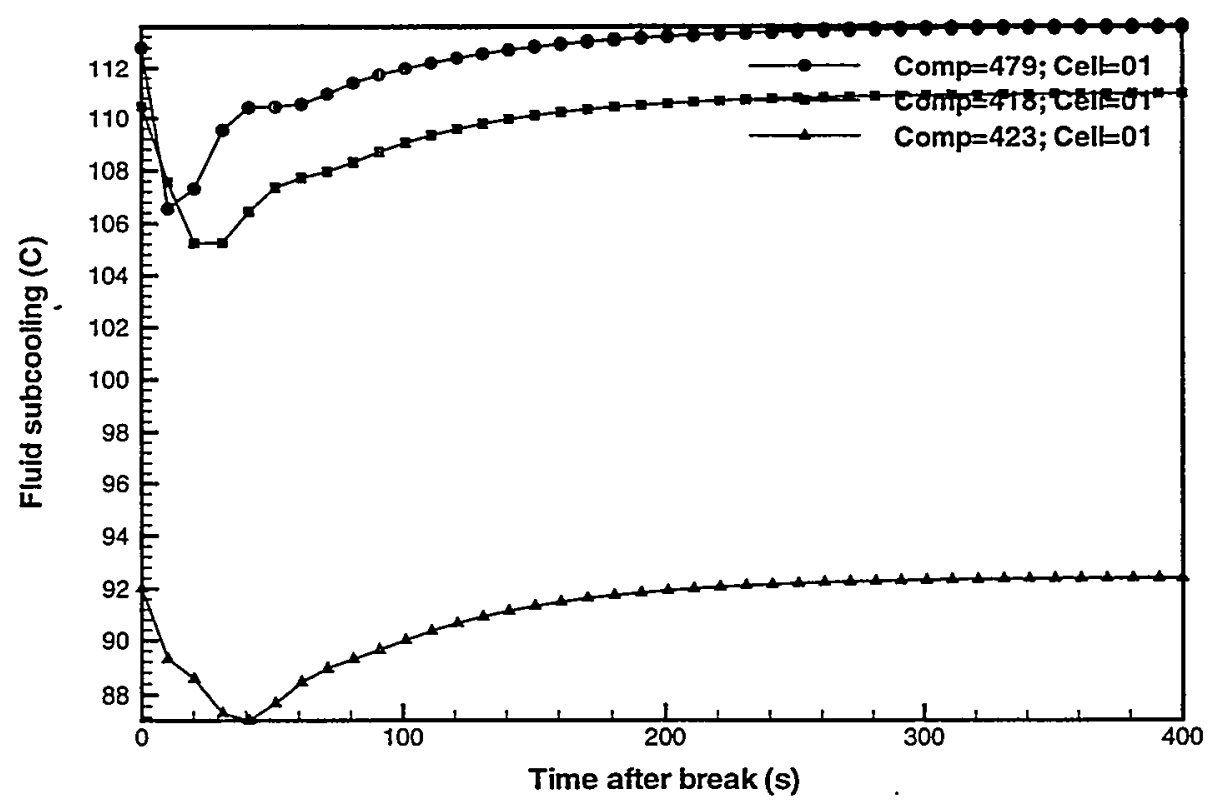

Figure B-4c Module 3 plenum fluid subcoolings for NO (False transient to establish steady-state). 


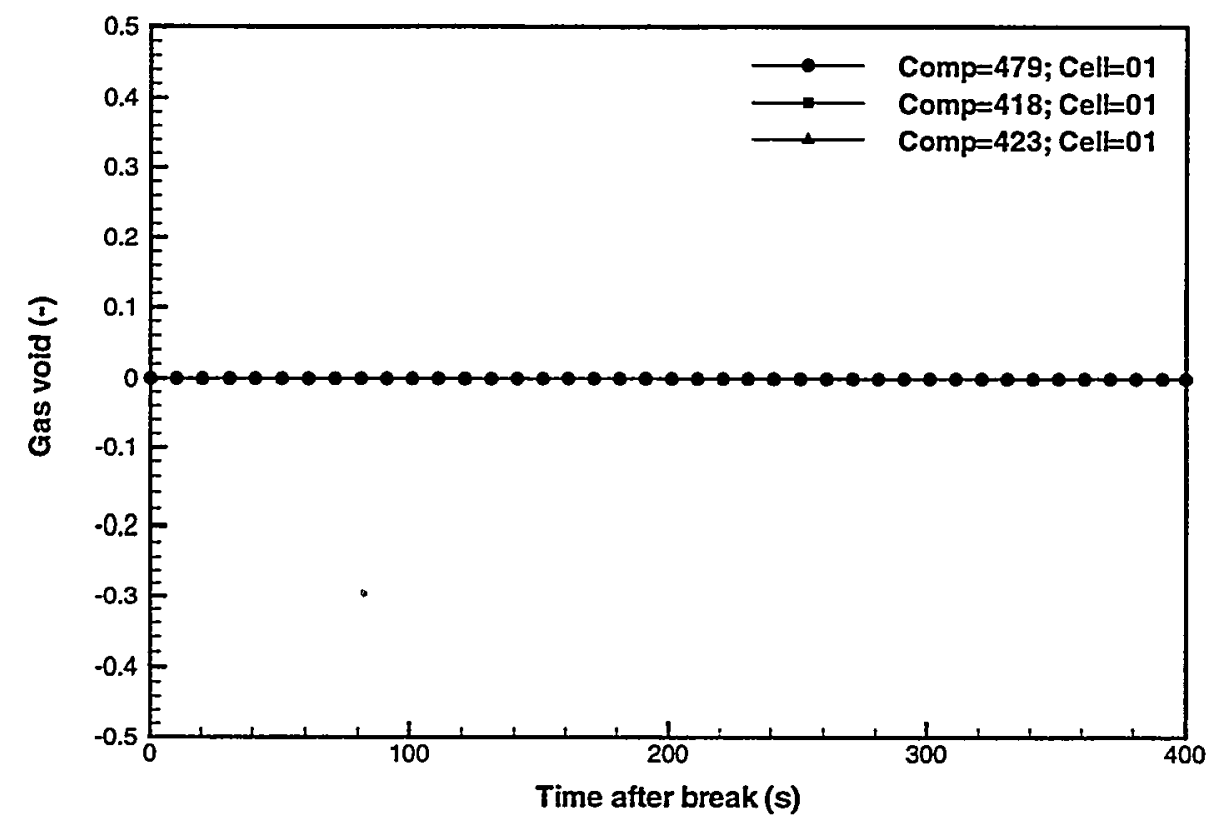

Figure B-4d Module 3 plenum void fractions for NO (False trañsient to establish steadystate).

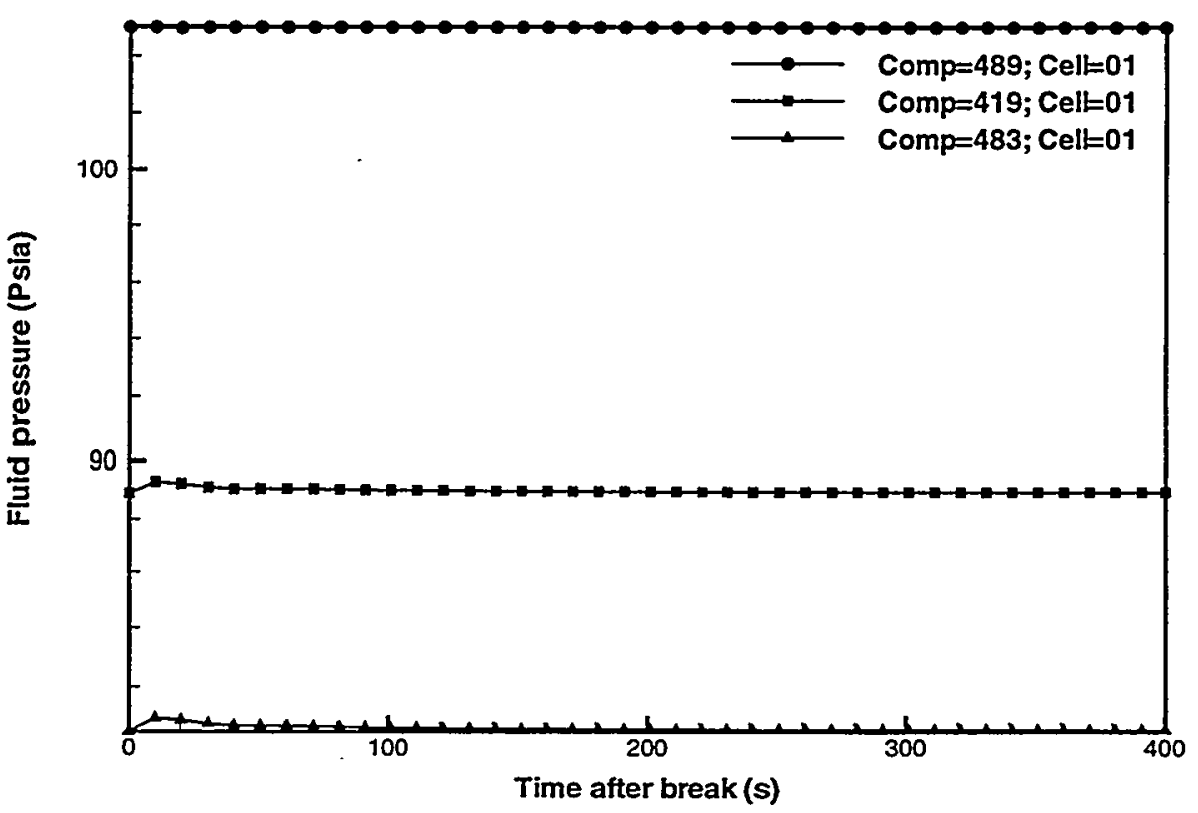

Figure B-5a Module 4 plenum fluid pressures for NO (False transient to establish steady-state). 


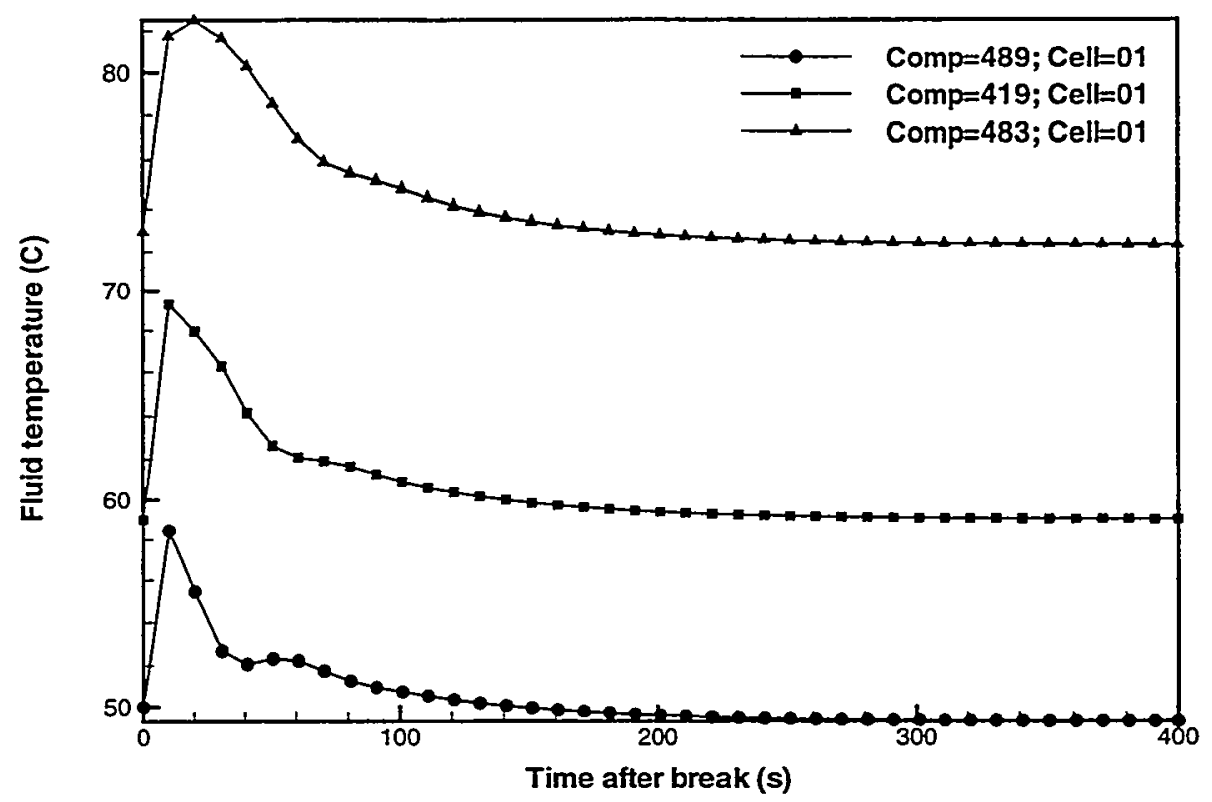

Figure B-5b Module 4 plenum fluid temperatures for NO (False transiient to establish steady-state).

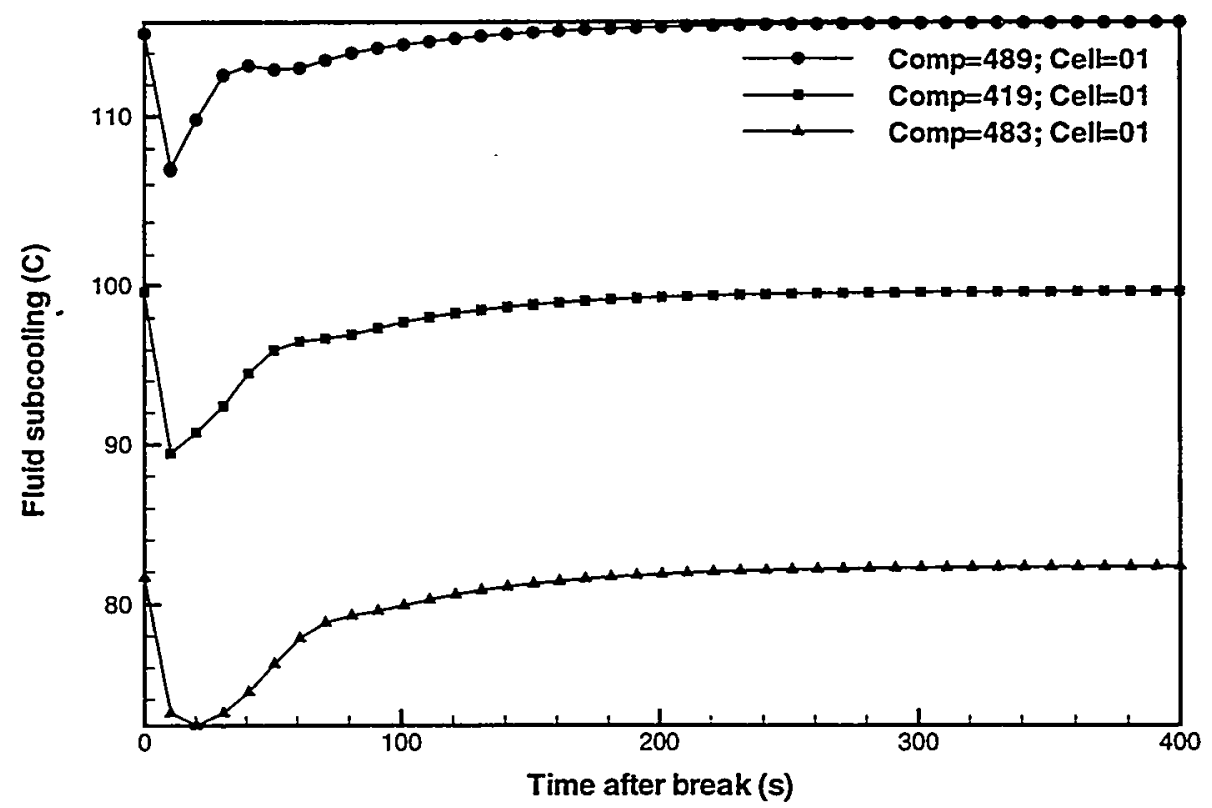

Figure B-5c Module 4 plenum fluid subcoolings for NO (False transient to establish steady-state). 


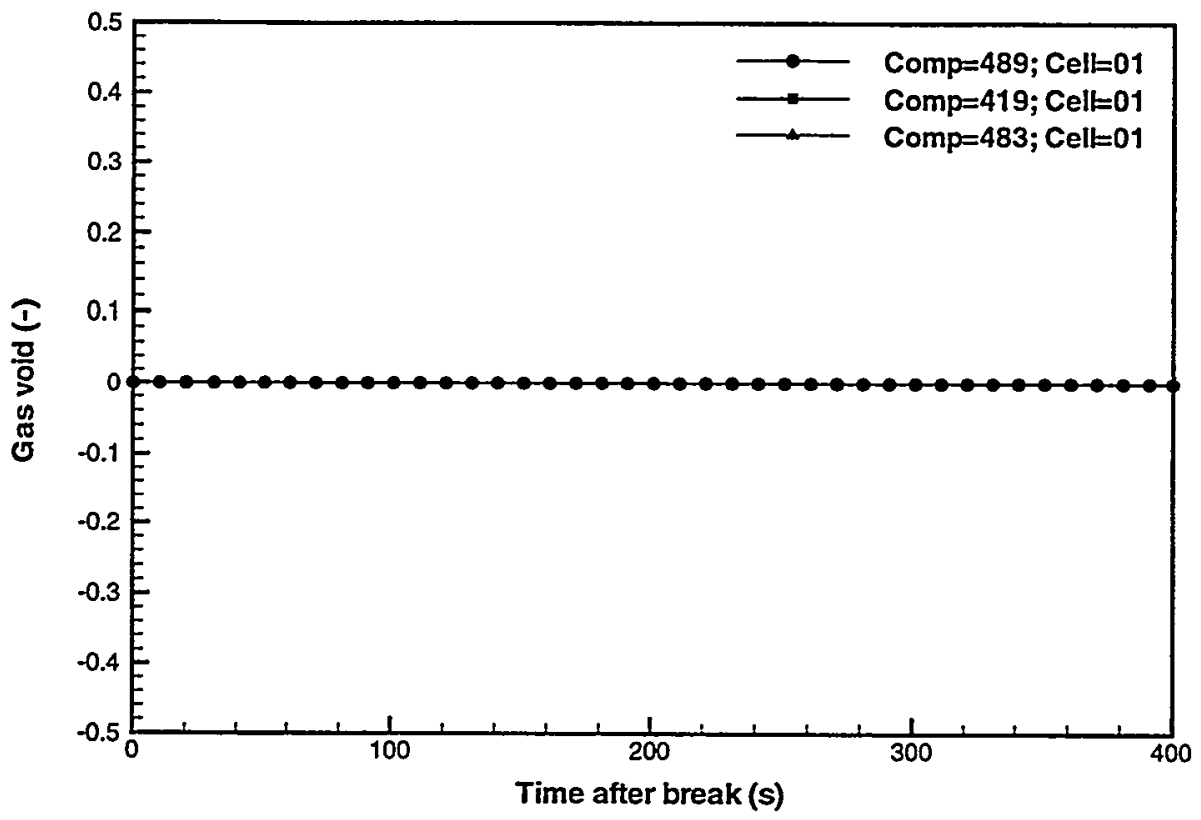

Figure B-5d Module 4 plenum void fractions for NO (False trañsient to establish steadystate).

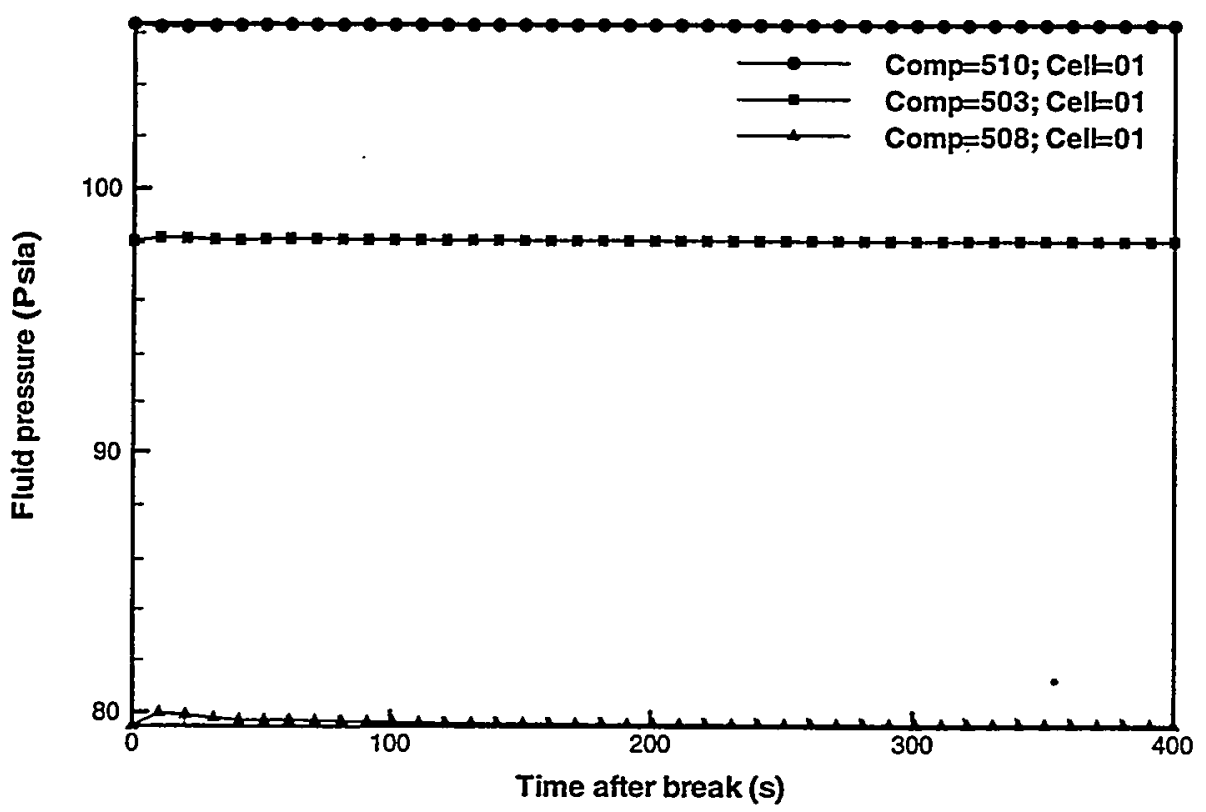

Figure B-6a Module 5 plenum fluid pressures for NO (False transient to establish steady-state). 


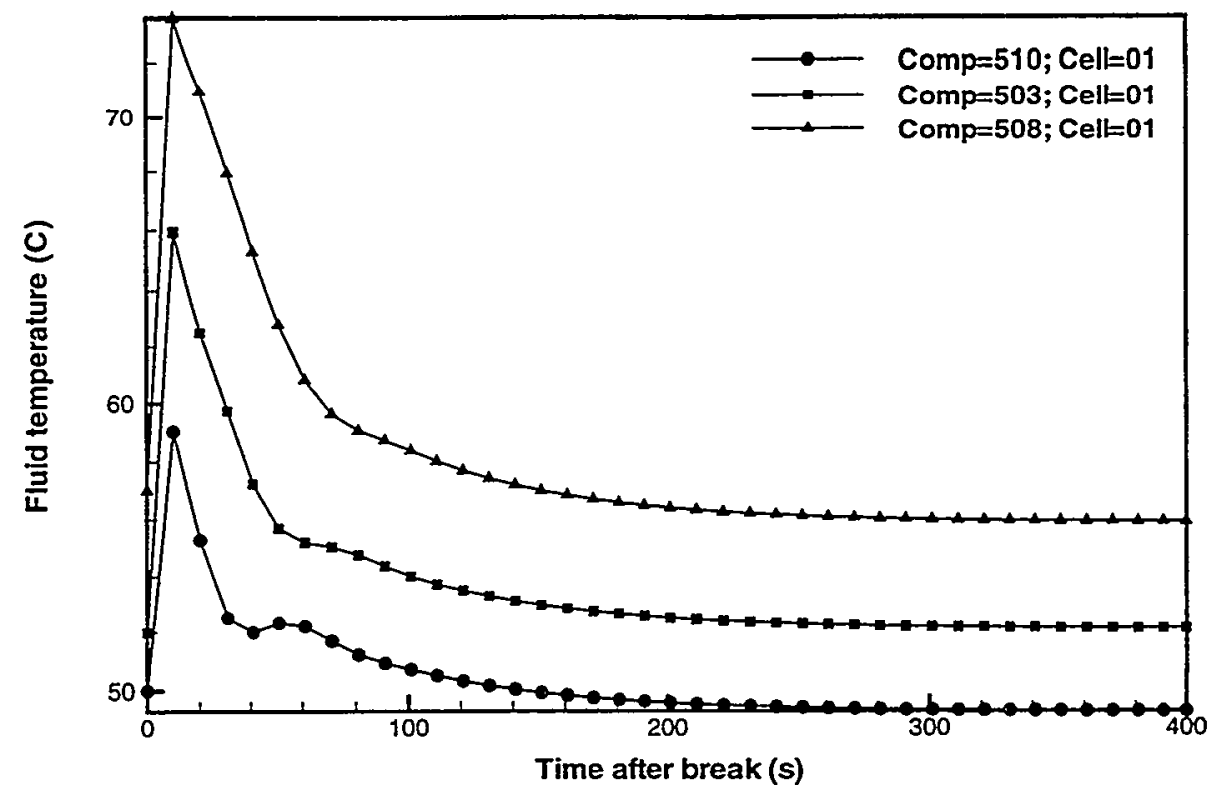

Figure B-6b Module 5 plenum fluid temperatures for NO (False transient to establish steady-state).

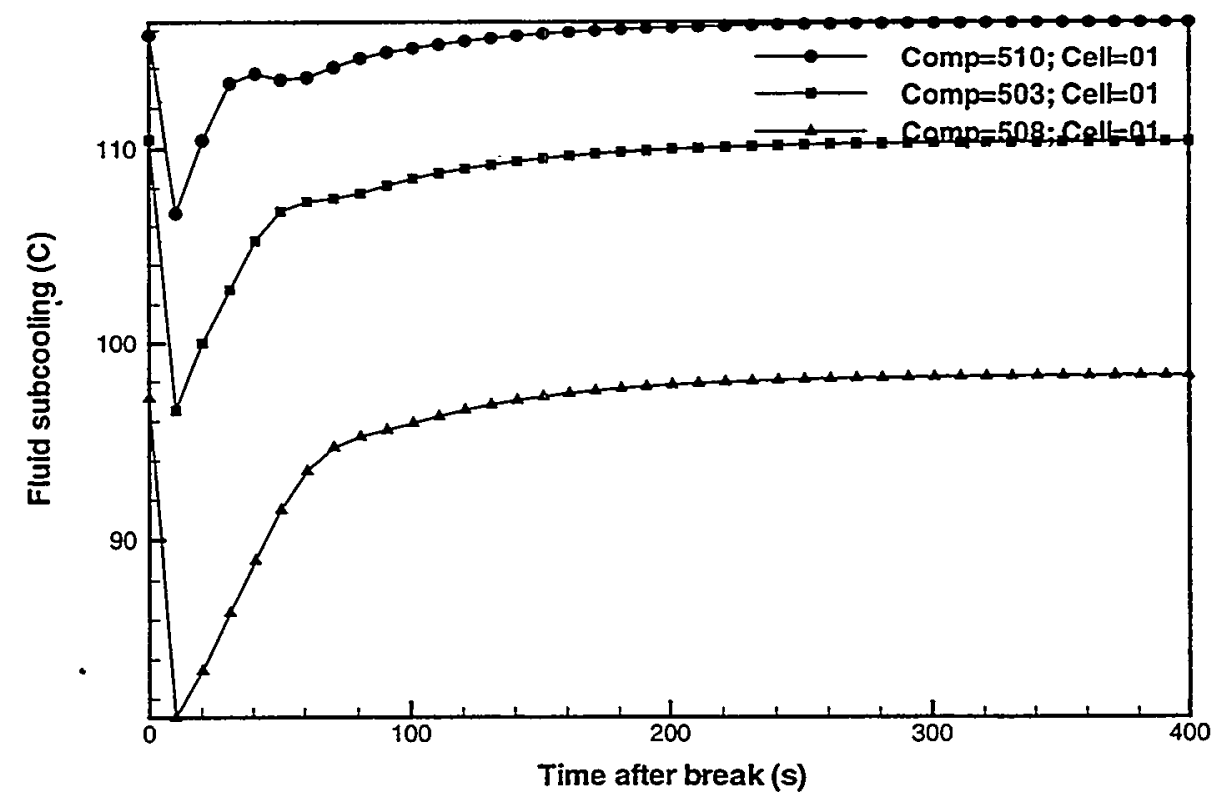

Figure B-6c Module 5 plenum fluid subcoolings for NO (False transient to establish steady-state). 


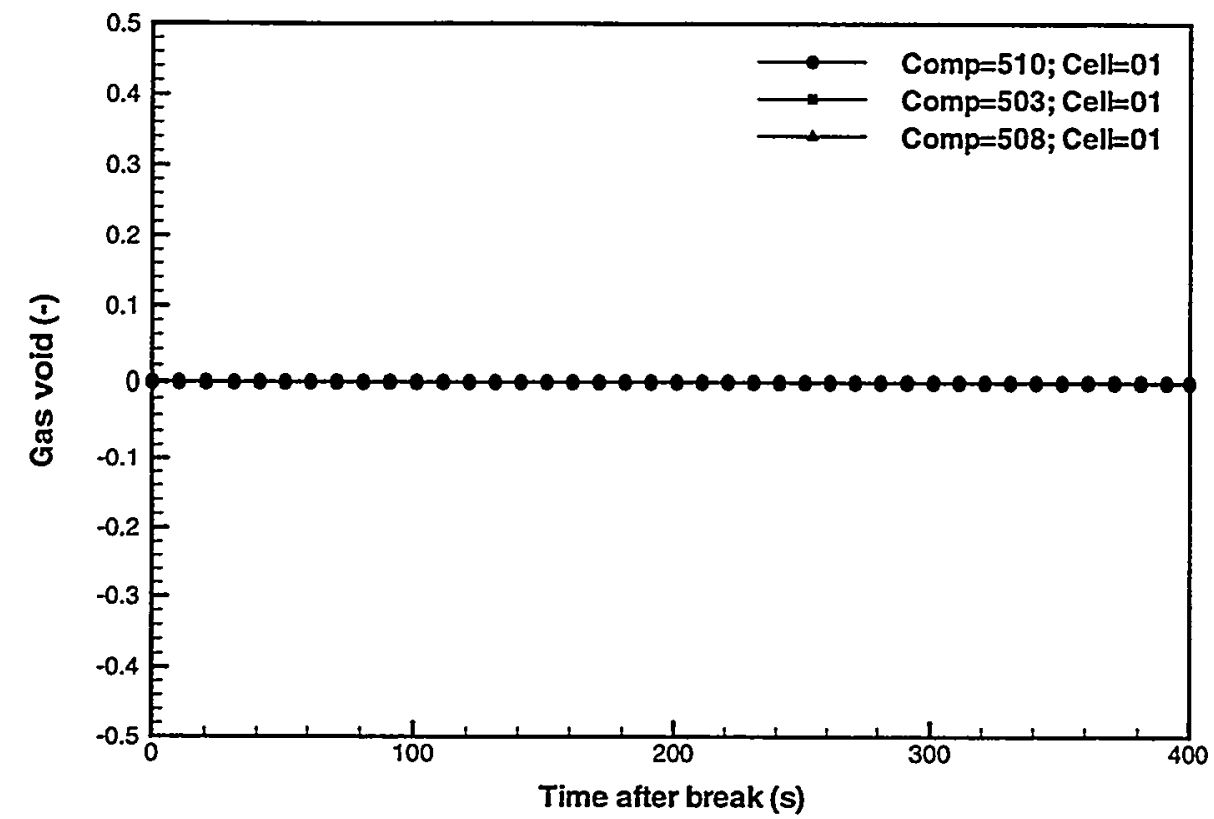

Figure B-6d Module 5 plenum void fractions for NO (False transient to establish steadystate).

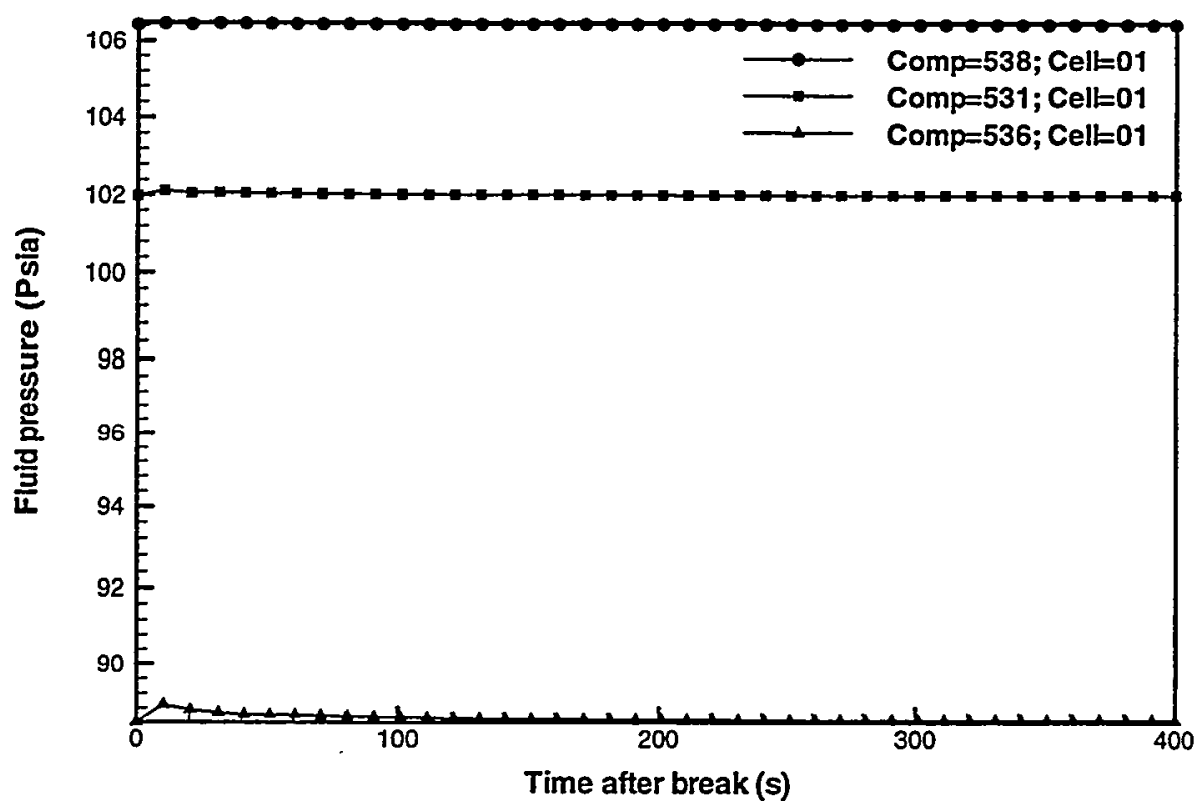

Figure B-7a Module 6 plenum fluid pressures for NO (False transient to establish steady-state). 


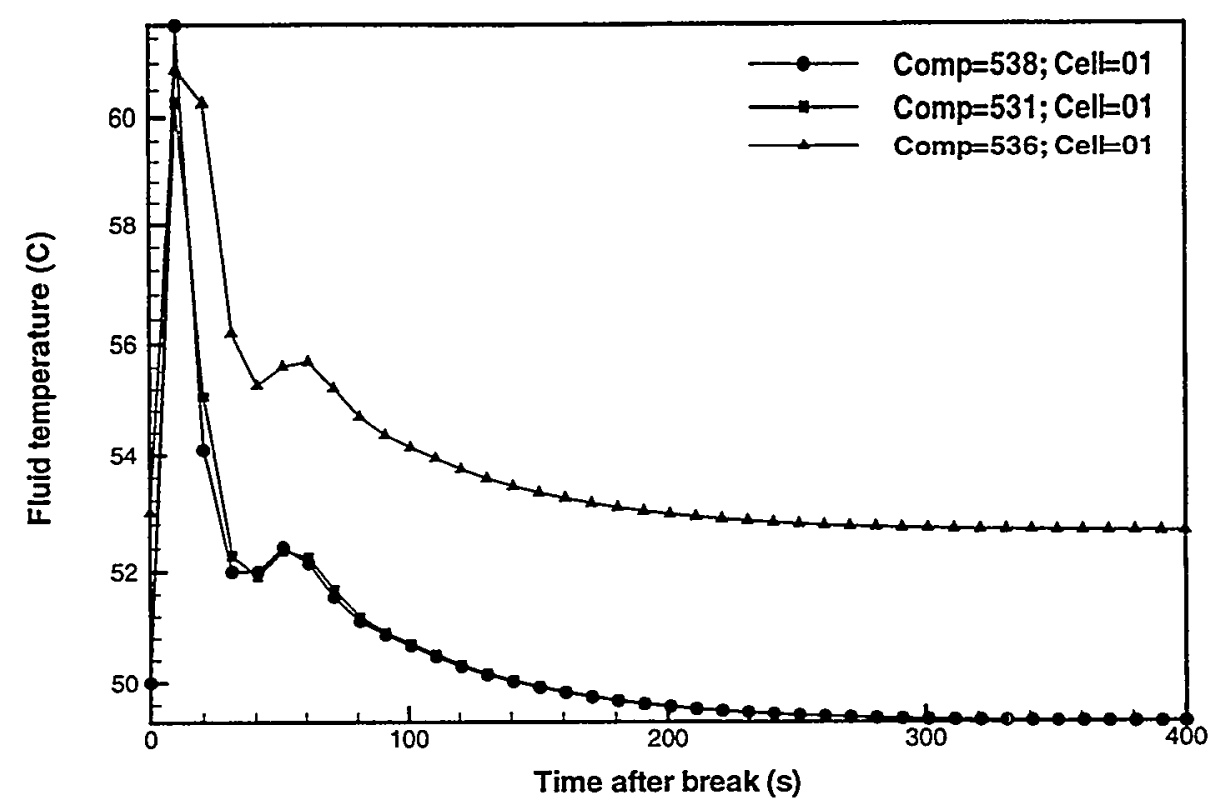

Figure B-7b Module 6 plenum fluid temperatures for NO (False tranisient to establish steady-state).

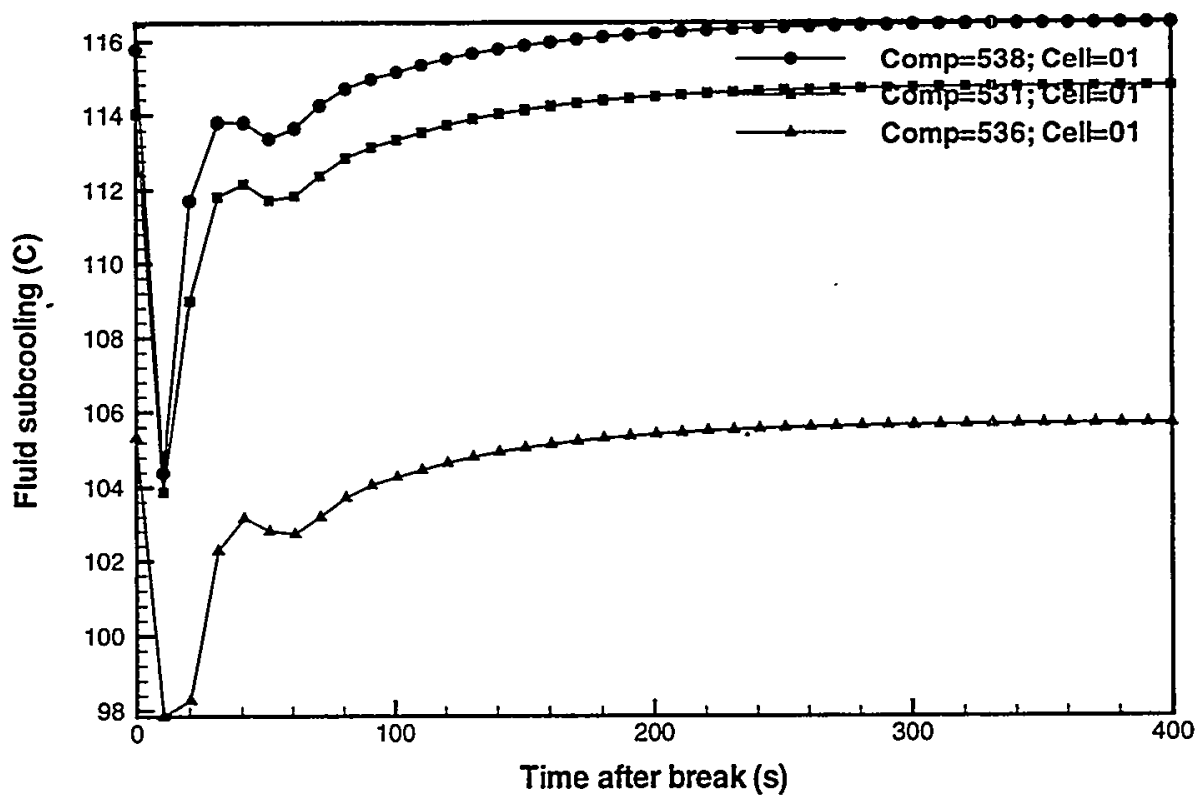

Figure B-7c Module 6 plenum fluid subcoolings for NO (False transient to establish steady-state). 


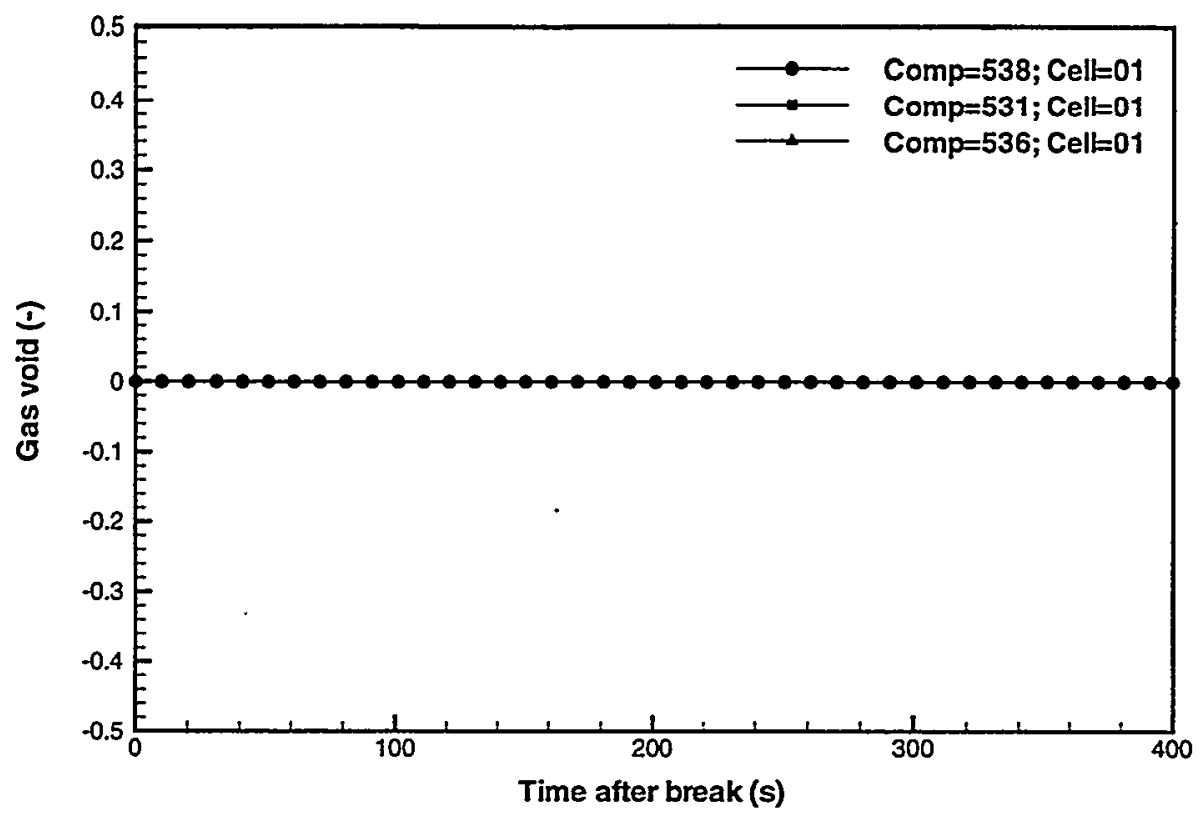

Figure B-7d Module 6 plenum void fractions for NO (False transient to establish steadystate). 


\section{Appendix B2 Normal Operation TRAC Pipe, Pump, and Valve Component} Figures

The following figures are from a TRAC simulation for normal operation:

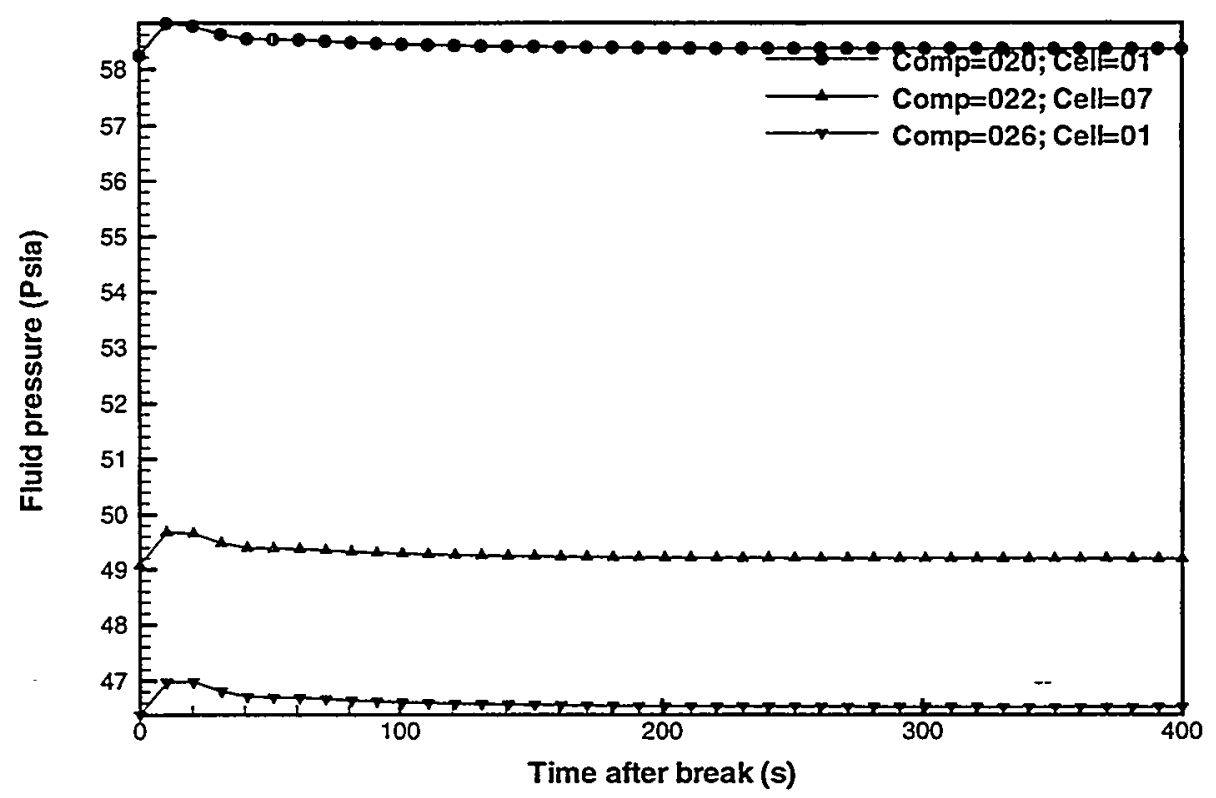

Figure B-8a Primary HR hot-leg piping fluid pressures for NO (False transient to establish steady-state). 


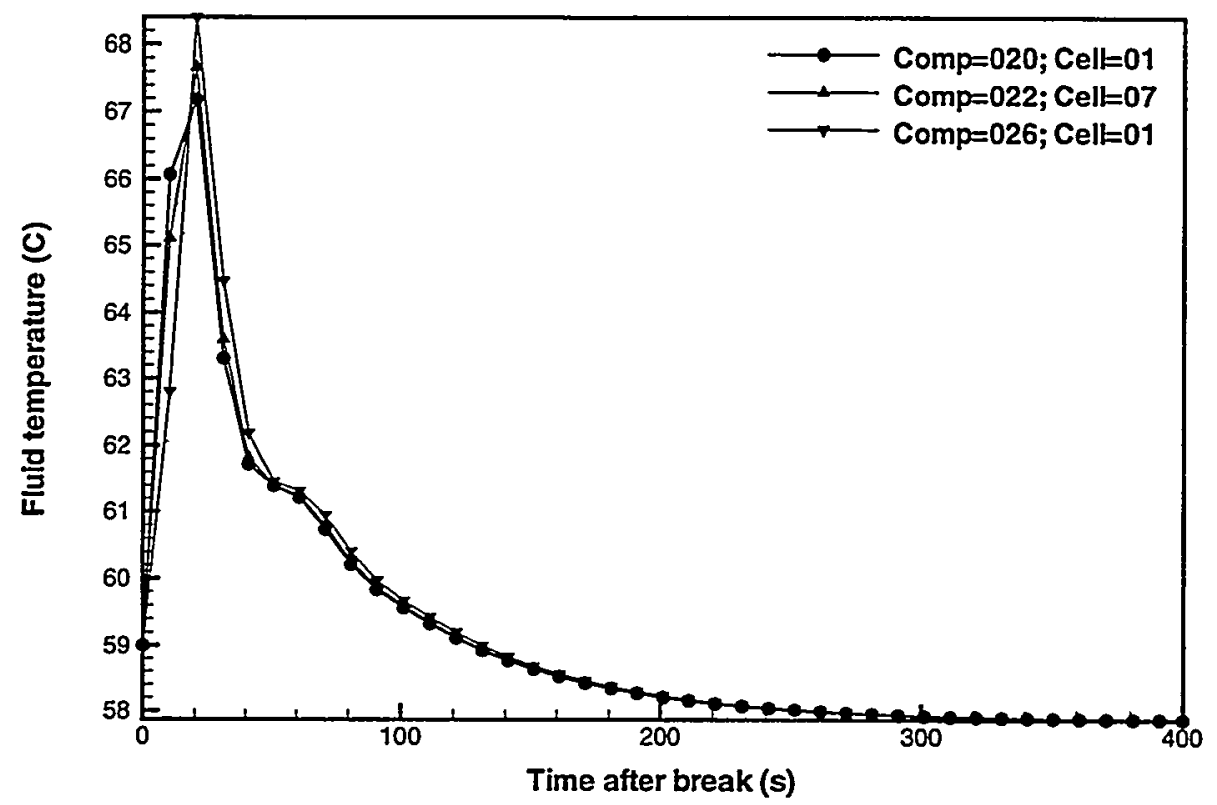

Figure B-8b Primary HR hot-leg piping fluid temperatures forr NO (False transient to establish steady-state).

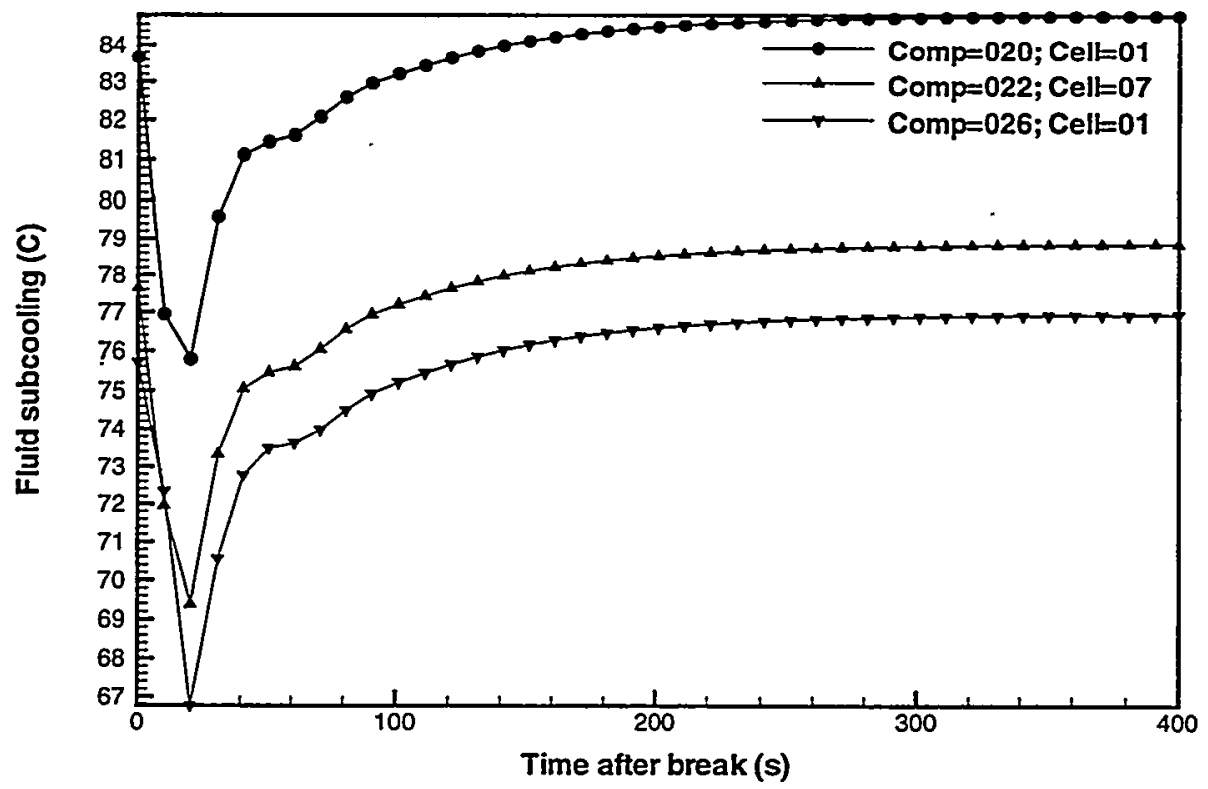

Figure B-8c Primary HR hot-leg piping fluid subcoolings for NO (False transient to establish steady-state). 


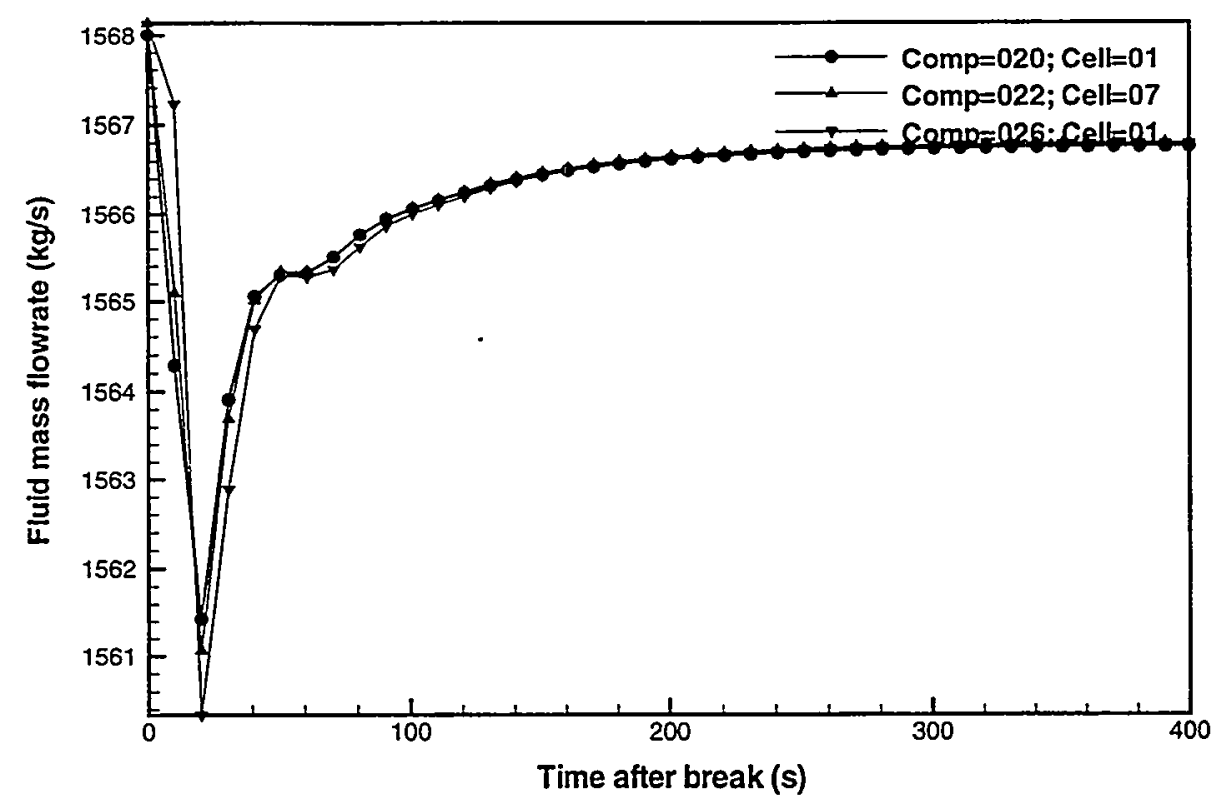

Figure B-8d Primary HR hot-leg piping liquid mass flowrates for NO (False transient to establish steady-state).

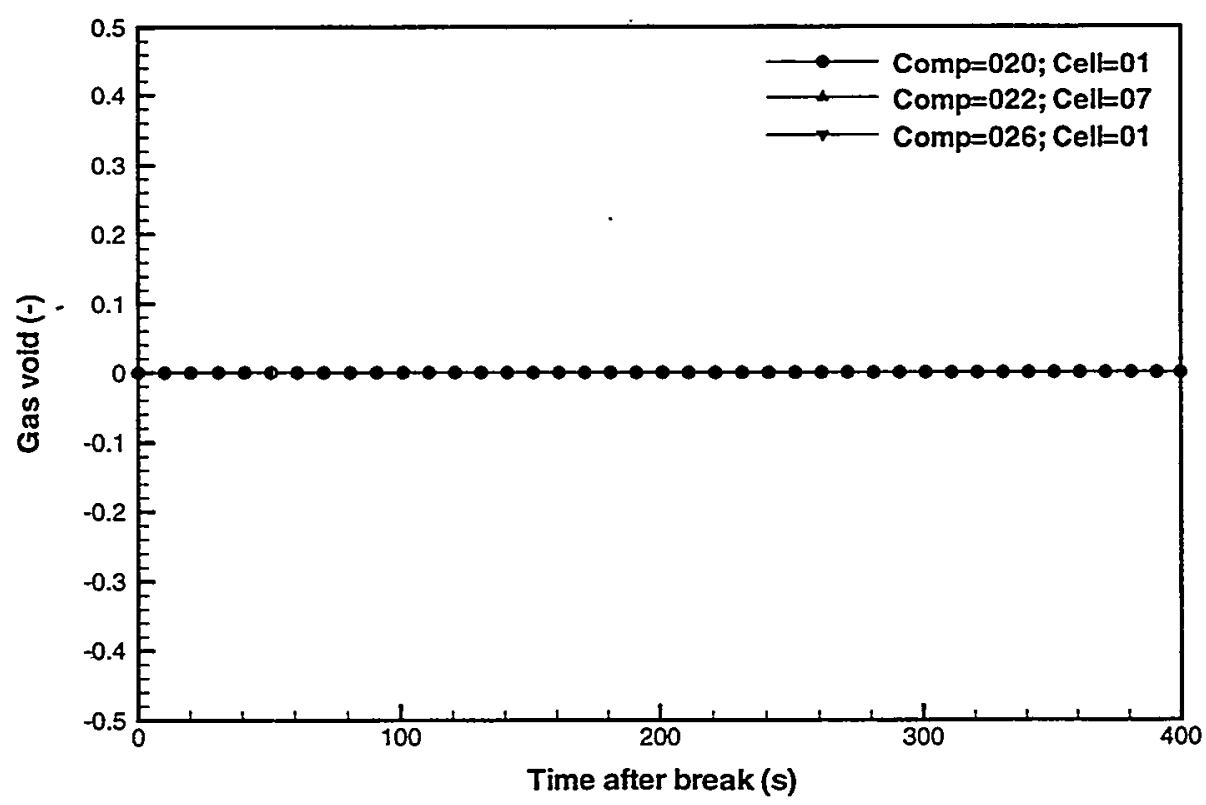

Figure B-8e Primary HR hot-leg piping void fractions for NO (False transient to establish steady-state). 


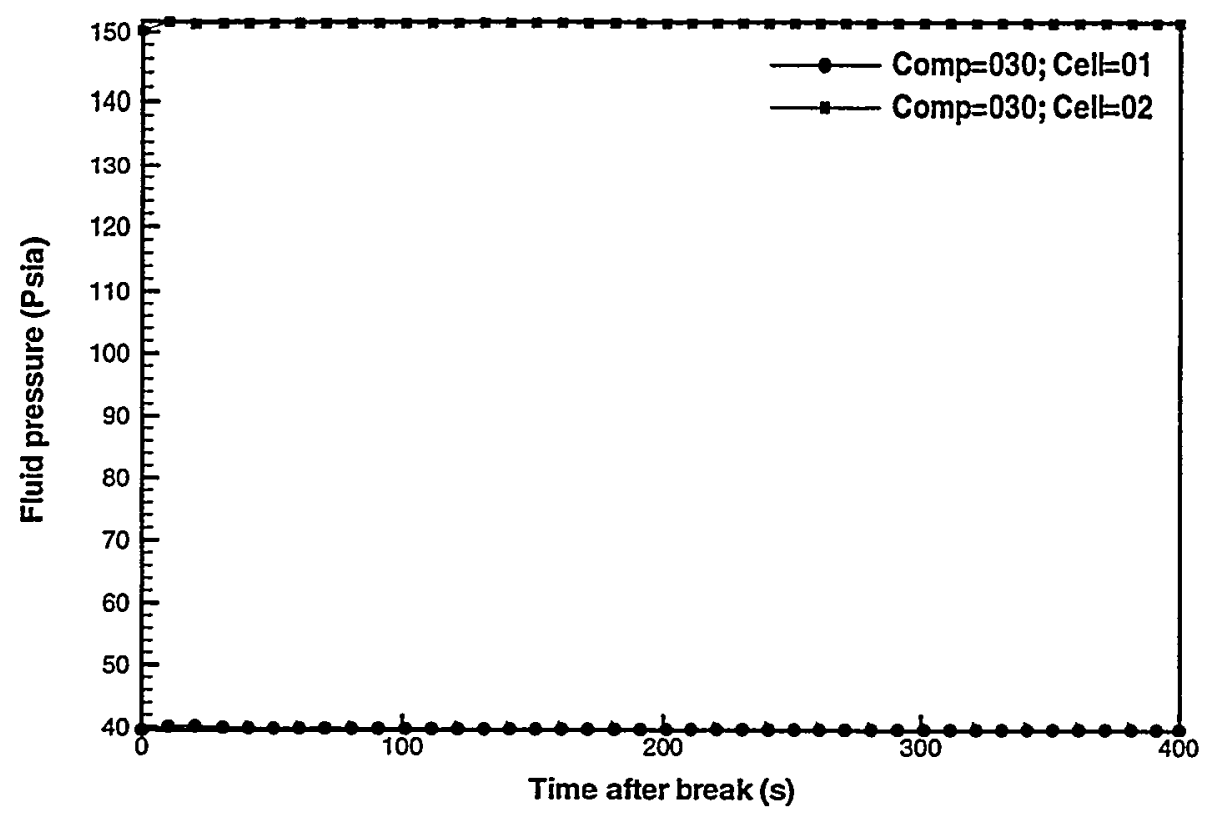

Figure B-9a Primary HR pump 1 fluid pressures for NO (FaTse transient to establish steady-state).

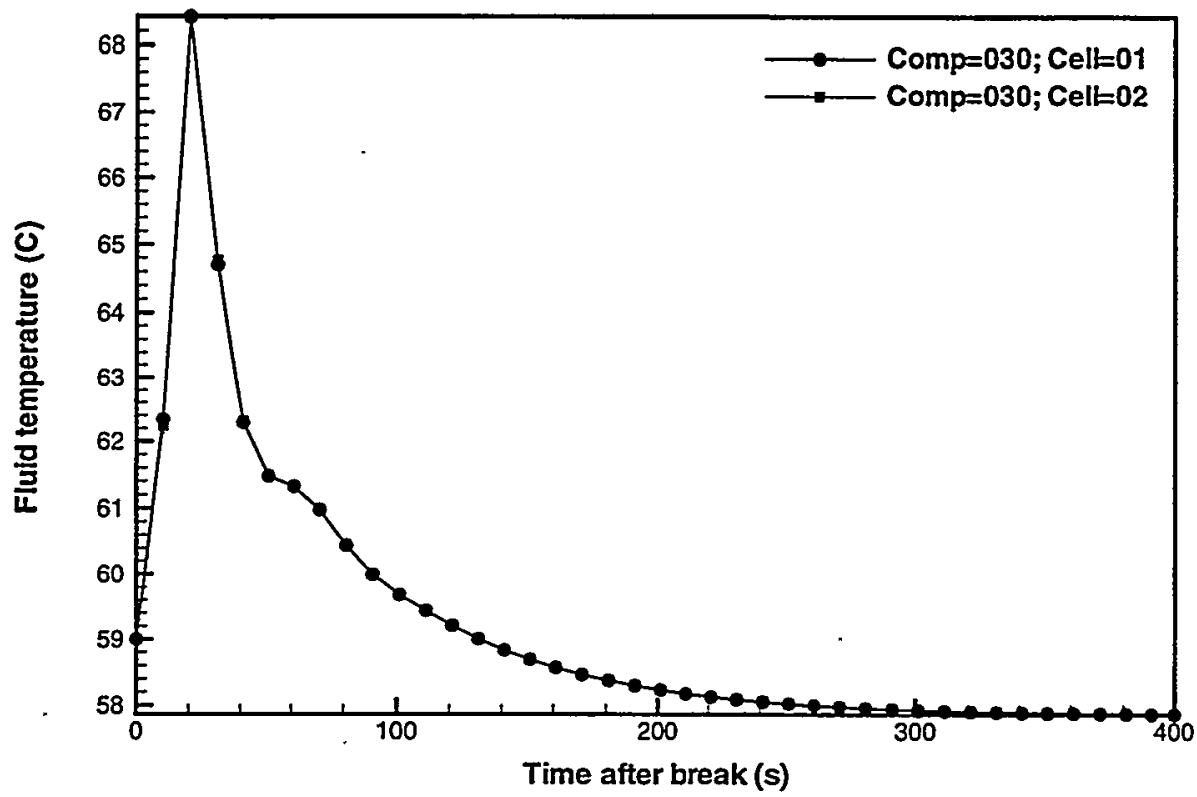

Figure B-9b Primary HR pump 1 fluid temperatures for NO (False transient to establish steady-state). 


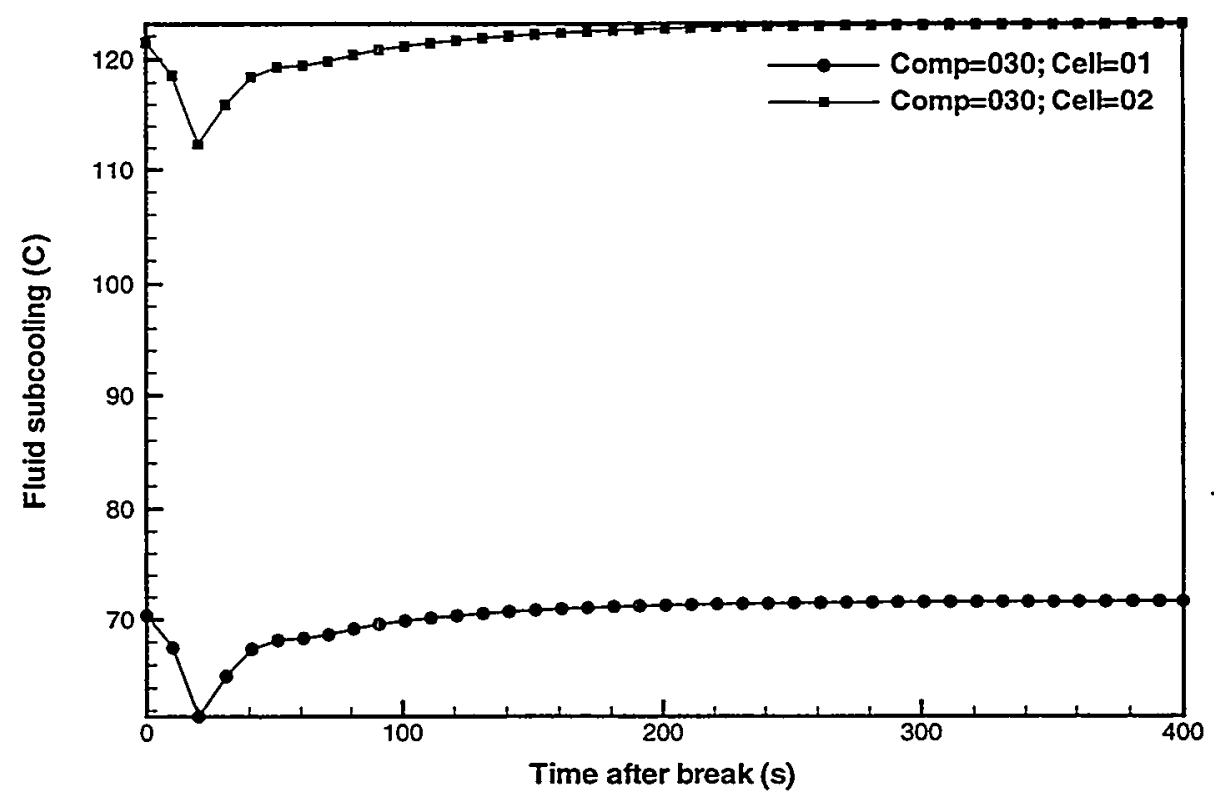

Figure B-9c Primary HR pump 1 fluid subcoolings for NO (False transient to establish steady-state).

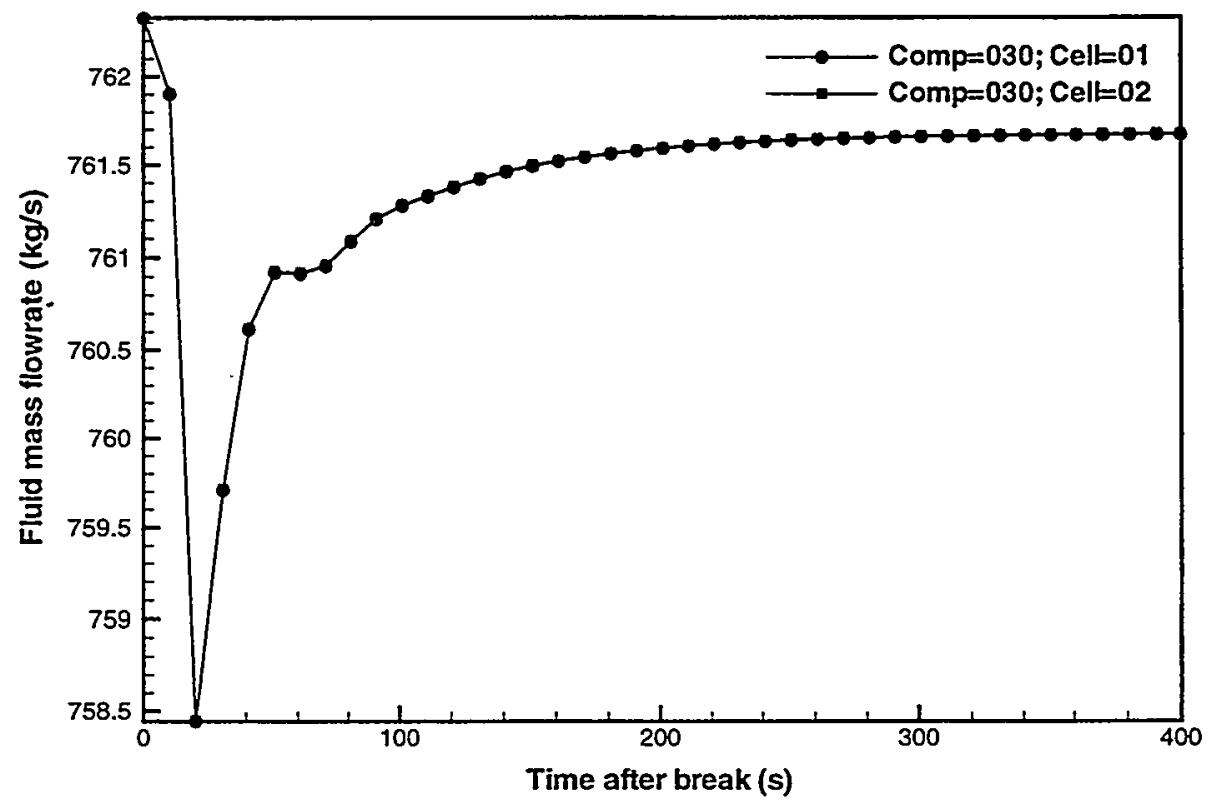

Figure B-9d Primary HR pump 1 liquid mass flowrates for NO (False transient to establish steady-state). 


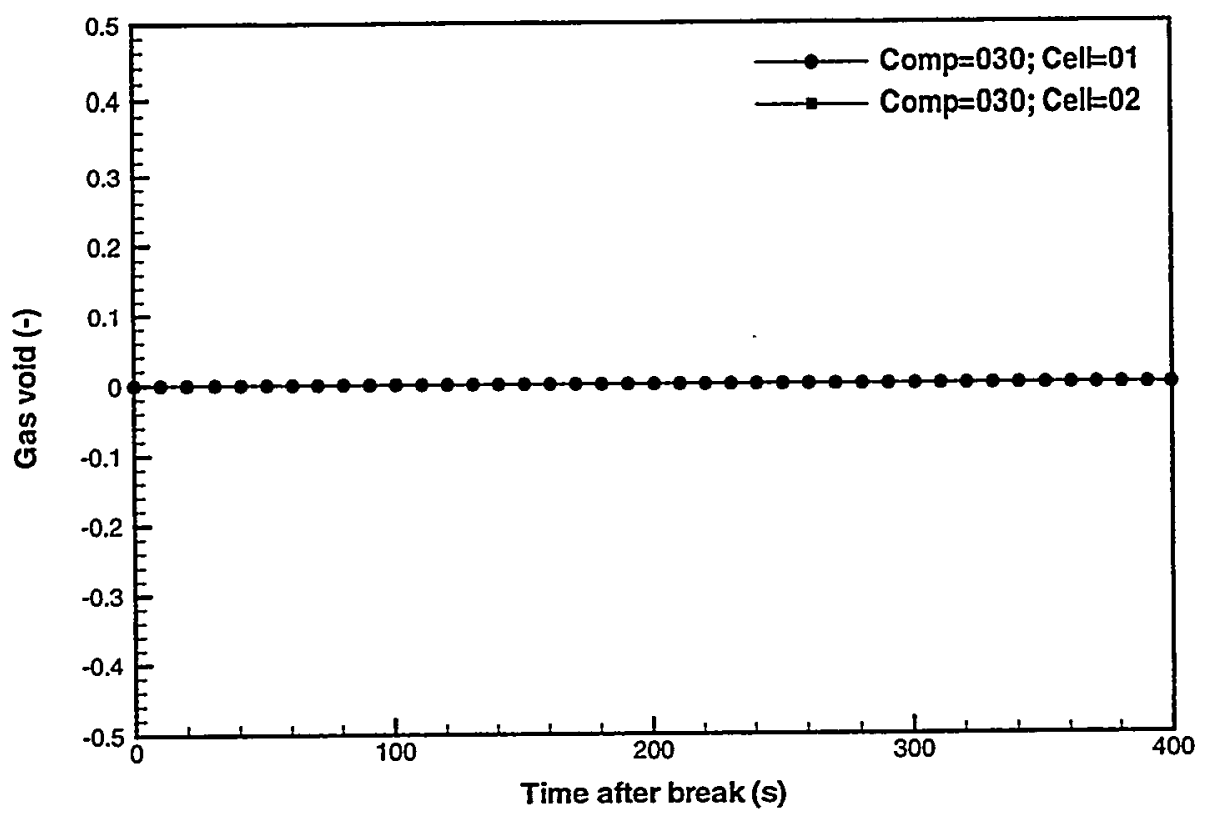

Figure B-9e Primary HR pump 1 void fractions for NO (False transient to establish steady-state).

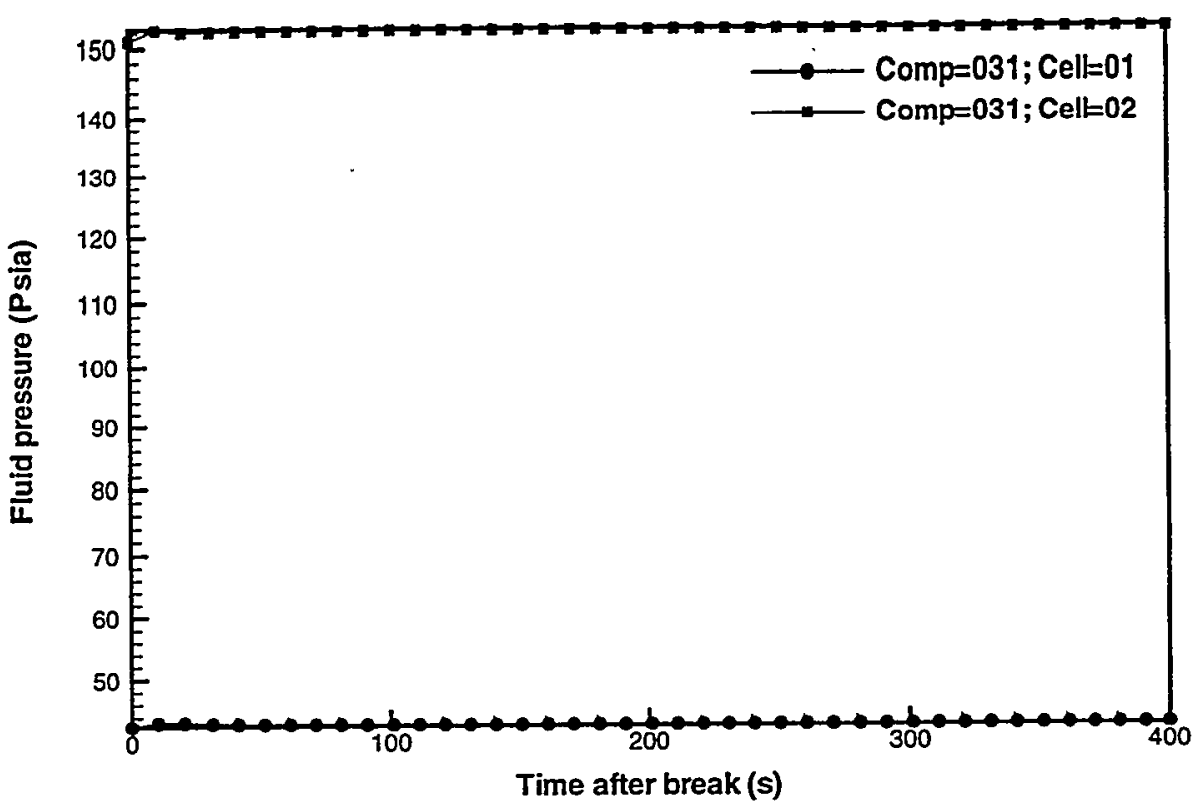

Figure B-10a Primary HR pump 2 fluid pressures for NO (False transient to establish steady-state). 


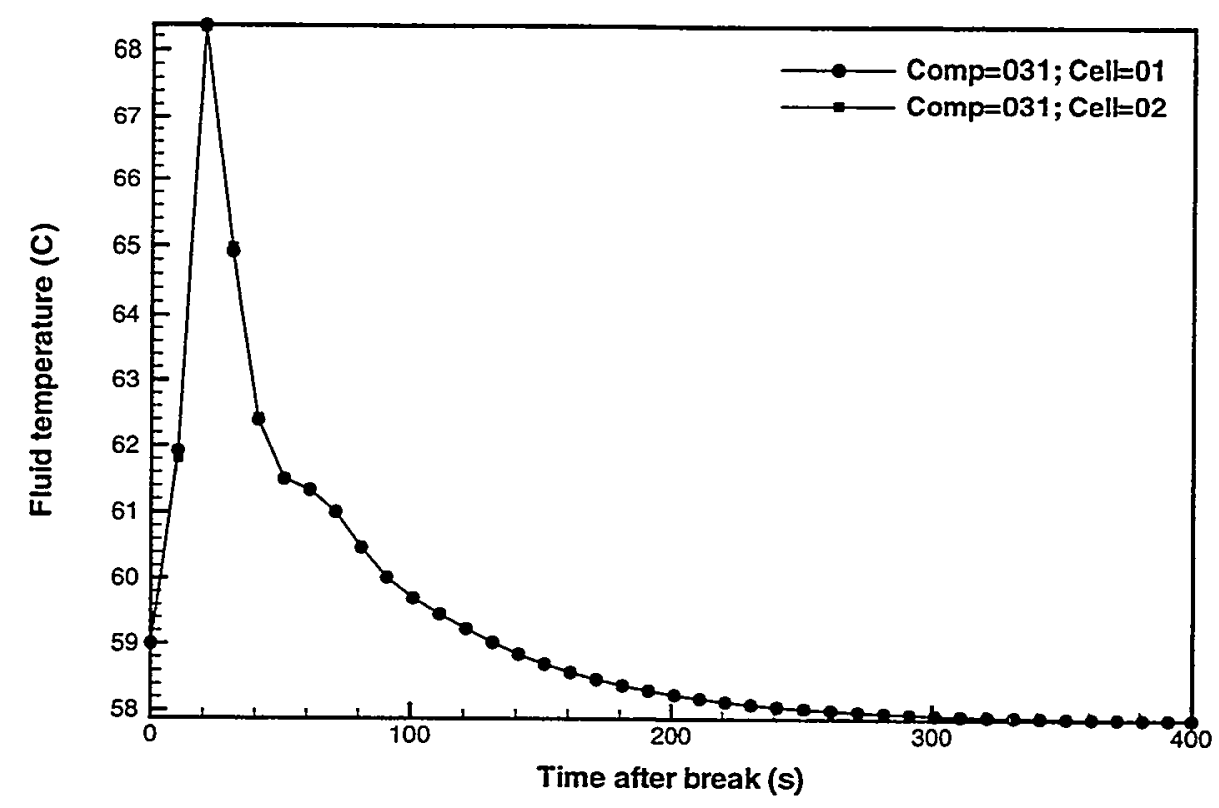

Figure B-10b Primary HR pump 2 fluid temperatures for NO (False transient to establish steady-state).

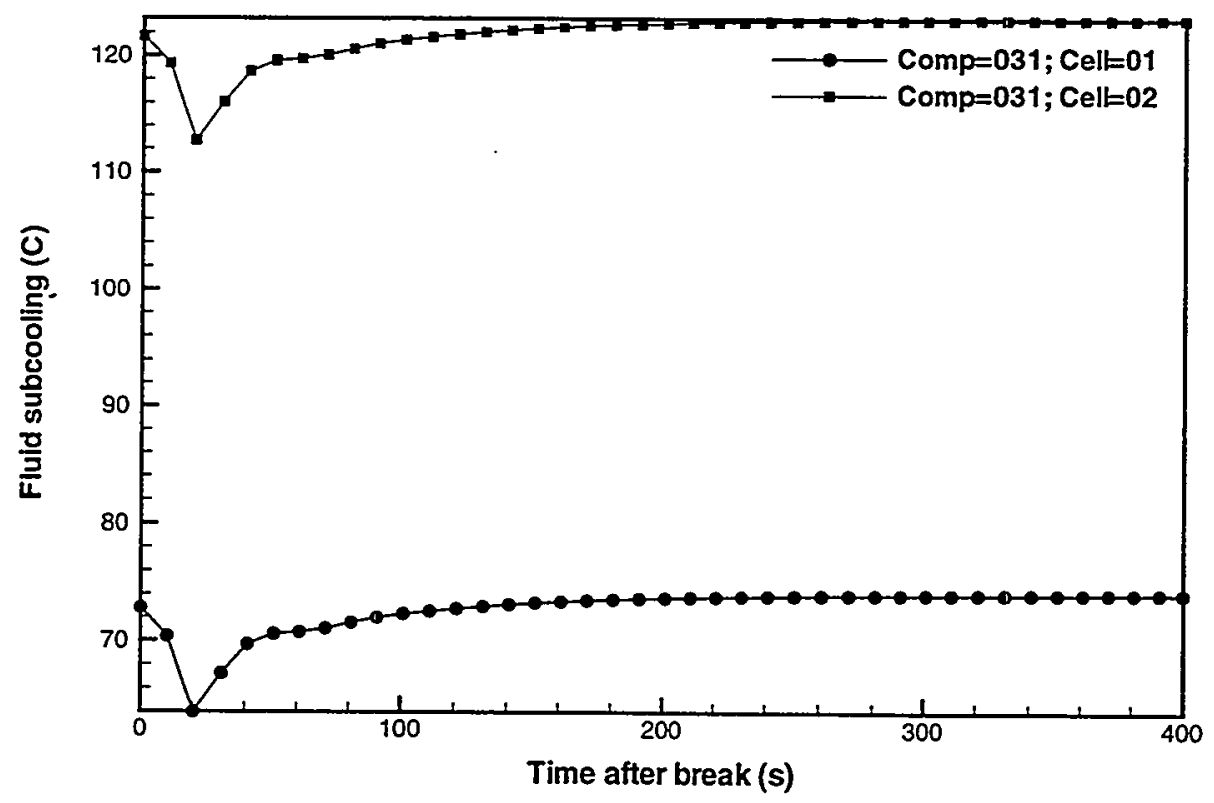

Figure B-10c Primary HR pump 2 fluid subcoolings for NO (False transient to establish steady-state). 


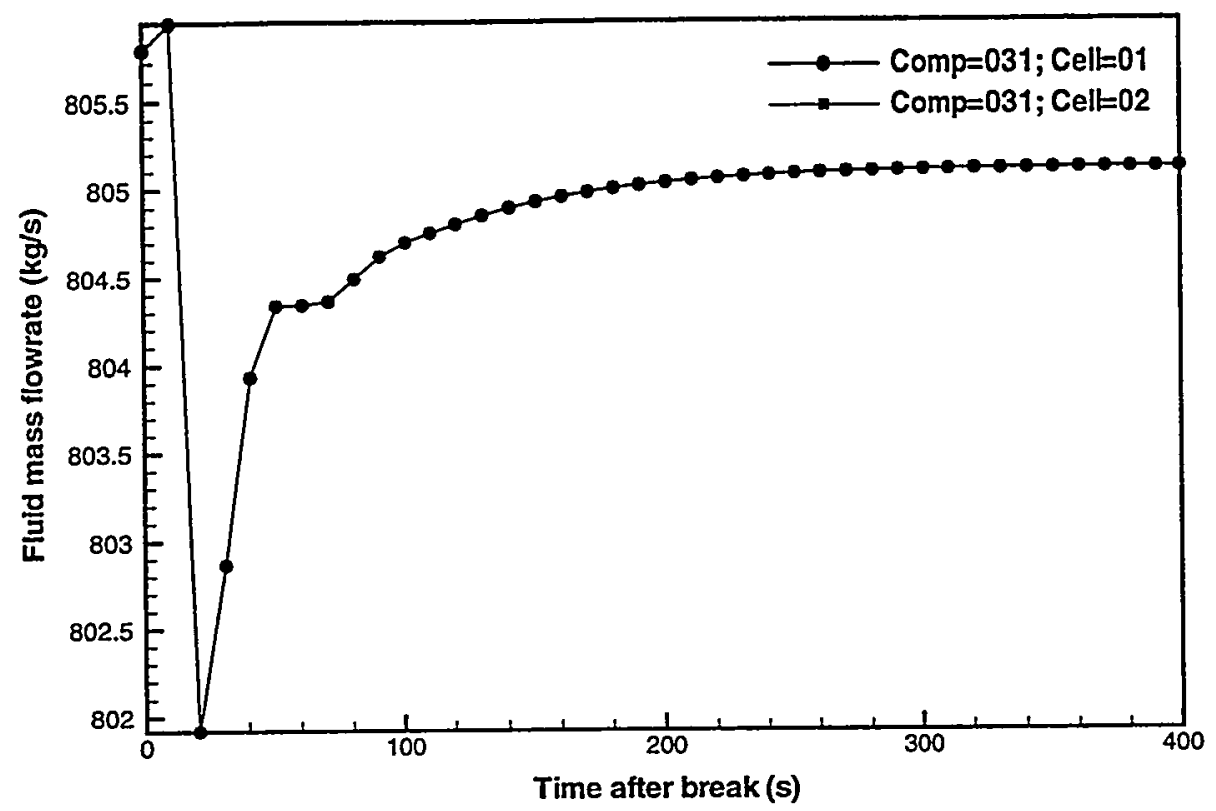

Figure B-10d Primary HR pump 2 liquid mass flowrates for NO (False transient to establish steady-state).

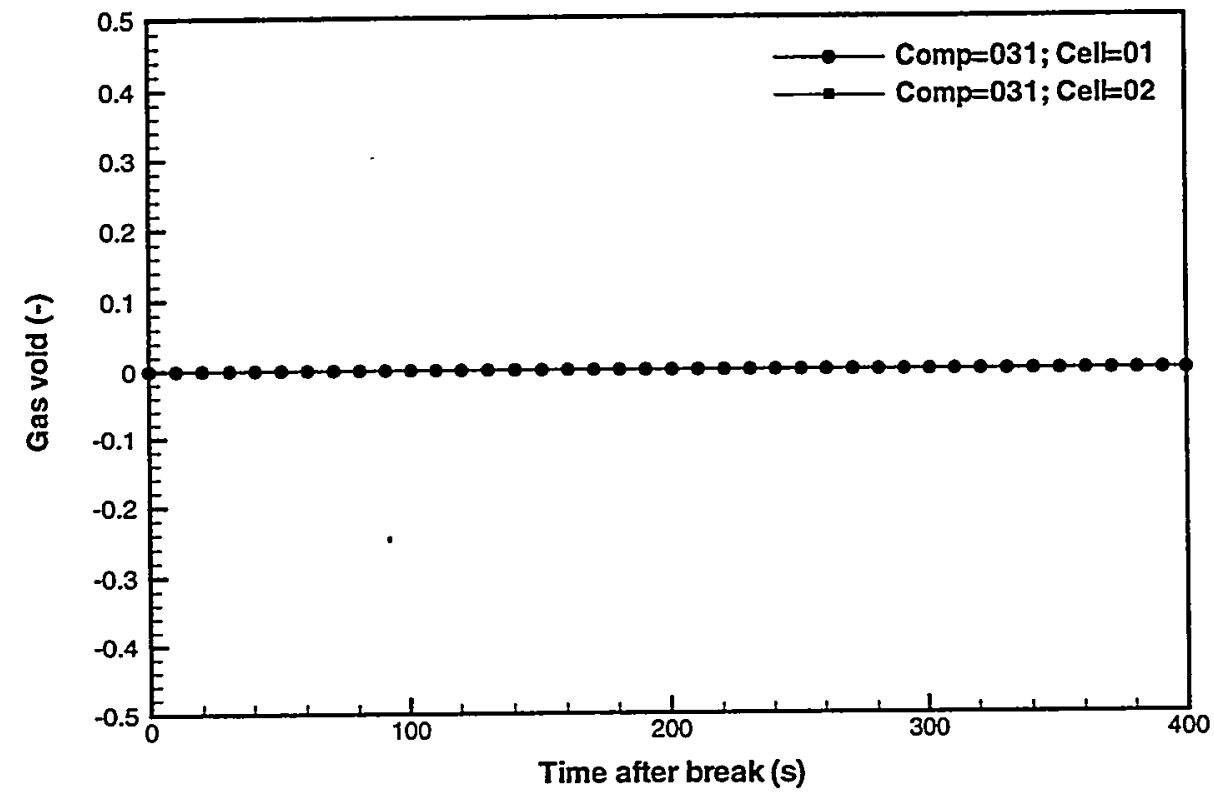

Figure B-10e Primary HR pump 2 void fractions for NO (False transient to establish steady-state). 
Report:

Section:

Date:

BLANKET SYSTEM NORMAL OPERATION

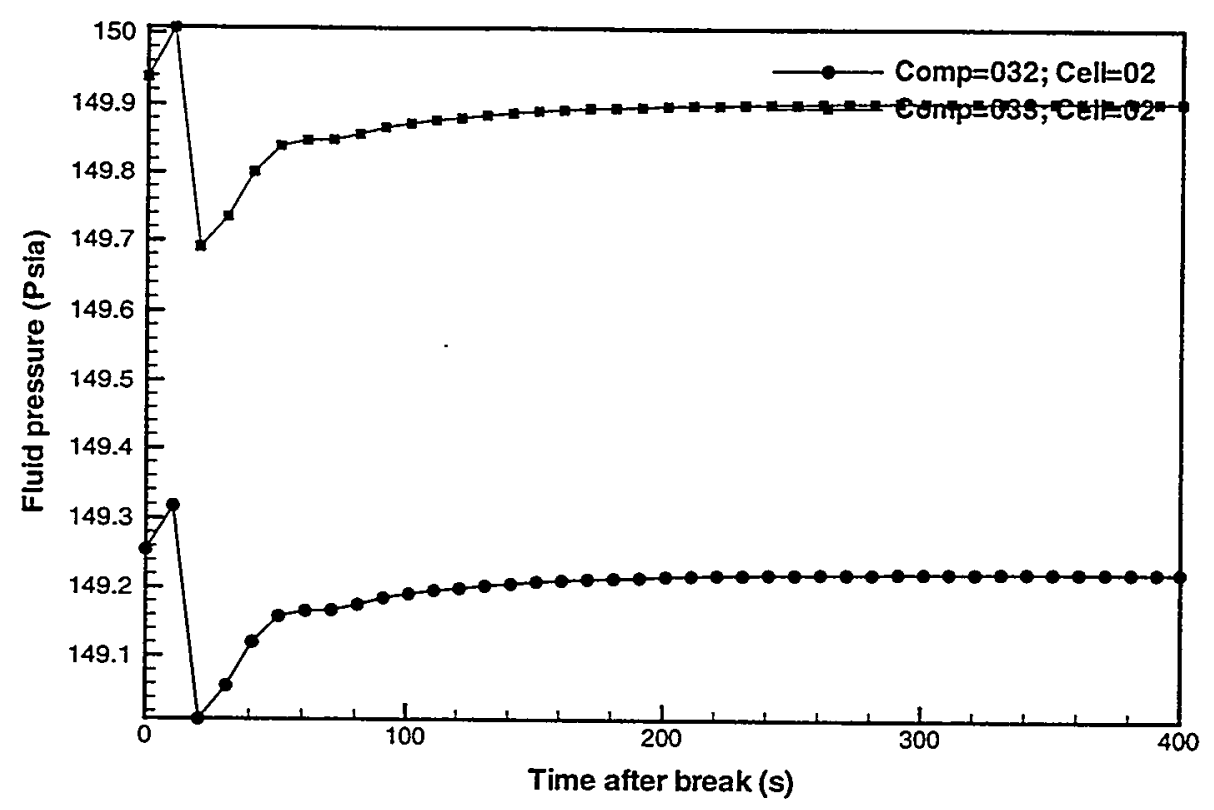

Figure B-11a Primary HR pump discharge piping fluid pressures for NO (False transient to establish steady-state).

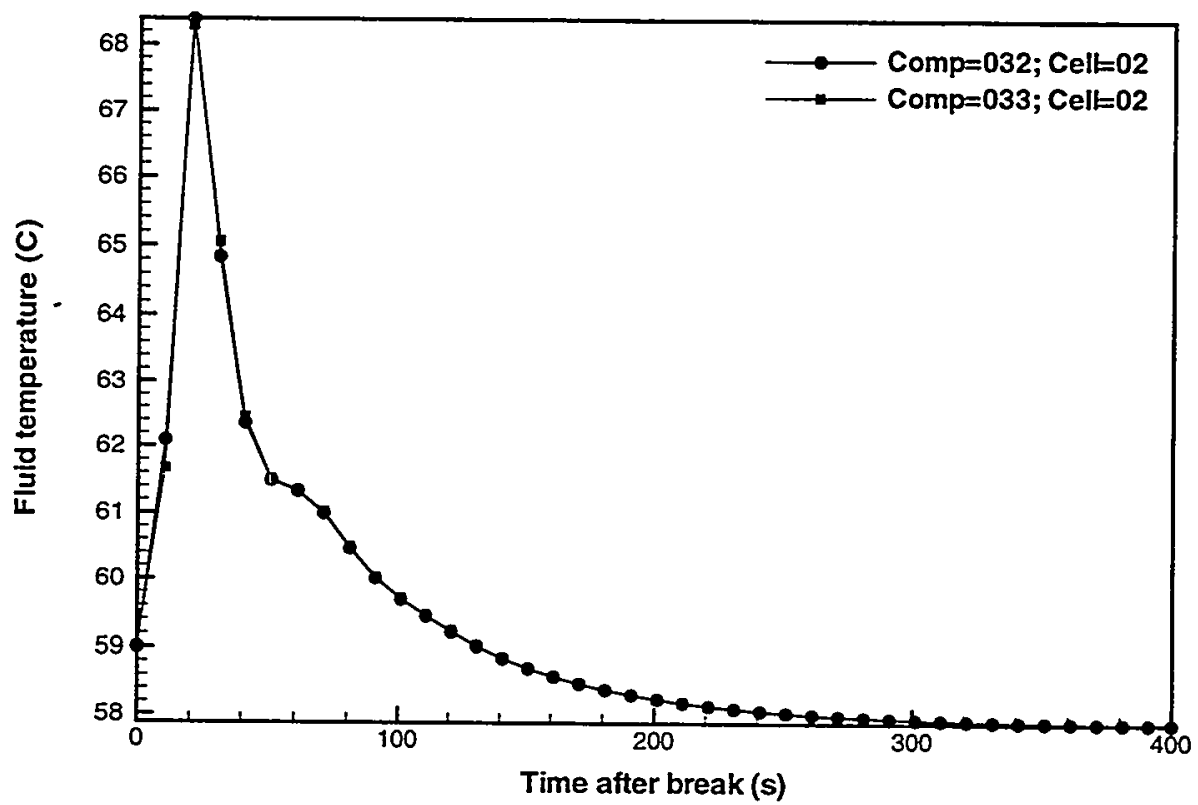

Figure B-11b Primary HR pump discharge piping fluid temperatures for NO (False transient to establish steady-state). 


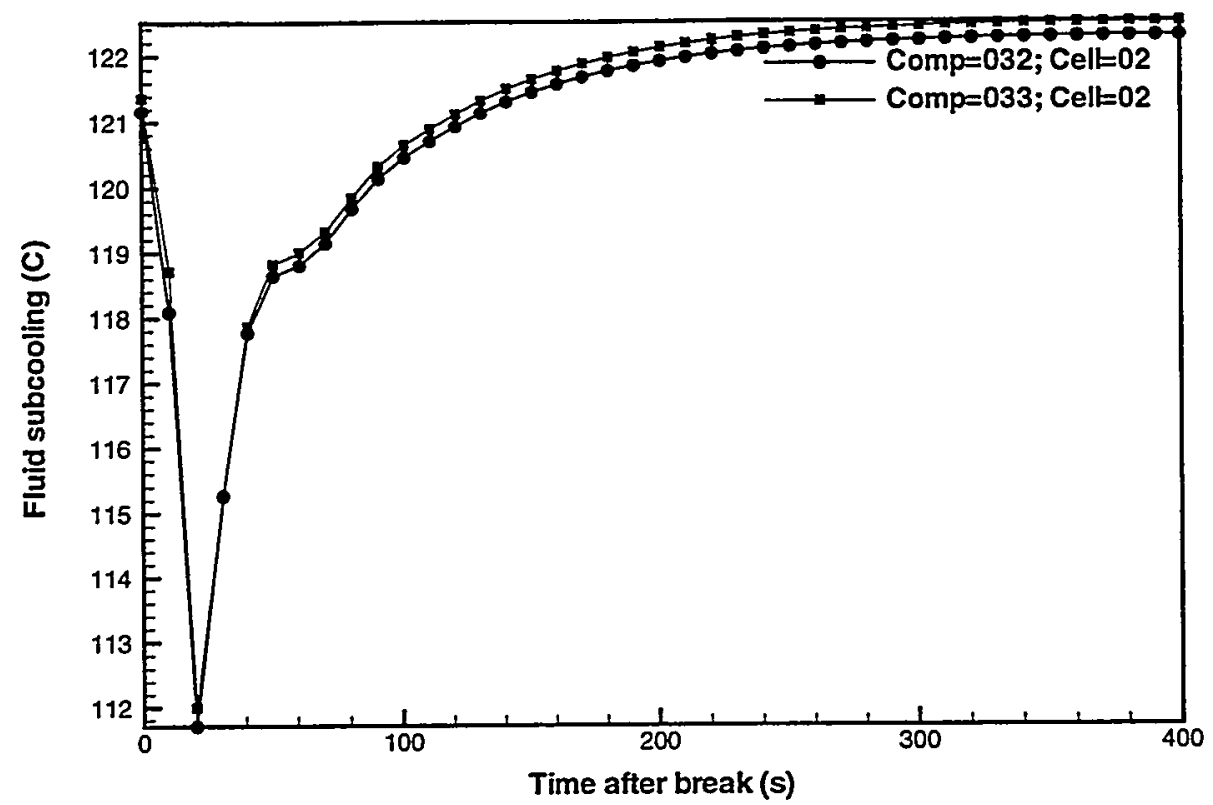

Figure B-11c Primary HR pump discharge piping fluid subcoolings for NO (False transient to establish steady-state).

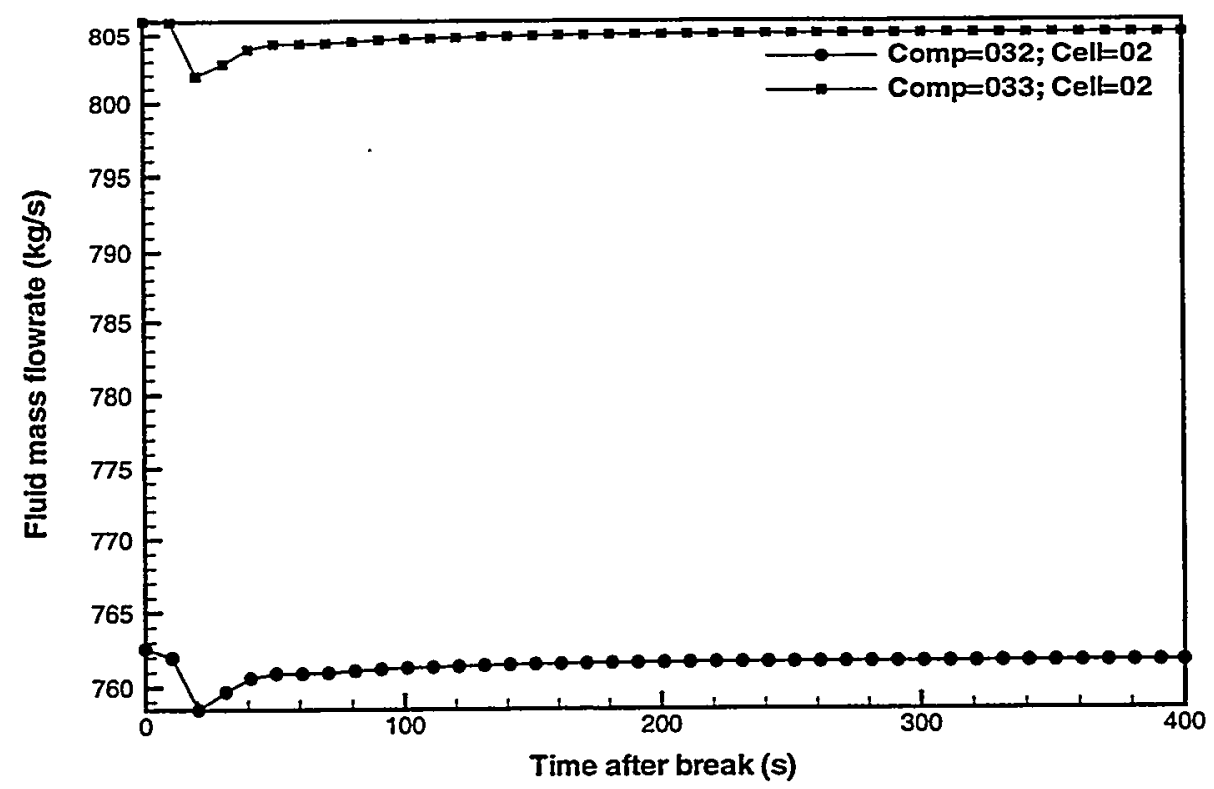

Figure B-11d Primary HR pump discharge piping liquid mass flowrates for NO (False transient to establish steady-state). 


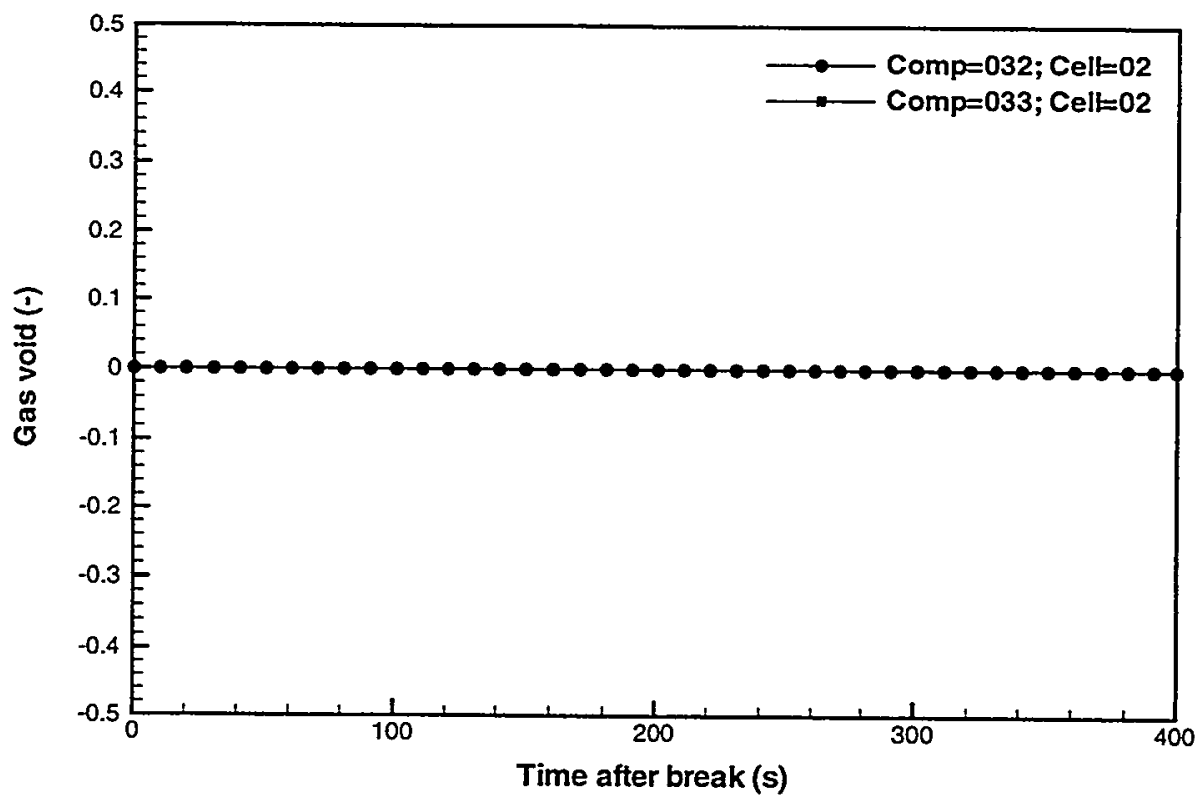

Figure B-11e Primary HR pump discharge piping void fractions for NO (False transient to establish steady-state).

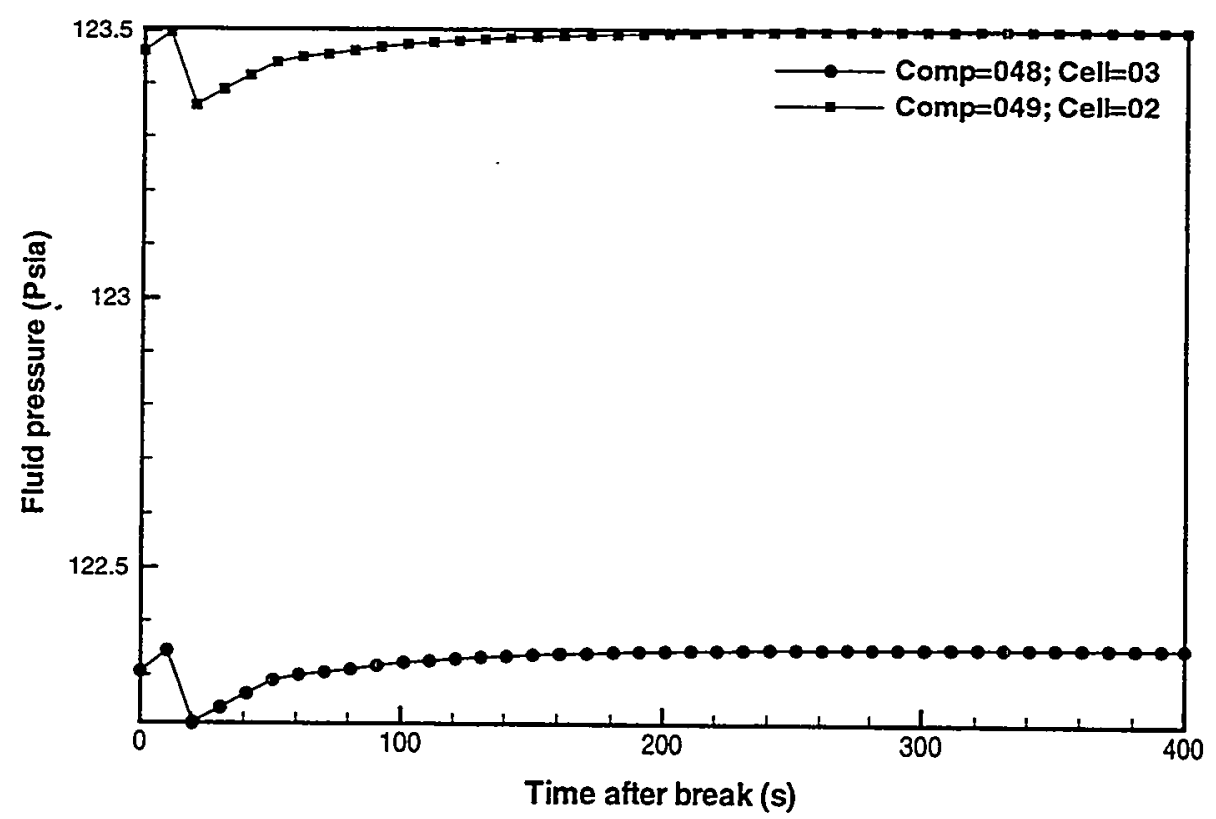

Figure B-12a Primary HR heat exchanger inlet piping fluid pressures for NO (False transient to establish steady-state). 


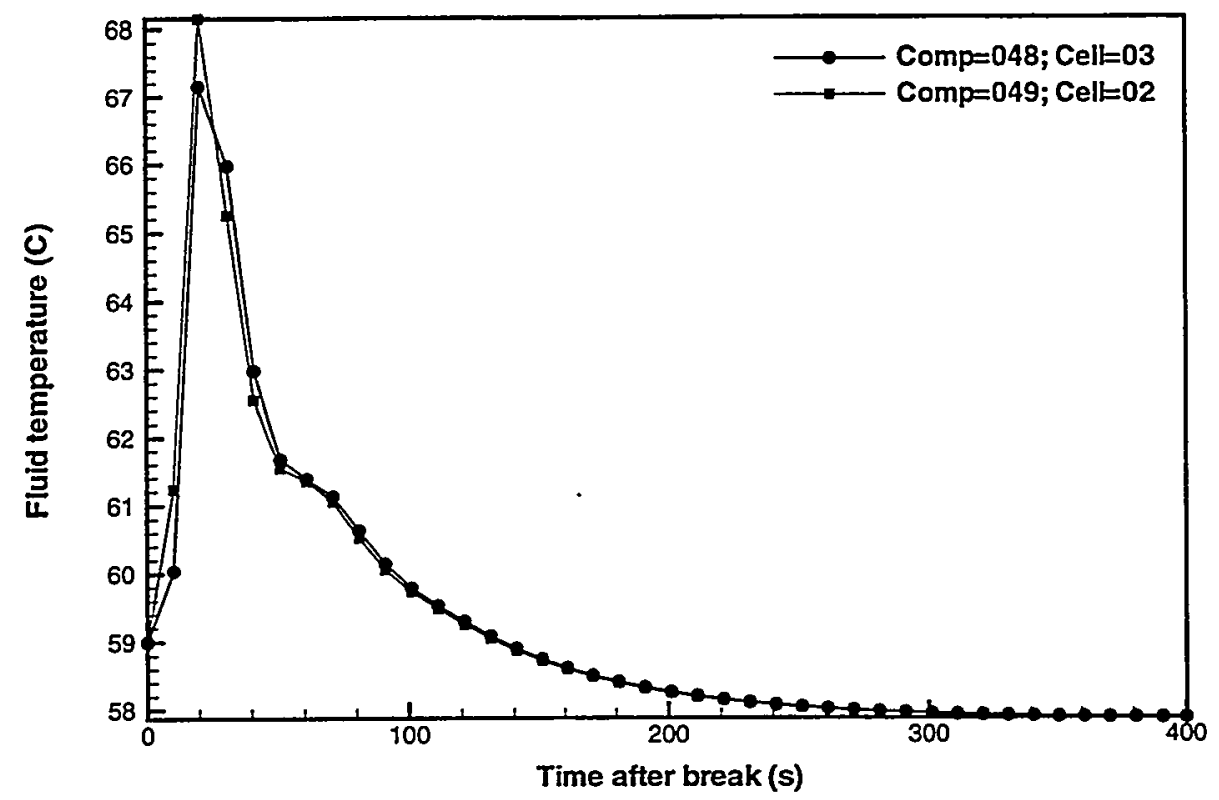

Figure B-12b Primary HR heat exchanger inlet piping fluid temperatures for NO (False transient to establish steady-state).

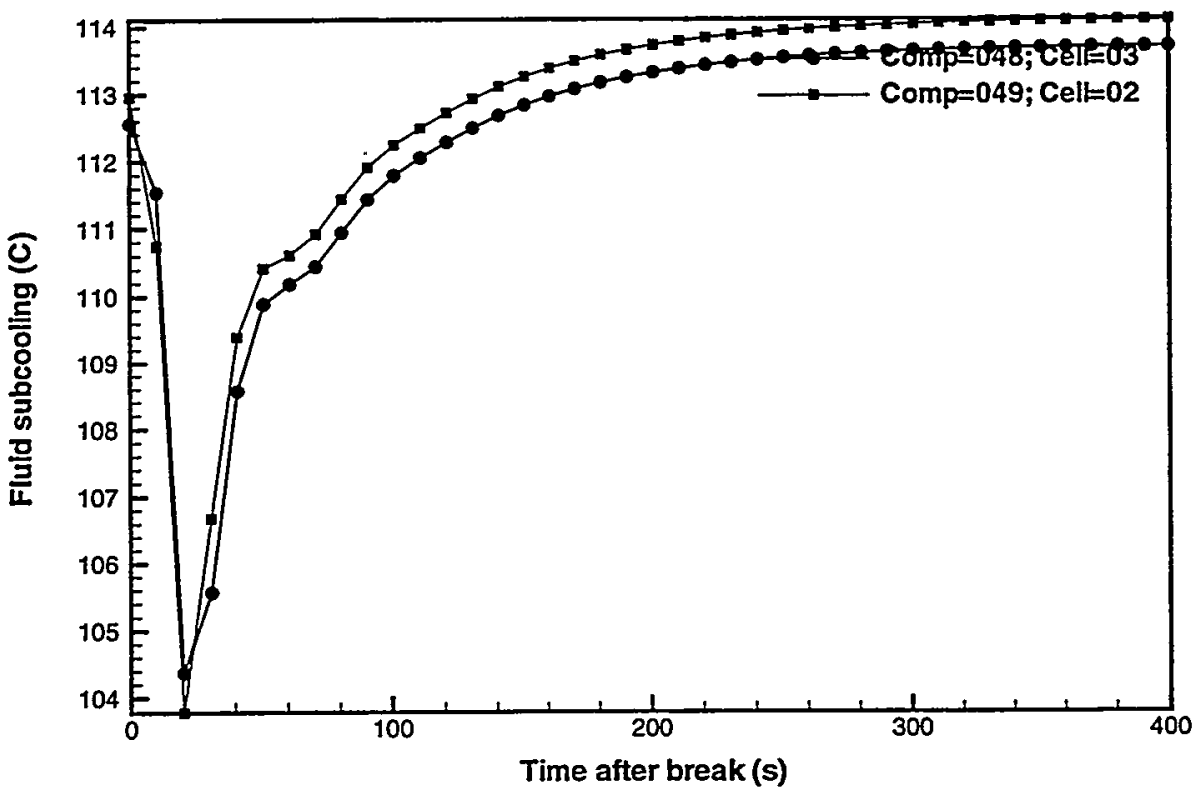

Figure B-12c Primary HR heat exchanger inlet piping fluid subcoolings for NO (False transient to establish steady-state). 


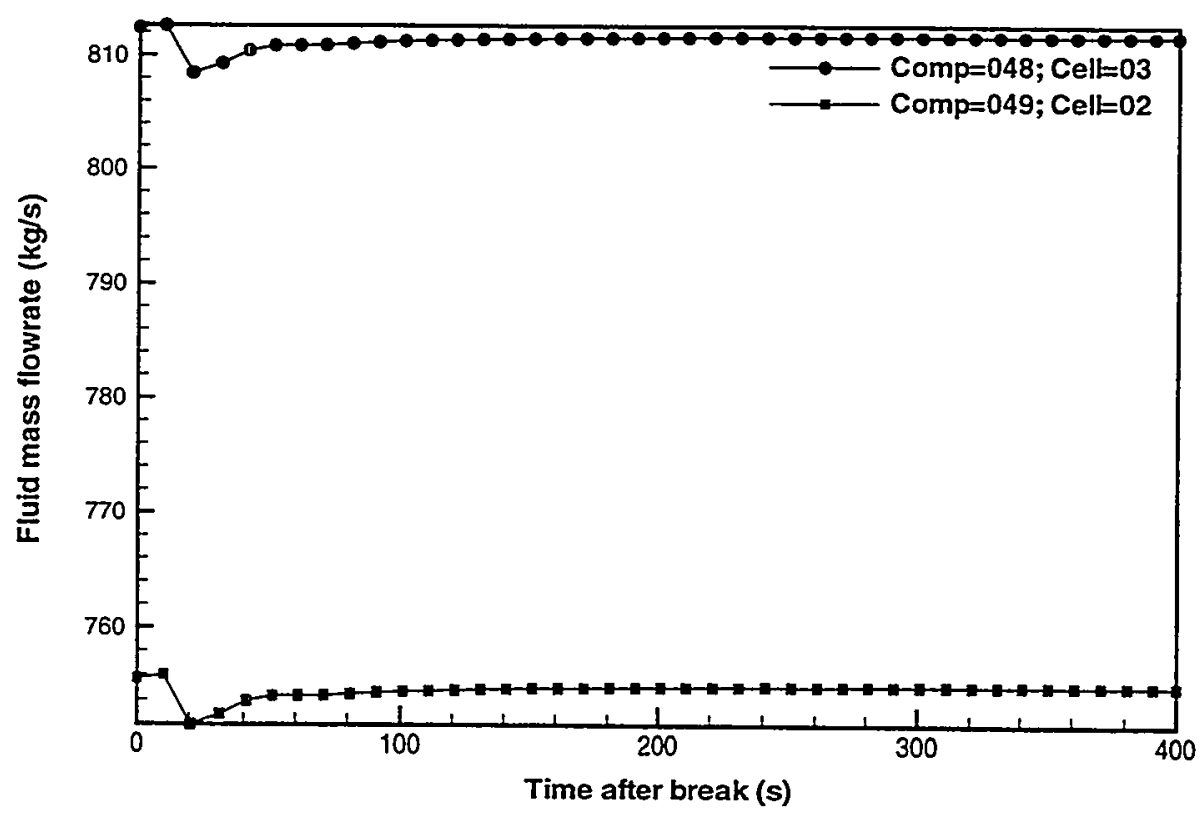

Figure B-12d Primary HR heat exchanger inlet piping liquid mass flowrates for NO (False transient to establish steady-state).

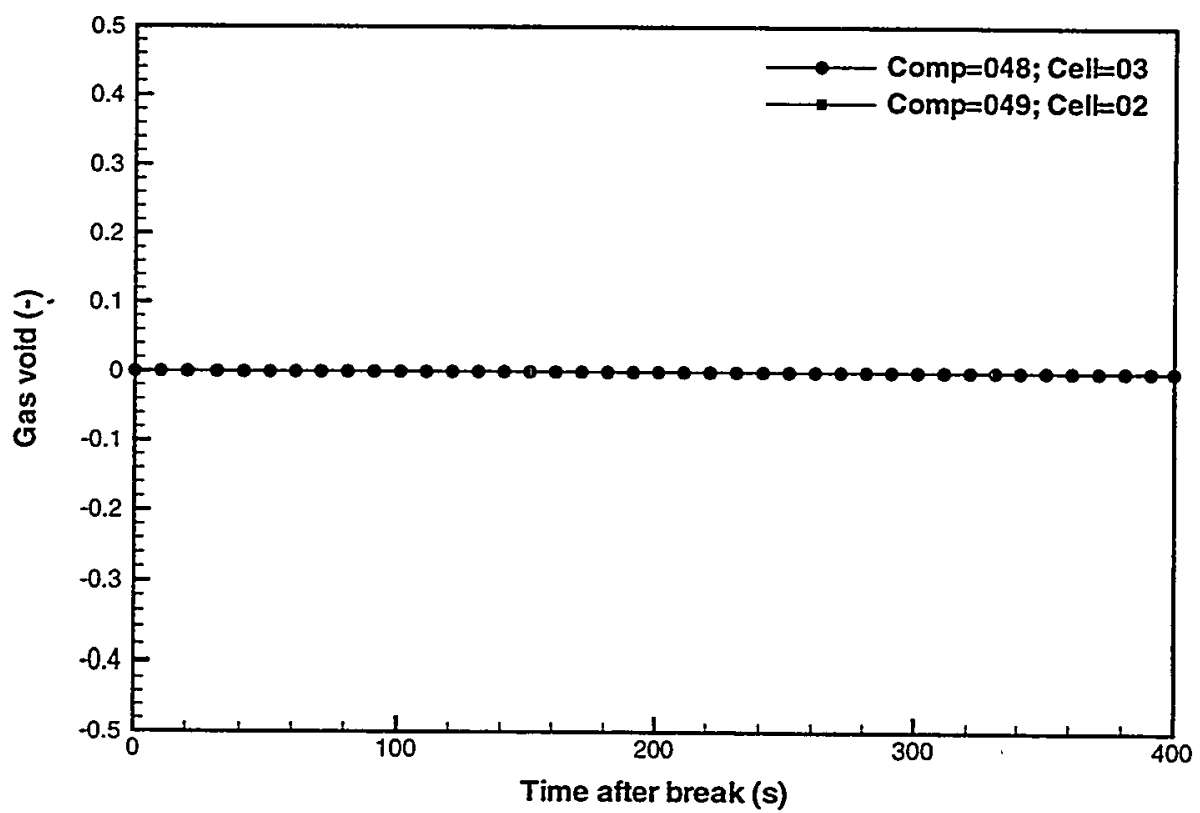

Figure B-12e Primary HR heat exchanger inlet piping void fractions for NO (False transient to establish steady-state). 


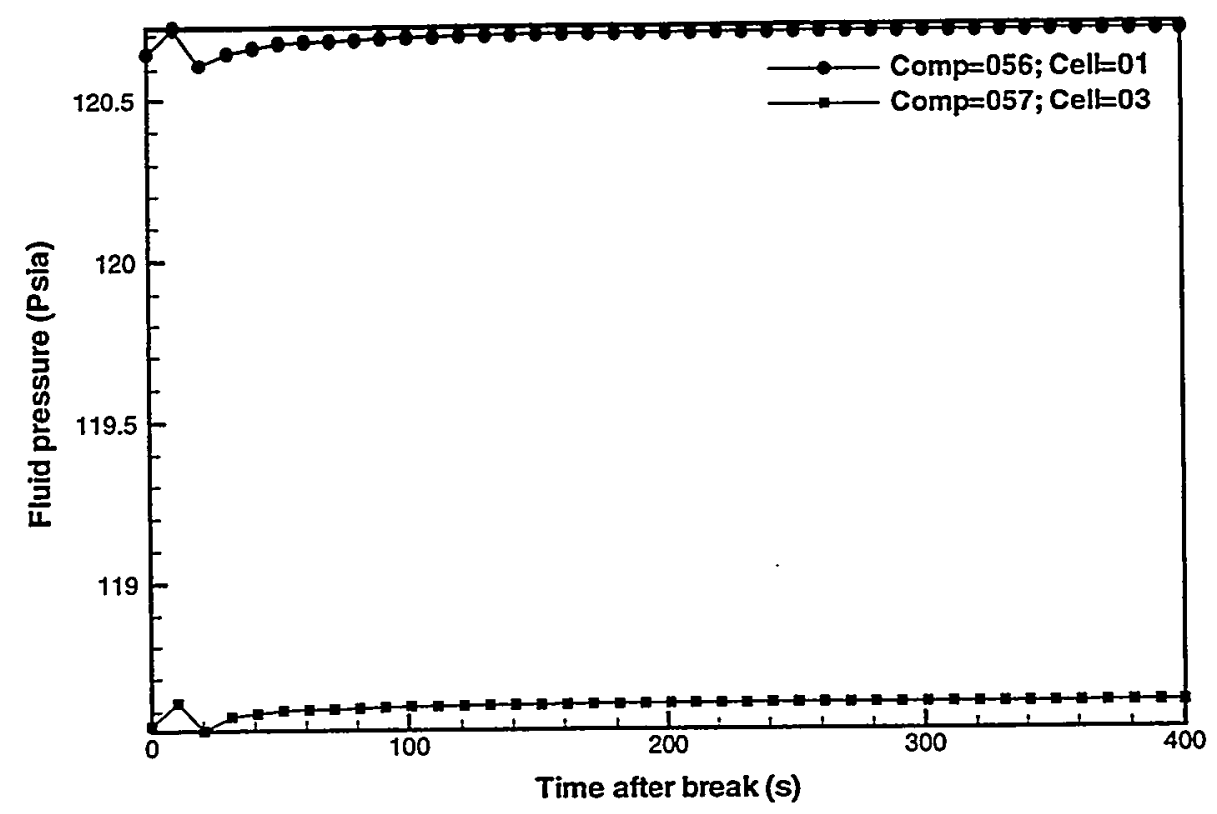

Figure B-13a Primary HR heat exchanger outlet piping fluid pressures for NO (False transient to establish steady-state).

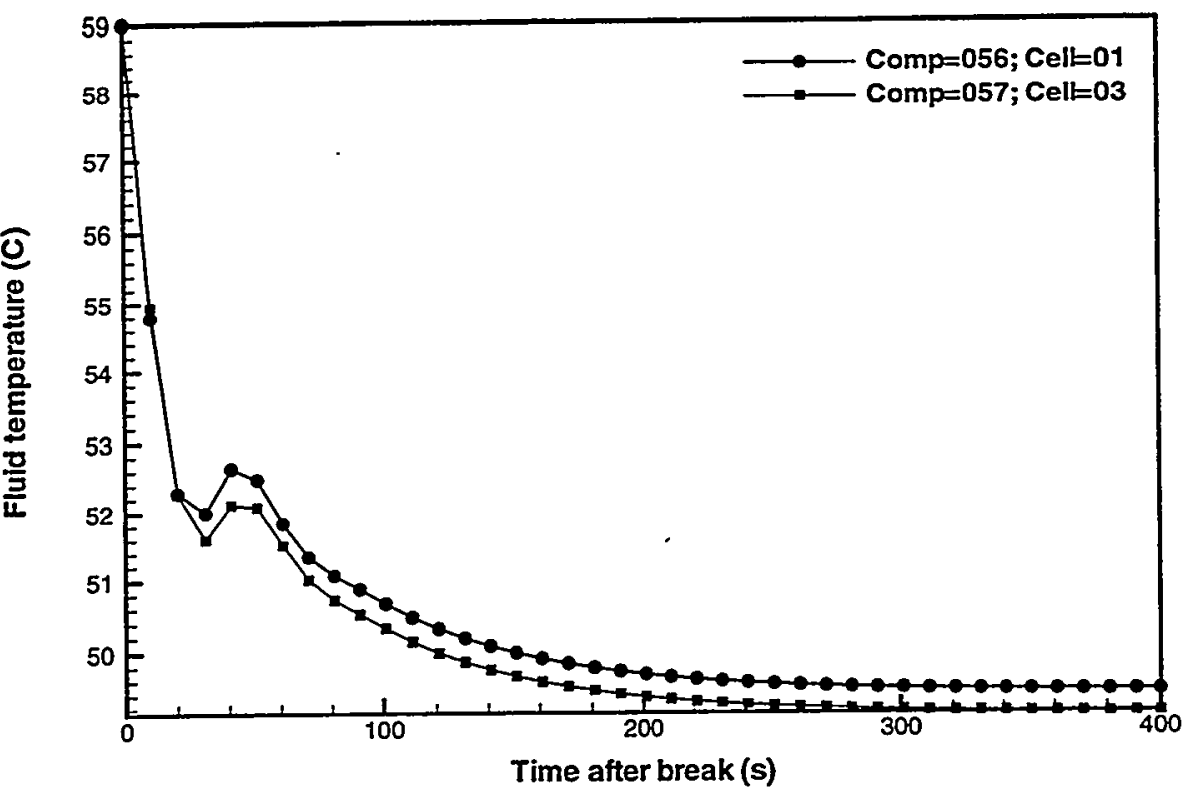

Figure B-13b Primary HR heat exchanger outlet piping fluid temperatures for NO (False transient to establish steady-state). 


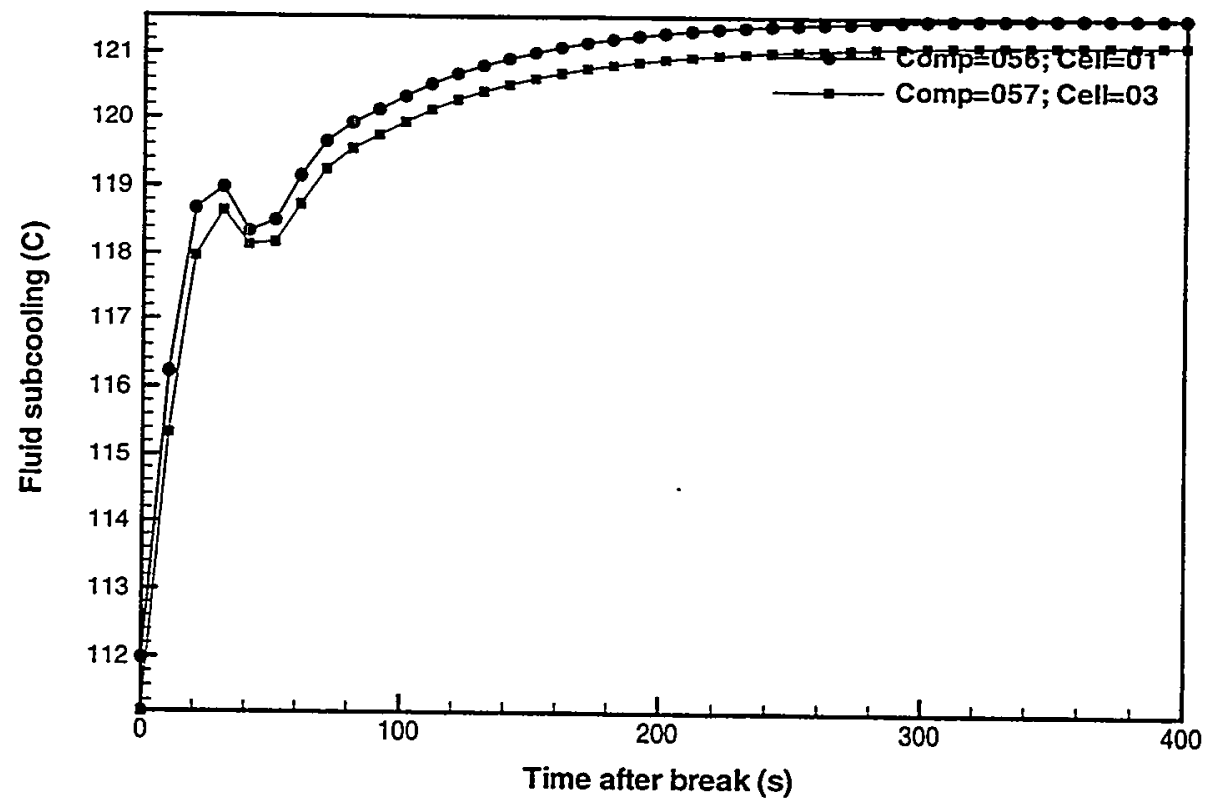

Figure B-13c Primary HR heat exchanger outlet piping fluid subcoolings for NO (False transient to establish steady-state).

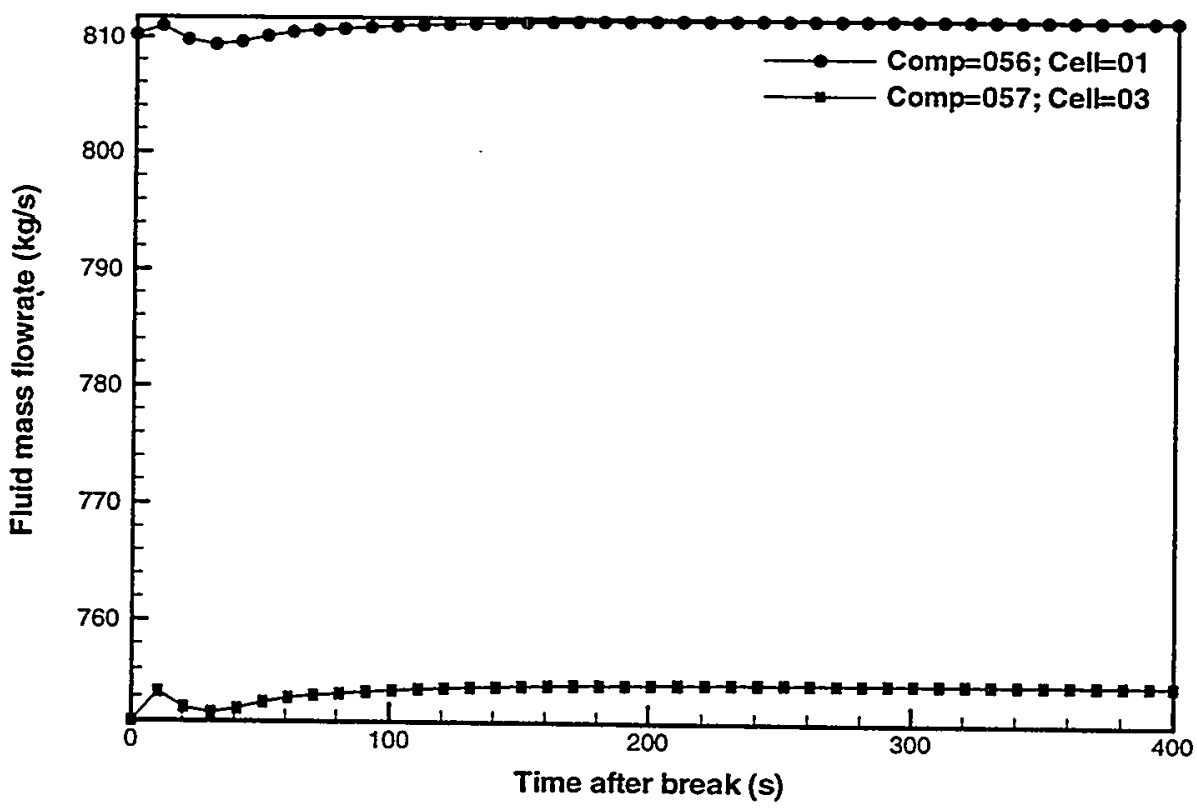

Figure B-13d Primary HR heat exchanger outlet piping liquid mass flowrates for NO (False transient to establish steady-state). 


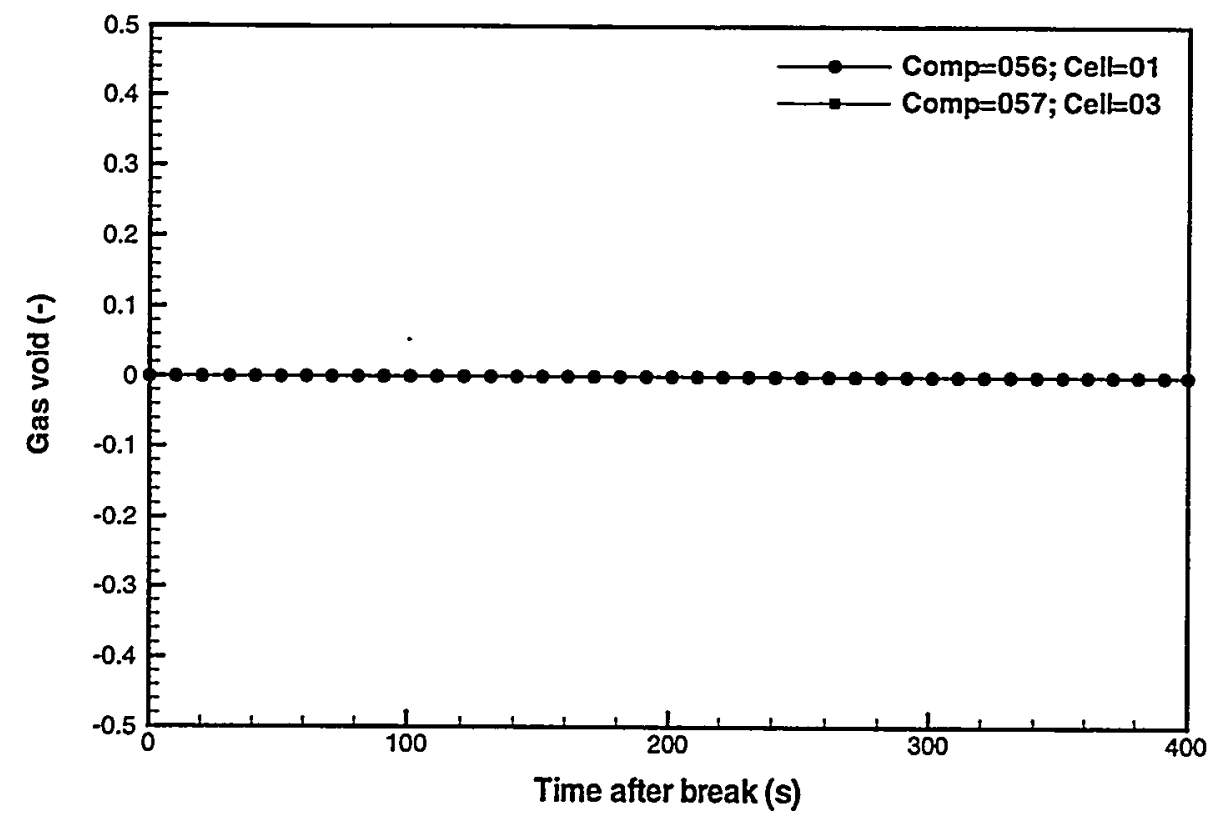

Figure B-13e Primary HR heat exchanger outlet piping void fractions for NO (False transient to establish steady-state).

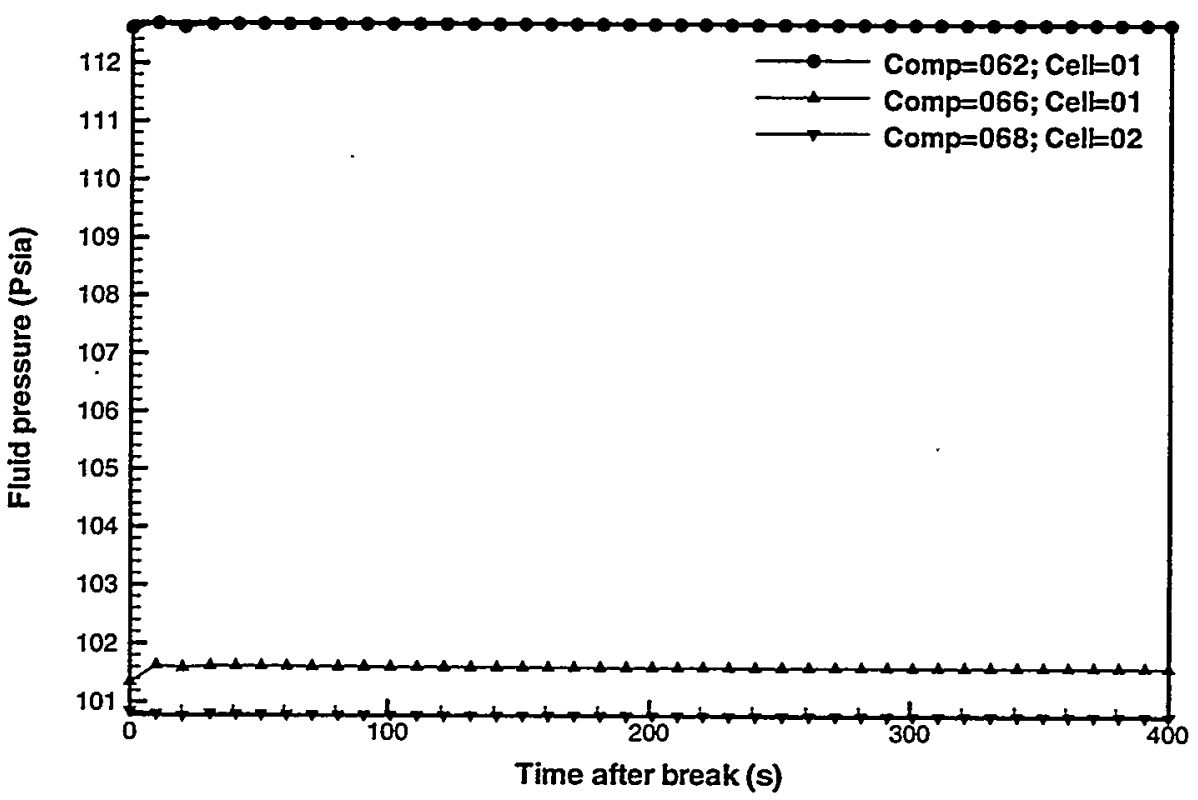

Figure B-14a Primary HR cold-leg piping fluid pressures for NO (False transient to establish steady-state). 


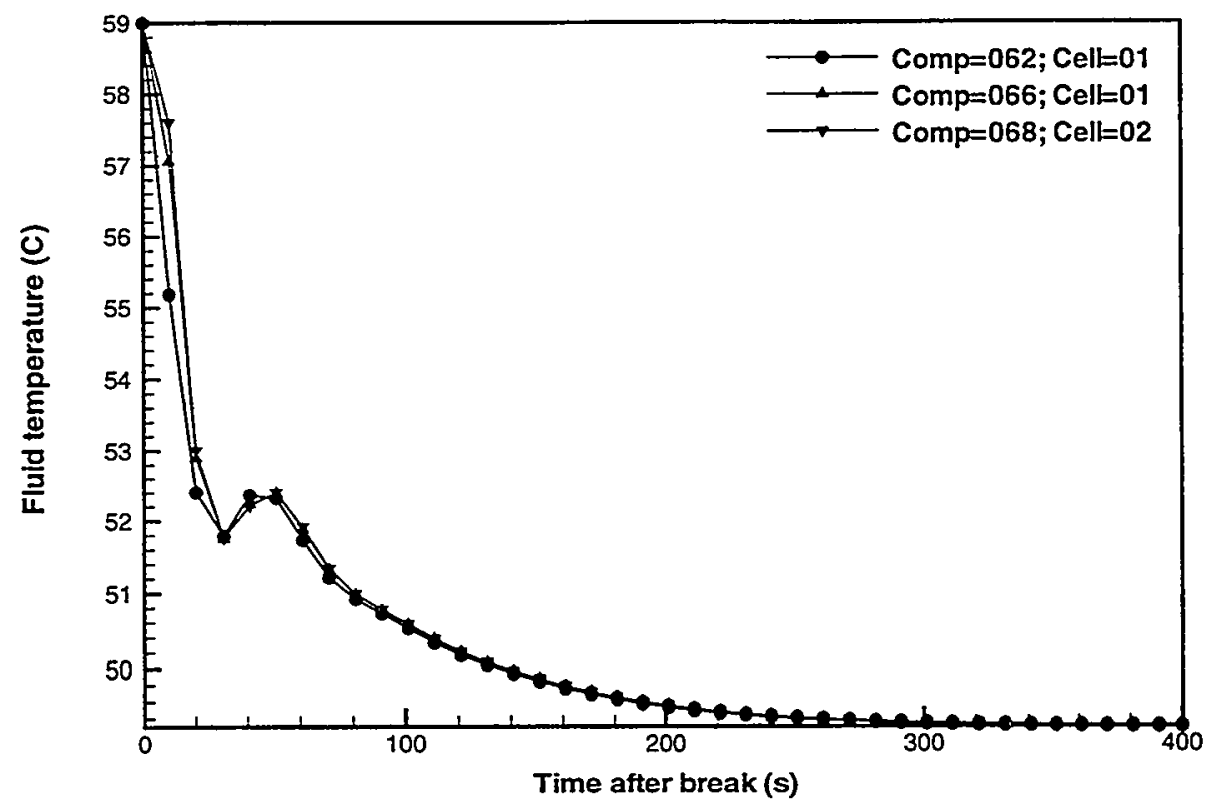

Figure B-14b Primary HR cold-leg piping fluid temperatures for NO tFalse transient to establish steady-state).

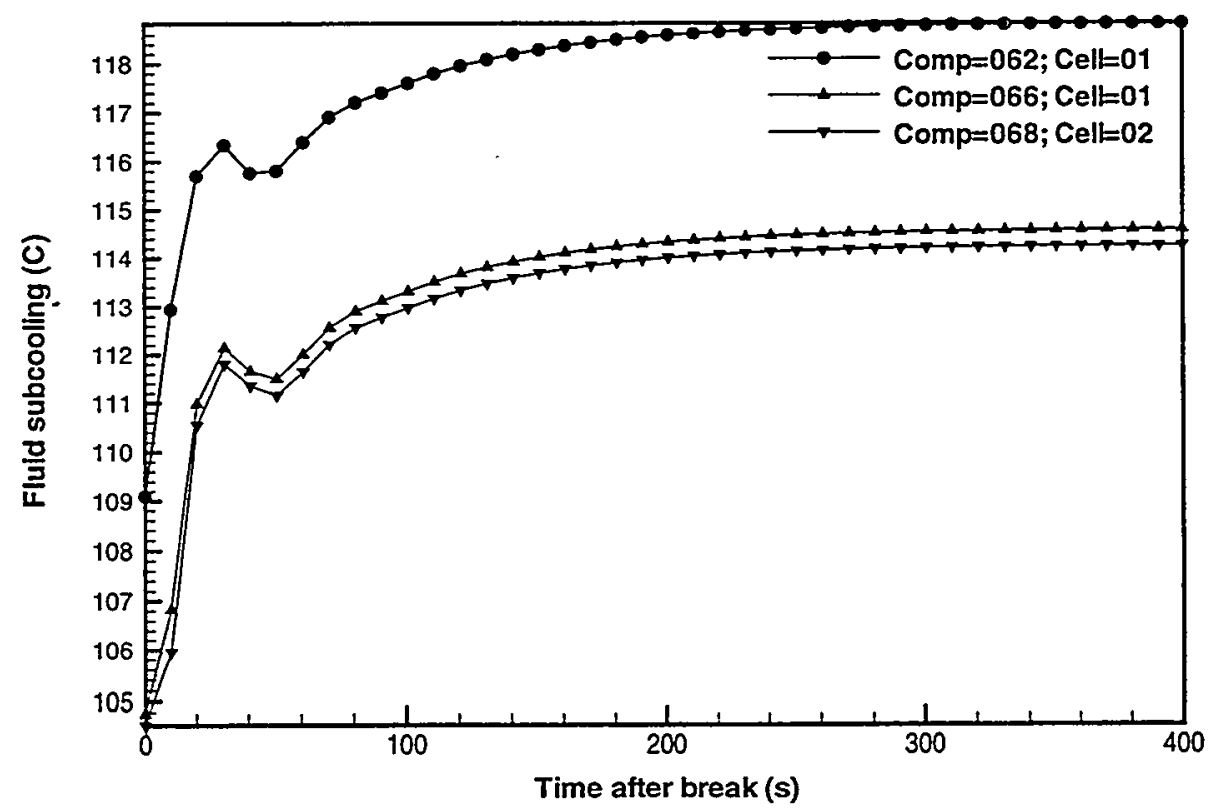

Figure B-14c Primary HR cold-leg piping fluid subcoolings for NO (False transient to establish steady-state). 


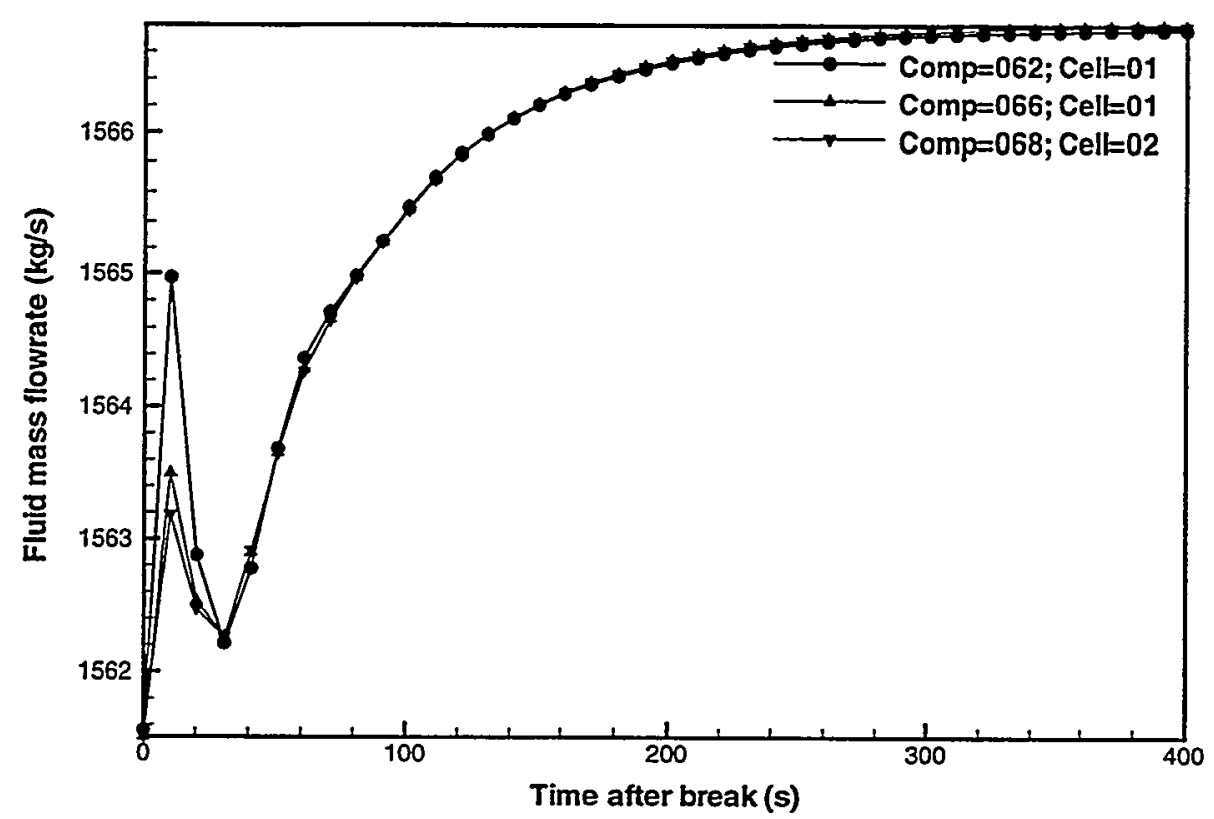

Figure B-14d Primary HR cold-leg piping liquid mass flowrates for NO (False transient to establish steady-state).

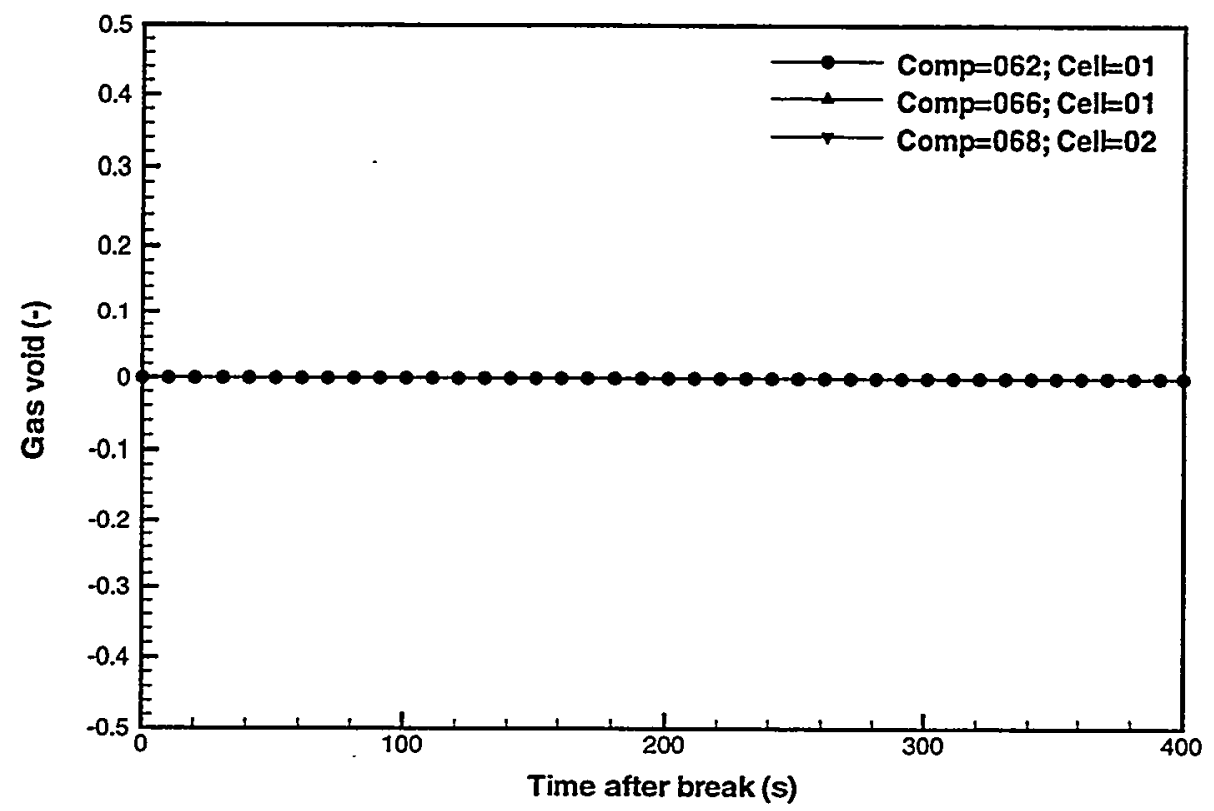

Figure B-14e Primary HR cold-leg piping void fractions for NO (False transient to establish steady-state). 


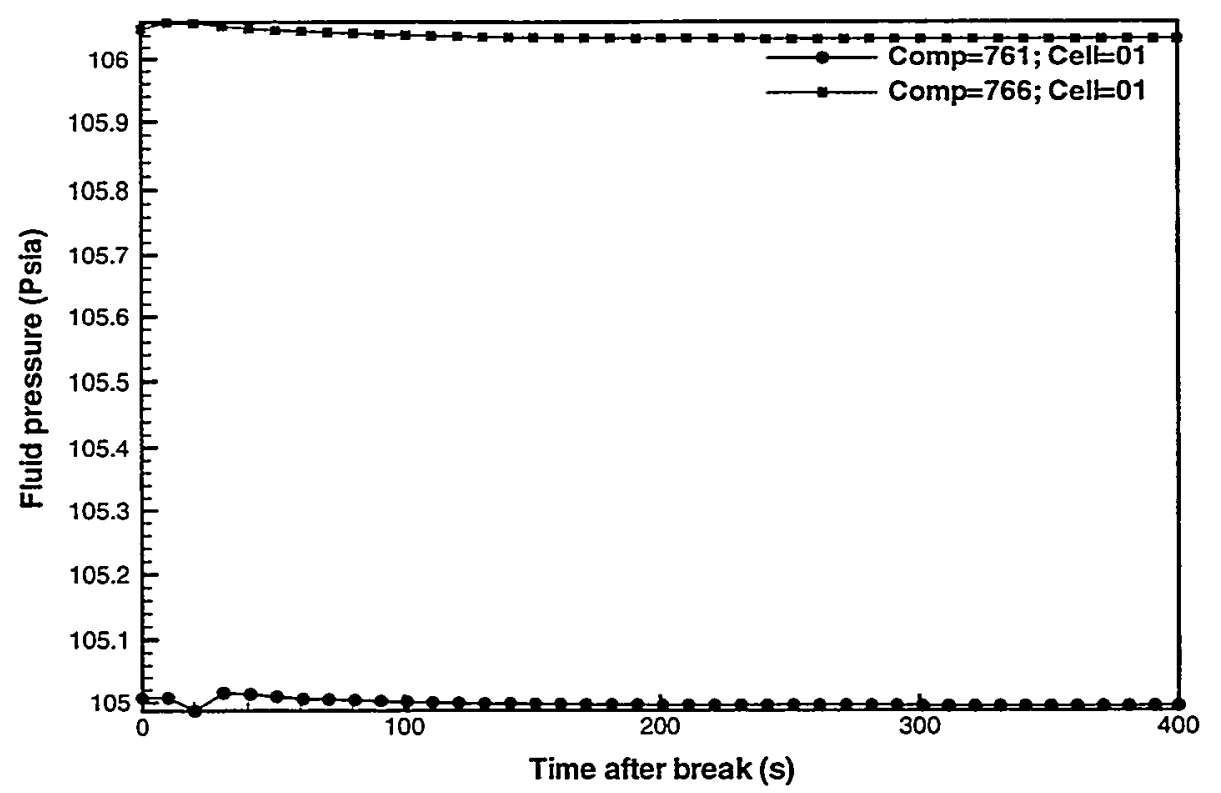

Figure B-15a Primary HR pressurizer and surge line fluid pressurës for NO (False transient to establish steady-state).

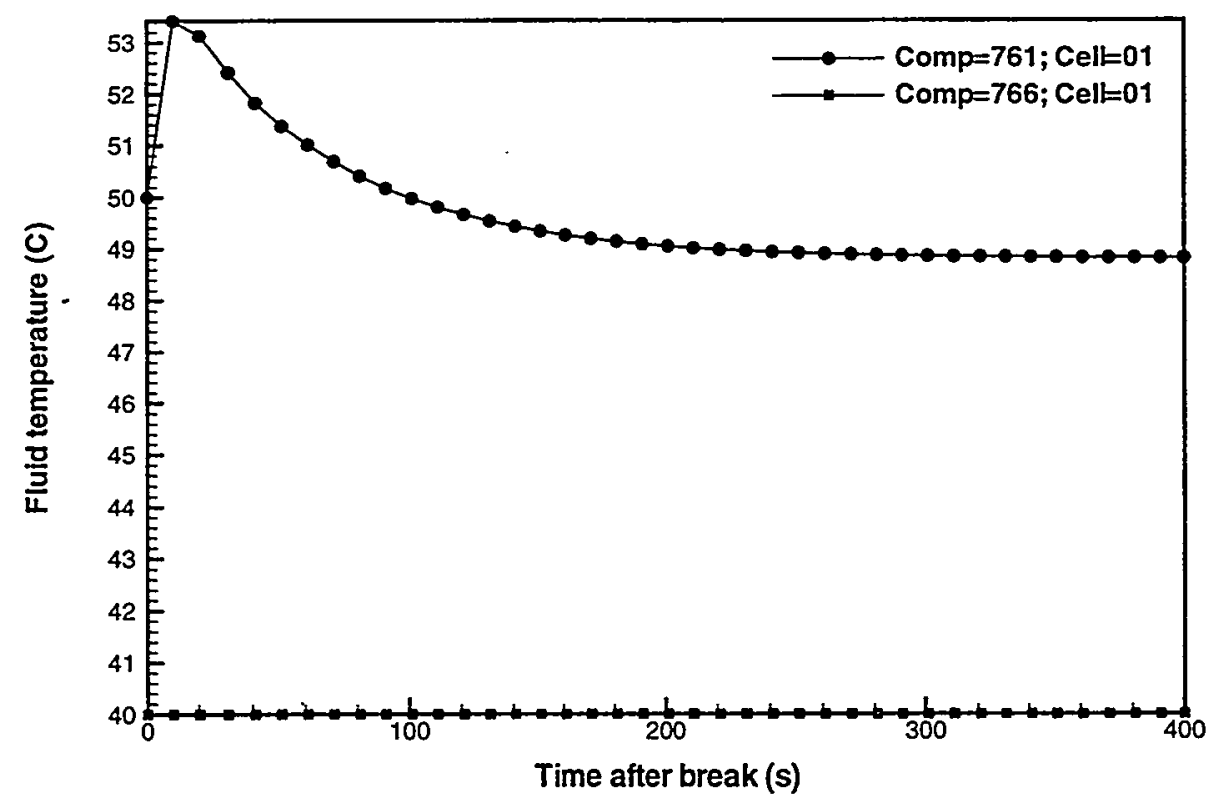

Figure B-15b Primary HR pressurizer and surge line fluid temperatures for NO (False transient to establish steady-state). 


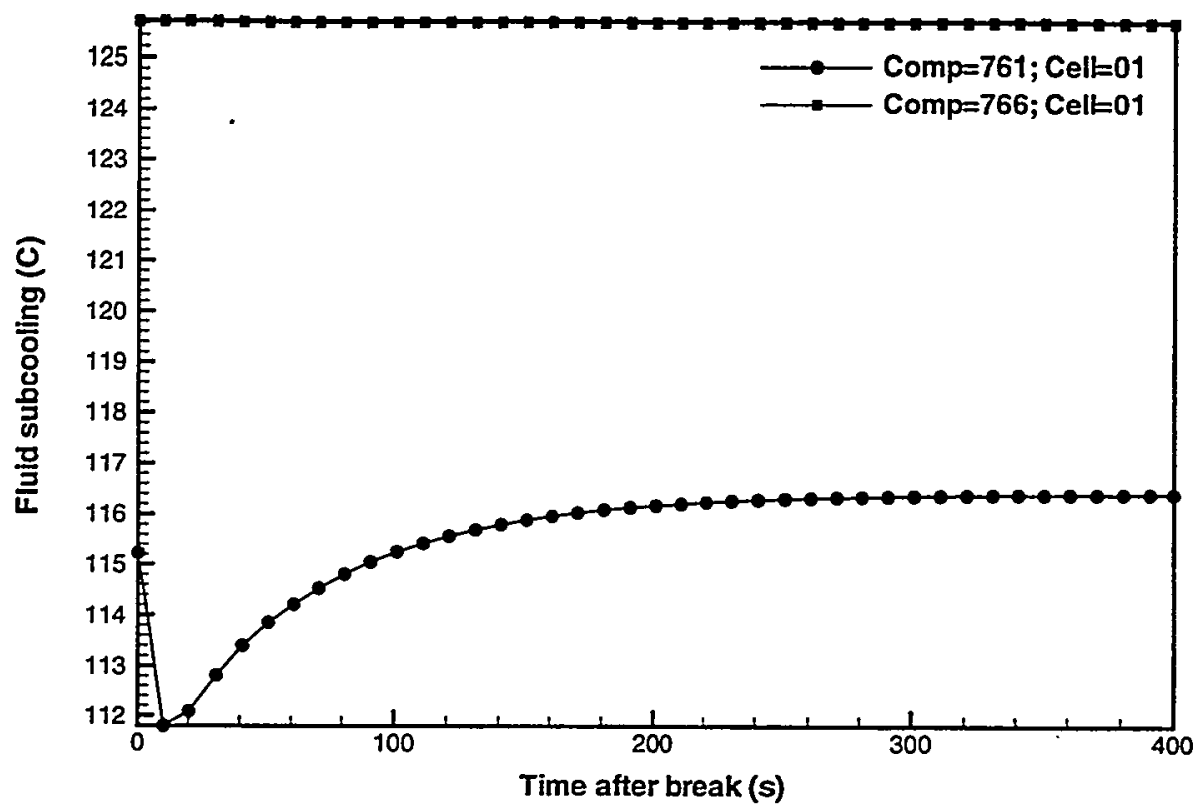

Figure B-15c Primary HR pressurizer and surge line fluid sübcoolings for NO (False transient to establish steady-state).

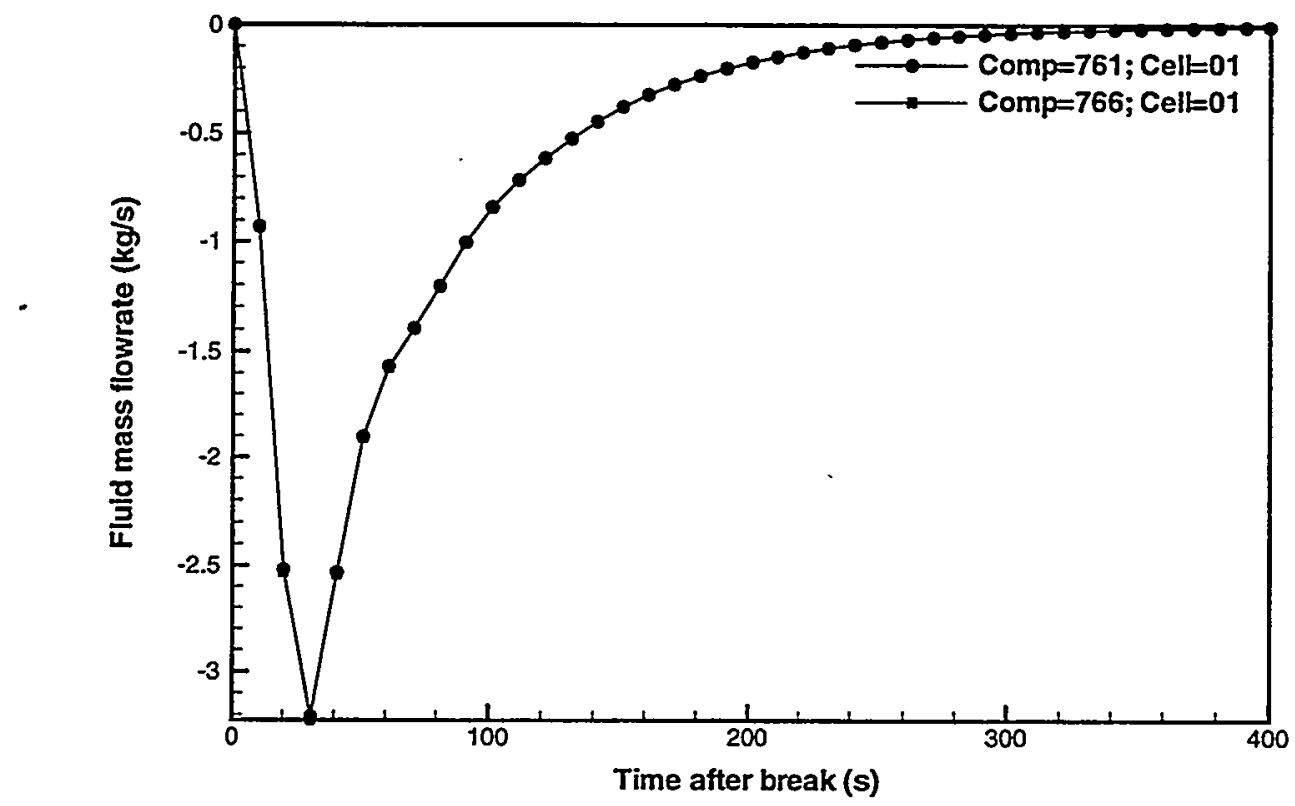

Figure B-15d Primary HR pressurizer and surge line liquid mass flowrates for NO (False transient to establish steady-state). 


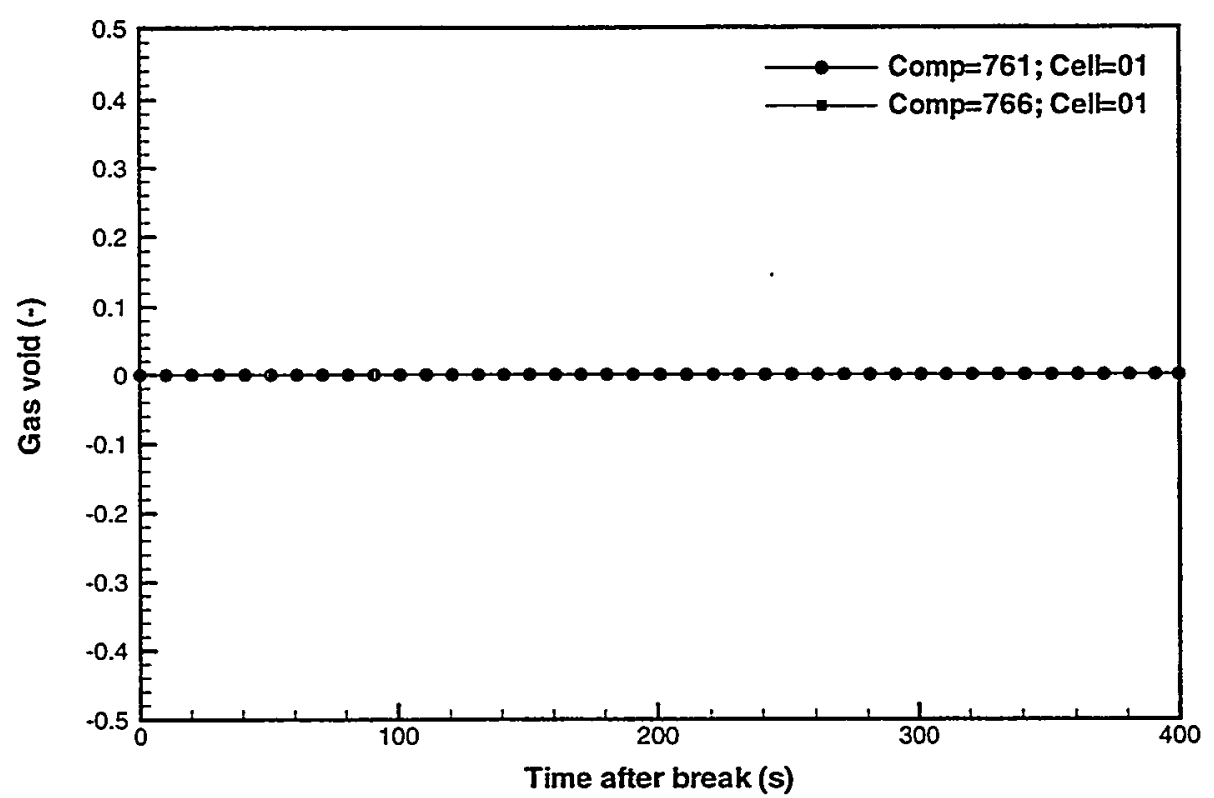

Figure B-15e Primary HR pressurizer and surge line void fractionš for NO (False transient to establish steady-state).

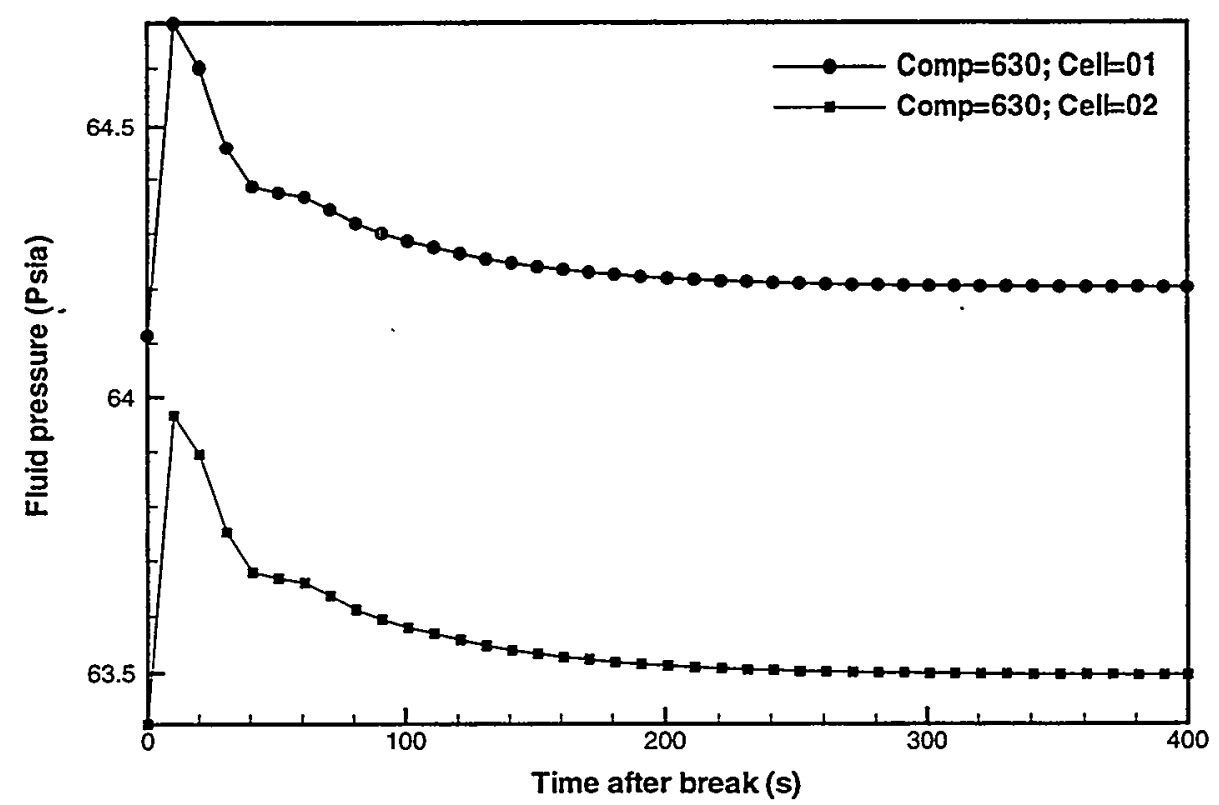

Figure B-16a Primary RHR pump fluid pressures for NO (False transient to establish steady-state). 


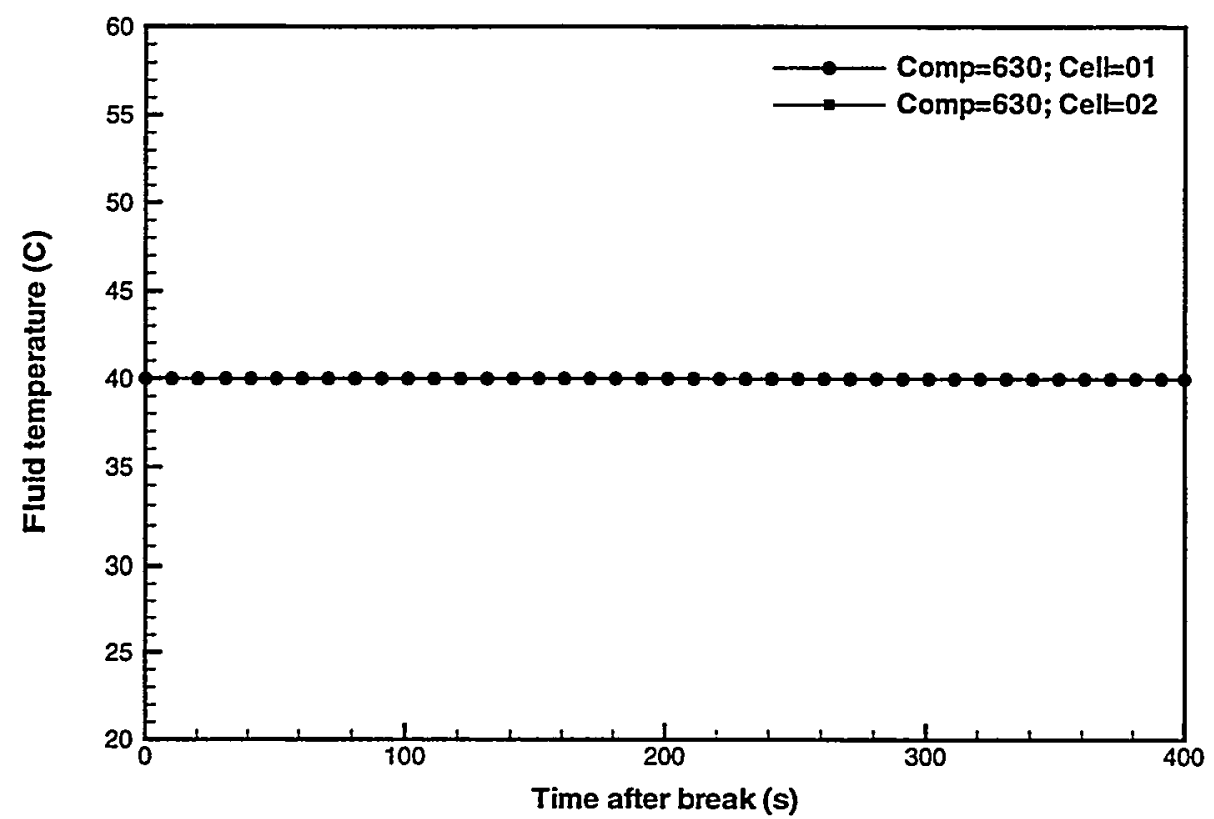

Figure B-16b Primary RHR pump fluid temperatures for NO (False transient to establish steady-state).

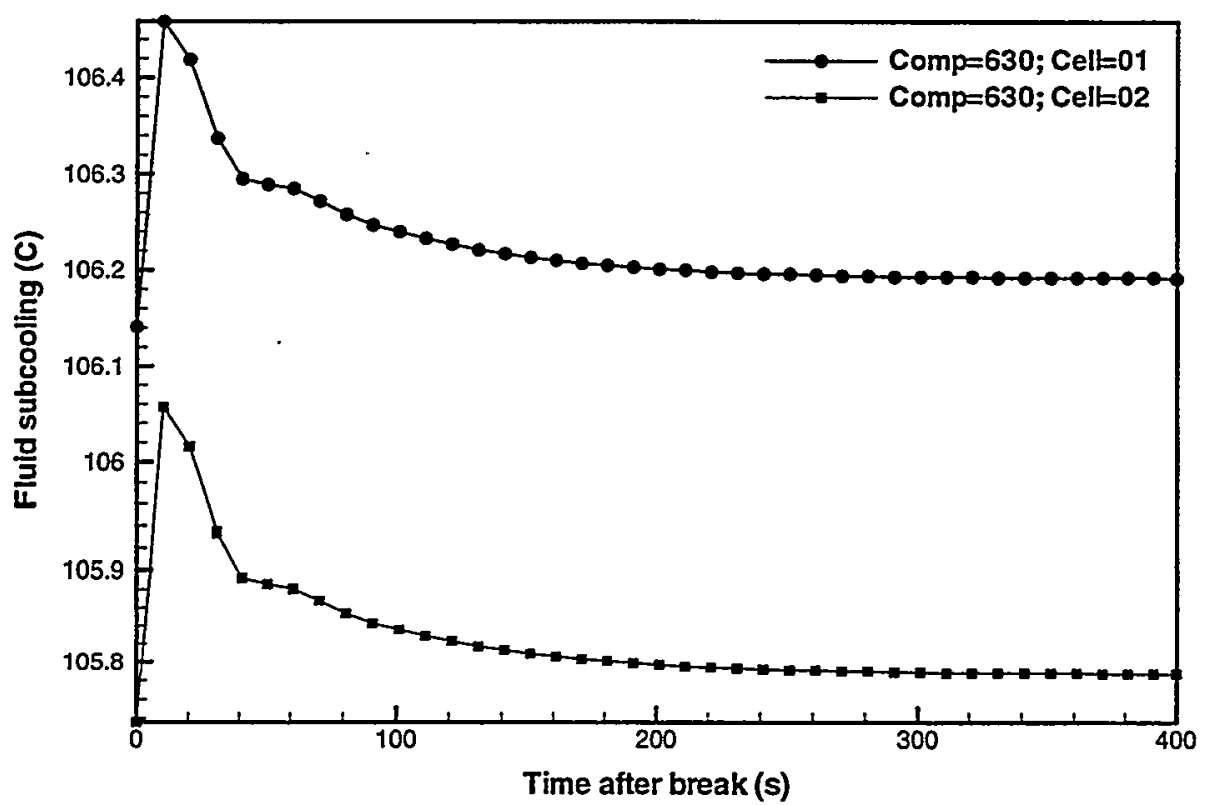

Figure B-16c Primary RHR pump fluid subcoolings for NO (False transient to establish steady-state). 


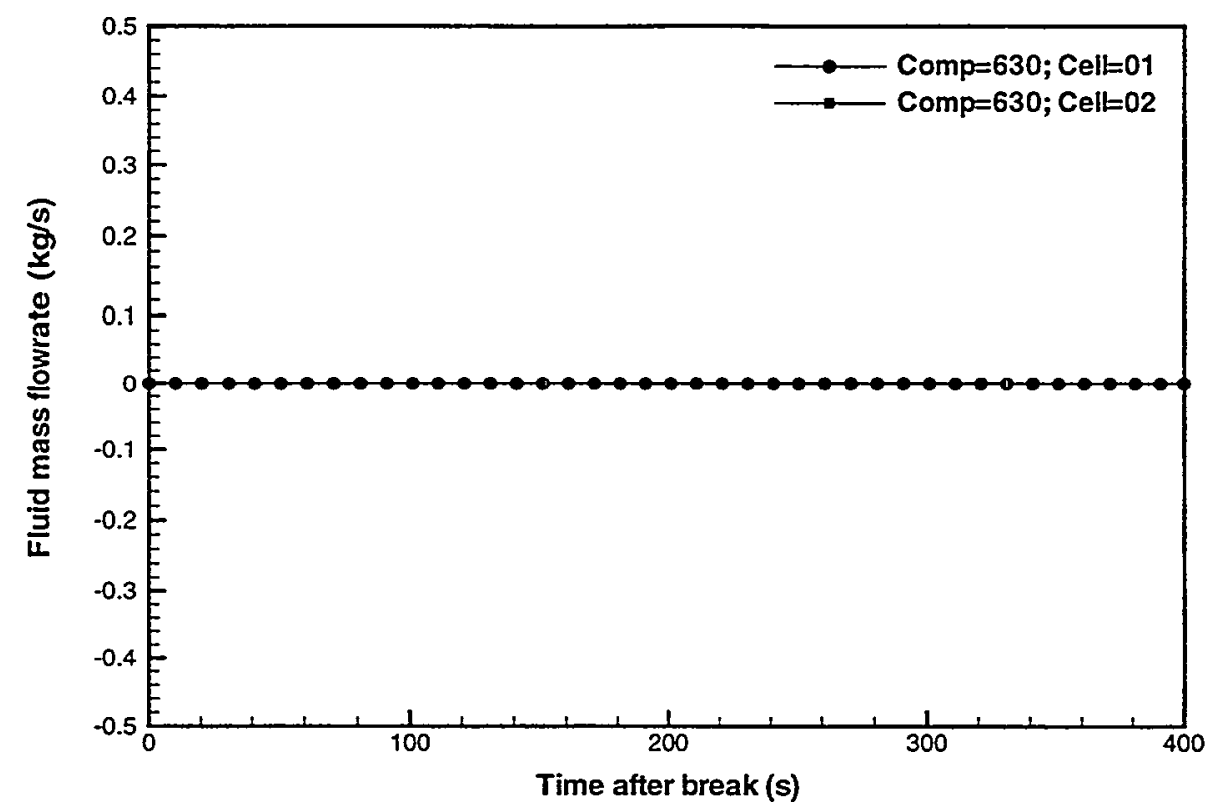

Figure B-16d Primary RHR pump liquid mass flowrates for NO (Fàlse transient to establish steady-state).

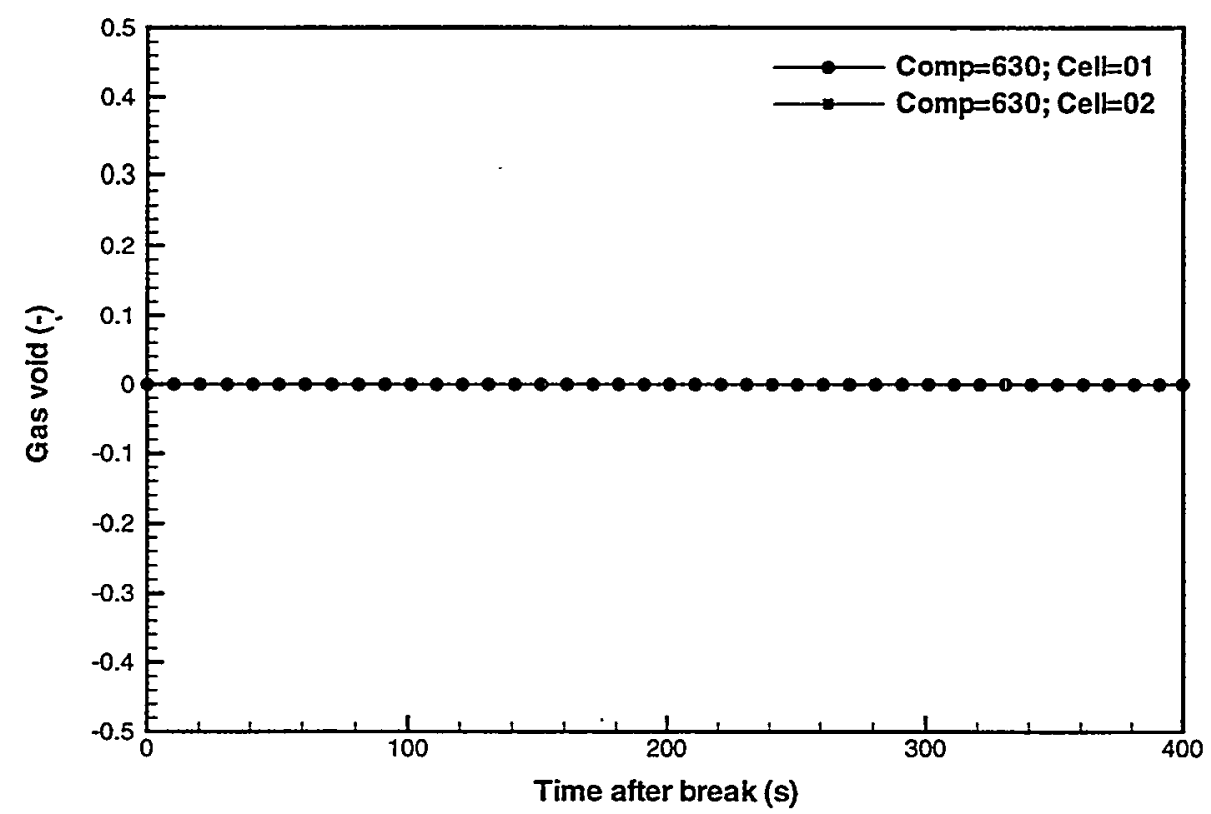

Figure B-16e Primary RHR pump void fractions for NO (False transient to establish steady-state). 


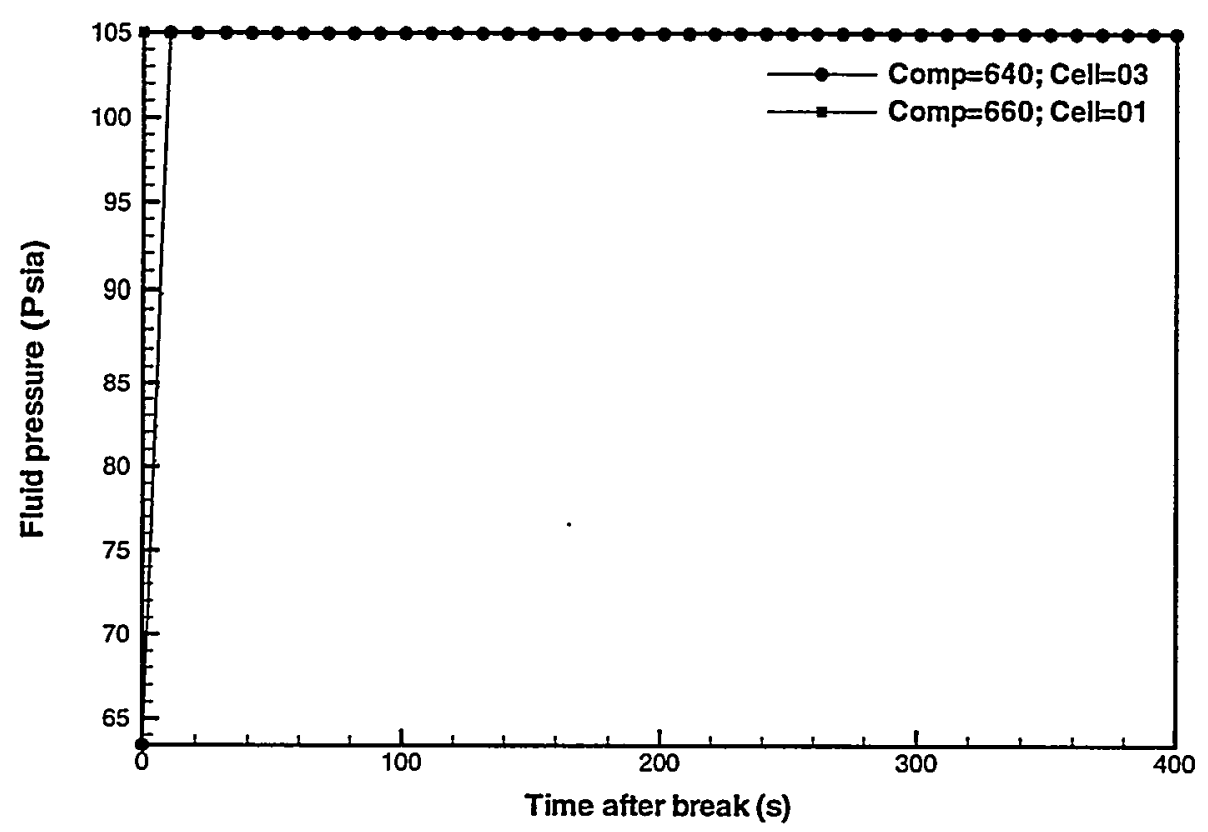

Figure B-17a Primary RHR heat exchanger fluid pressures for NO (False transient to establish steady-state).

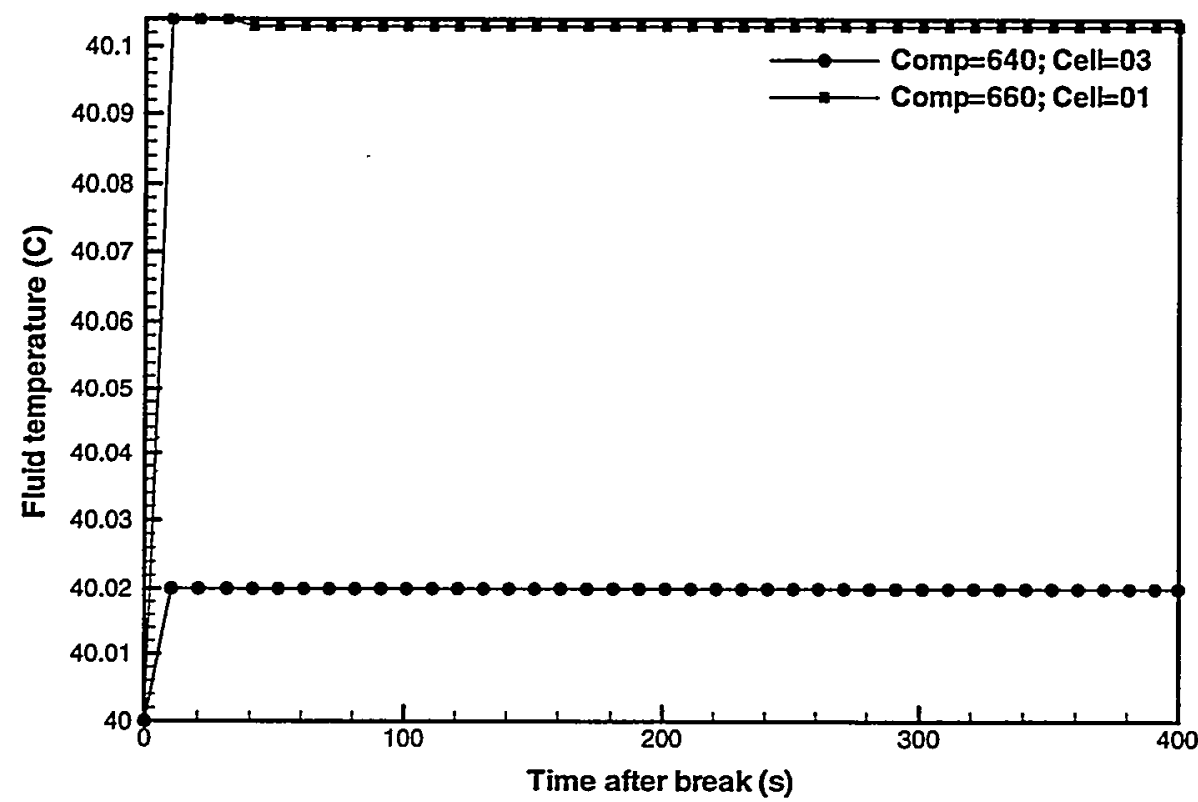

Figure B-17b Primary RHR heat exchanger fluid temperatures for NO (False transient to establish steady-state). 


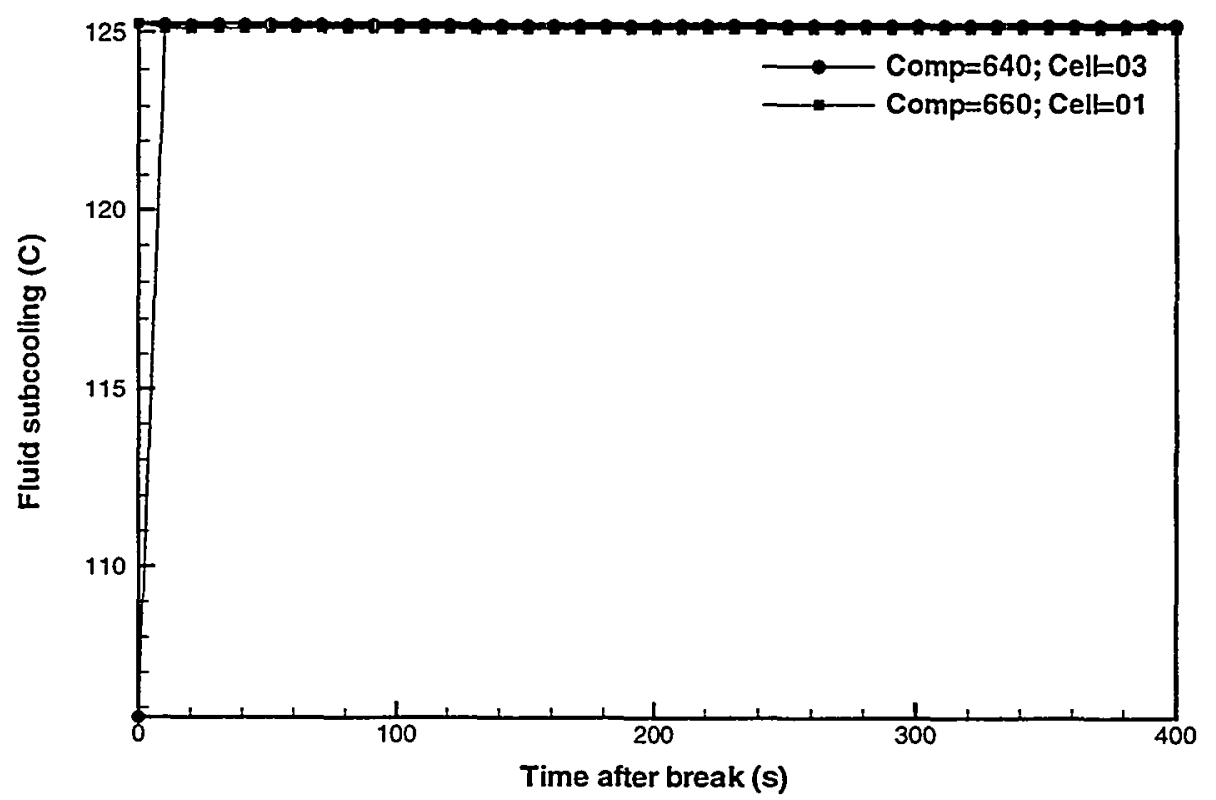

Figure B-17c Primary RHR heat exchanger fluid subcoolings for NO'False transient to establish steady-state).

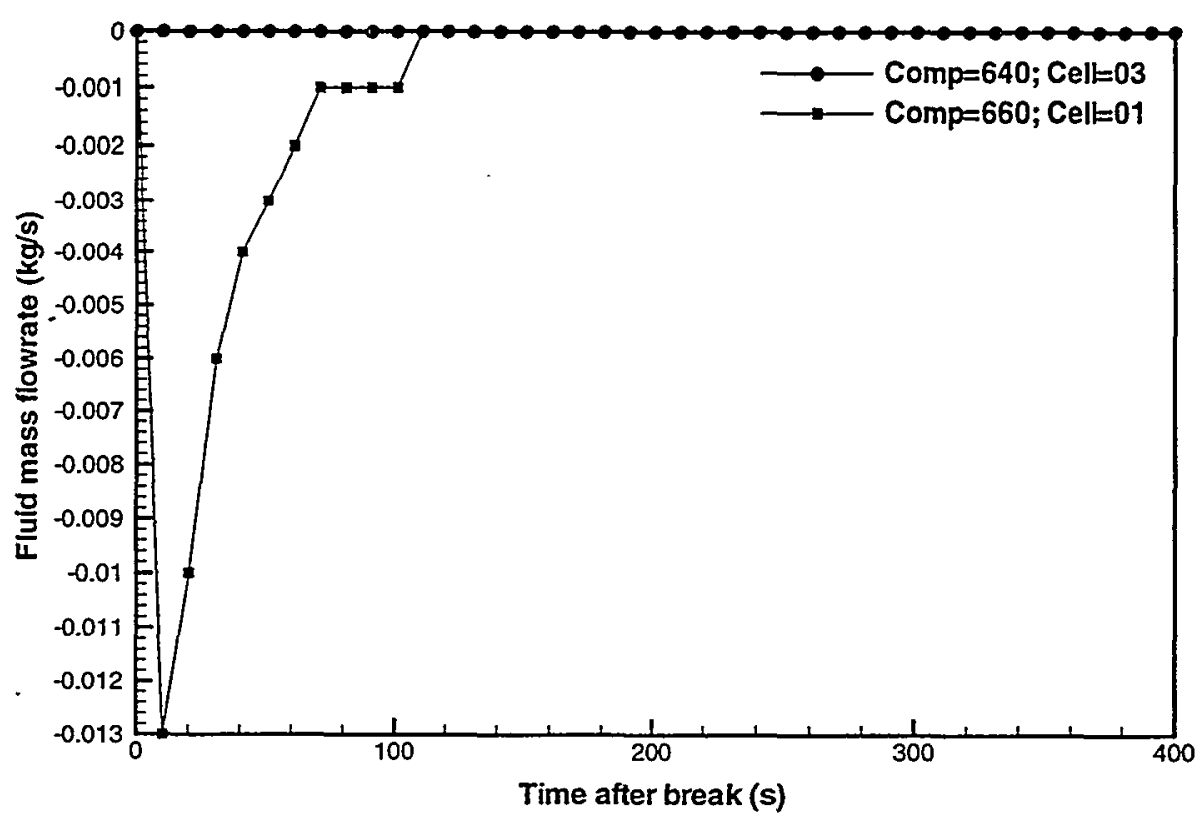

Figure B-17d Primary RHR heat exchanger liquid mass flowrates for NO (False transient to establish steady-state). 


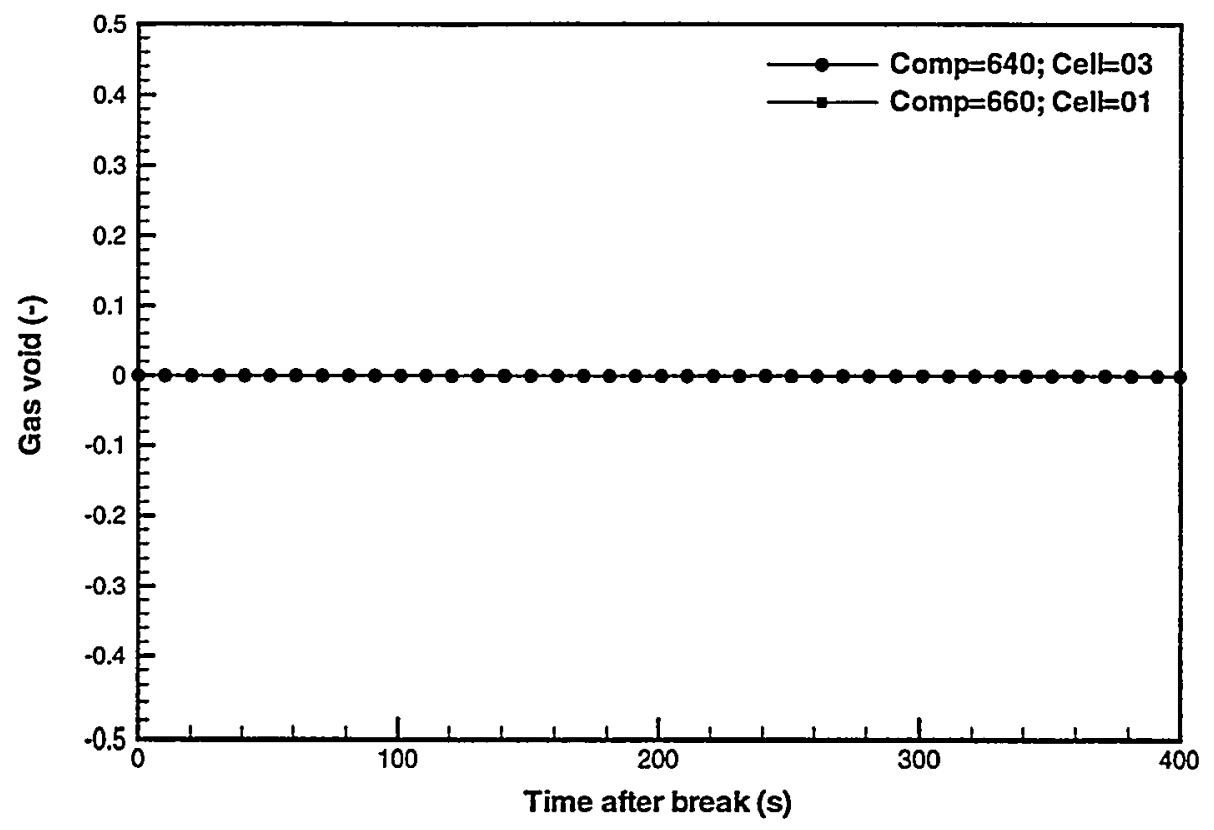

Figure B-17e Primary RHR heat exchanger void fractions for NO (False transient to establish steady-state).

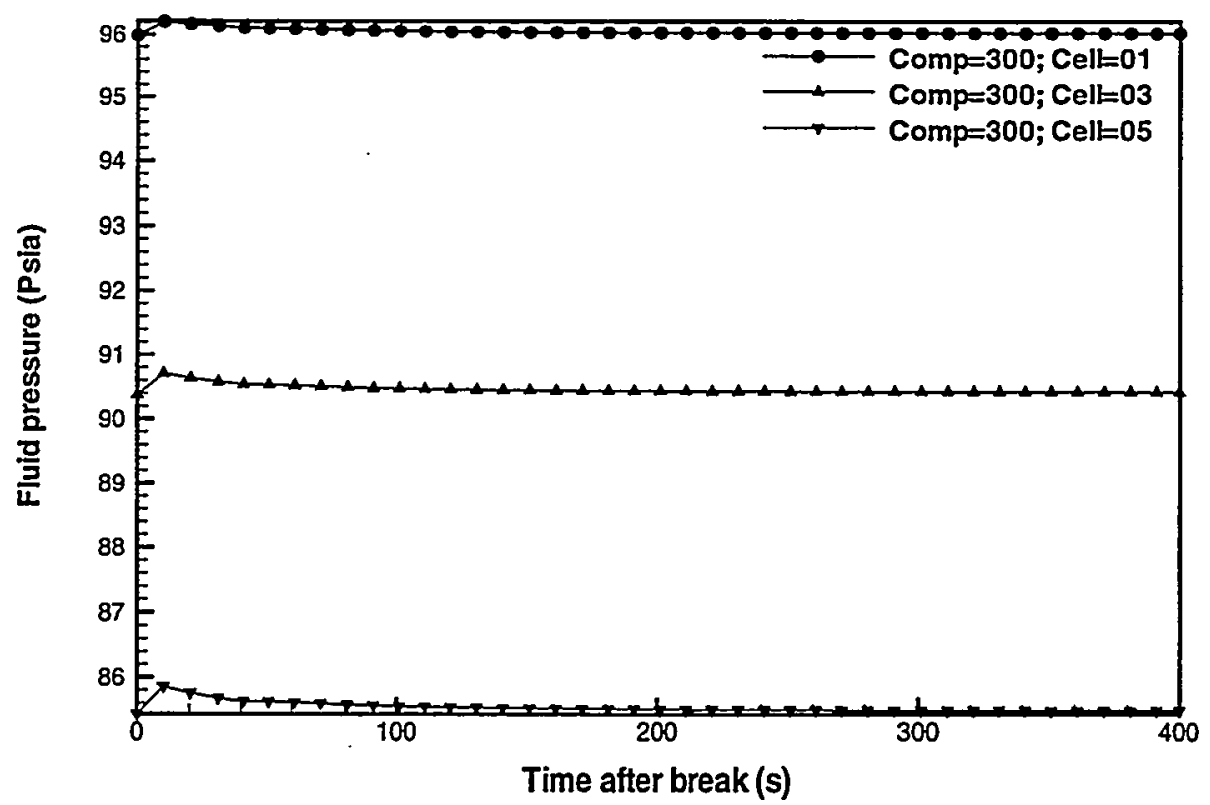

Figure B-18a Module 1 channel fluid pressures for NO (False transient to establish steady-state). 


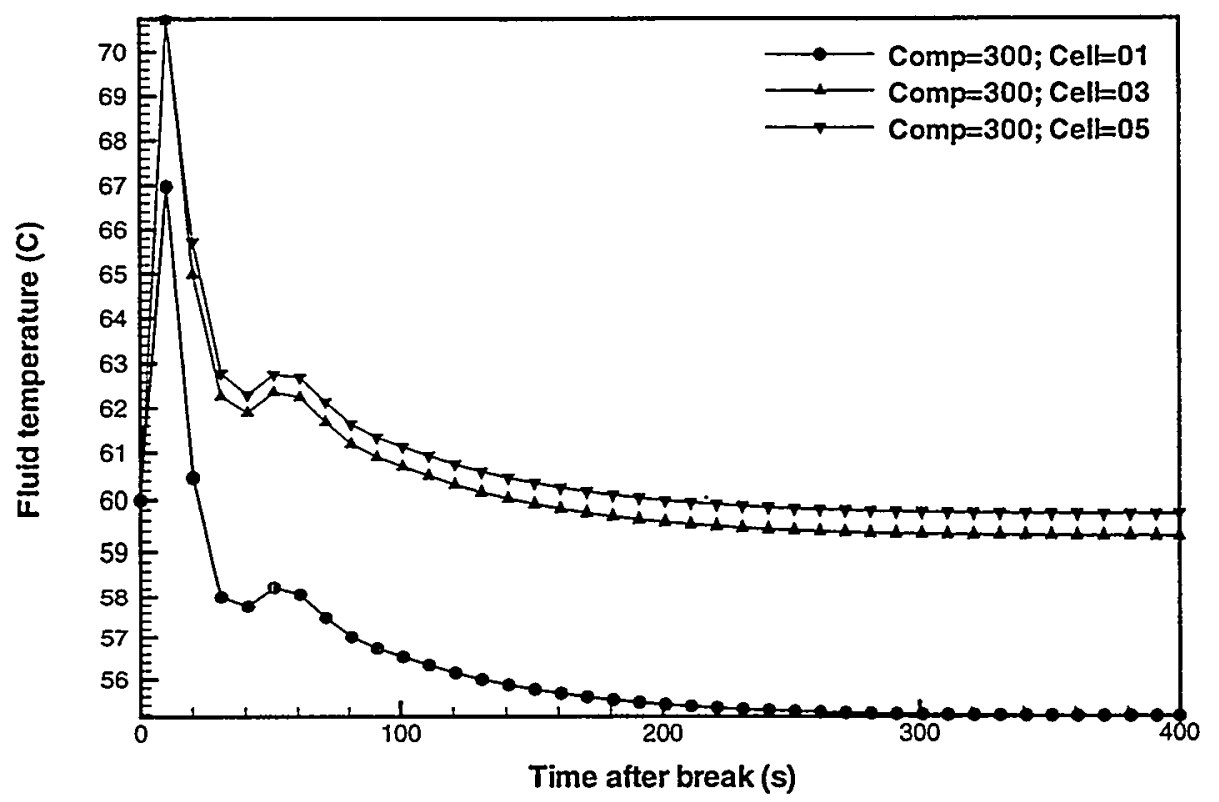

Figure B-18b Module 1 channel fluid temperatures for NO (False transient to establish steady-state).

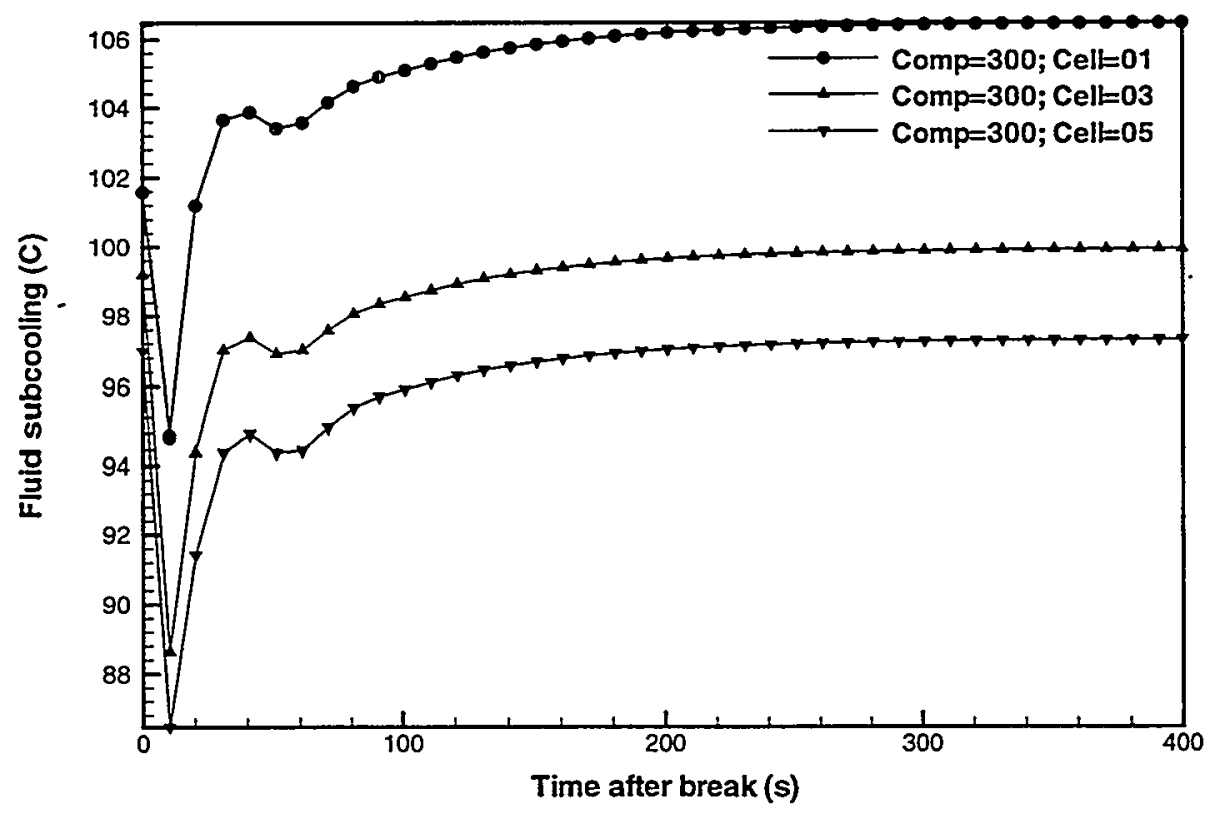

Figure B-18c Module 1 channel fluid subcoolings for NO (False transient to establish steady-state). 


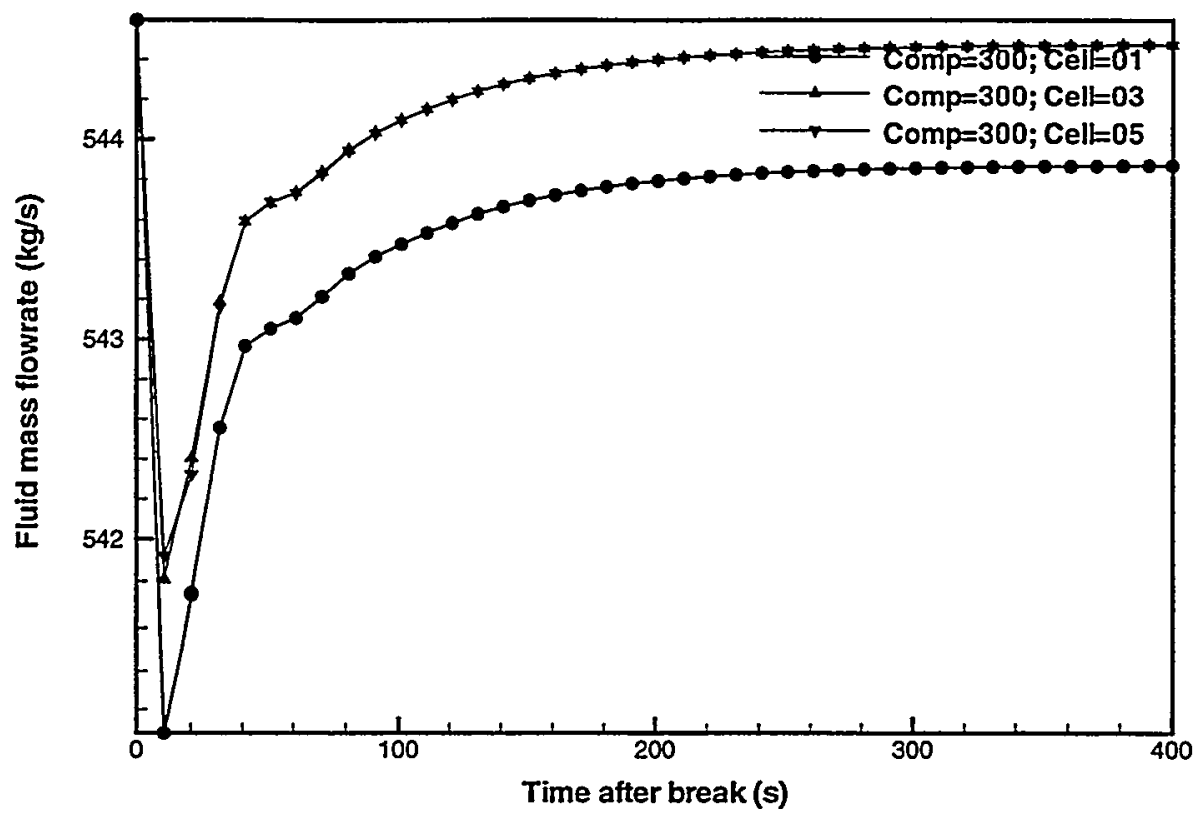

Figure B-18d Module 1 channel liquid mass flowrates for NO (False transient to establish steady-state).

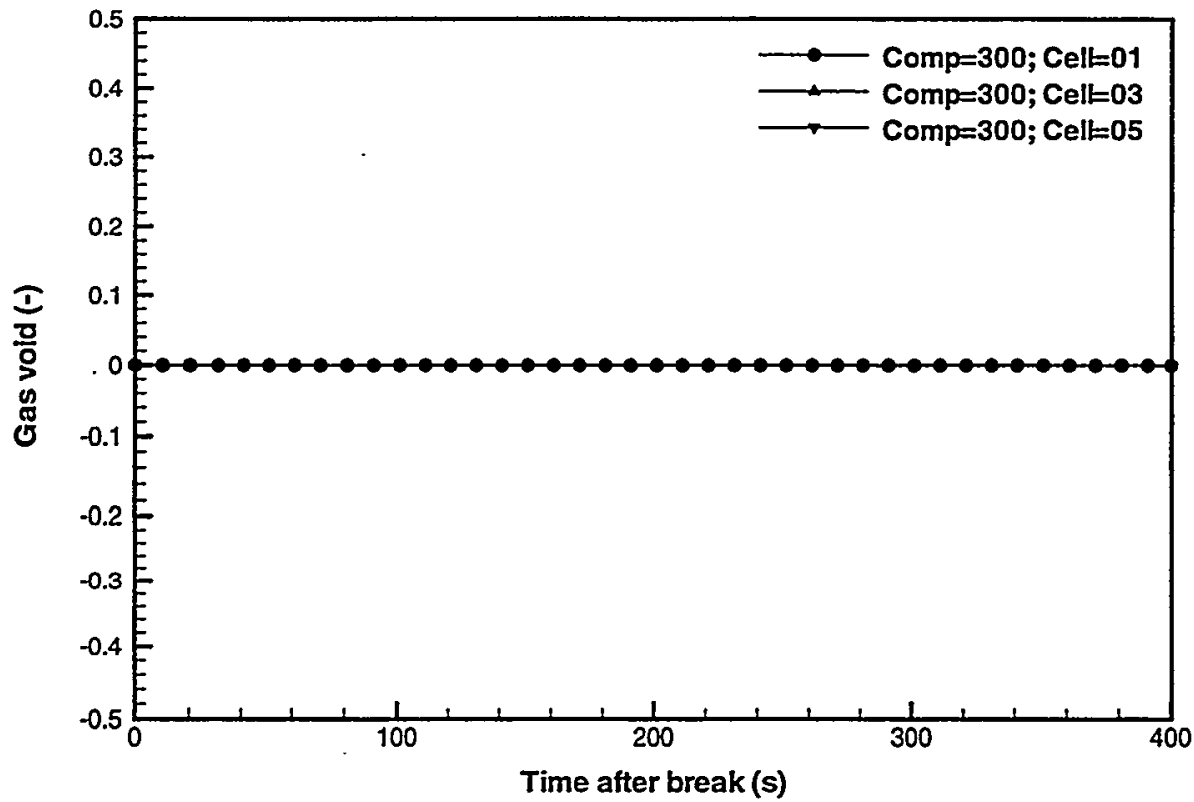

Figure B-8e Module 1 channel void fractions for NO (False transient to establish steadystate). 


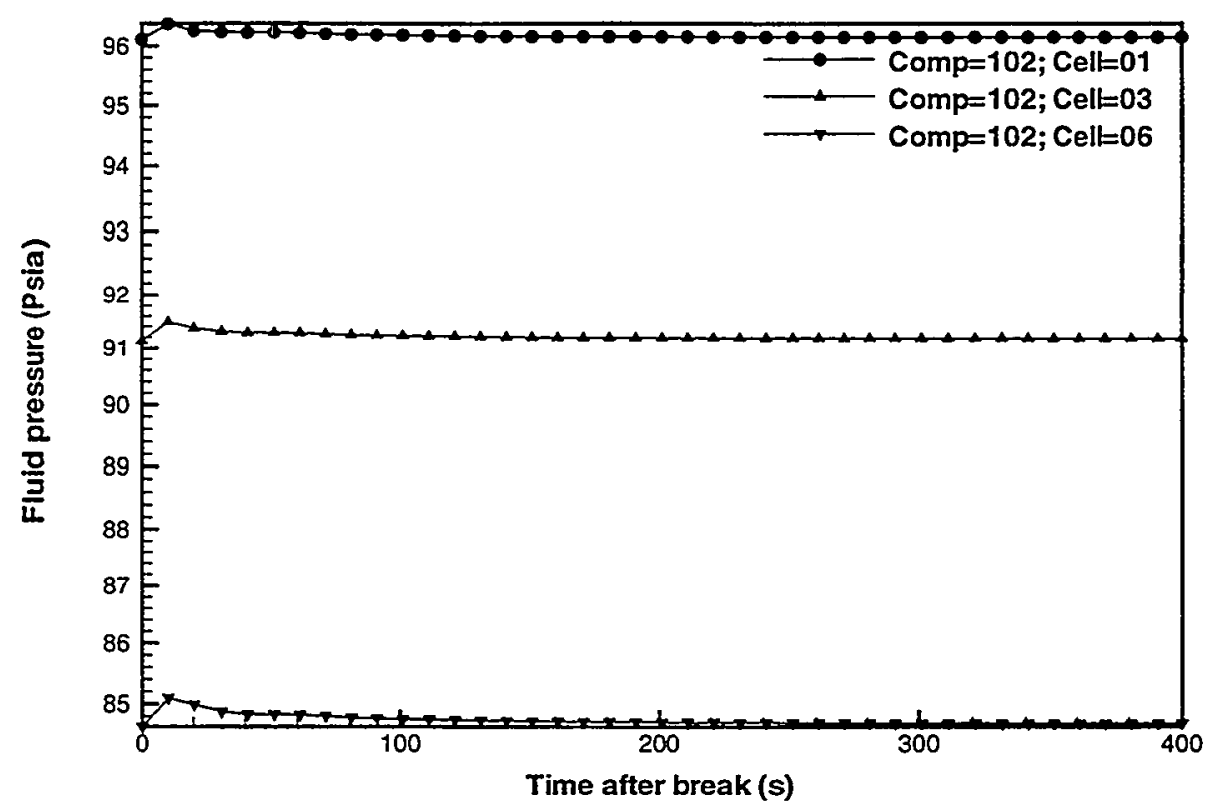

Figure B-19a Module 2 channel fluid pressures for NO (False transient to establish steady-state).

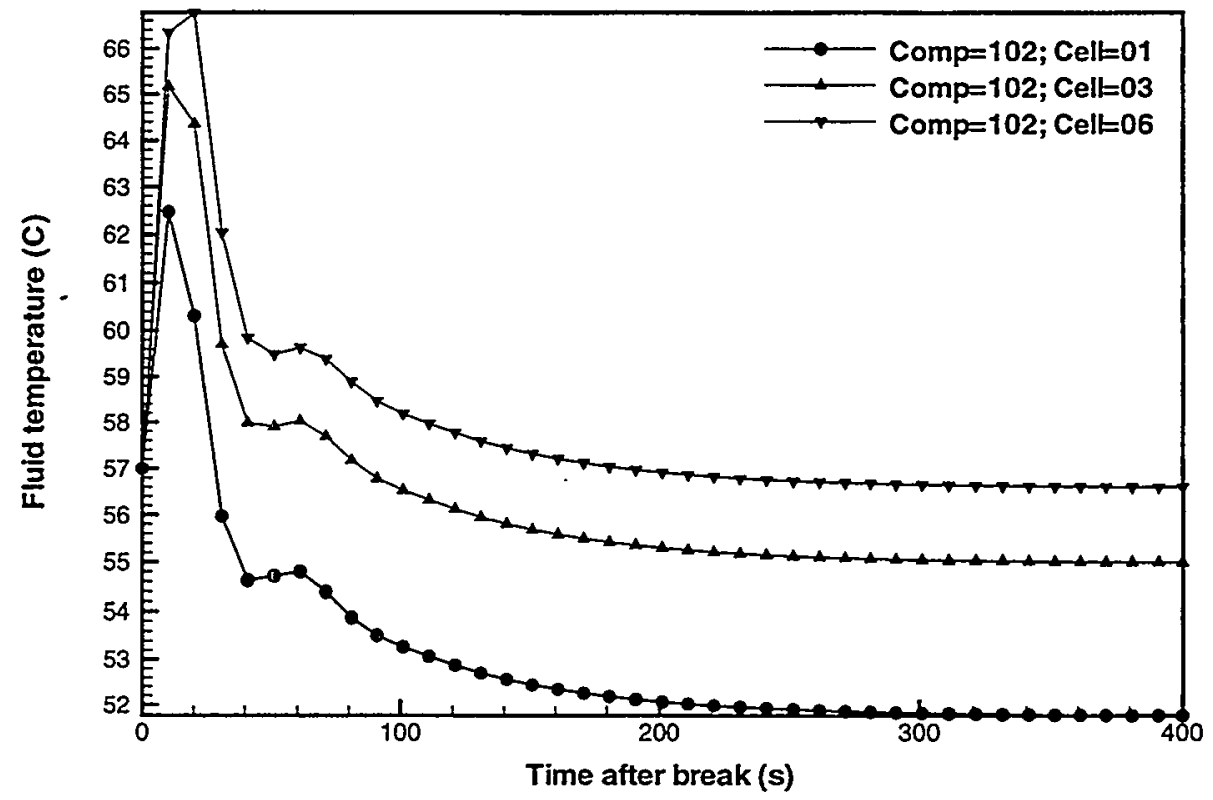

Figure B-19b Module 2 channel fluid temperatures for NO (False transient to establish steady-state). 


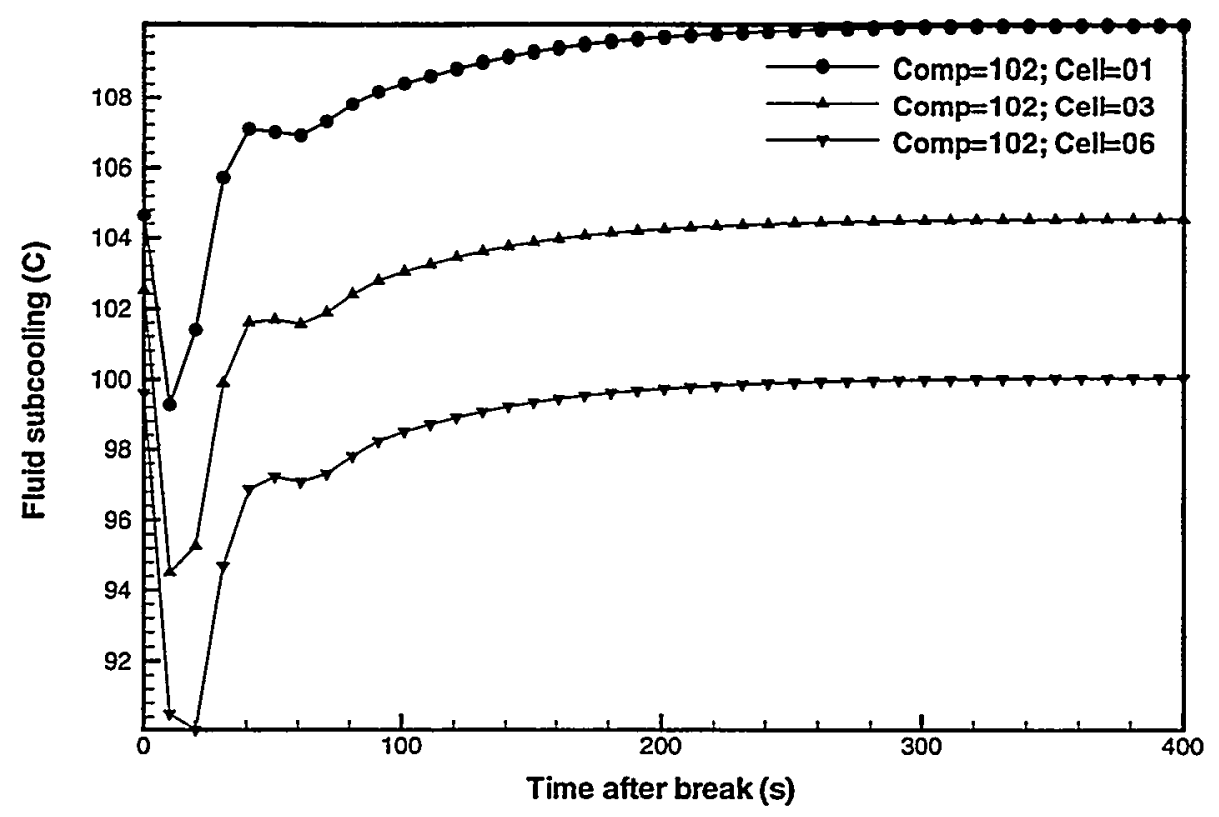

Figure B-19c Module 2 channel fluid subcoolings for NO (Fatse transient to establish steady-state).

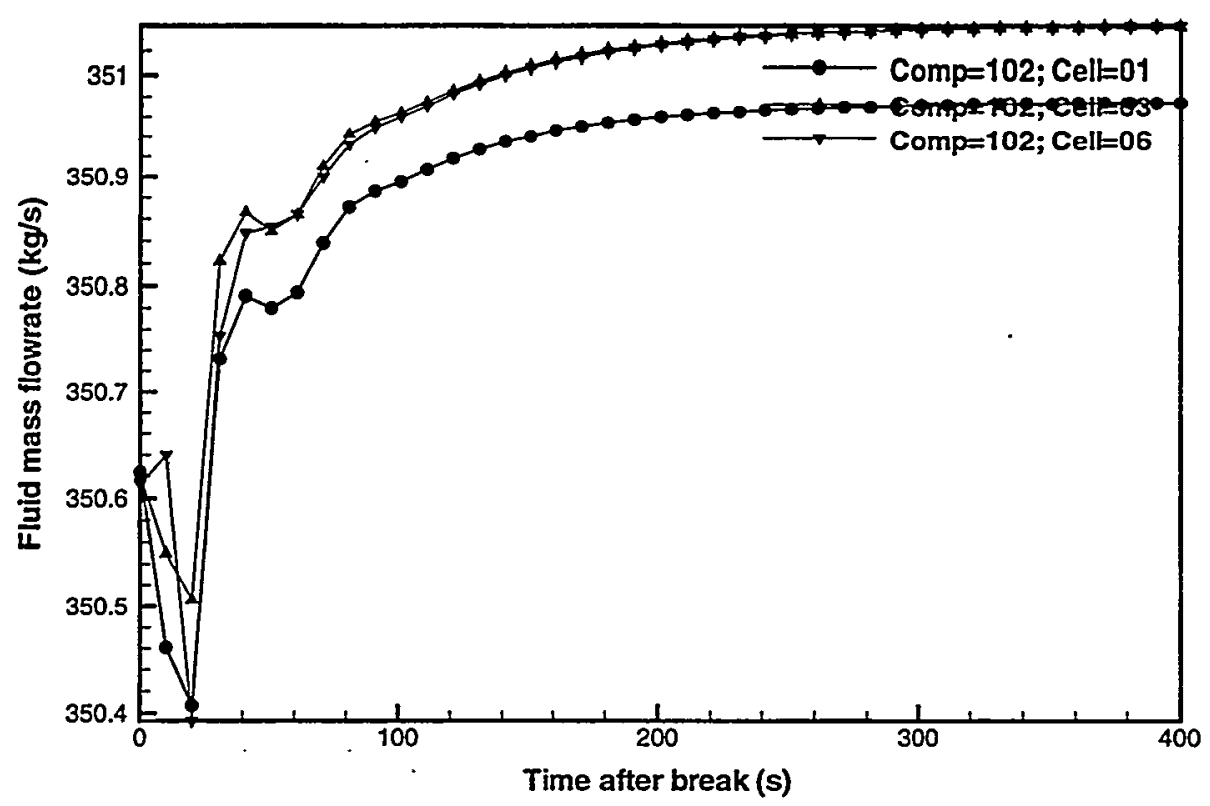

Figure B-19d Module 2 channel liquid mass flowrates for NO (False transient to establish steady-state). 


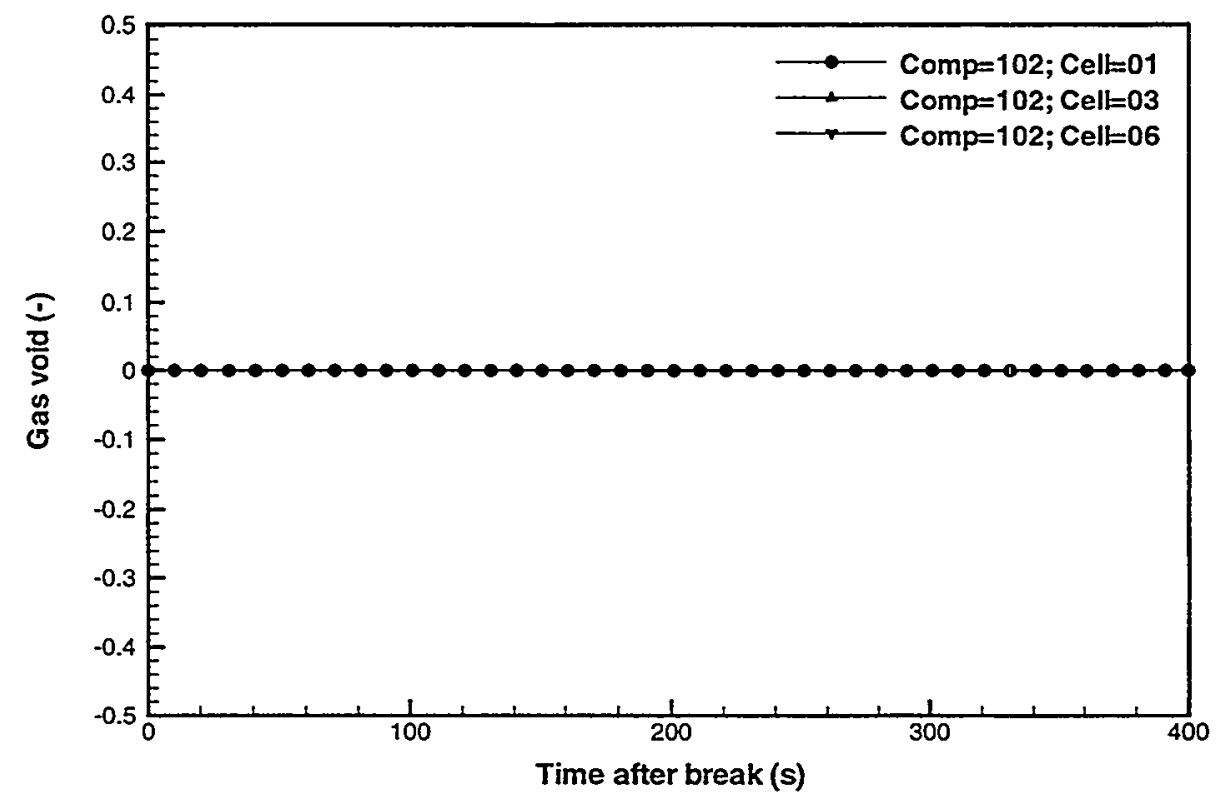

Figure B-19e Module 2 channel Module 2 channel void fractions for NO (False transient to establish steady-state).

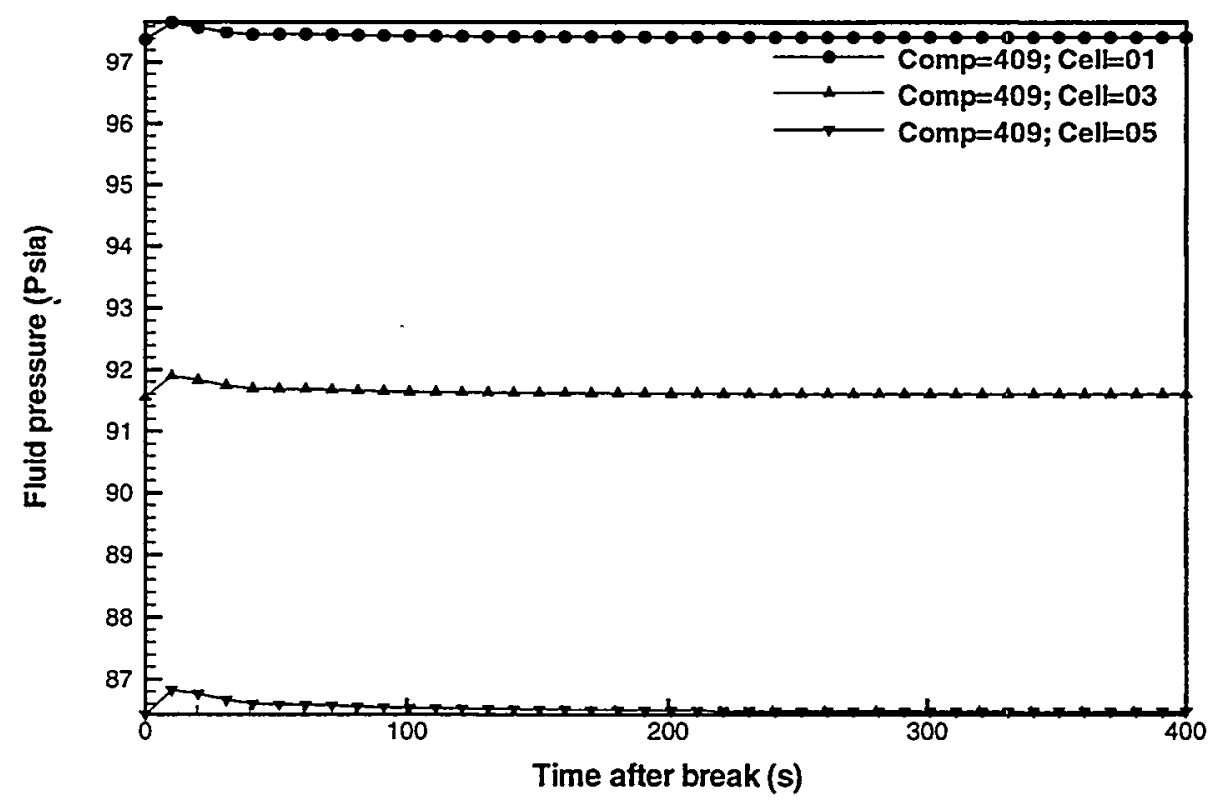

Figure B-20a Module 3 channel fluid pressures for NO (False transient to establish steady-state). 


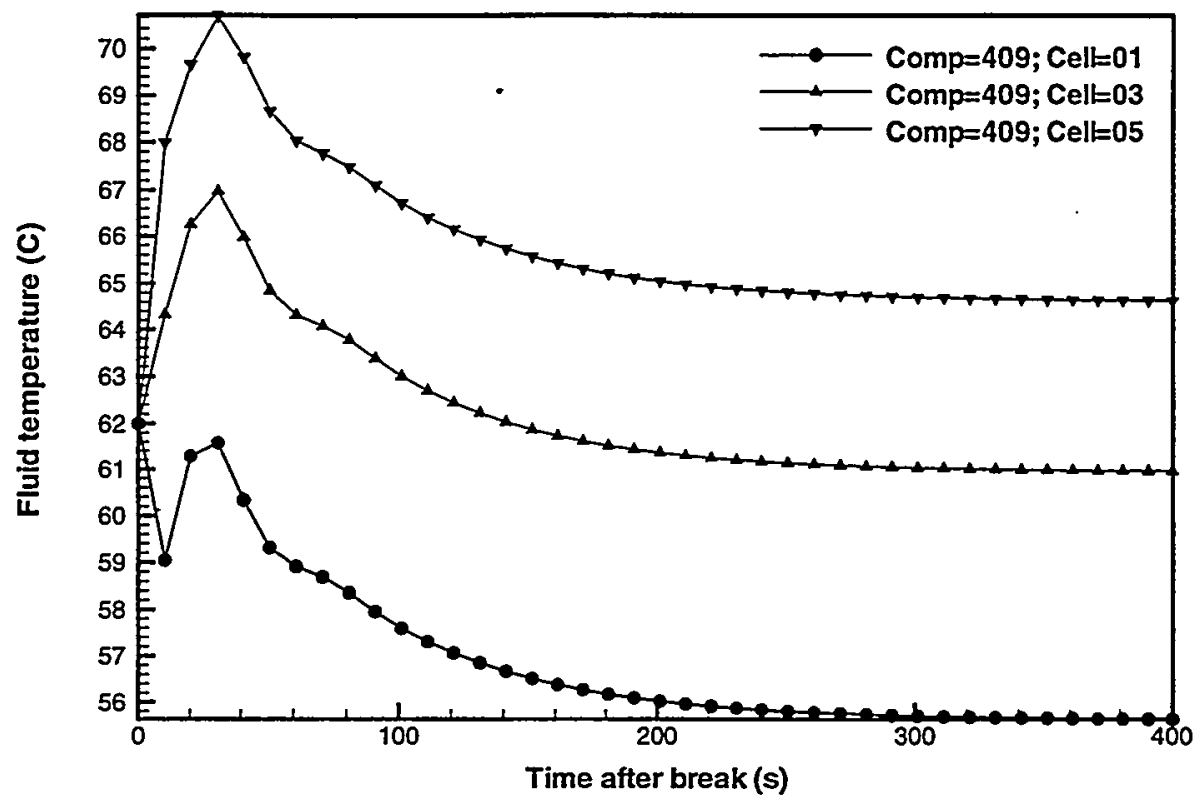

Figure B-20b Module 3 channel Module 3 channel fluid temperatures for NO (False transient to establish steady-state).

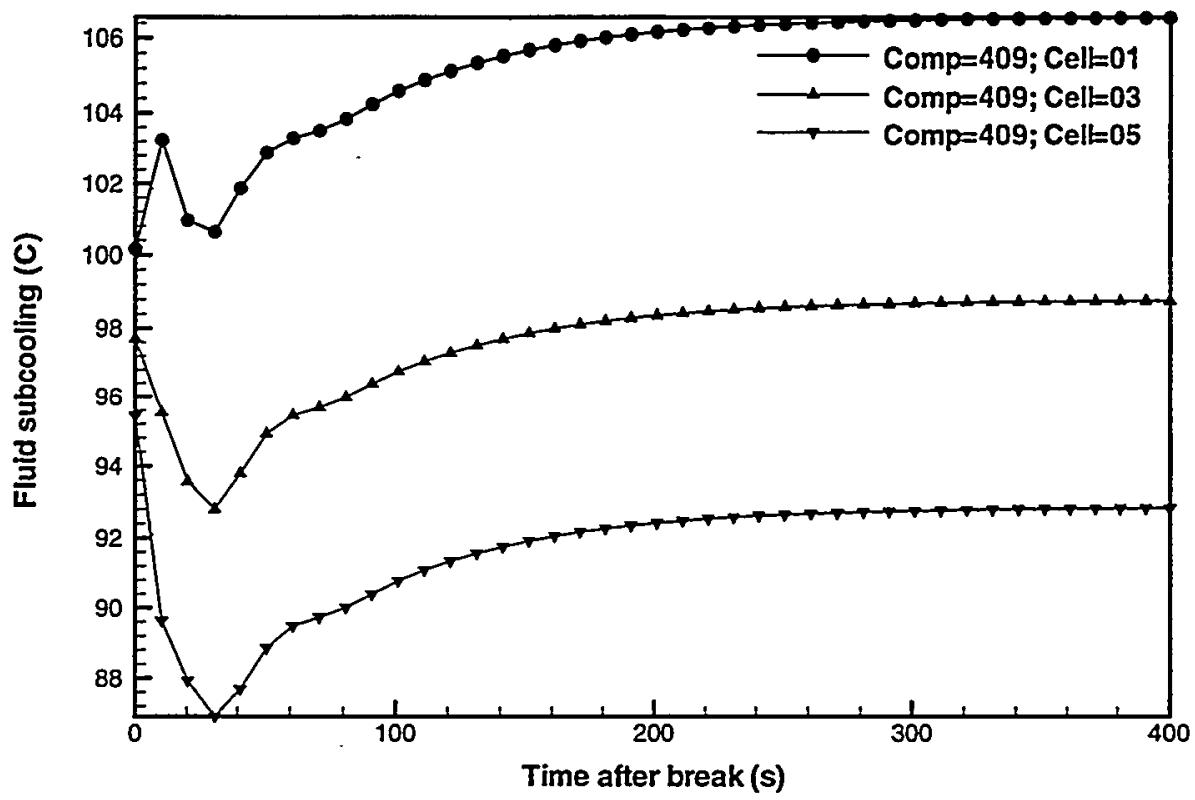

Figure B-20c Module 3 channel fluid subcoolings for NO (False transient to establish steady-state). 


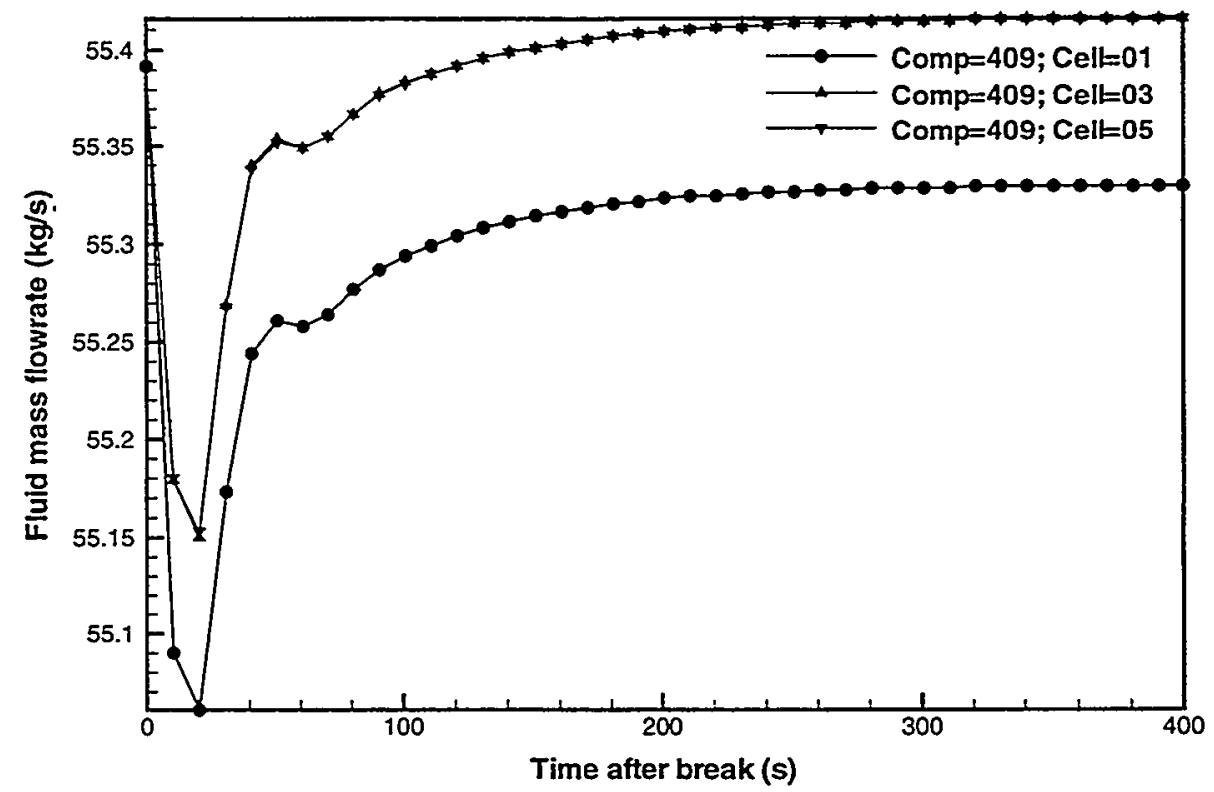

Figure B-20d Module 3 channel liquid mass flowrates for NO (False transient to establish steady-state).

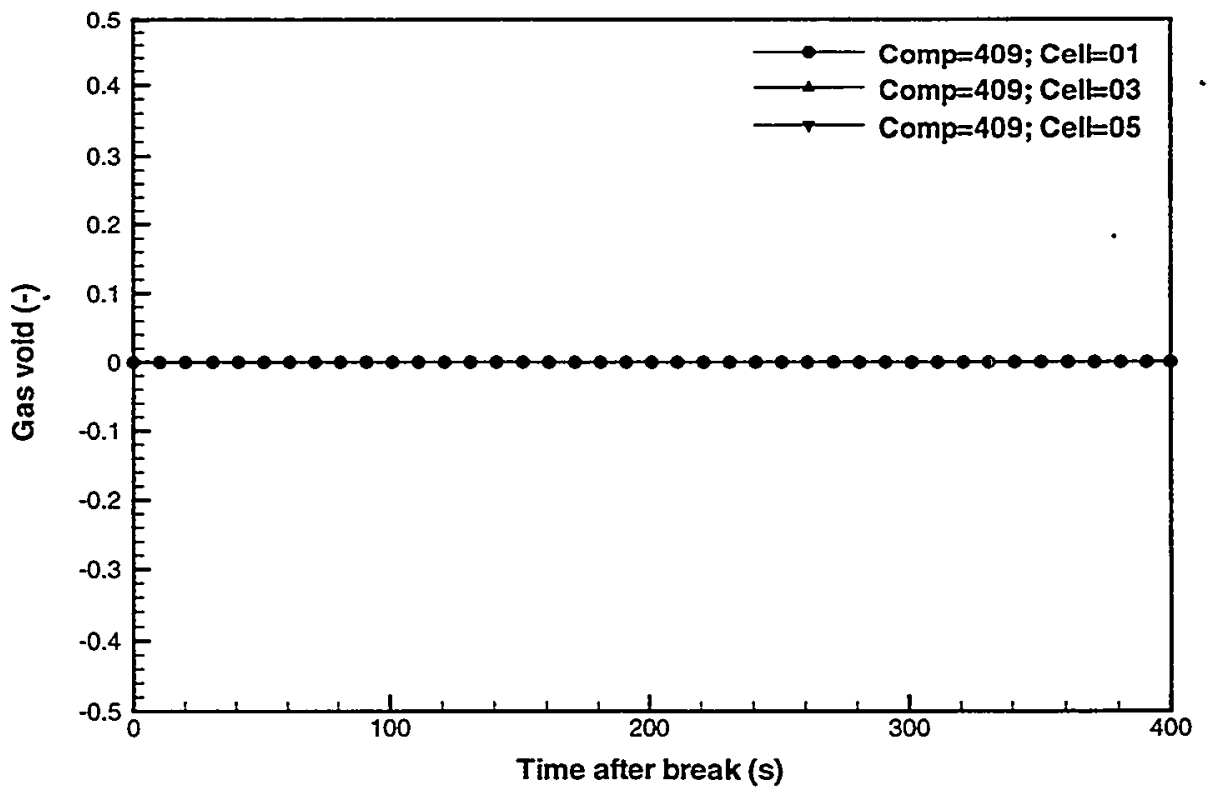

Figure B-20e Module 3 channel void fractions for NO (False transient to establish steady-state). 


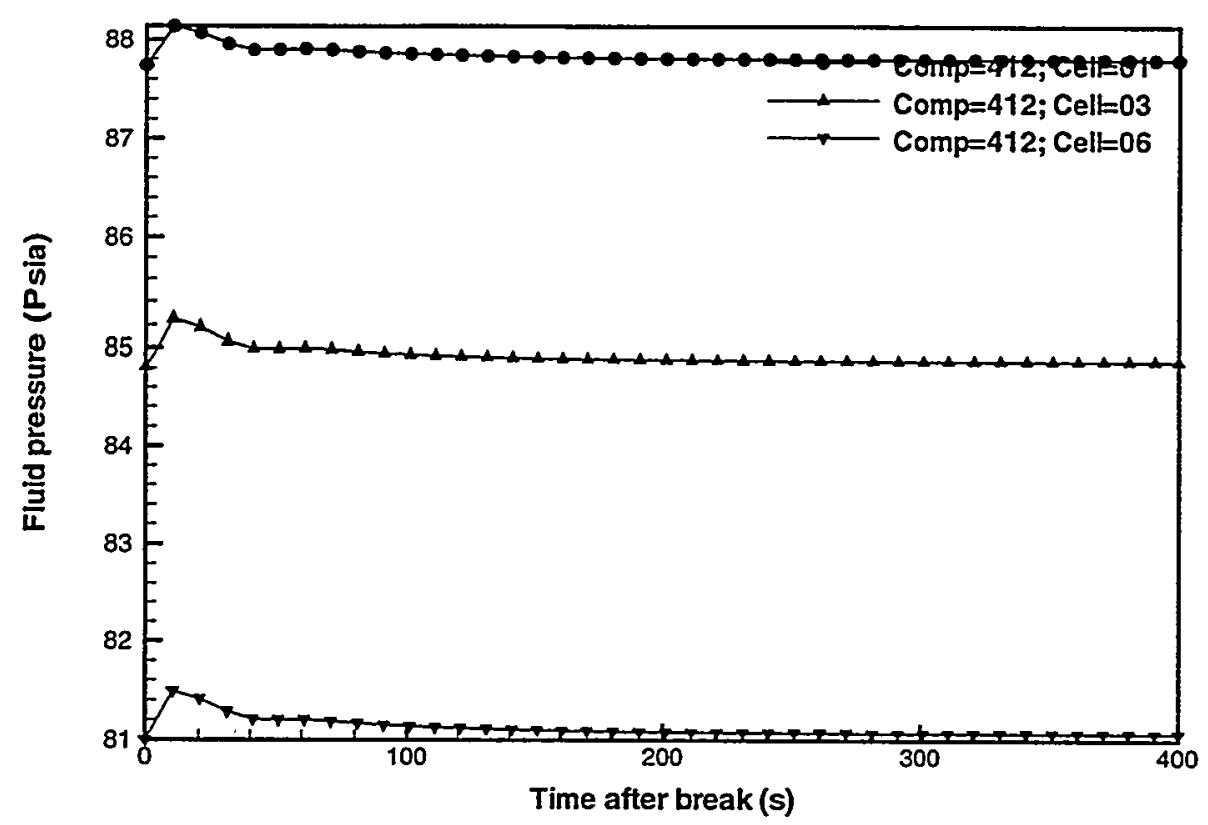

Figure B-21a Module 4 channel fluid pressures for NO (False transient to establish steady-state).

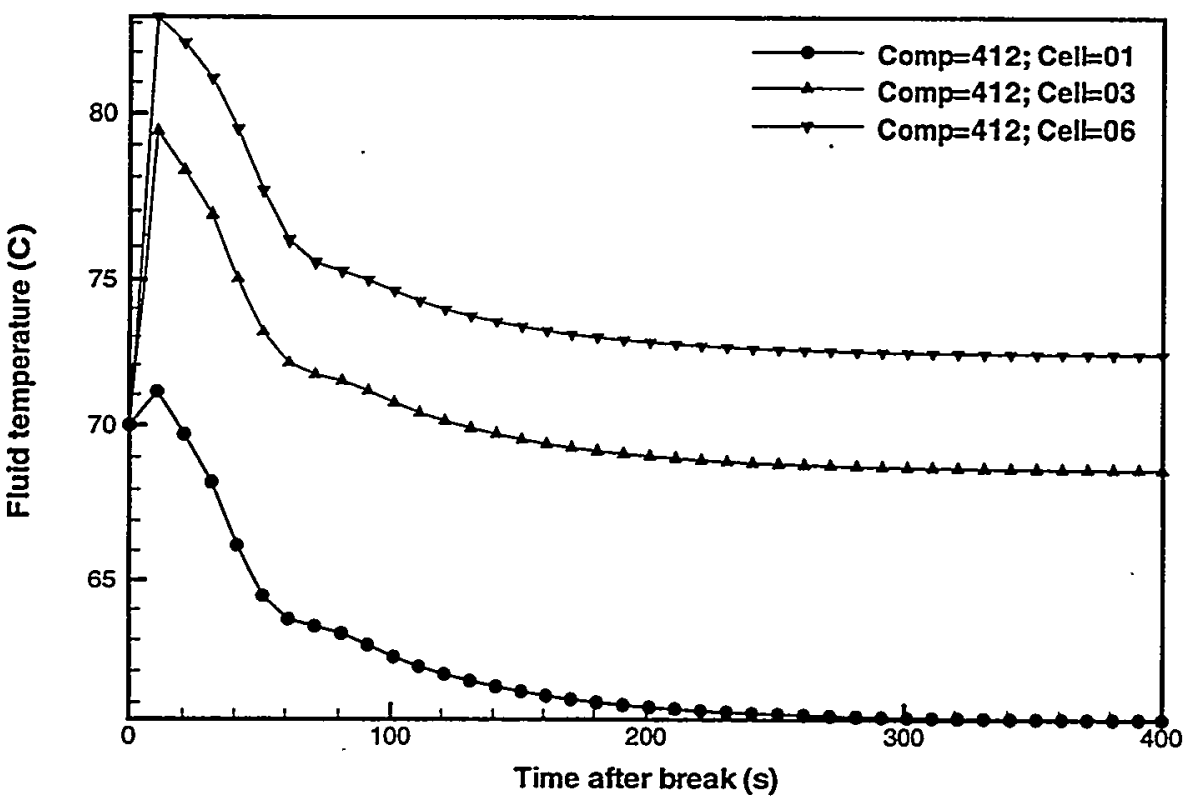

Figure B-21b Module 4 channel fluid temperatures for NO (False transient to establish steady-state). 


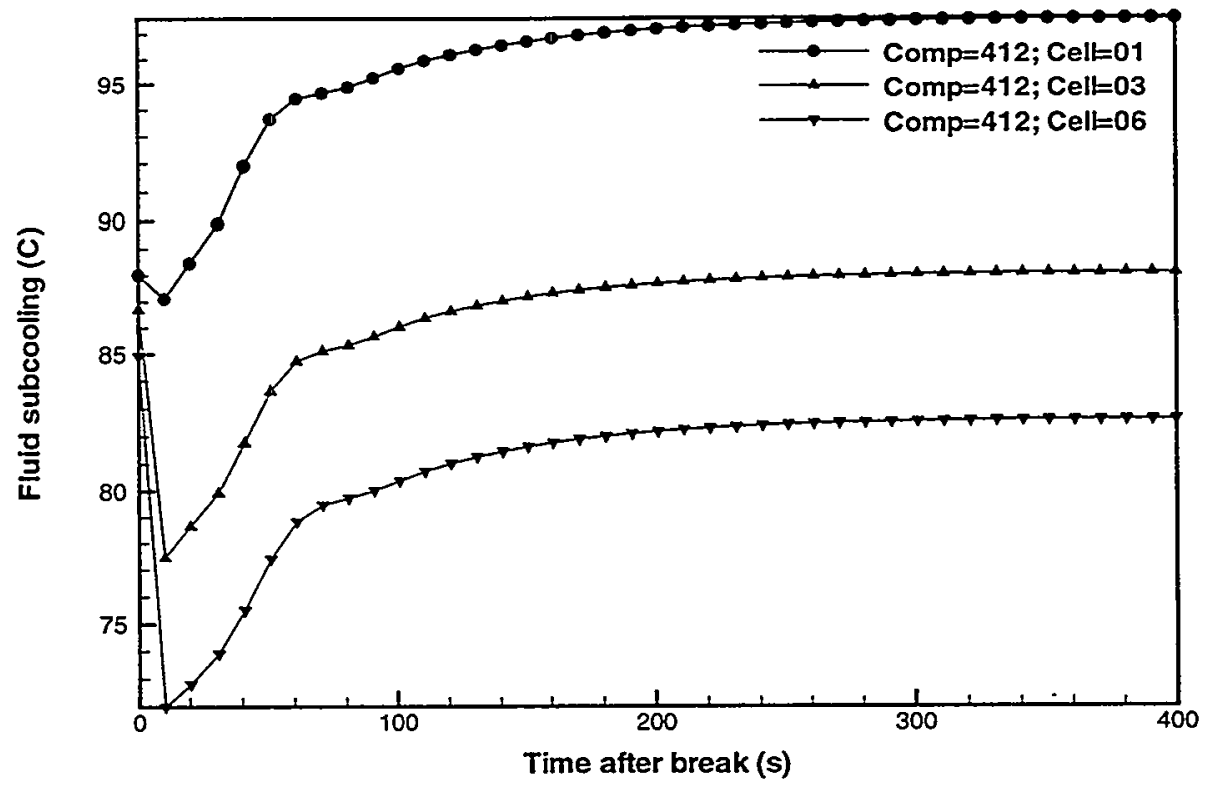

Figure B-21c Module 4 channel fluid subcoolings for NO (False transient to establish steady-state).

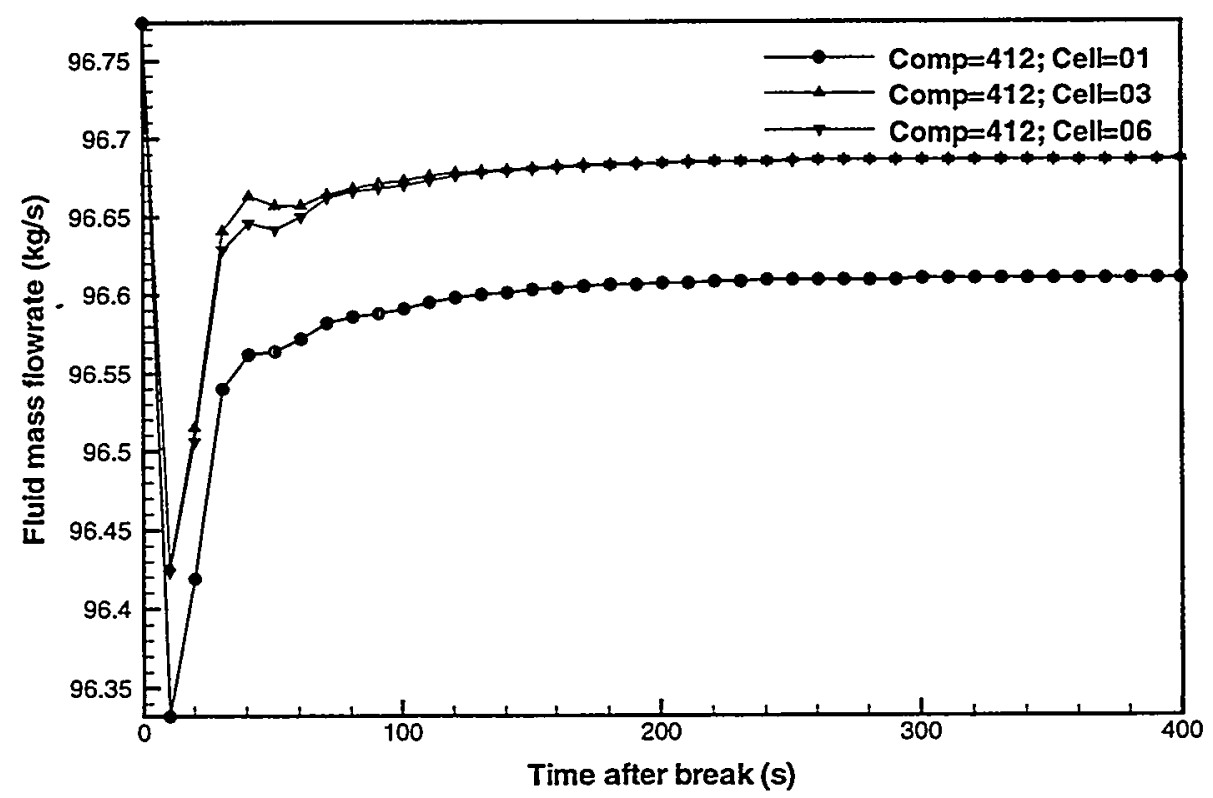

Figure B-21d Module 4 channel liquid mass flowrates for NO (False transient to establish steady-state). 


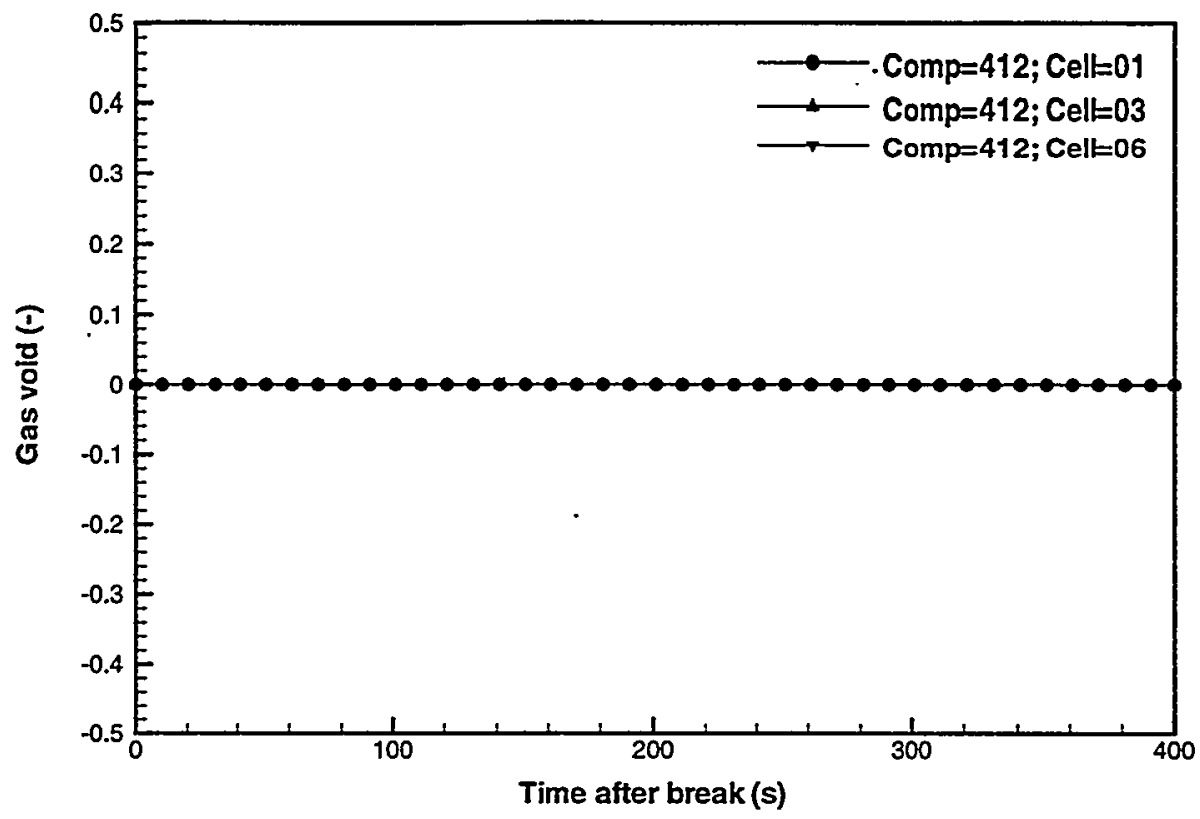

Figure B-21e Module 4 channel void fractions for NO (False transient to establish steady-state).

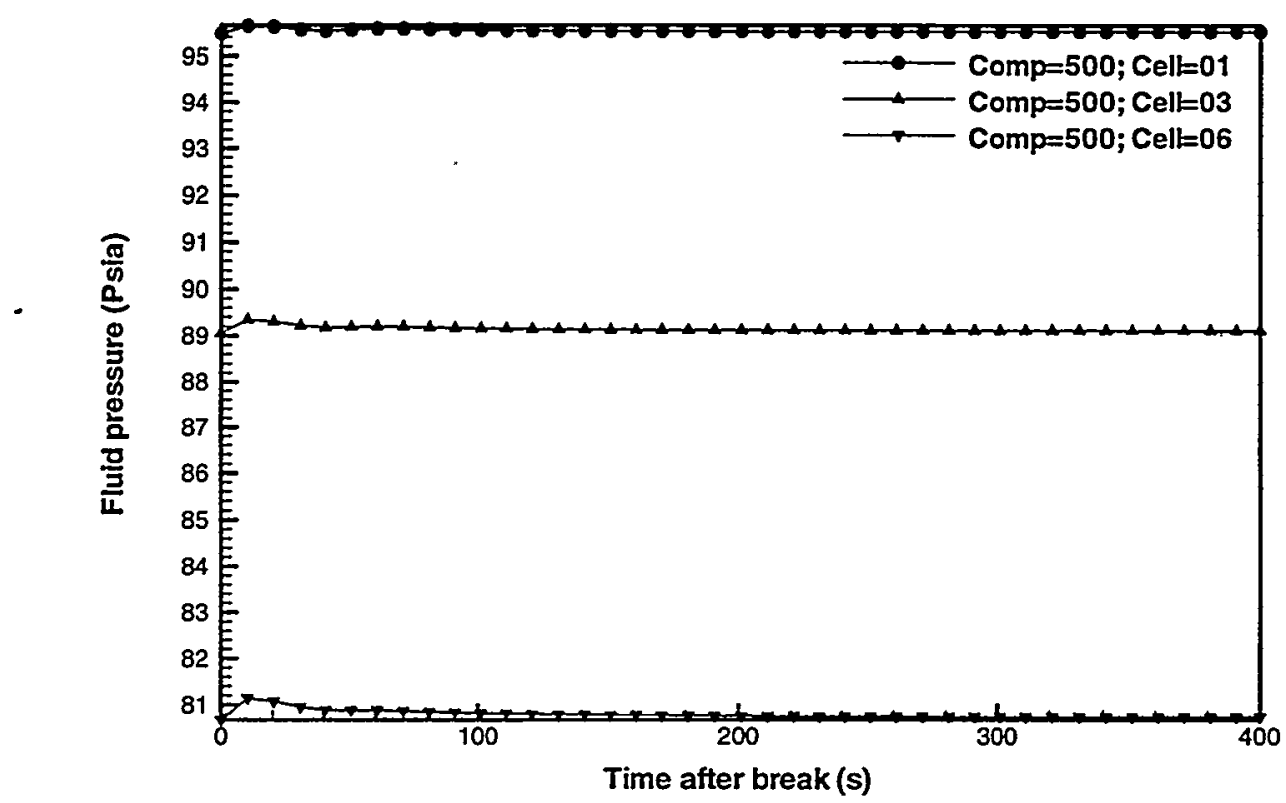

Figure B-22a Module 5 channel fluid pressures for NO (False transient to establish steady-state). 


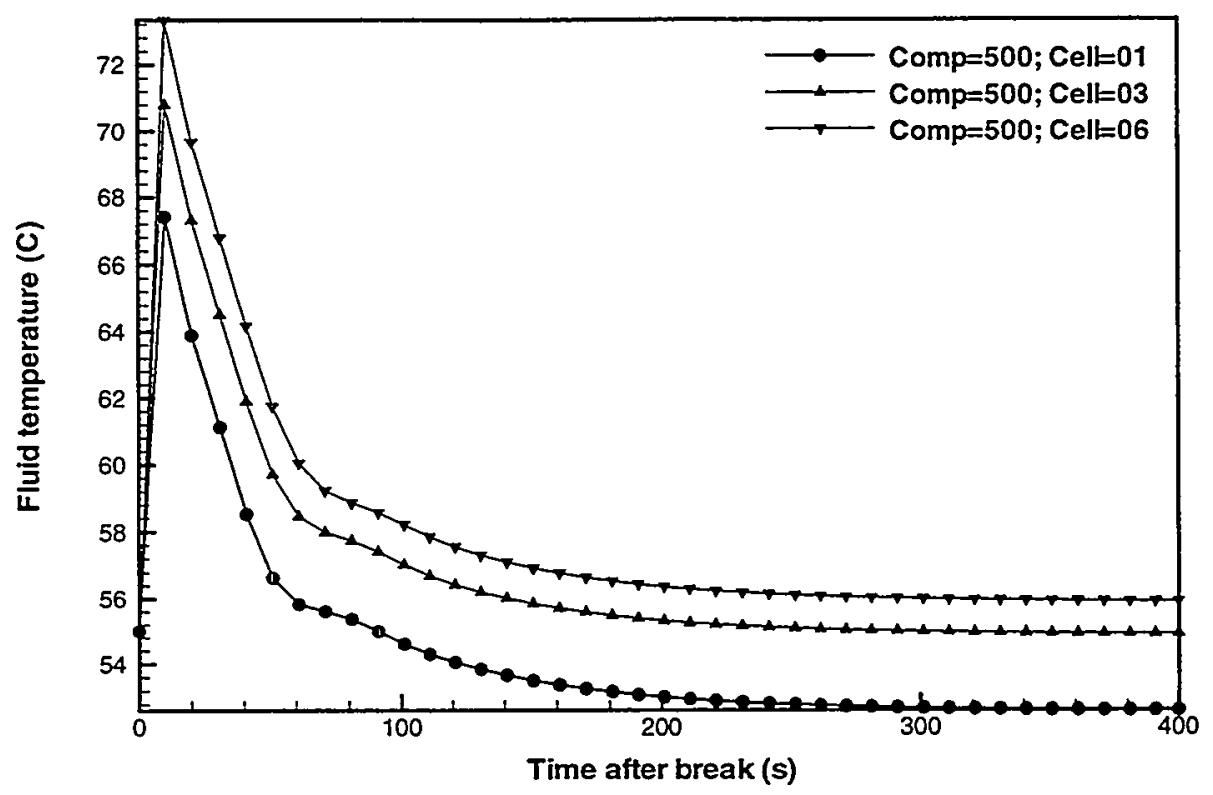

Figure B-22b Module 5 channel fluid temperatures for NO (False transient to establish steady-state).

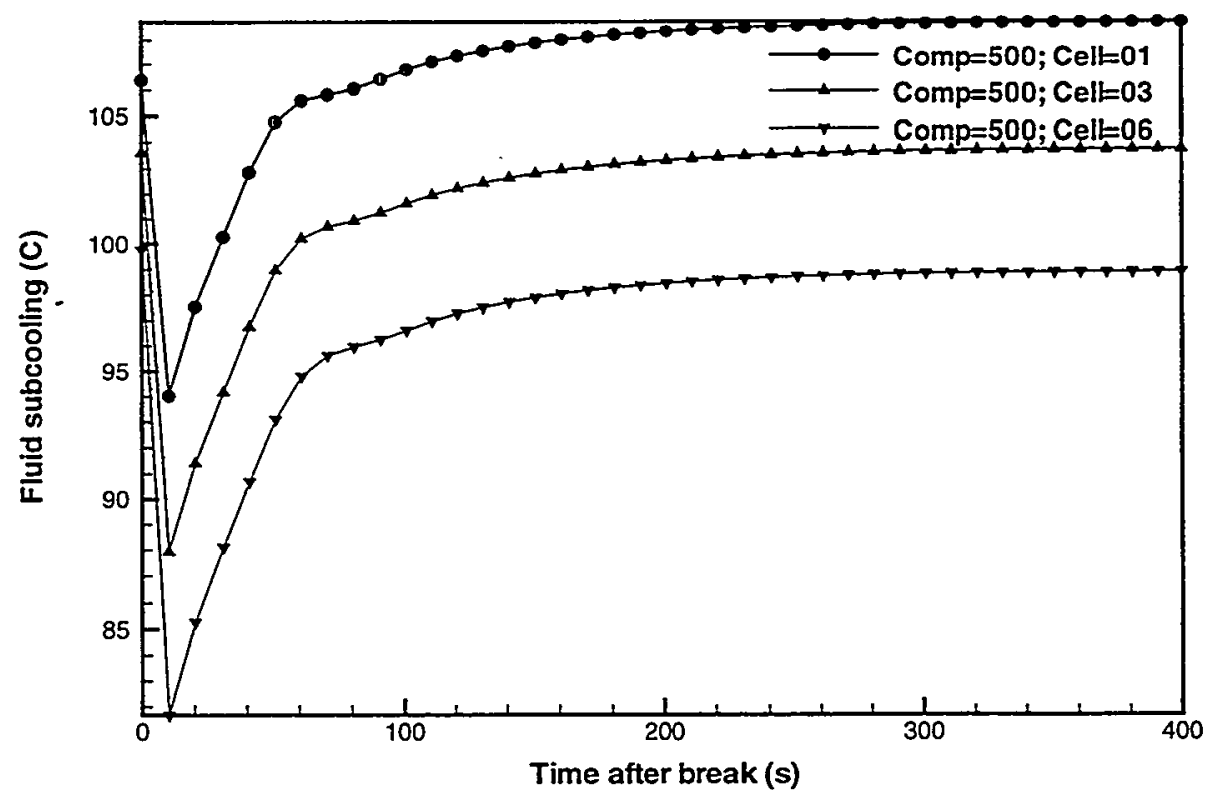

Figure B-22c Module 5 channel fluid subcoolings for NO (False transient to establish steady-state). 


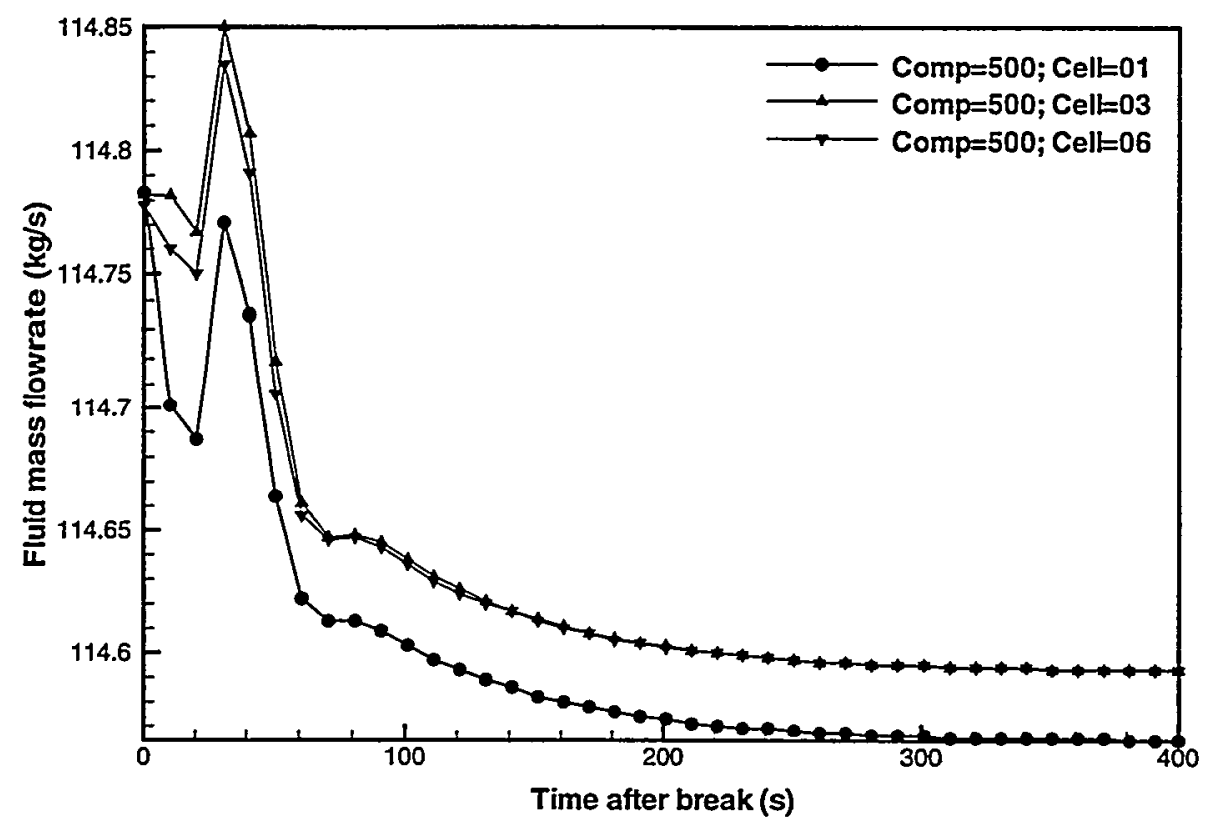

Figure B-22d Module 5 channel liquid mass flowrates for NO (False transient to establish steady-state).

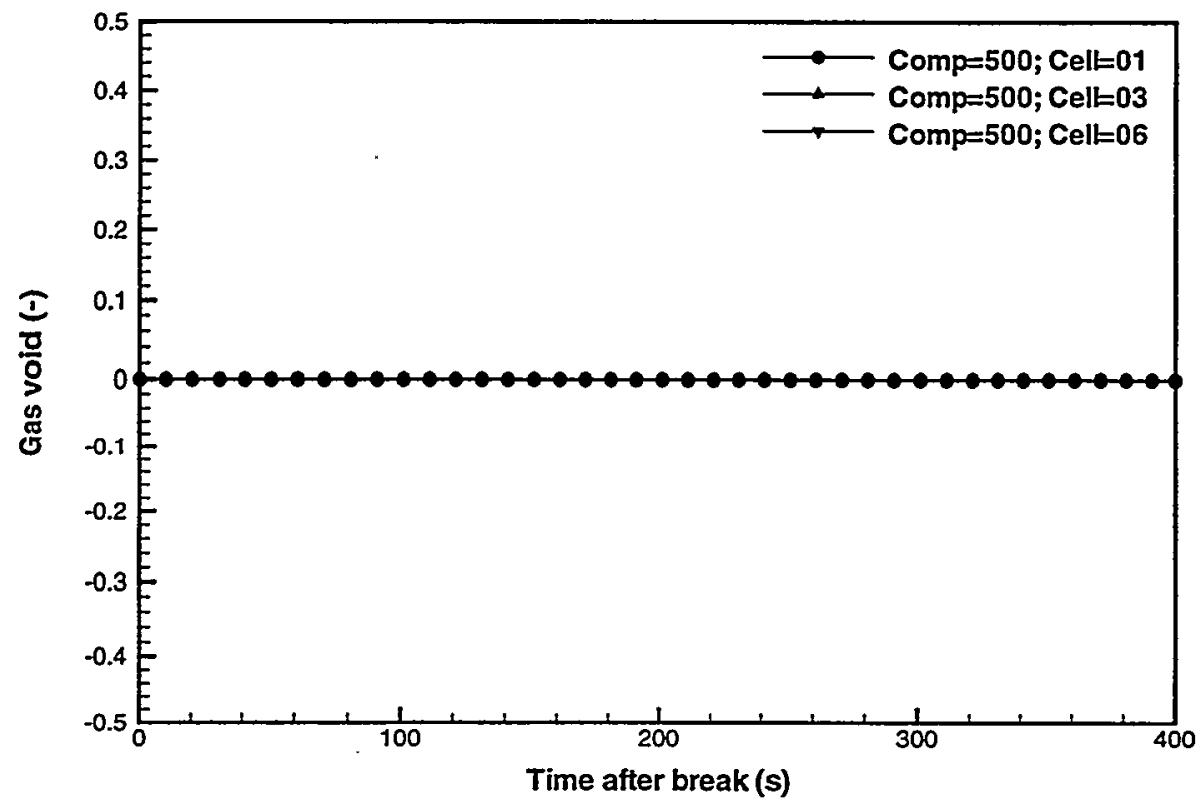

Figure B-22e Module 5 channel void fractions for NO (False transient to establish steady-state). 


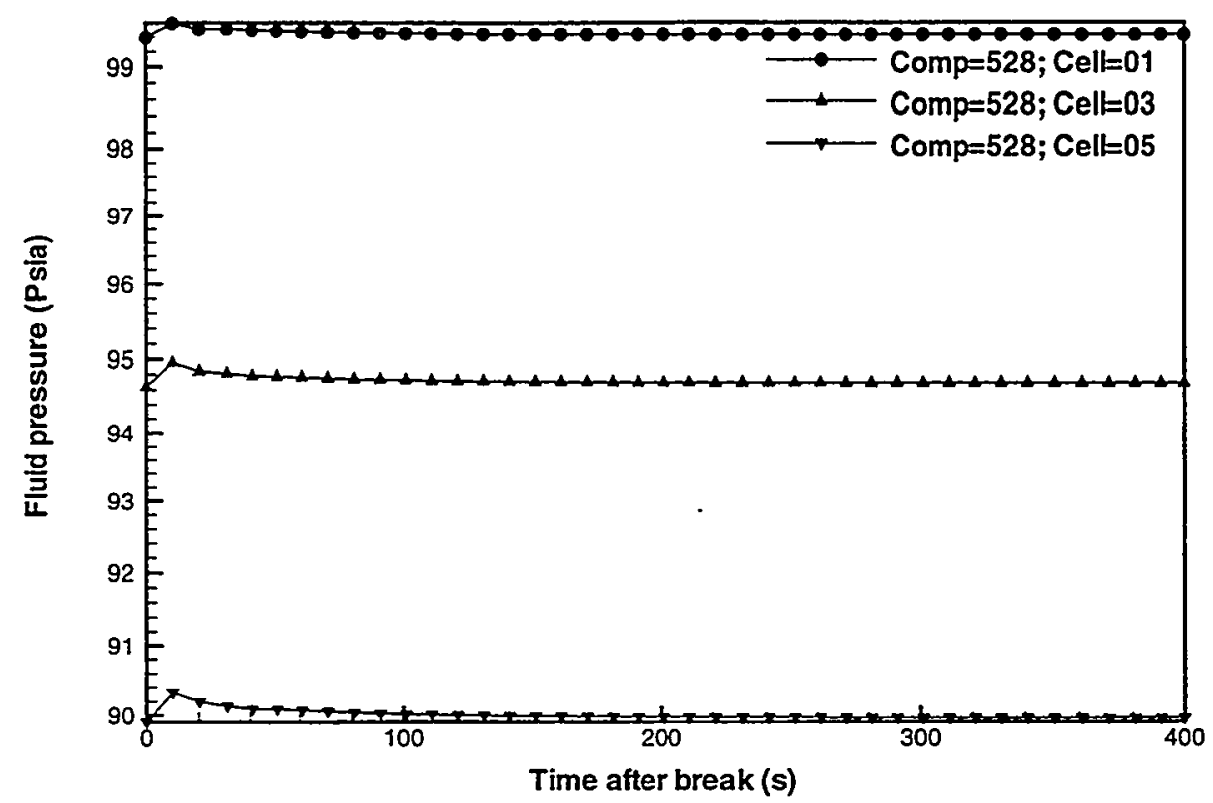

Figure B-23a Module 6 channel fluid pressures for NO (False transient to establish steady-state).

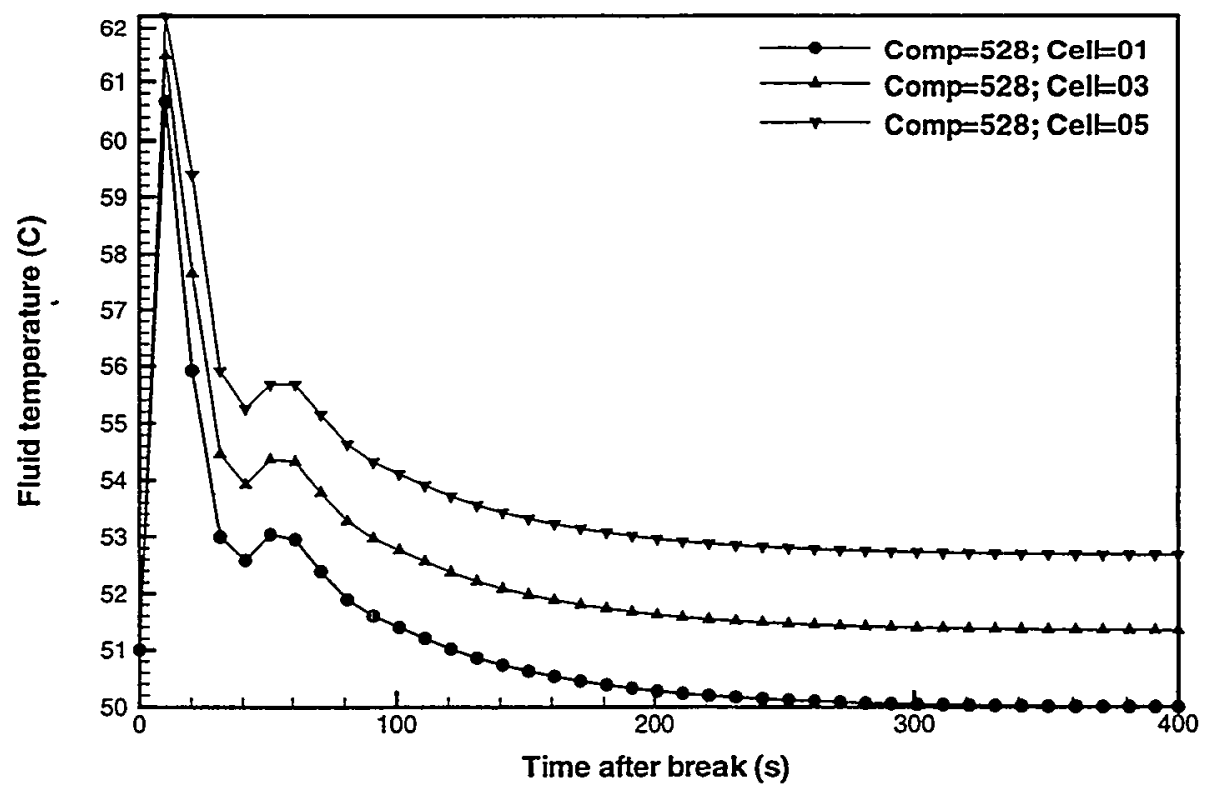

Figure B-23b Module 6 channel fluid temperatures for NO (False transient to establish steady-state). 


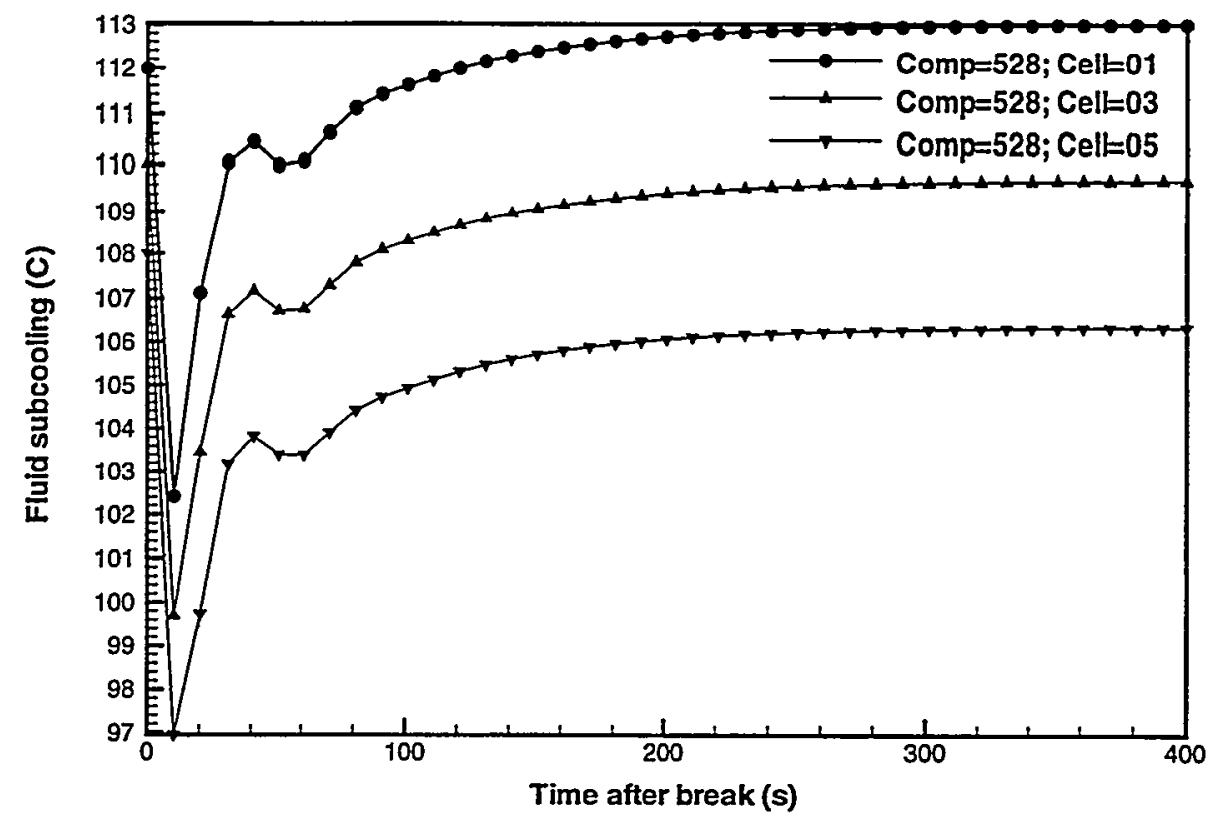

Figure B-23c Module 6 channel fluid subcoolings for.NO (Fatse transient to establish steady-state).

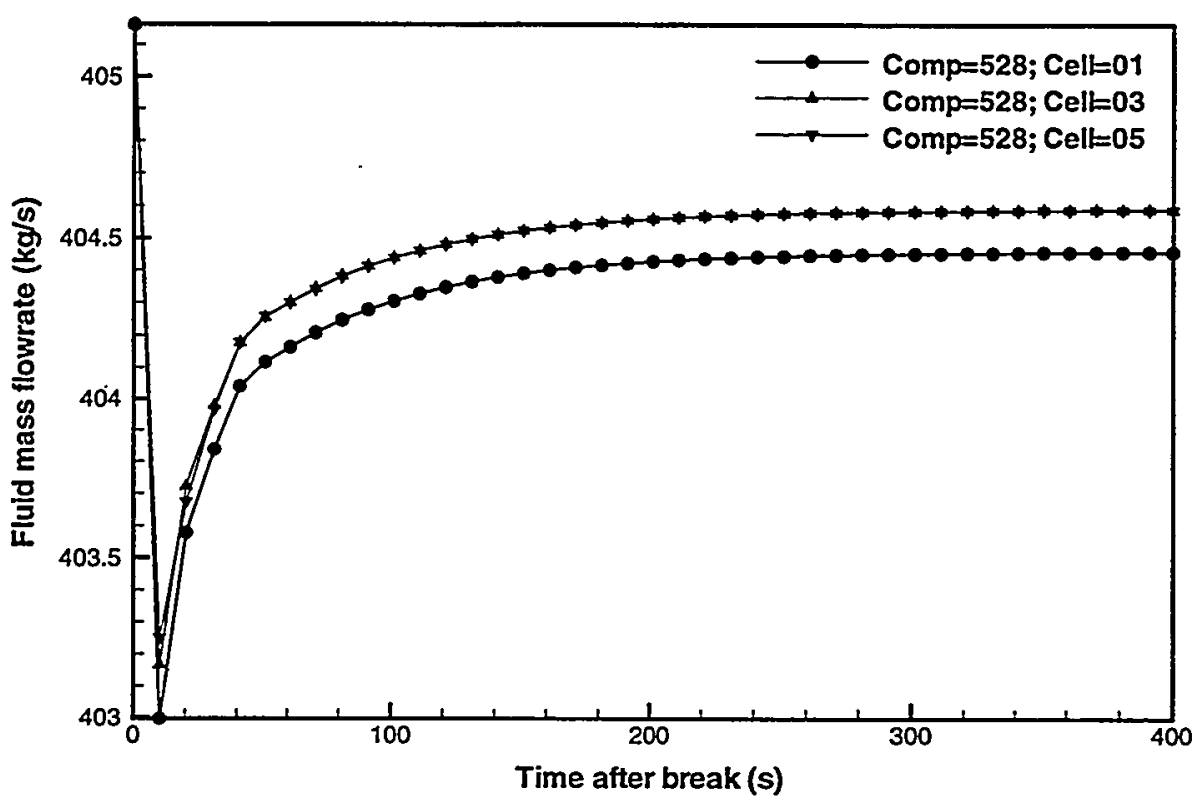

Figure B-23d Module 6 channel liquid mass flowrates for NO (False transient to establish steady-state). 


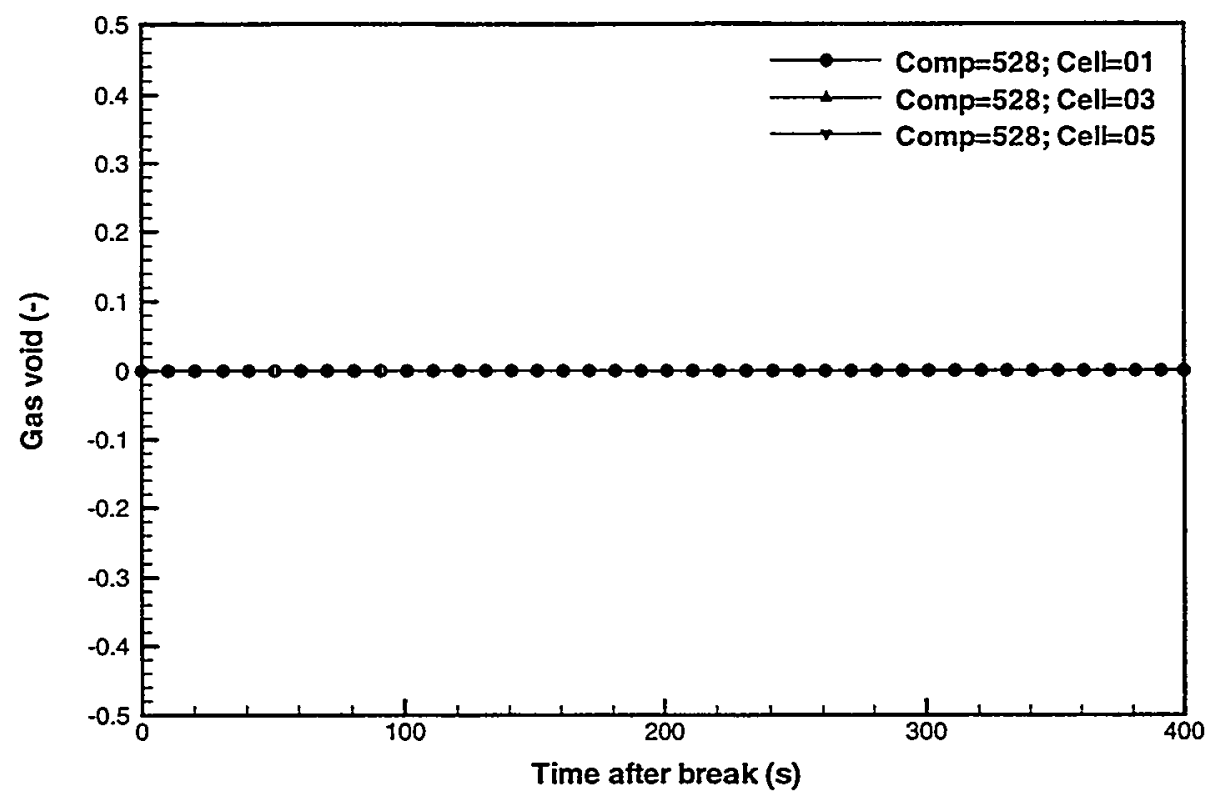

Figure B-23e Module 6 channel void fractions for NO (False transient to establish steady-state).

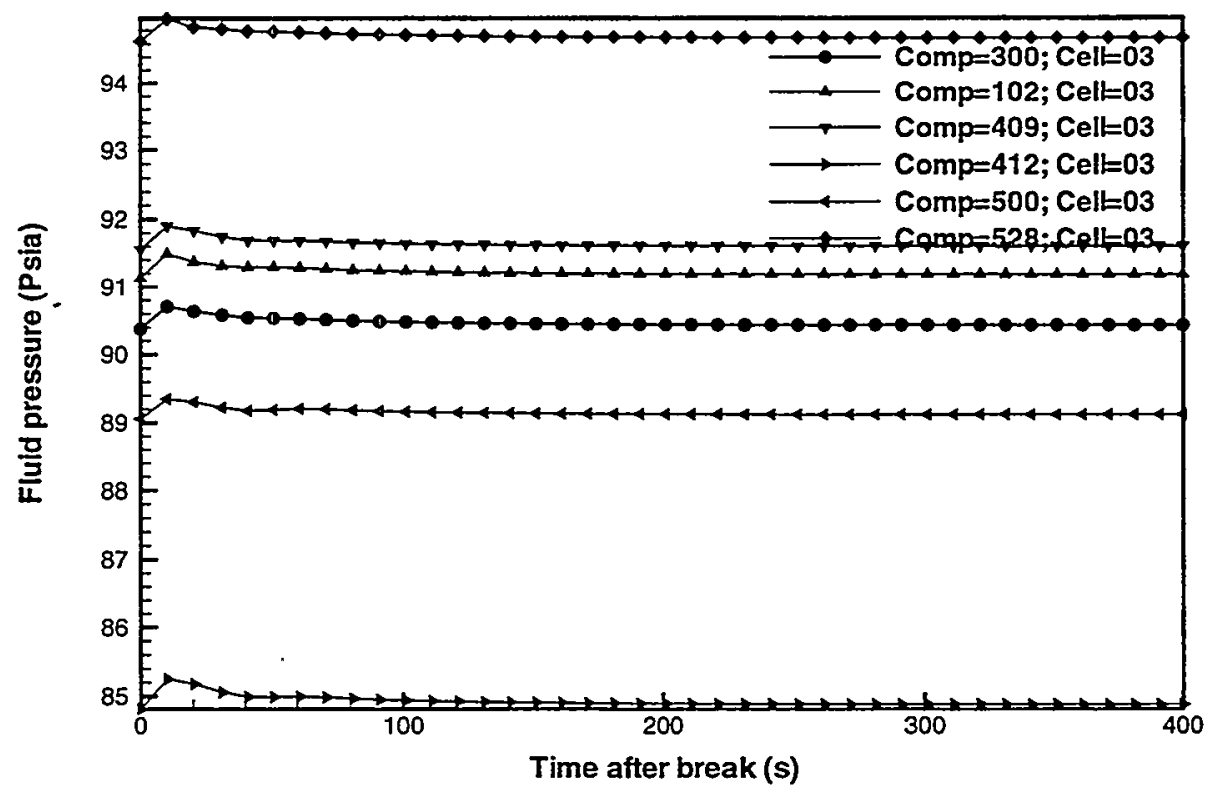

Figure B-24a Mid-plane module fluid pressures for NO (False transient to establish steady-state). 


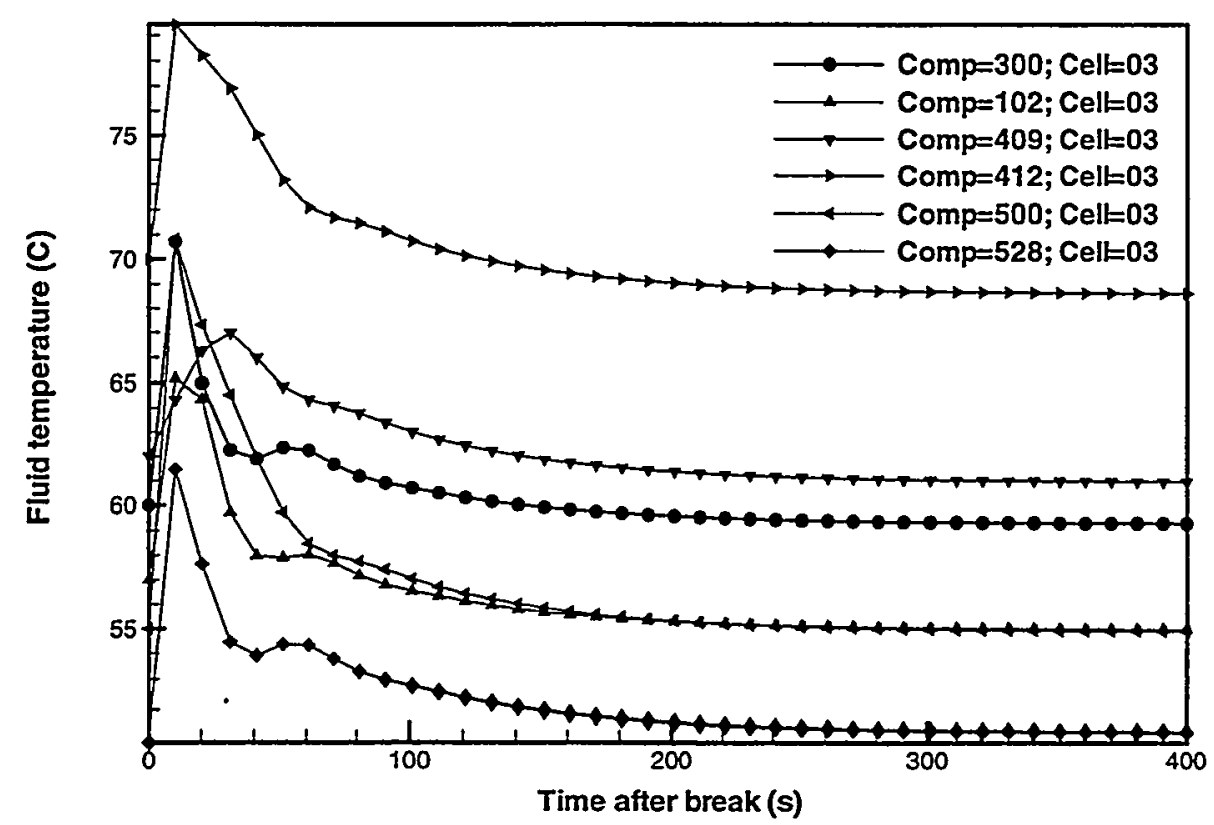

Figure B-24b Mid-plane module fluid temperatures for NO (False transient to establish steady-state).

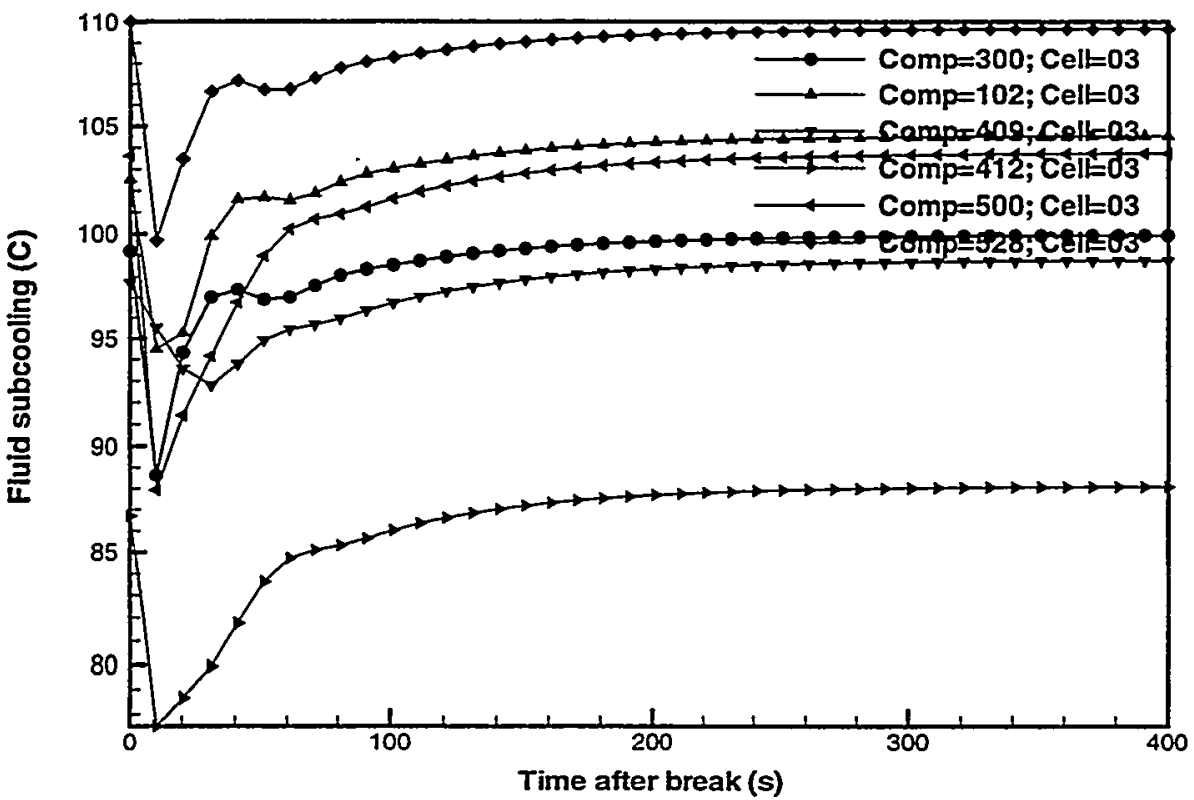

Figure B-24c Mid-plane module fluid subcoolings for NO (False transient to establish steady-state). 


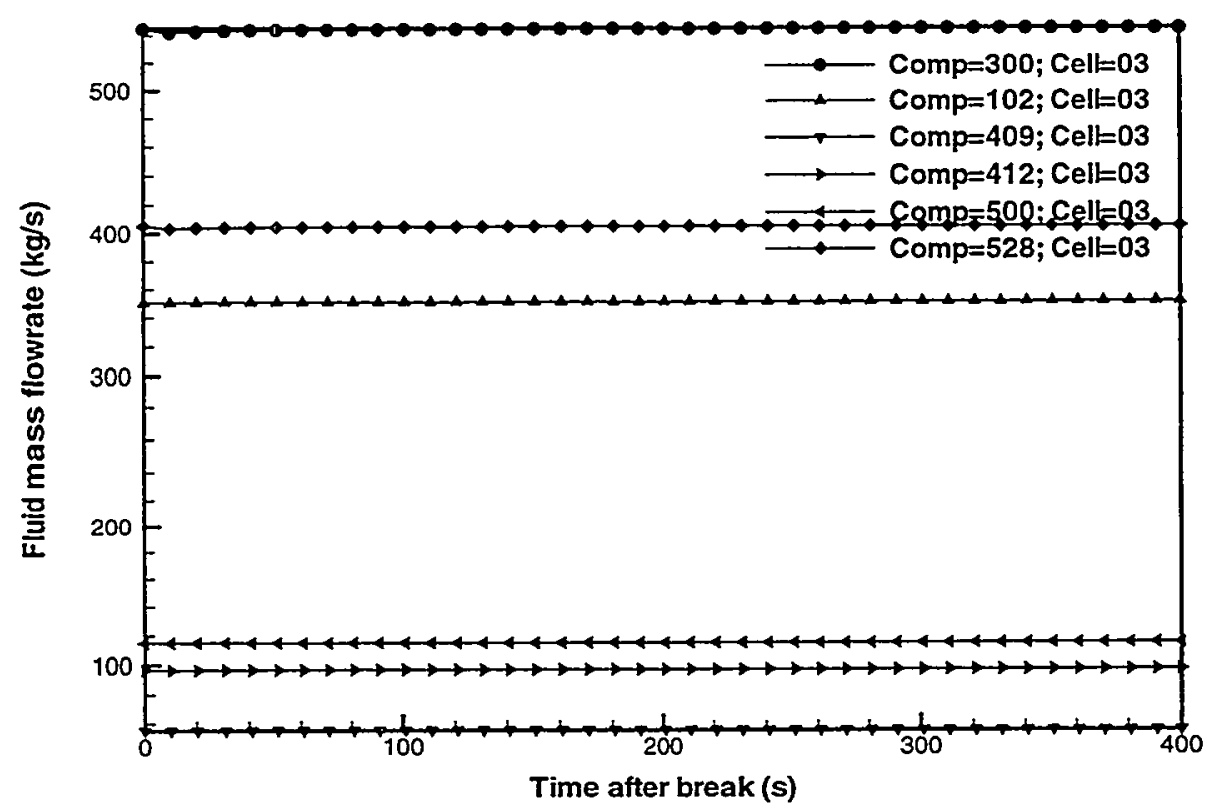

Figure B-24d Mid-plane module liquid mass flowrates for NO (False transient to establish steady-state).

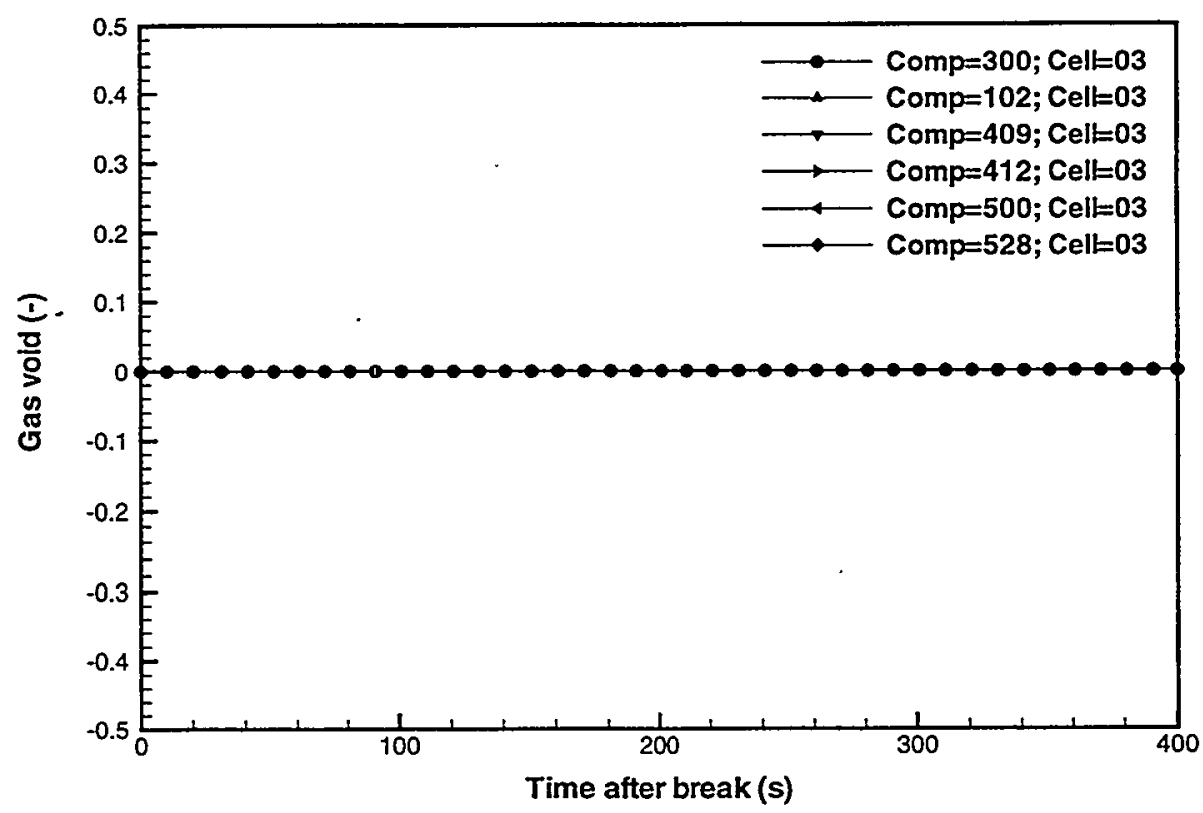

Figure B-24e Mid-plane module void fractions for NO (False transient to establish steady-state). 


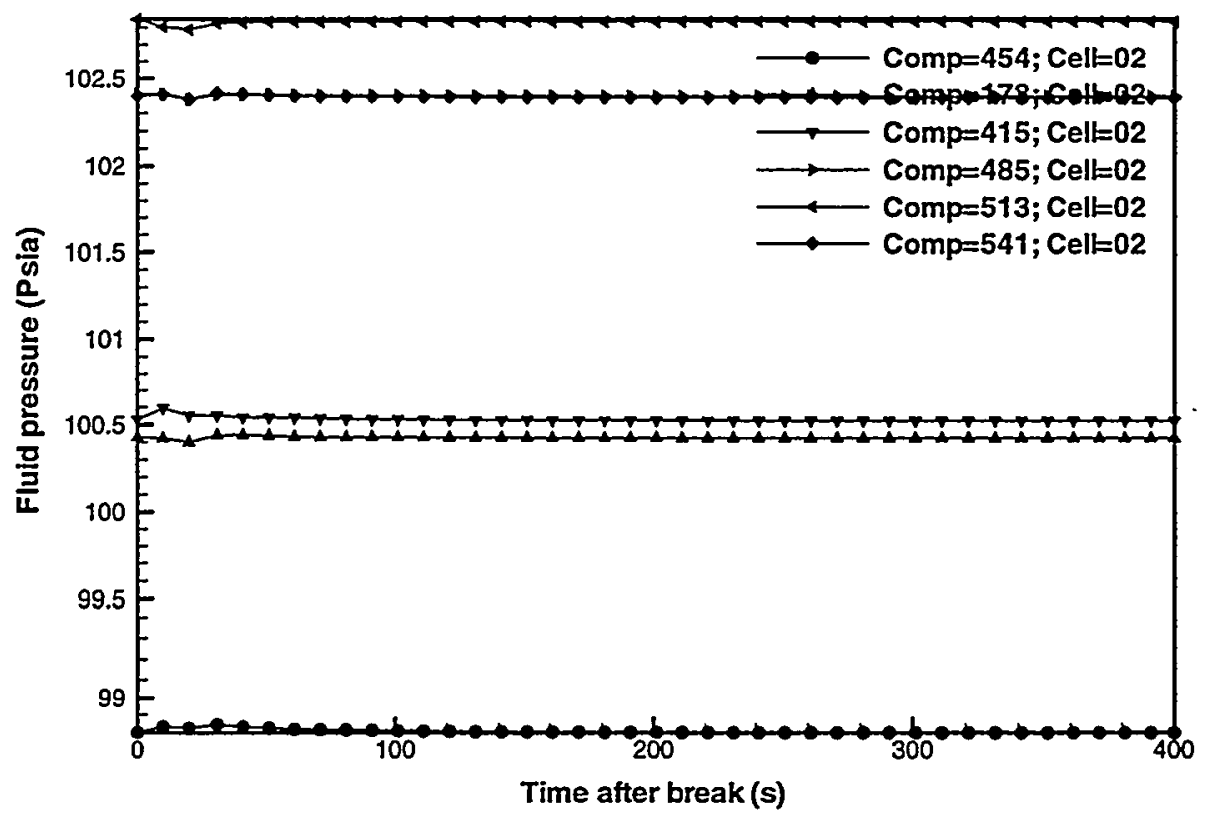

Figure B-25a Module inlet fluid pressures for NO (False transient to establish steadystate).

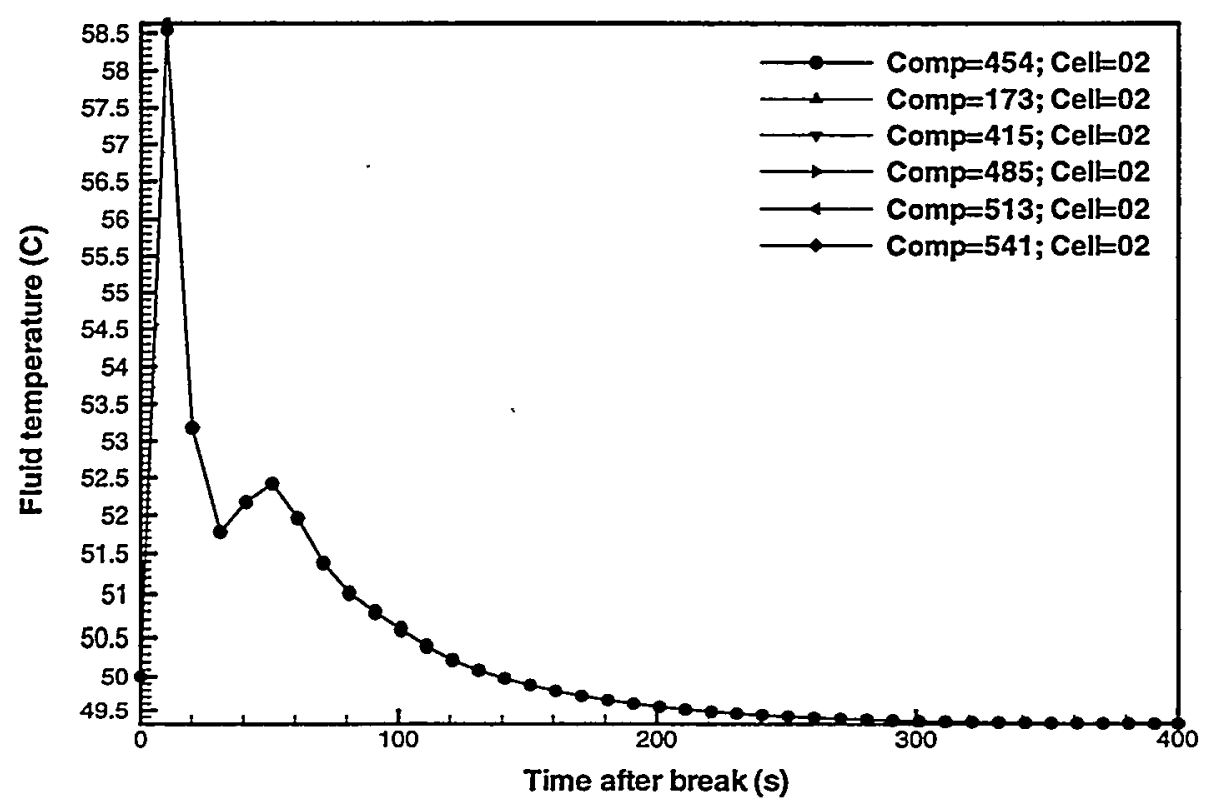

Figure B-25b Module inlet fluid temperatures for NO (False transient to establish steadystate). 


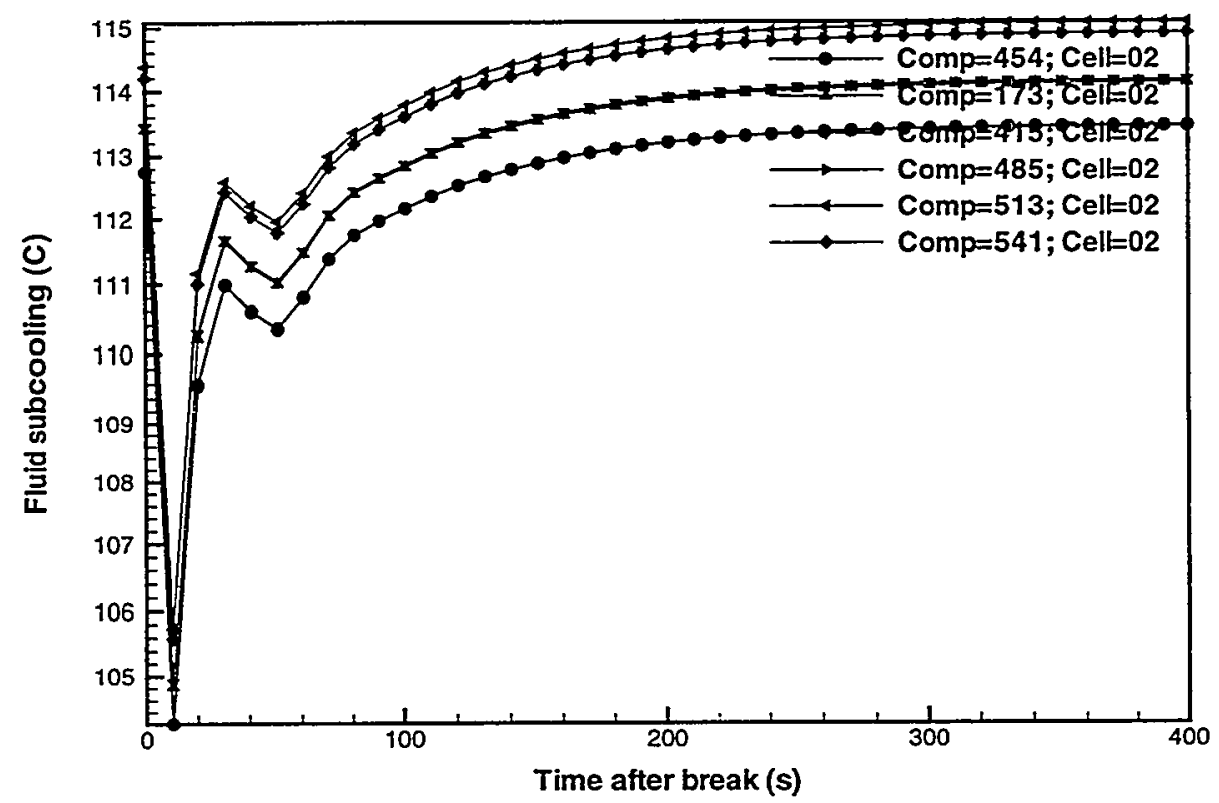

Figure B-25c Module inlet fluid subcoolings for NO (False transient to establish steadystate).

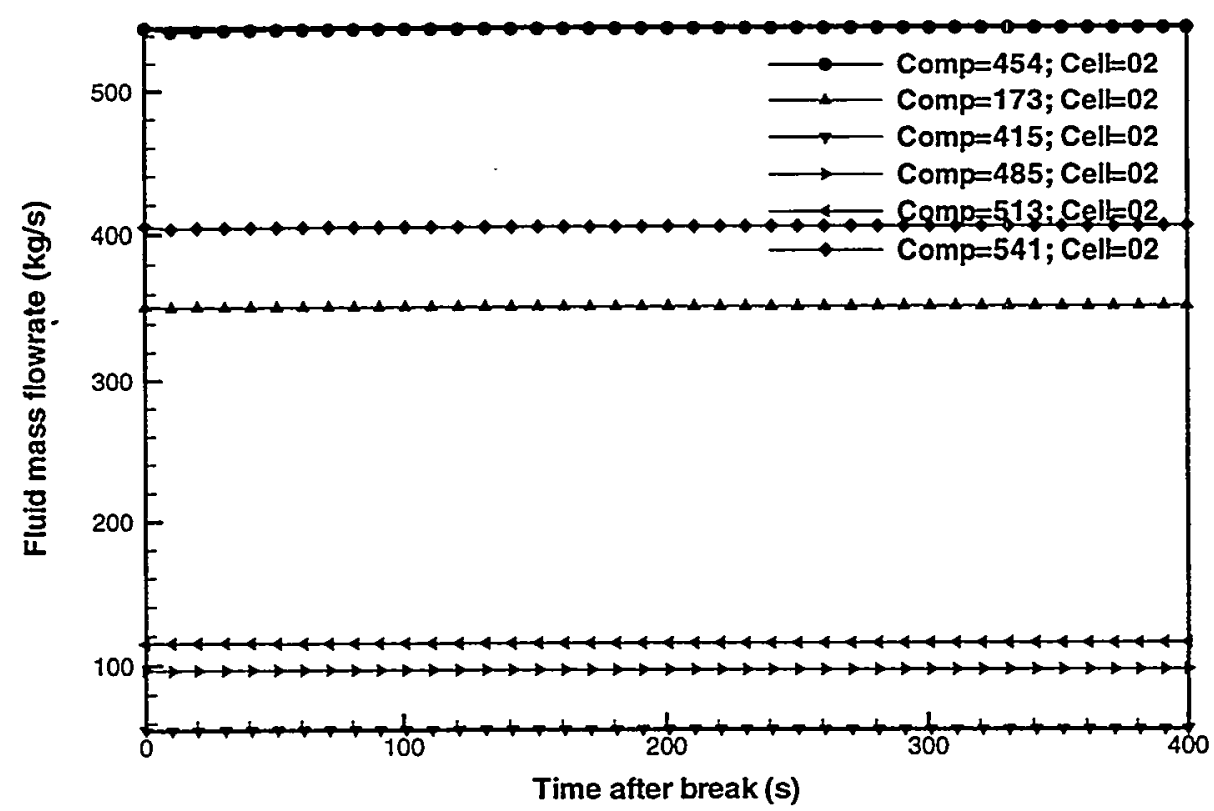

Figure B-25d Module inlet liquid mass flowrates for NO (False transient to establish steady-state). 


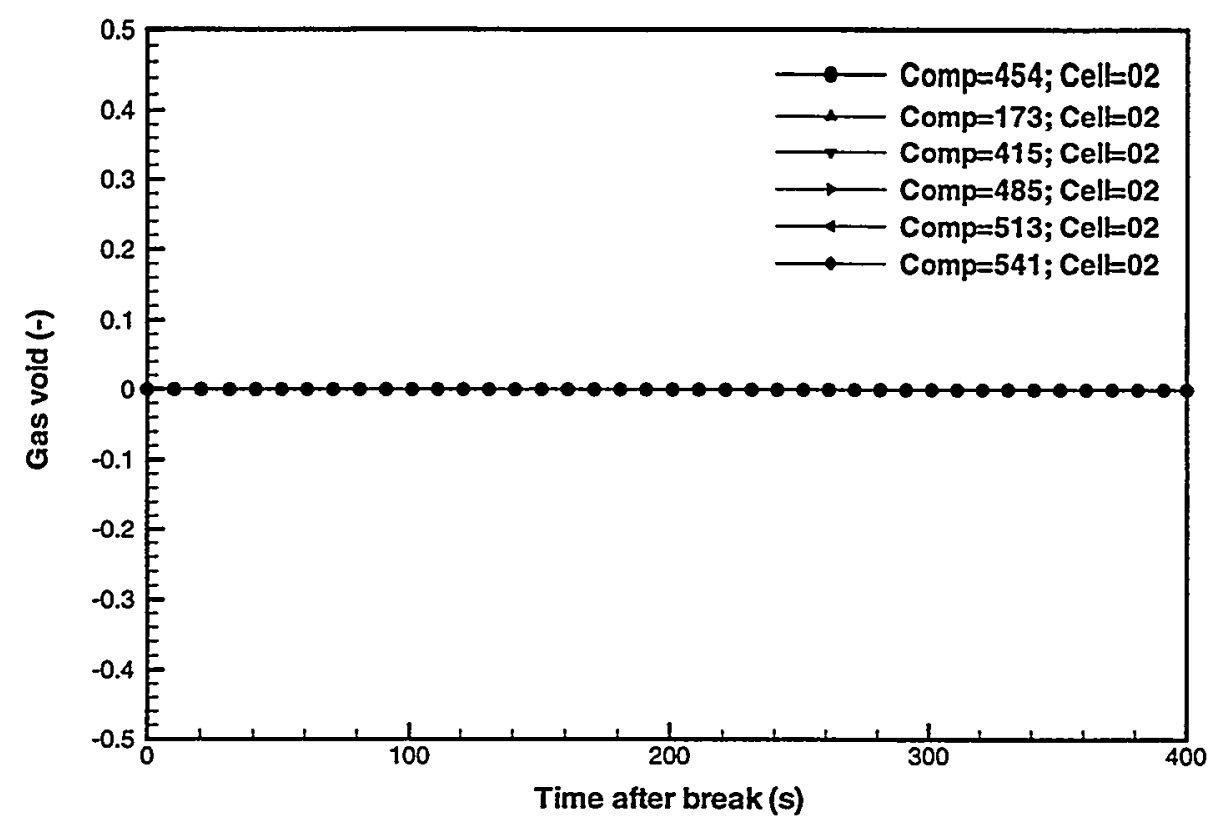

Figure B-25e Module inlet void fractions for NO (False transient to establish steadystate).

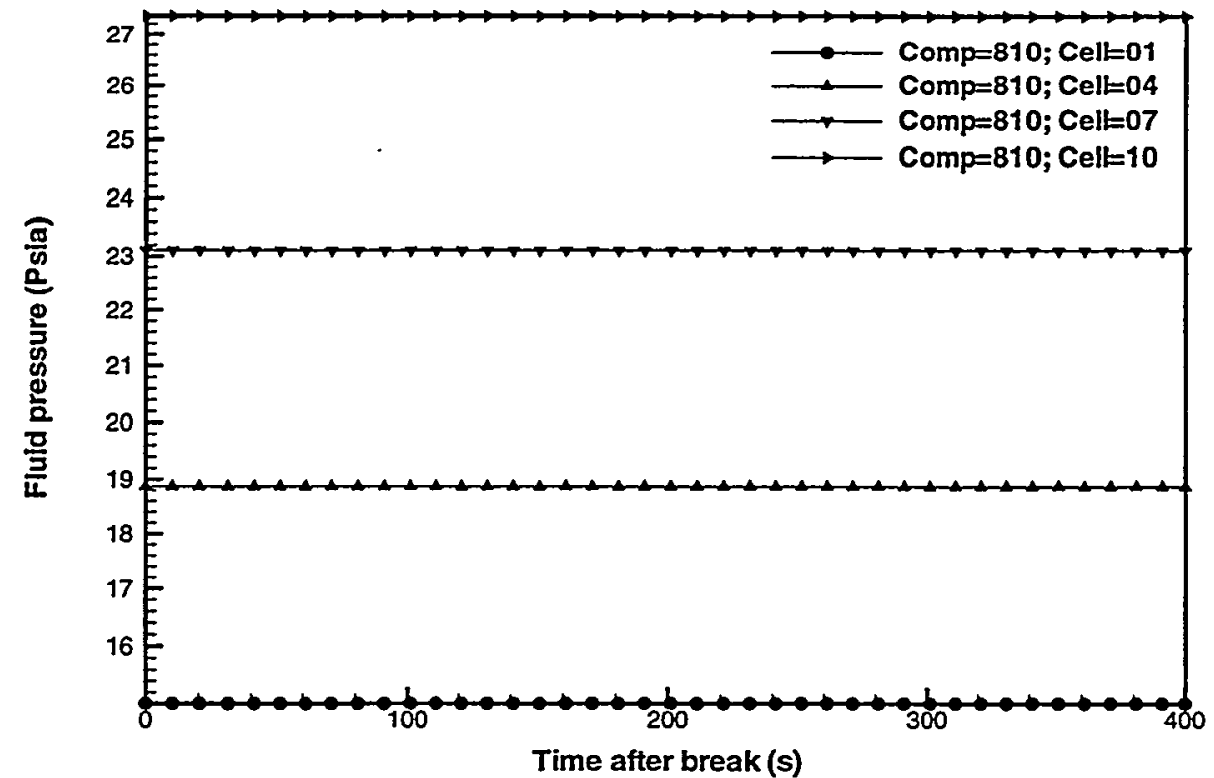

Figure B-26a Cavity pool fluid pressures for NO (False transient to establish steadystate). 
WESTINGHOUSE SAVANNAH RIVER COMPANY

BLANKET SYSTEM NORMAL OPERATION
Report: WSRC-TR-98-0057

Section: Appendix B

Date:

Page:

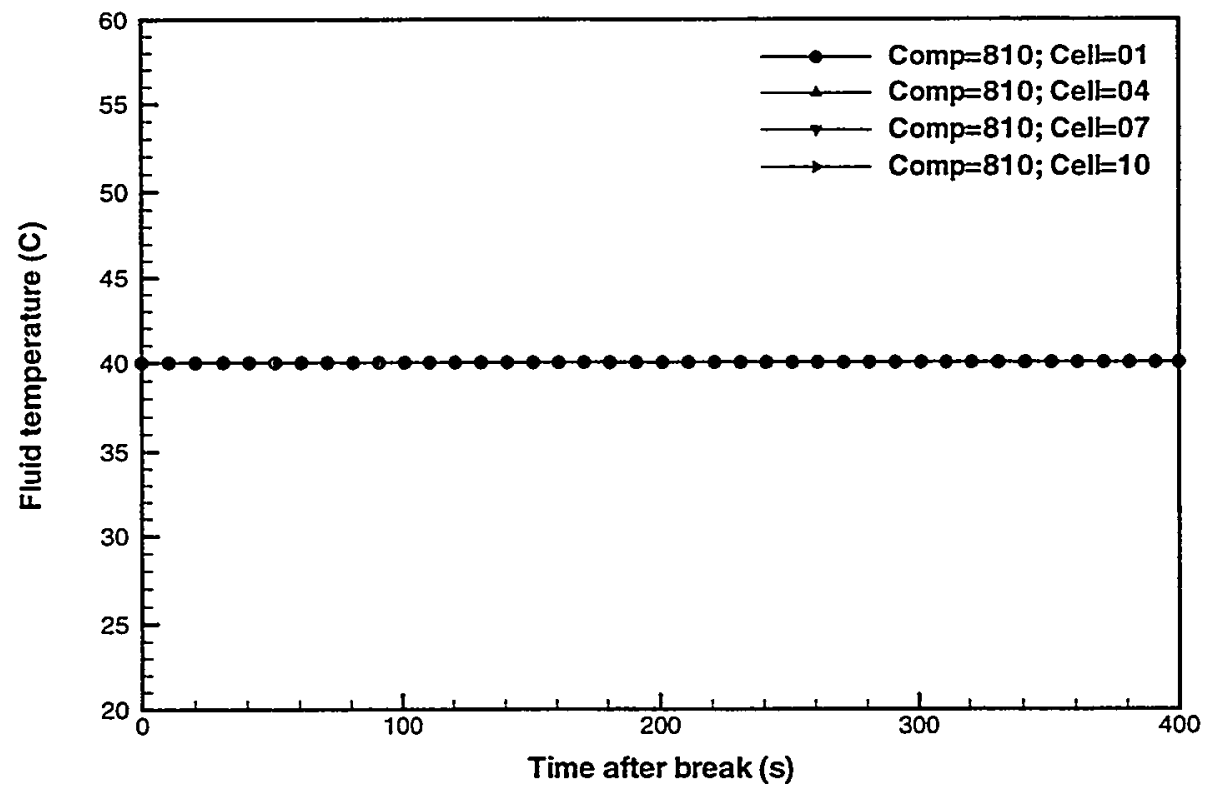

Figure B-26b Cavity pool fluid temperatures for NO (False transient to establish steadystate).

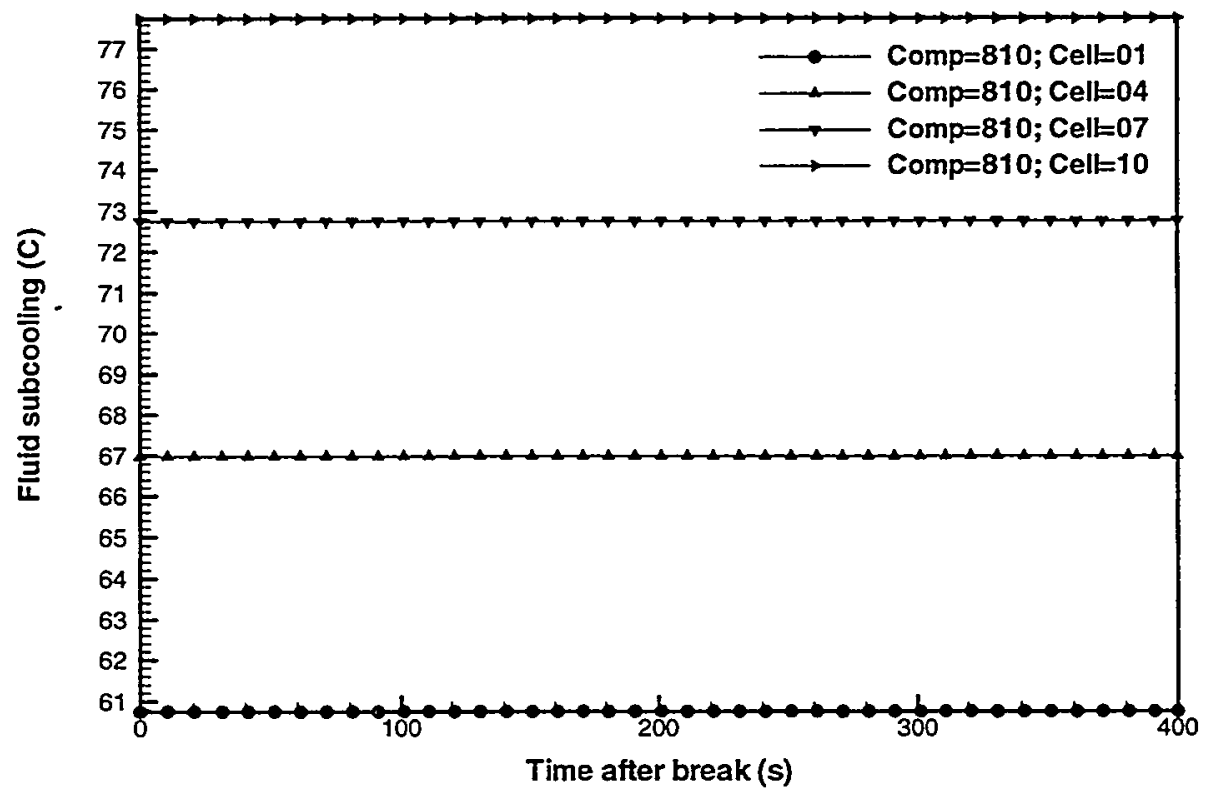

Figure B-26c Cavity pool fluid subcoolings for NO (False transient to establish steadystate). 


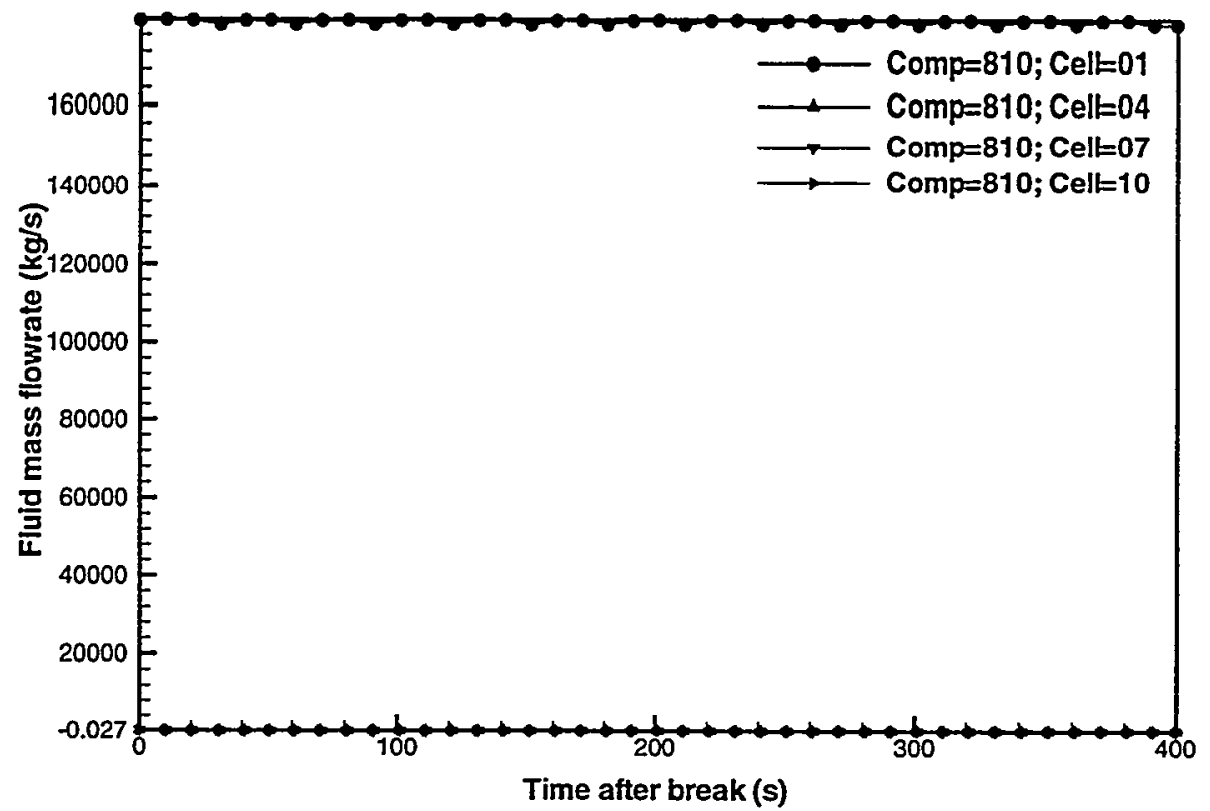

Figure B-26d Cavity pool liquid mass flowrates for NO (False transient to establish steady-state).

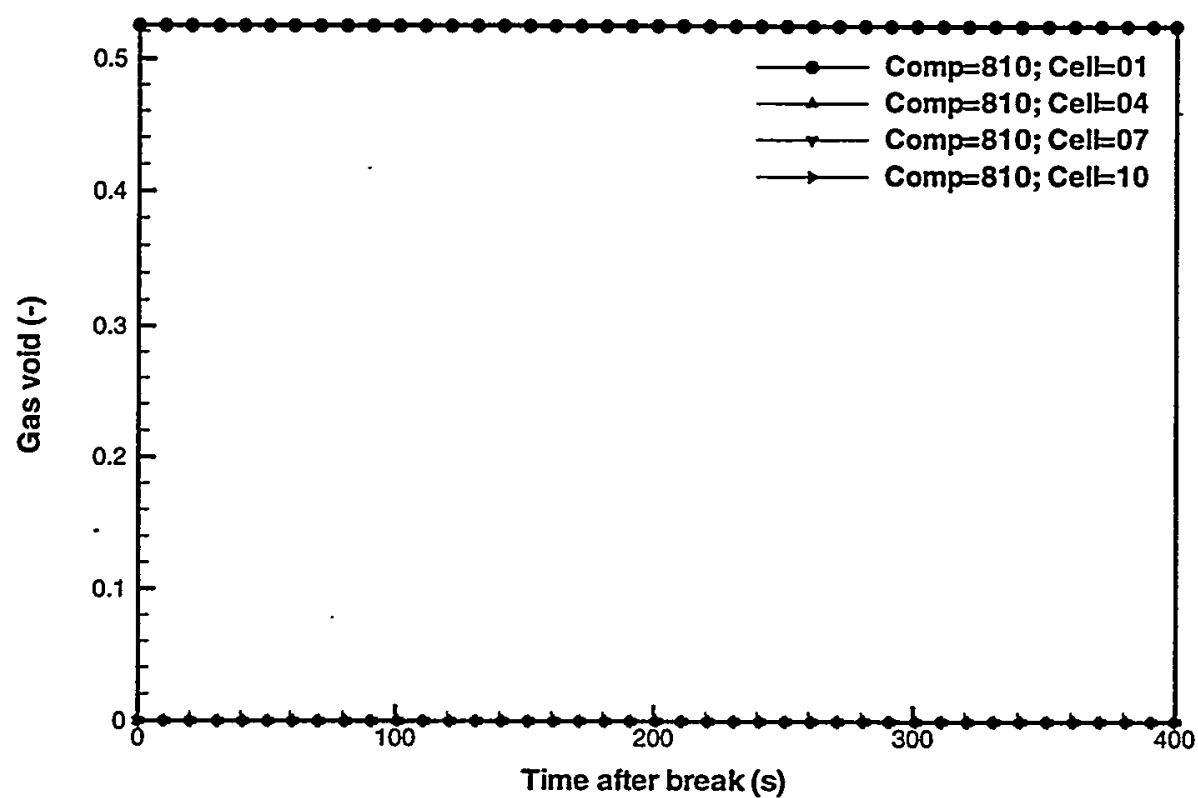

Figure B-26e Cavity pool void fractions for NO (False transient to establish steadystate). 


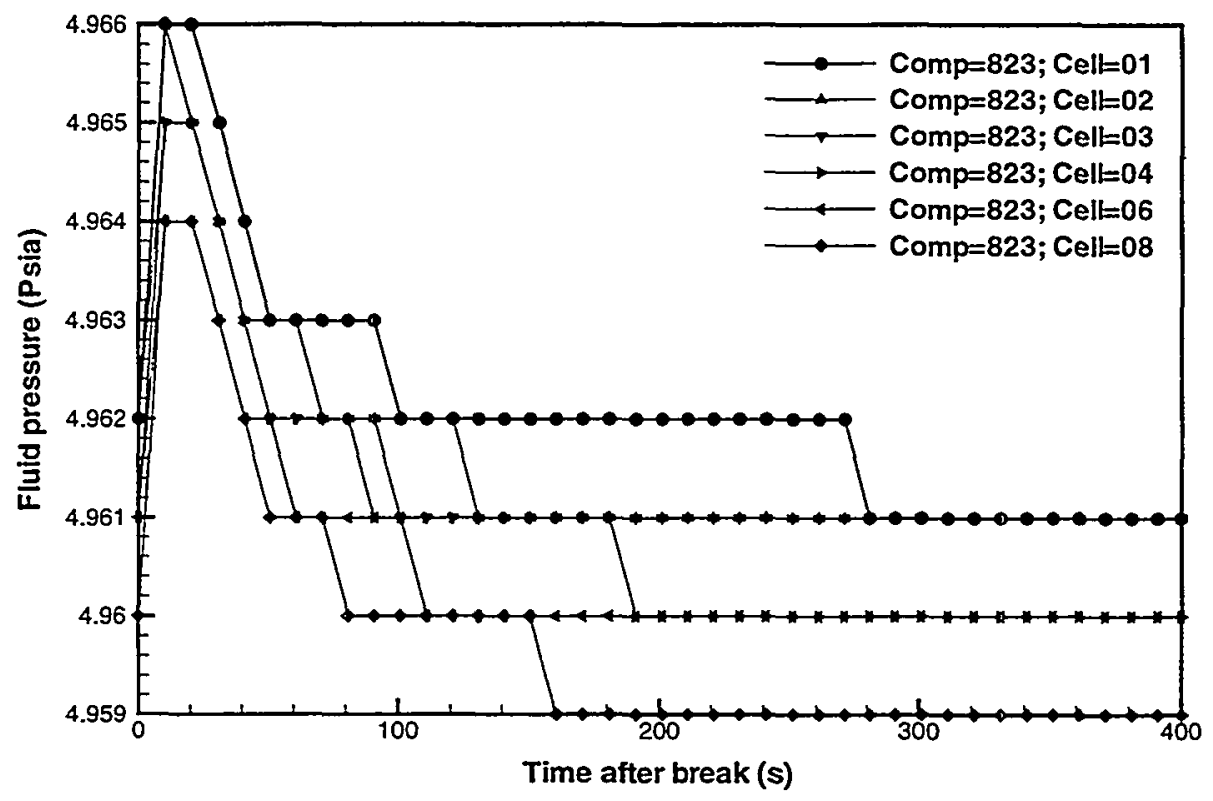

Figure B-27a Below top shield cavity vessel fluid pressures for NO (False transient to establish steady-state).

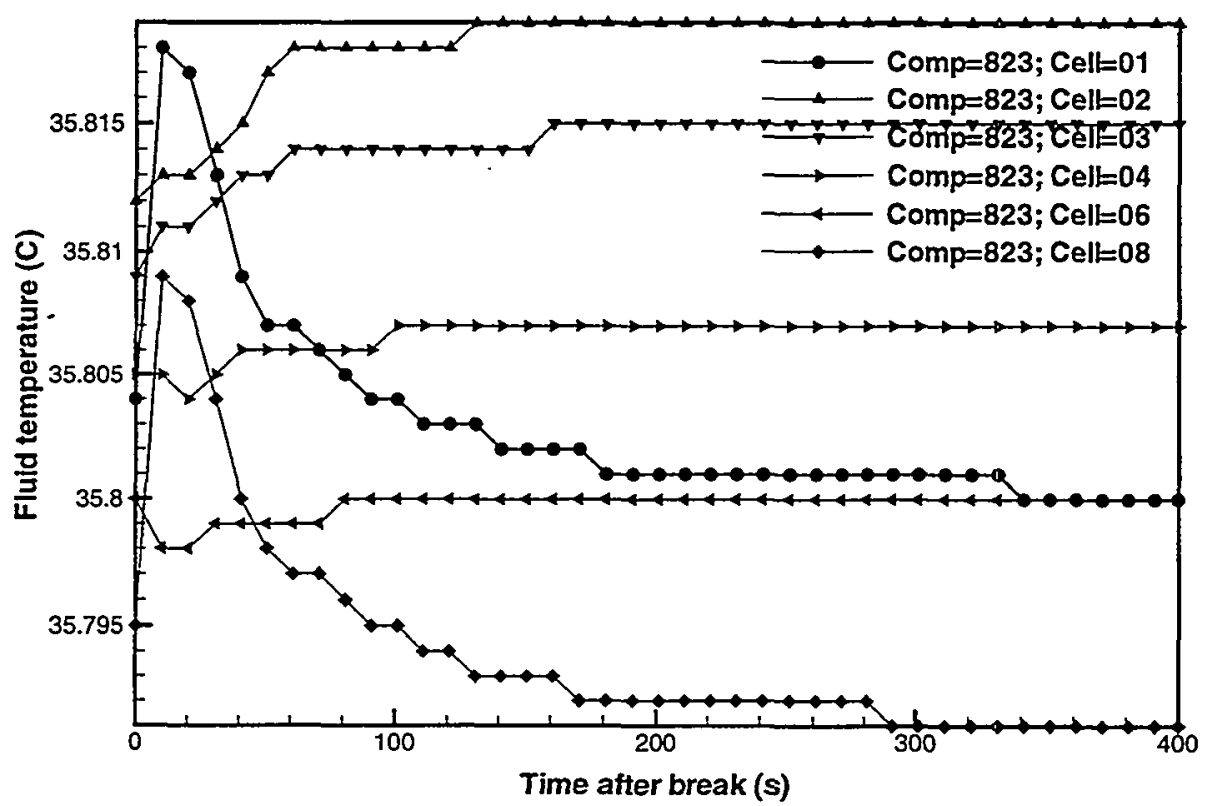

Figure B-27b Below top shield cavity vessel fluid temperatures for NO (False transient to establish steady-state). 


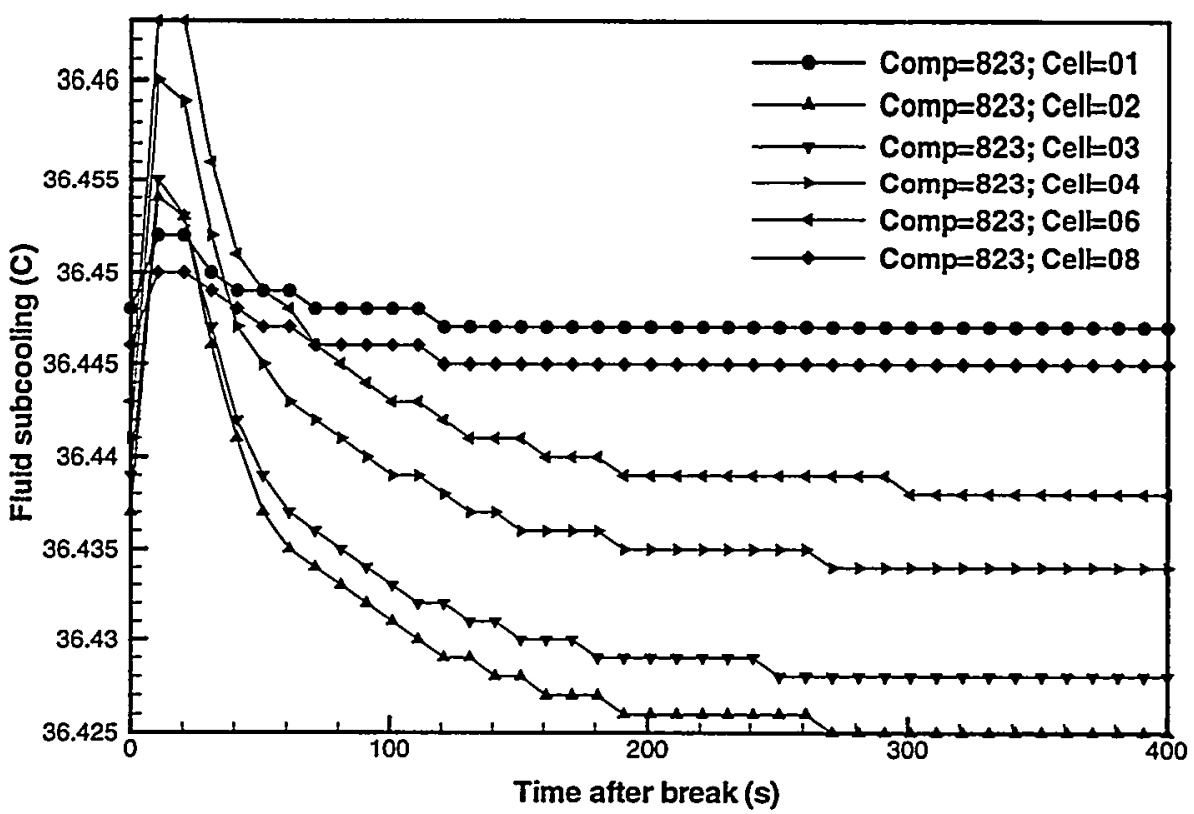

Figure B-27c Below top shield cavity vessel fluid subcoolings for NO (False transient to establish steady-state).

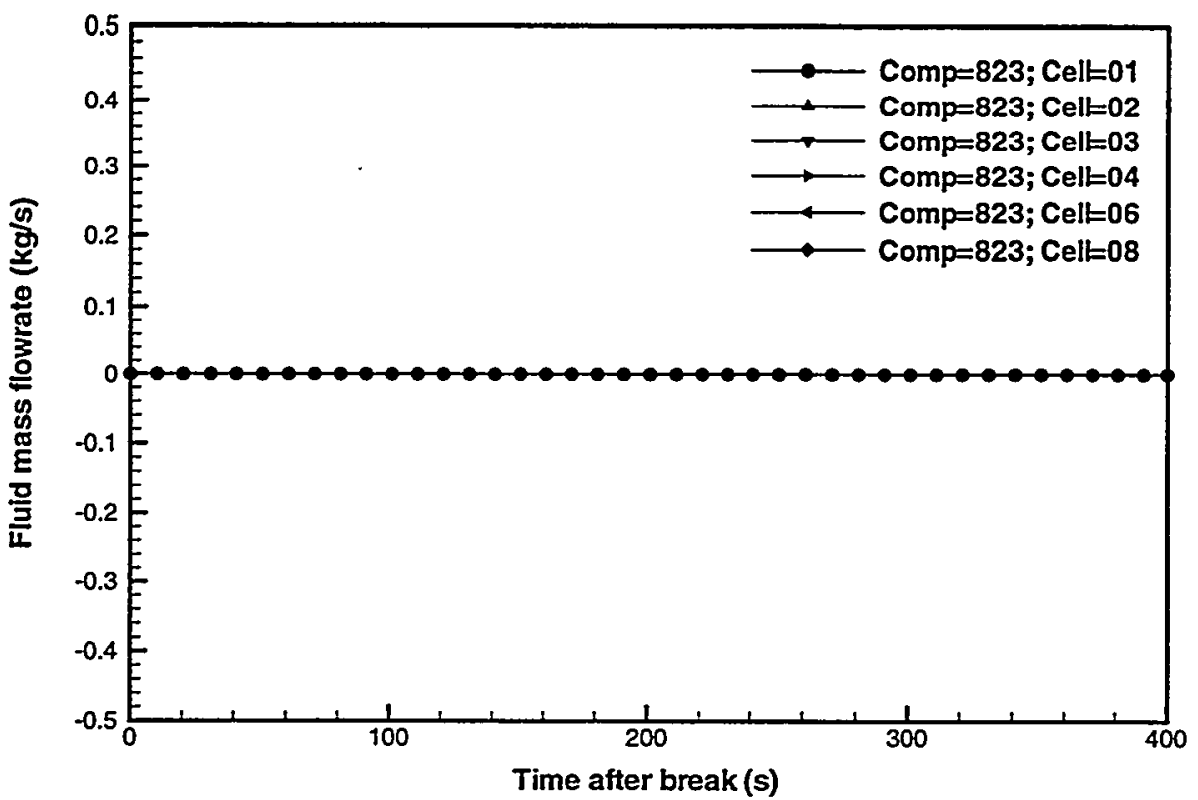

Figure B-27d Below top shield cavity vessel liquid mass flowrates for NO (False transient to establish steady-state). 


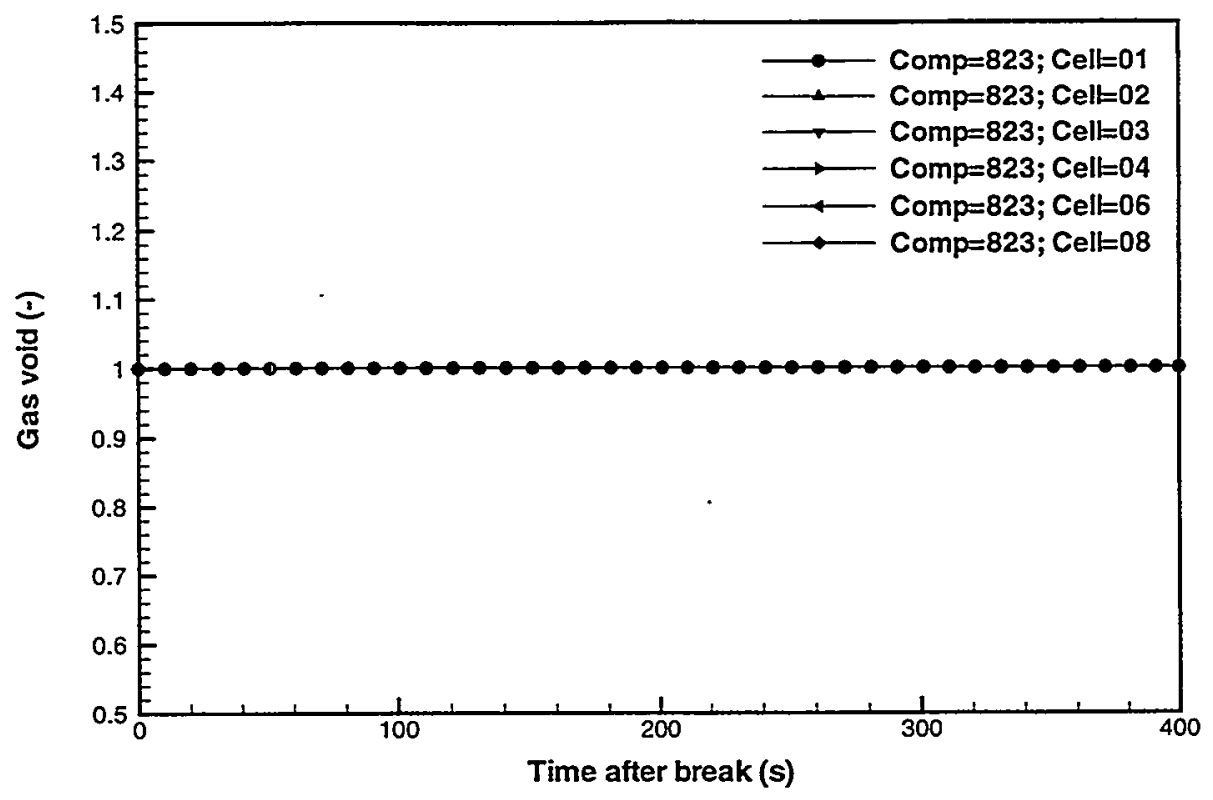

Figure B-27e Below top shield cavity vessel Below top shield cavity vessel void fractions for NO (False transient to establish steady-state).

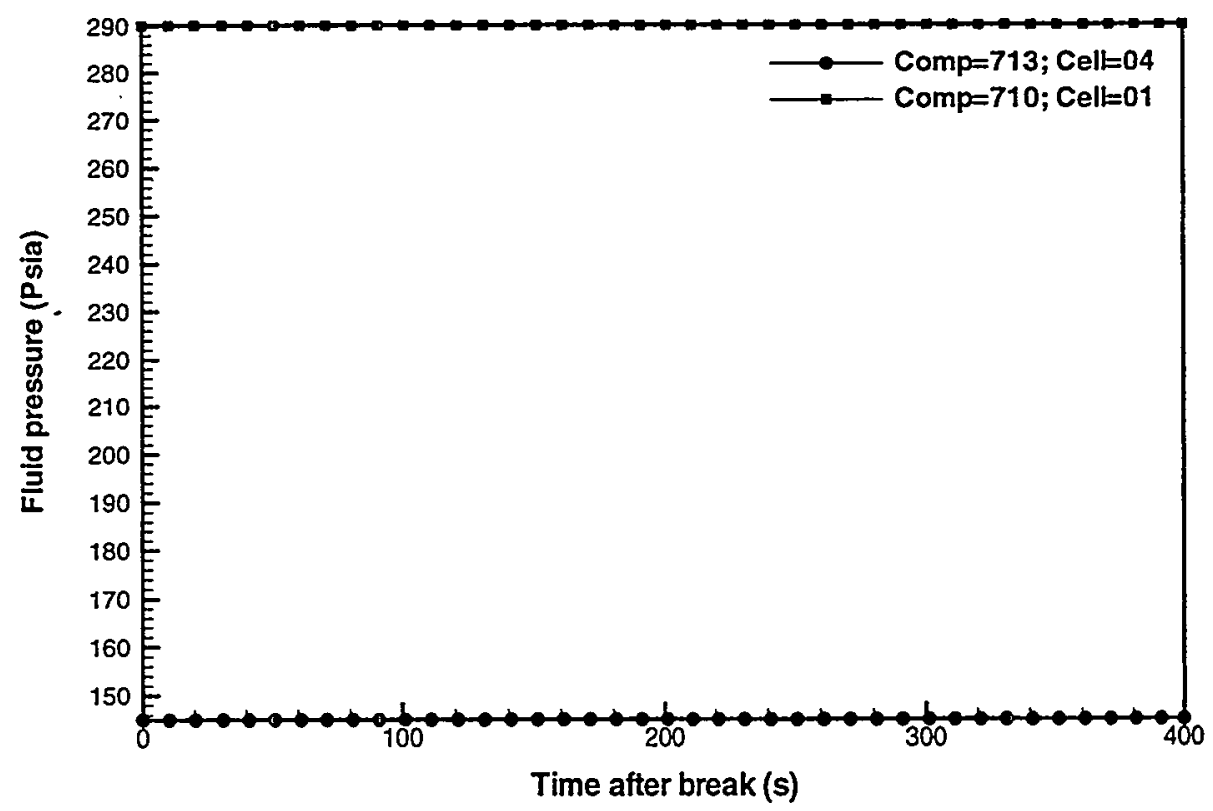

Figure B-28a HR heat exchanger 1 secondary side fluid pressures for NO (False transient to establish steady-state). 


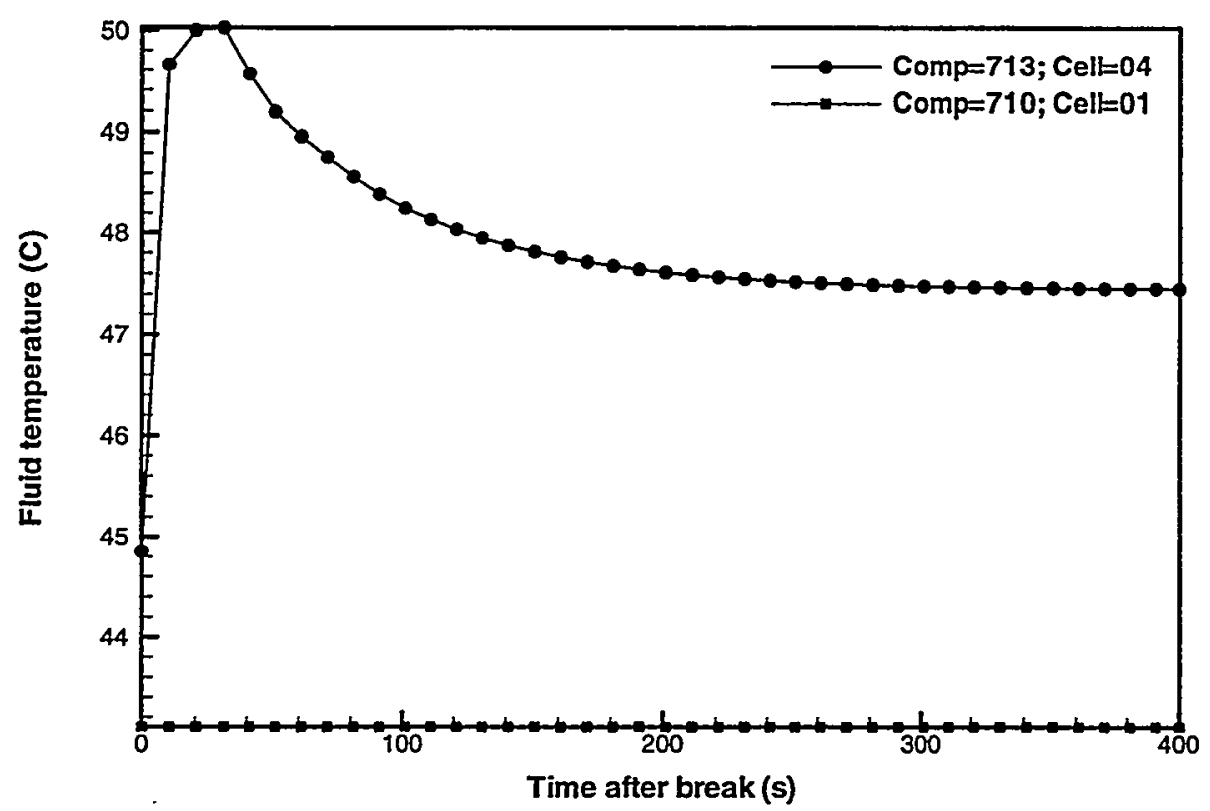

Figure B-28b HR heat exchanger 1 secondary side fluid temperatures for NO (False transient to establish steady-state).

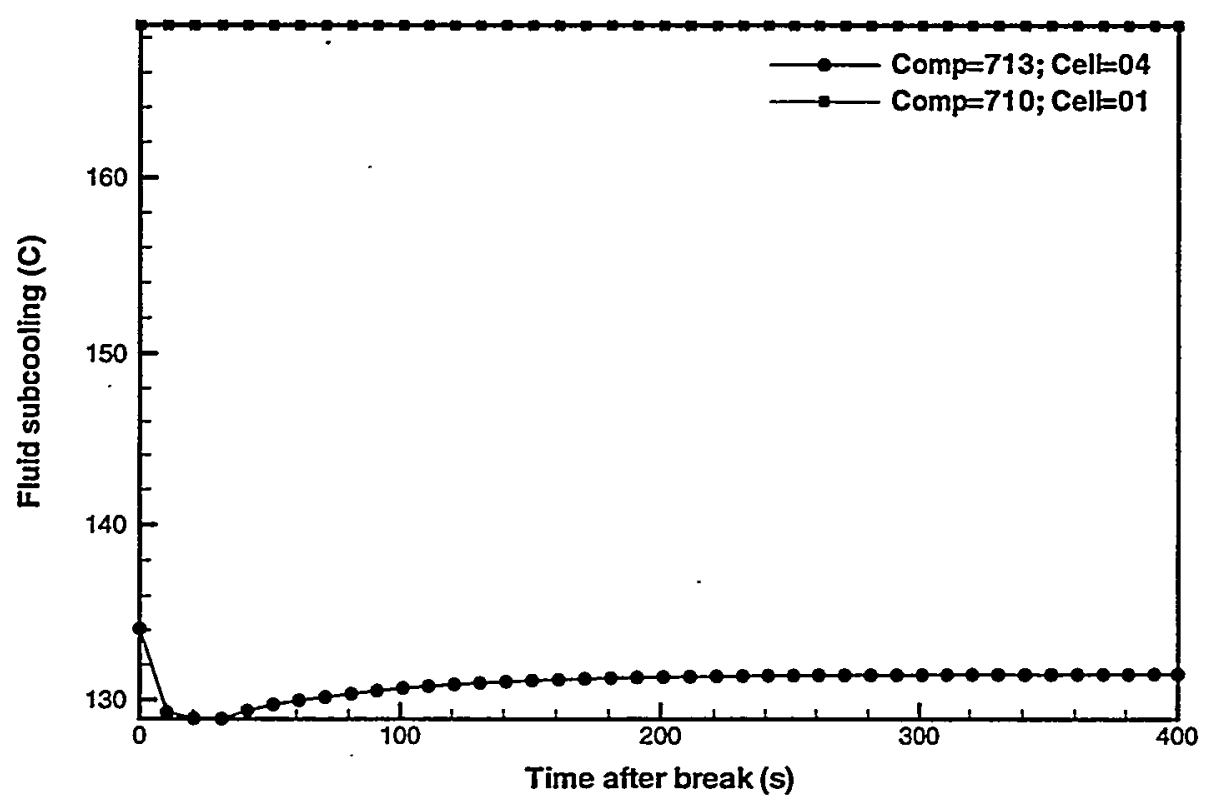

Figure B-28c HR heat exchanger 1 secondary side fluid subcoolings for NO (False transient to establish steady-state). 


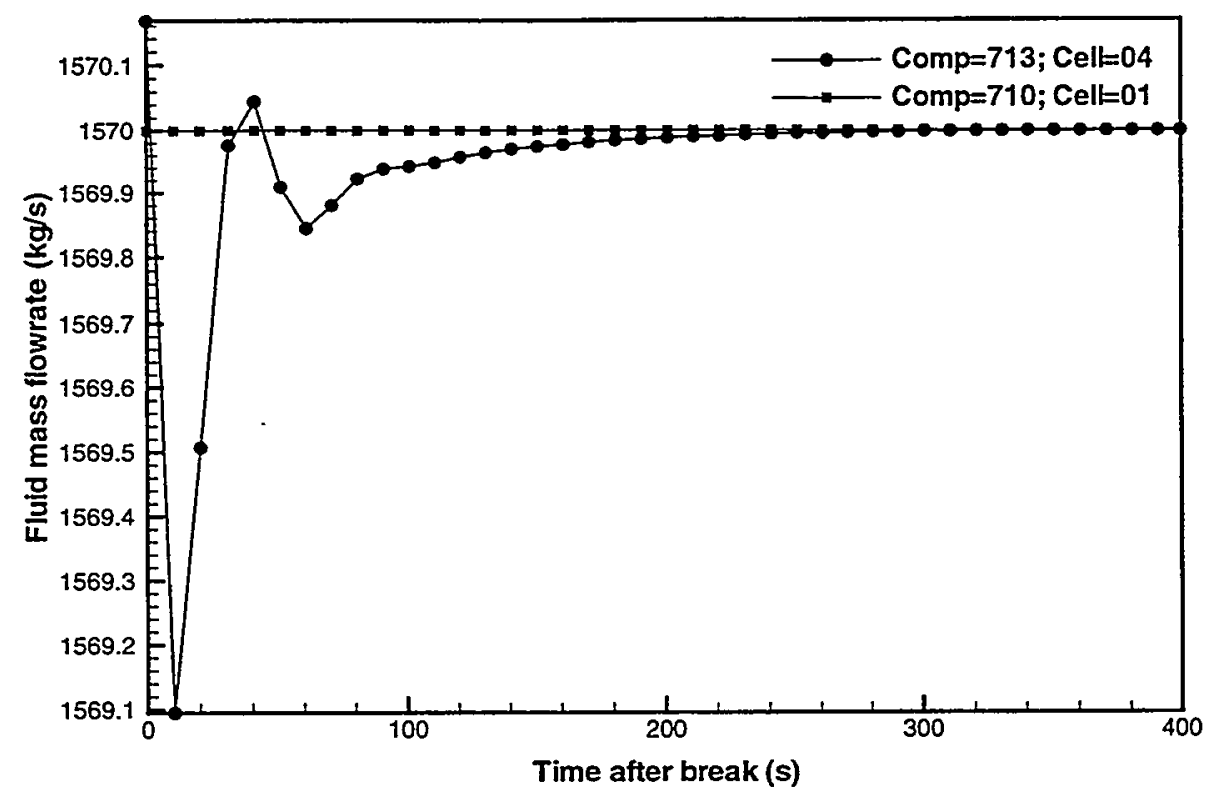

Figure B-28d HR heat exchanger 1 secondary side liquid mass flowrates for NO (False transient to establish steady-state).

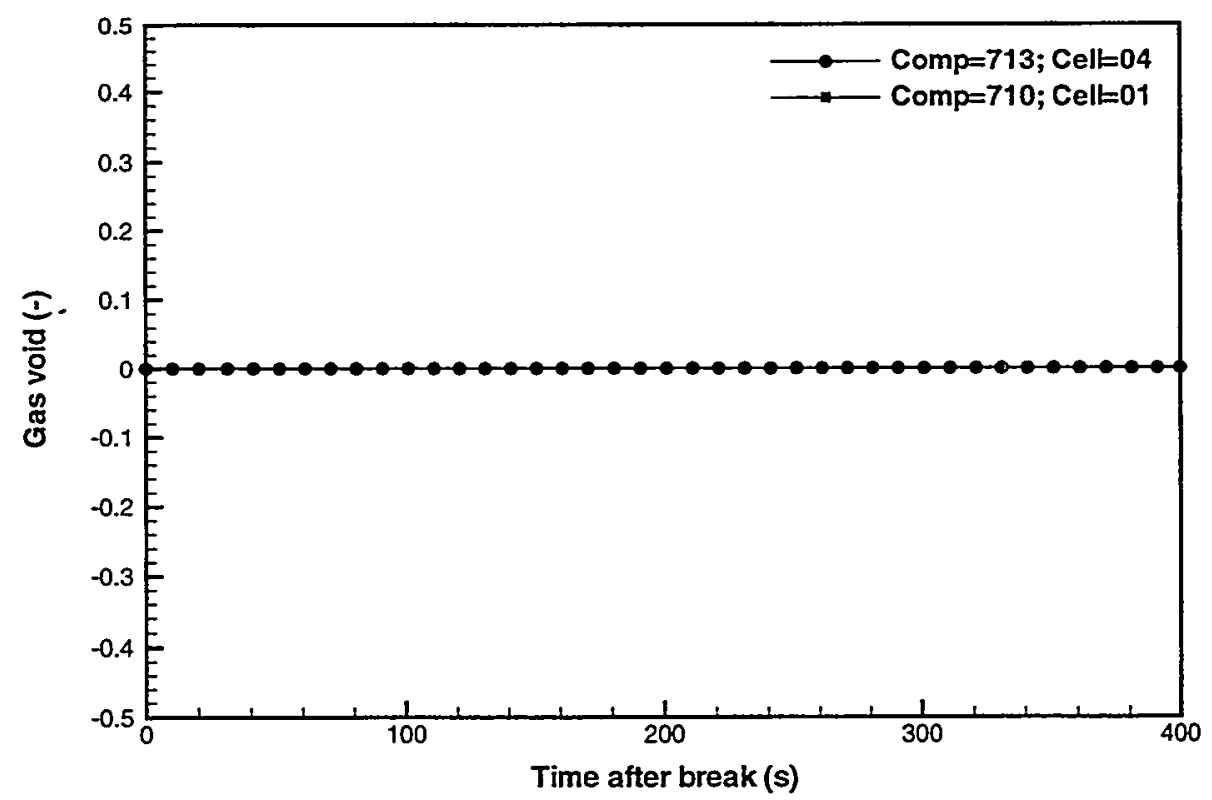

Figure B-28e HR heat exchanger 1 secondary side HR heat exchanger 1 secondary side Below top shield cavity vessel void fractions for NO (False transient to establish steady-state). 


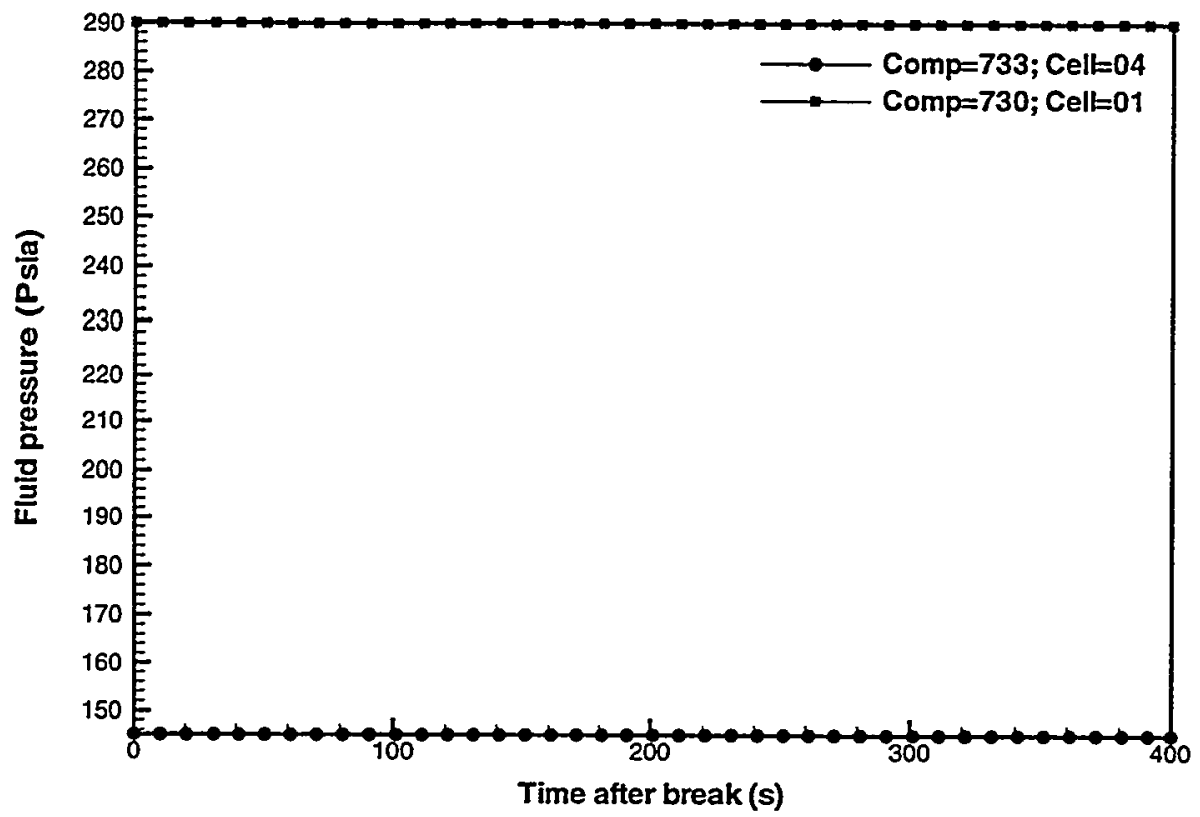

Figure B-29a HR heat exchanger 2 secondary side fluid pressures for NO (False transient to establish steady-state).

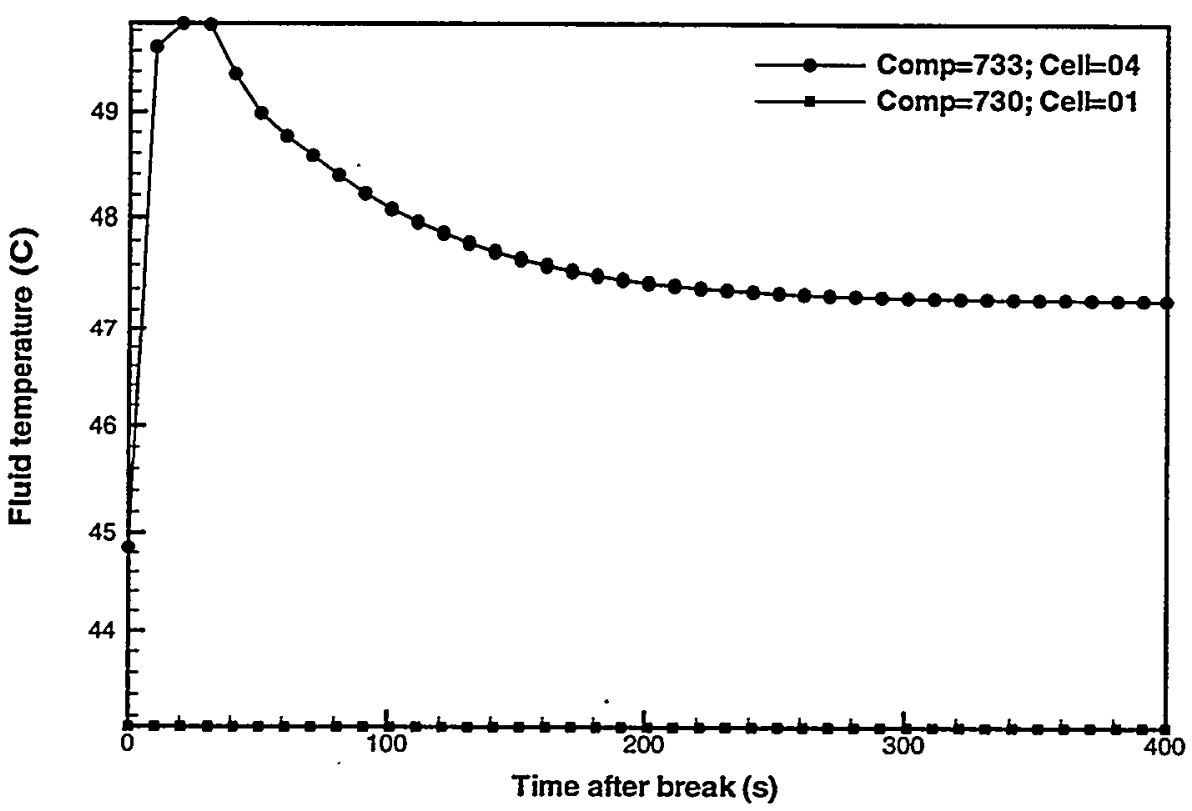

Figure B-29b HR heat exchanger 2 secondary side fluid temperatures for NO (False transient to establish steady-state). 


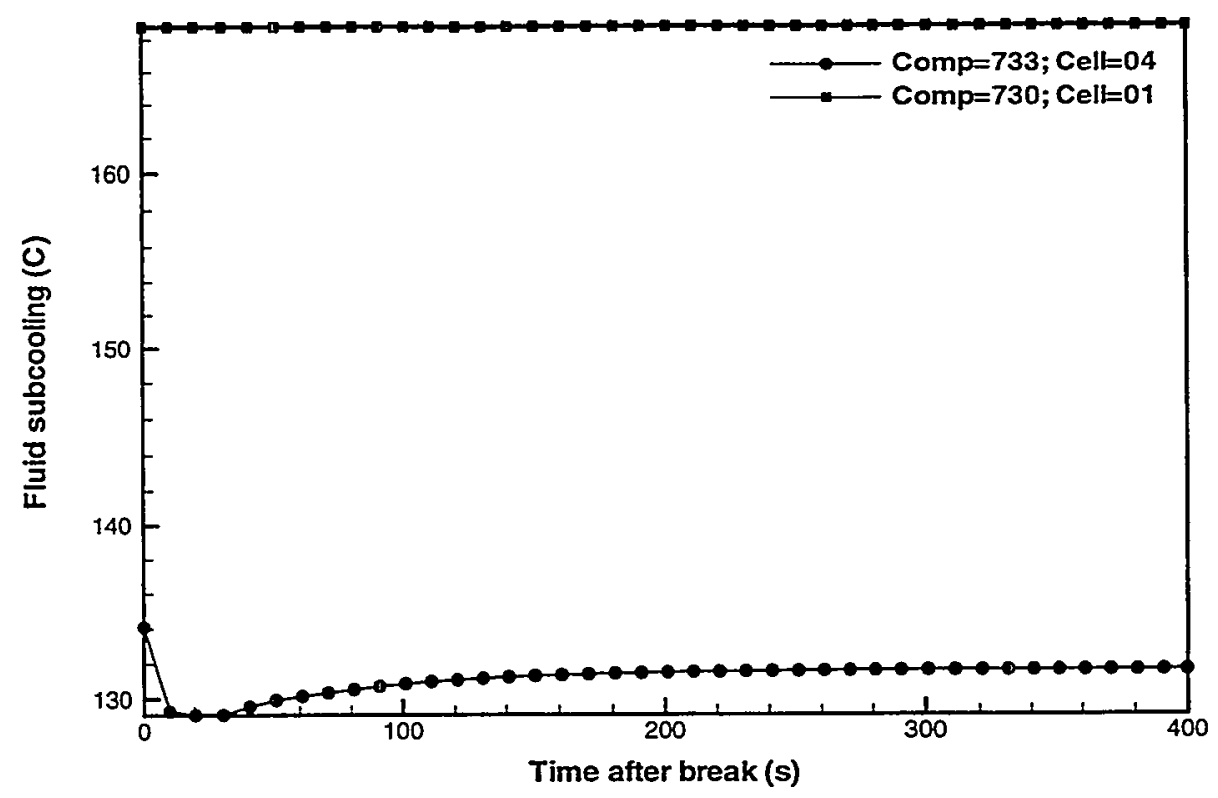

Figure B-29c HR heat exchanger 2 secondary side fluid subcoolings for NO (False transient to establish steady-state).

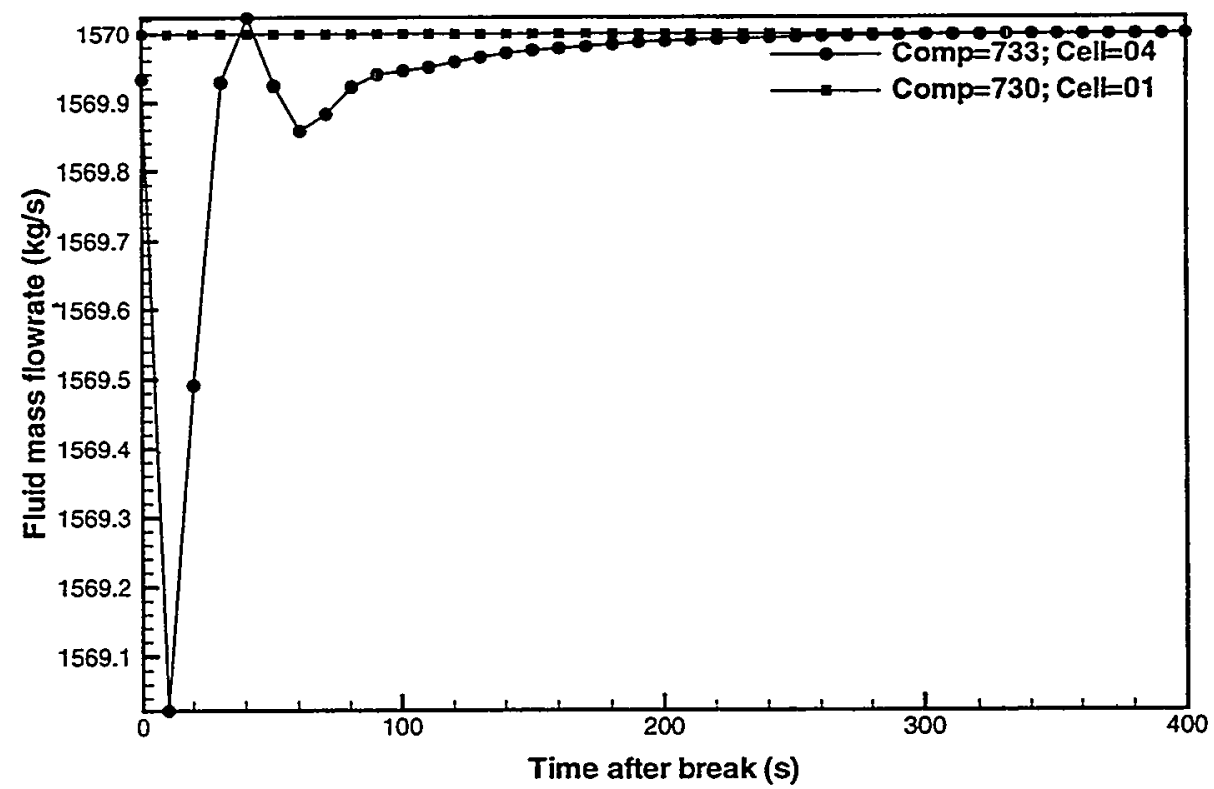

Figure B-29d HR heat exchanger 2 secondary side liquid mass flowrates for NO (False transient to establish steady-state). 


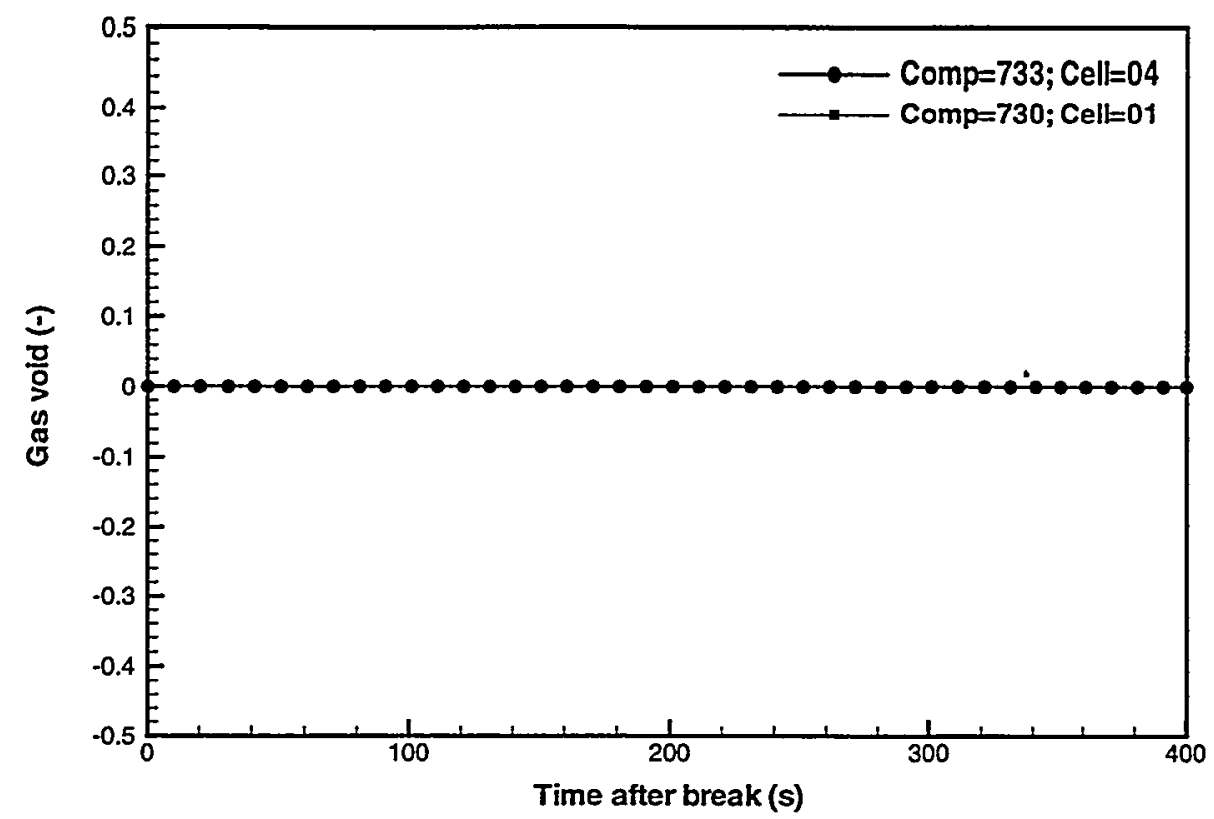

Figure B-29e HR heat exchanger 2 secondary side HR heat-exchanger 1 secondary side Below top shield cavity vessel void fractions for NO (False transient to establish steady-state).

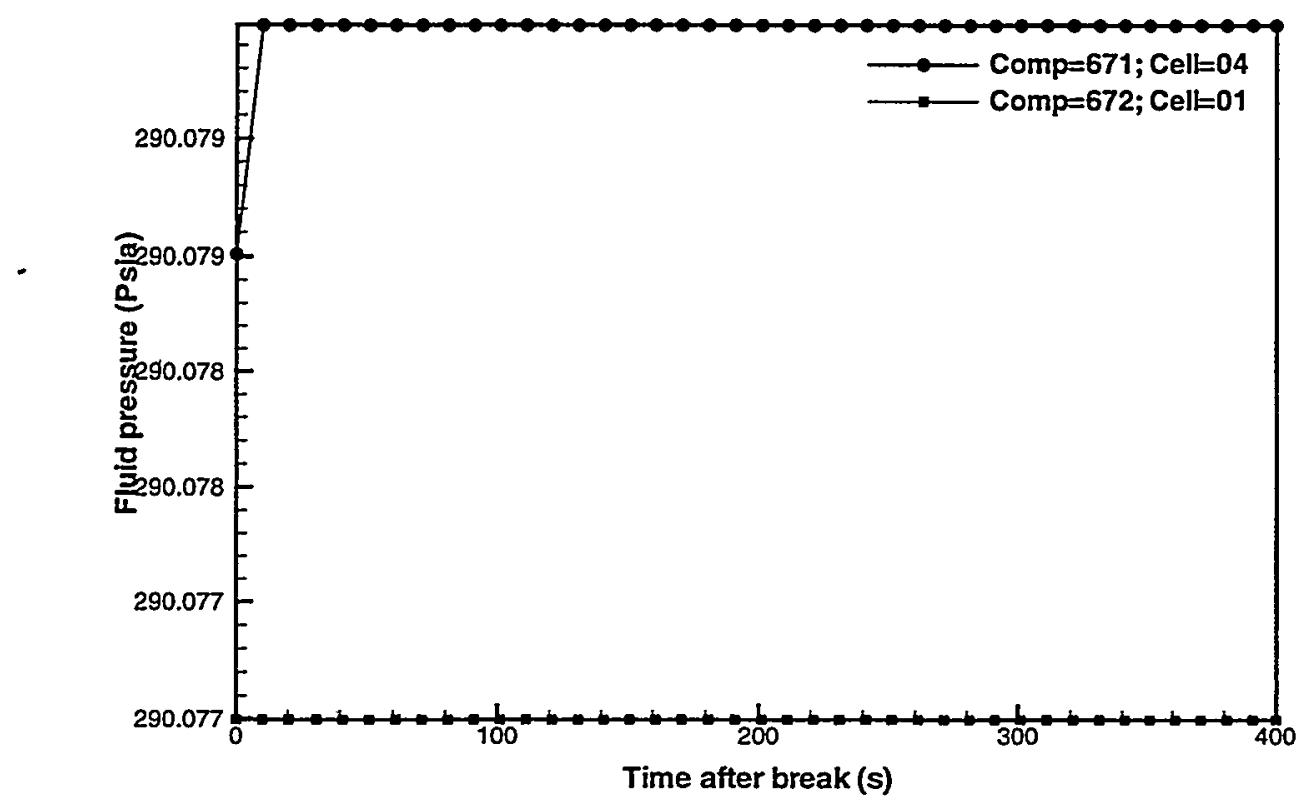

Figure B-30a RHR heat exchanger secondary side fluid pressures for NO (False transient to establish steady-state). 


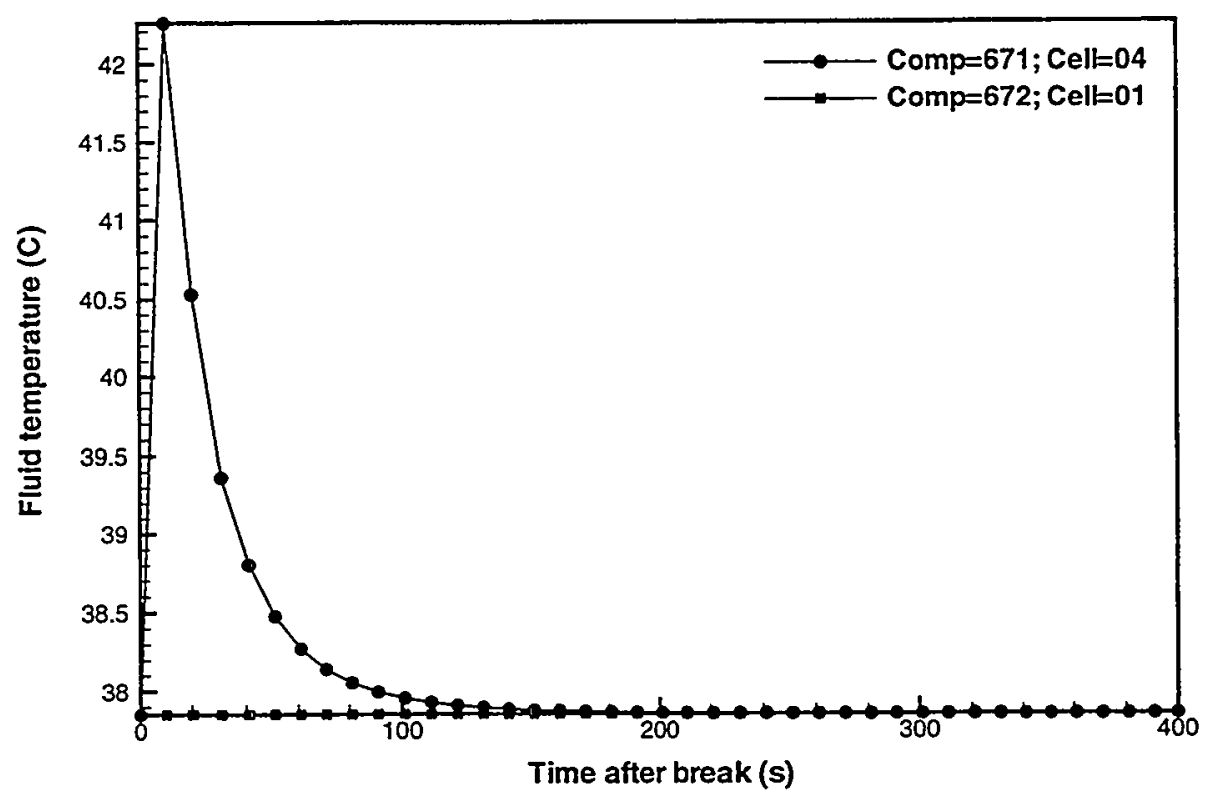

Figure B-30b RHR heat exchanger secondary side fluid temperatures for NO (False transient to establish steady-state).

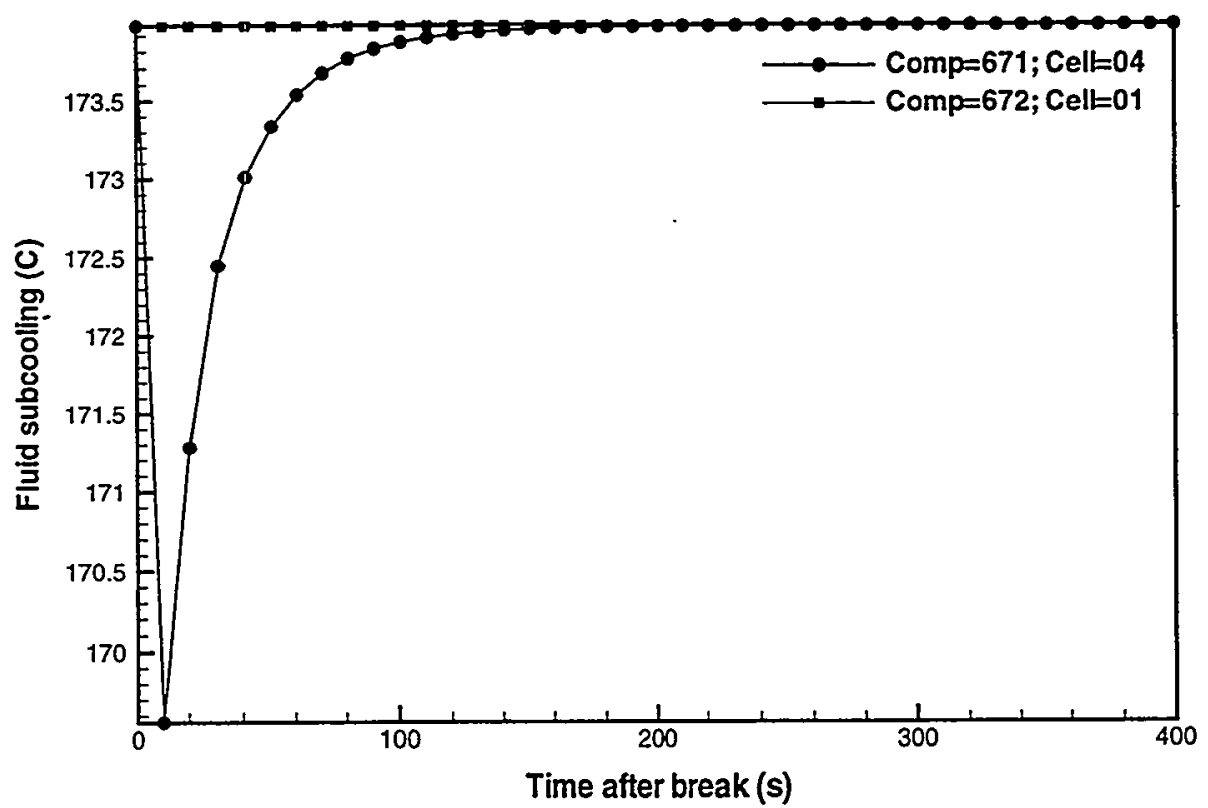

Figure B-30c RHR heat exchanger secondary side fluid subcoolings for NO (False transient to establish steady-state). 


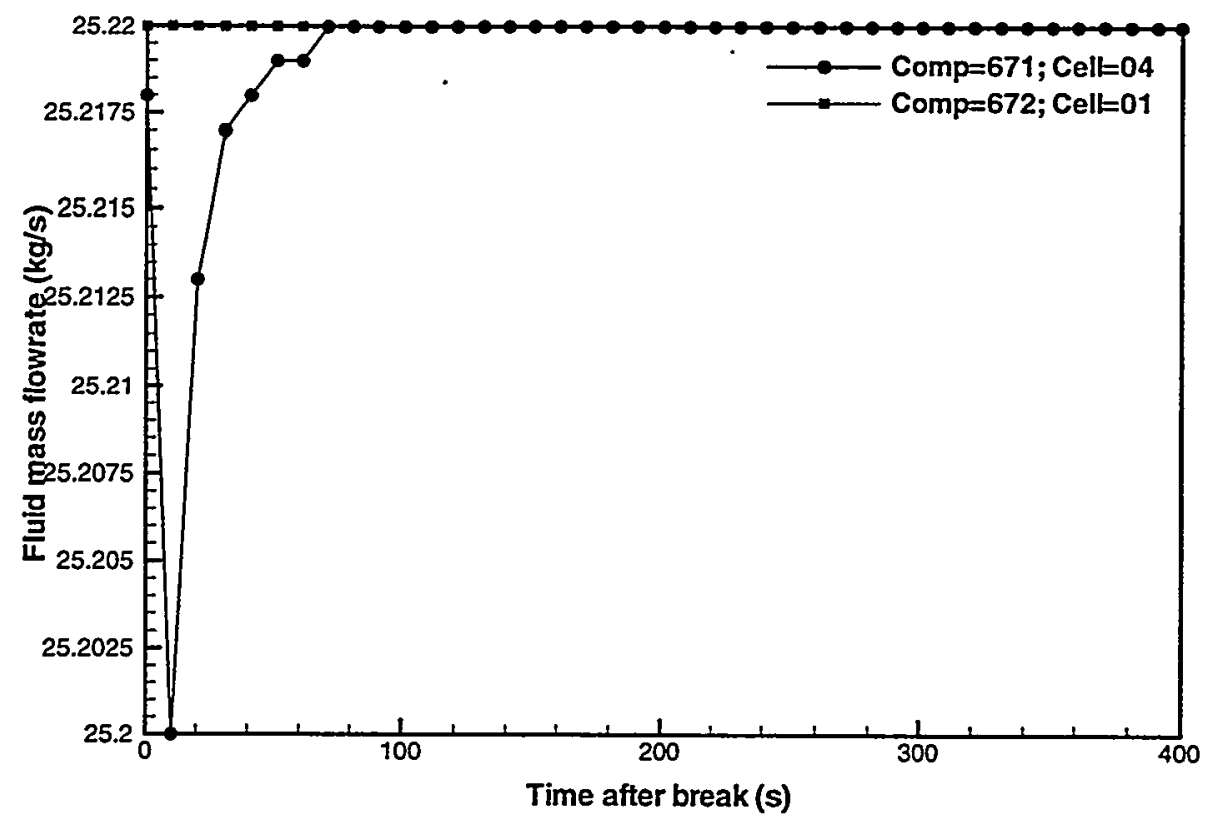

Figure B-30d RHR heat exchanger secondary side liquid mass flowrates for NO (False transient to establish steady-state).

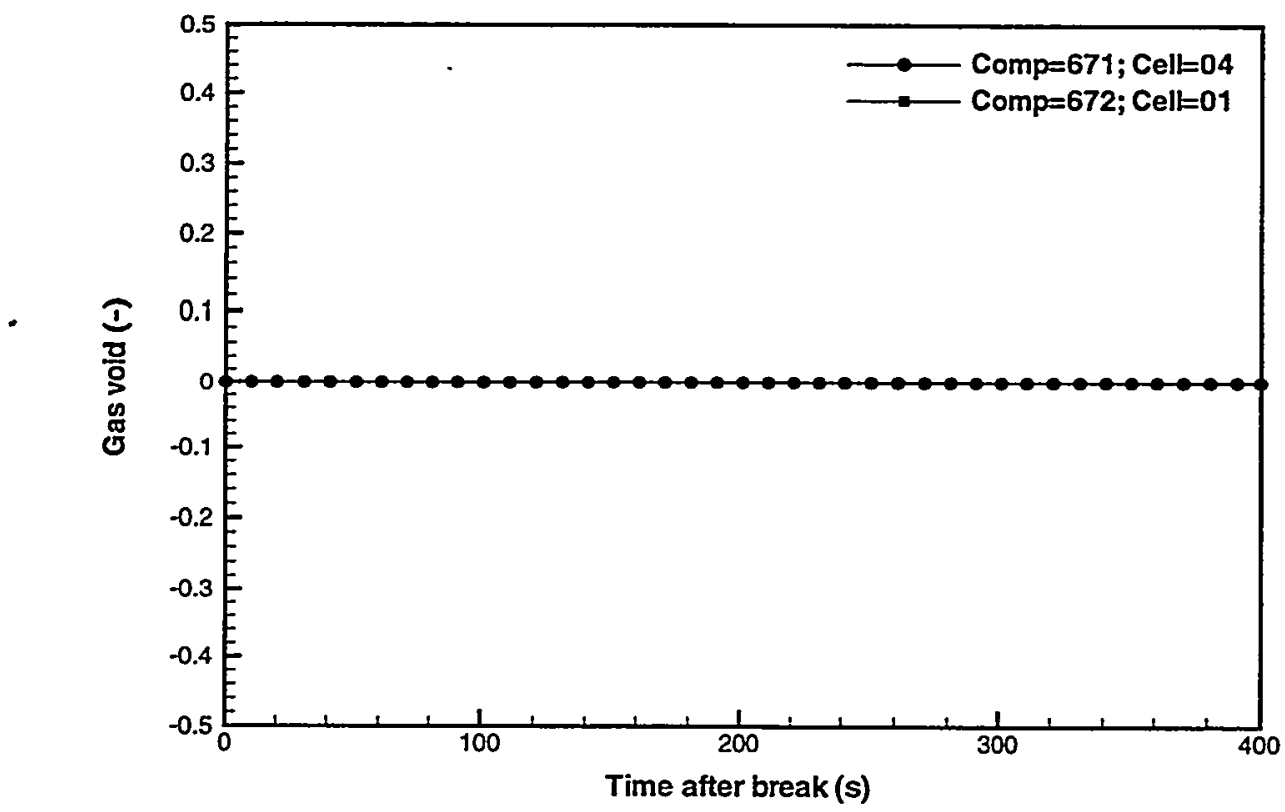

Figure B-30e RHR heat exchanger secondary side HR heat exchanger 1 secondary side Below top shield cavity vessel void fractions for NO (False transient to establish steadystate). 


\section{Appendix B3 Normal Operation TRAC Heat Structure Component Figures}

The following figures are from a TRAC simulation for normal operation:

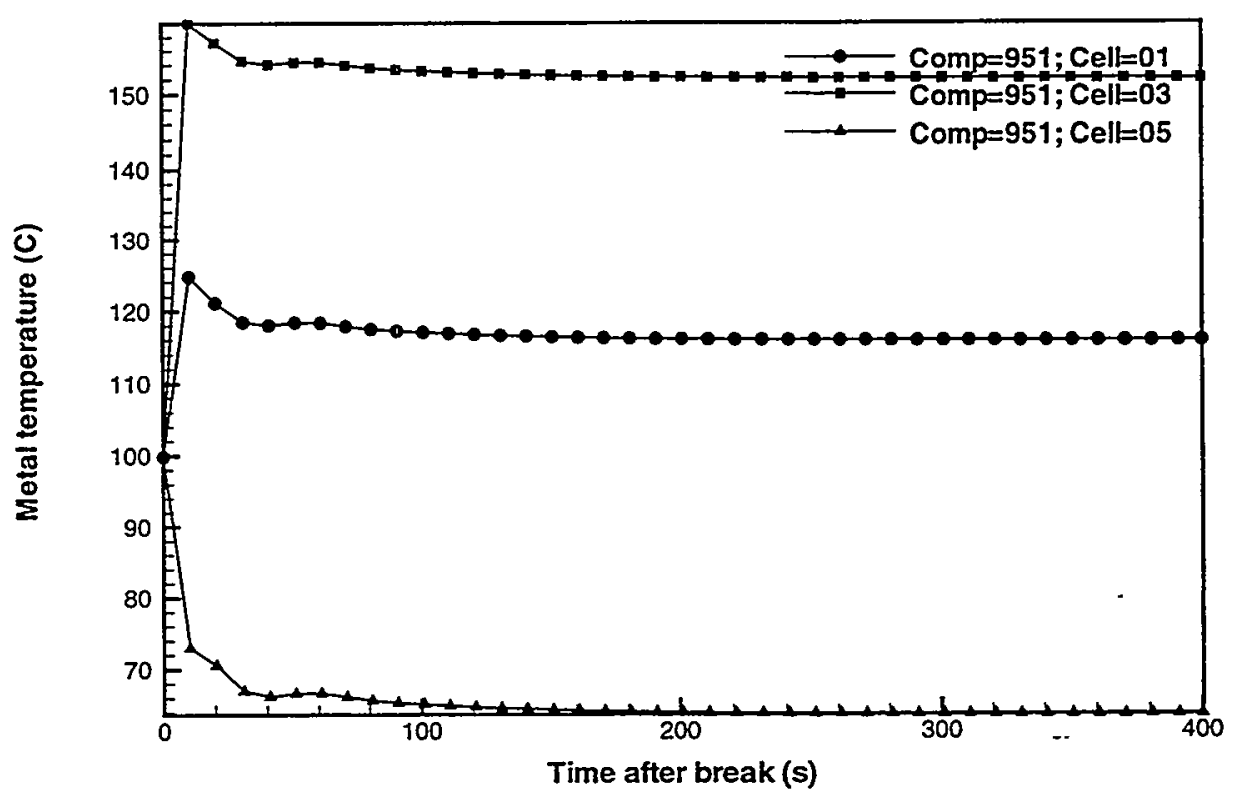

Figure B-31 Module 1 upflow section bottom, mid-plane, and top maximum lead metal temperatures for NO (False transient to establish steady-state). 


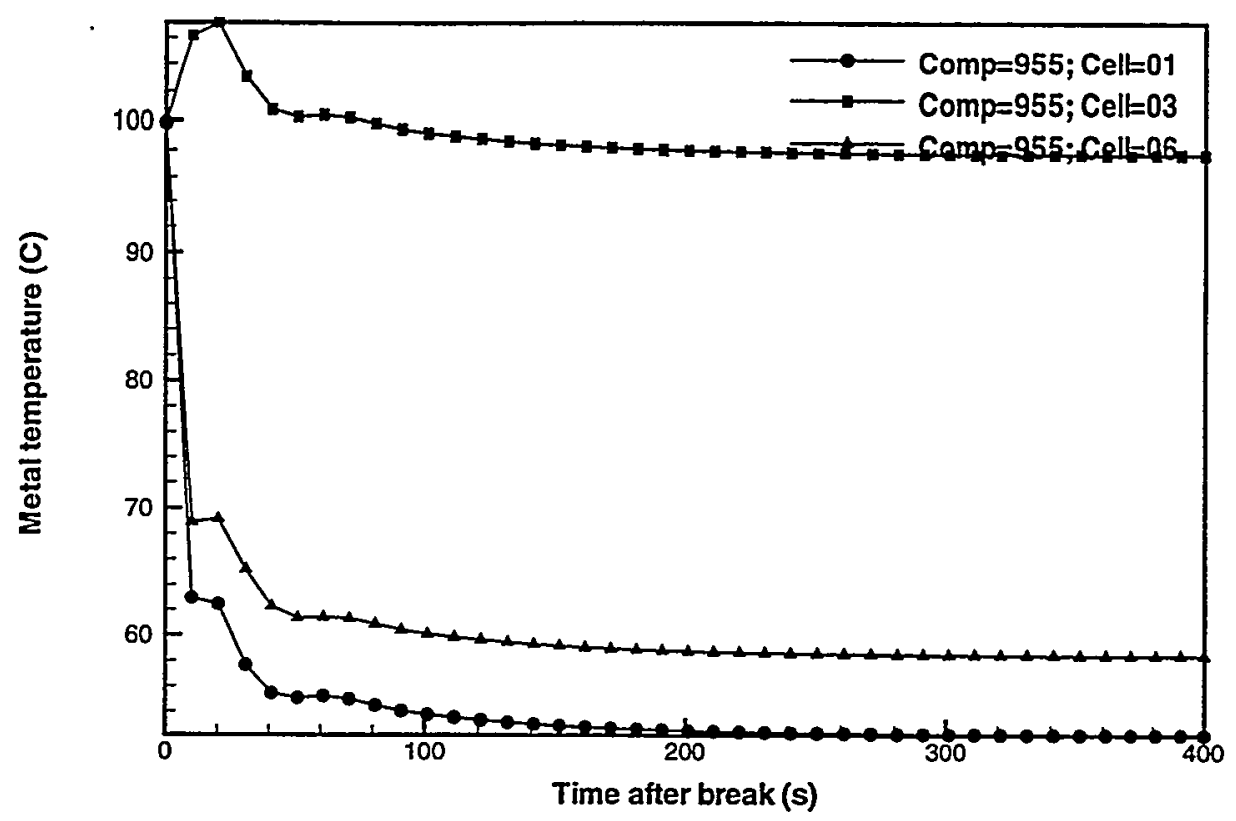

Figure B-32 Module 2 upflow section bottom, mid-plane, and-top maximum lead metal temperatures for NO (False transient to establish steady-state).

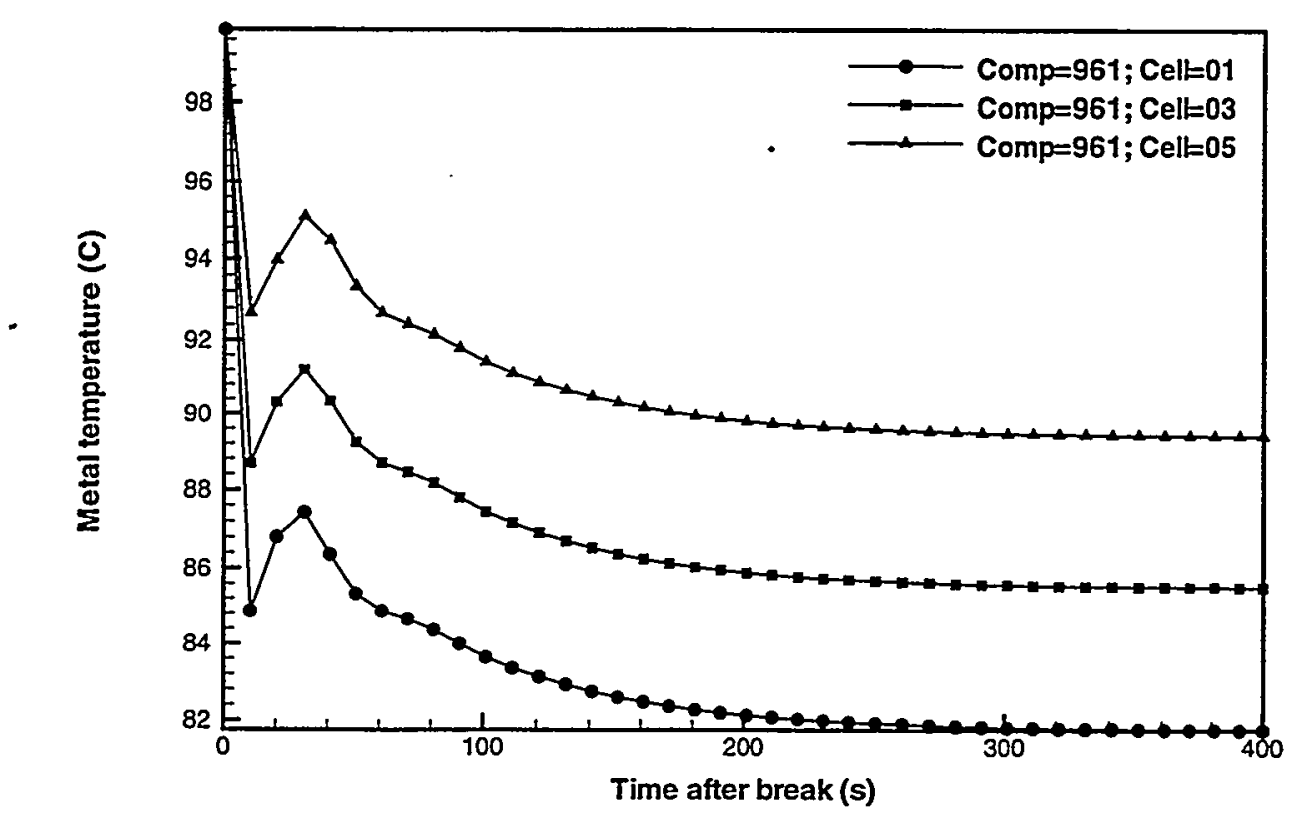

Figure B-33 Module 3 upflow section bottom, mid-plane, and top maximum lead metal temperatures for NO (False transient to establish steady-state). 


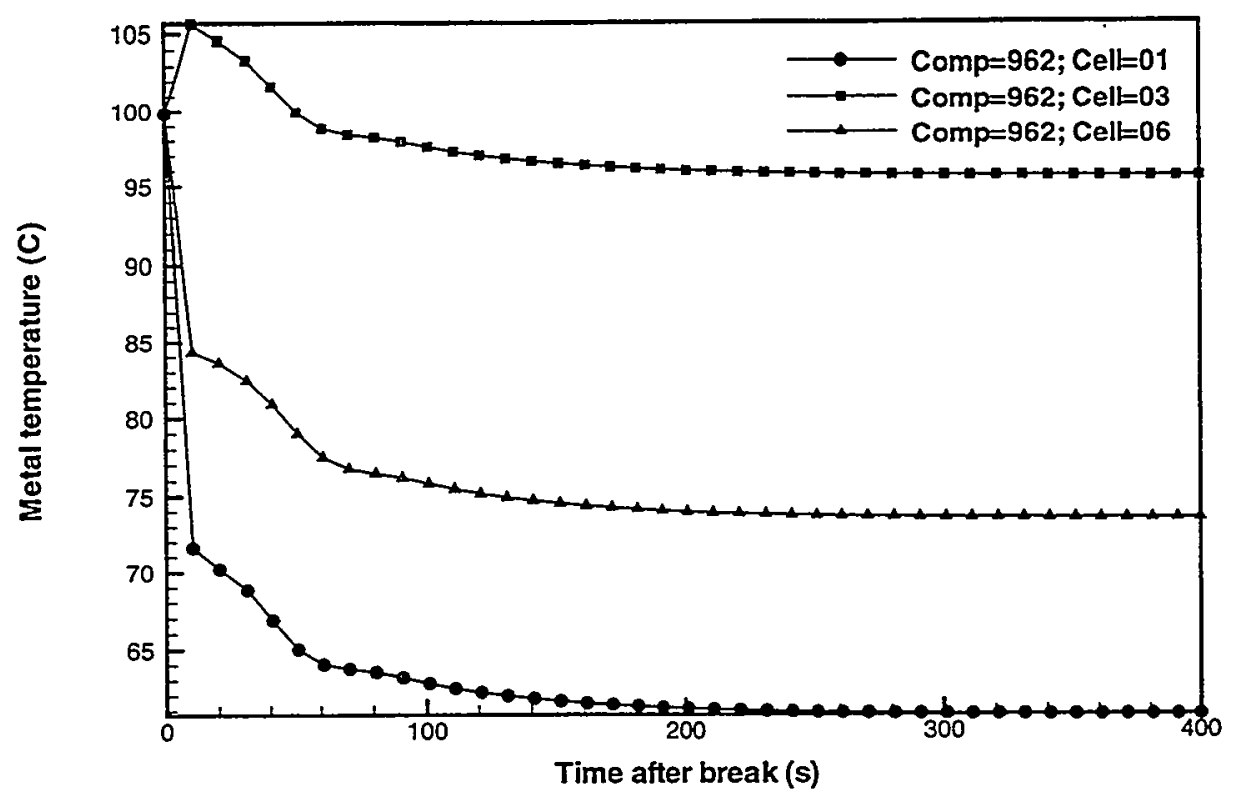

Figure B-34 Module 4 upflow section bottom, mid-plane, and top maximum lead metal temperatures for NO (False transient to establish steady-state).

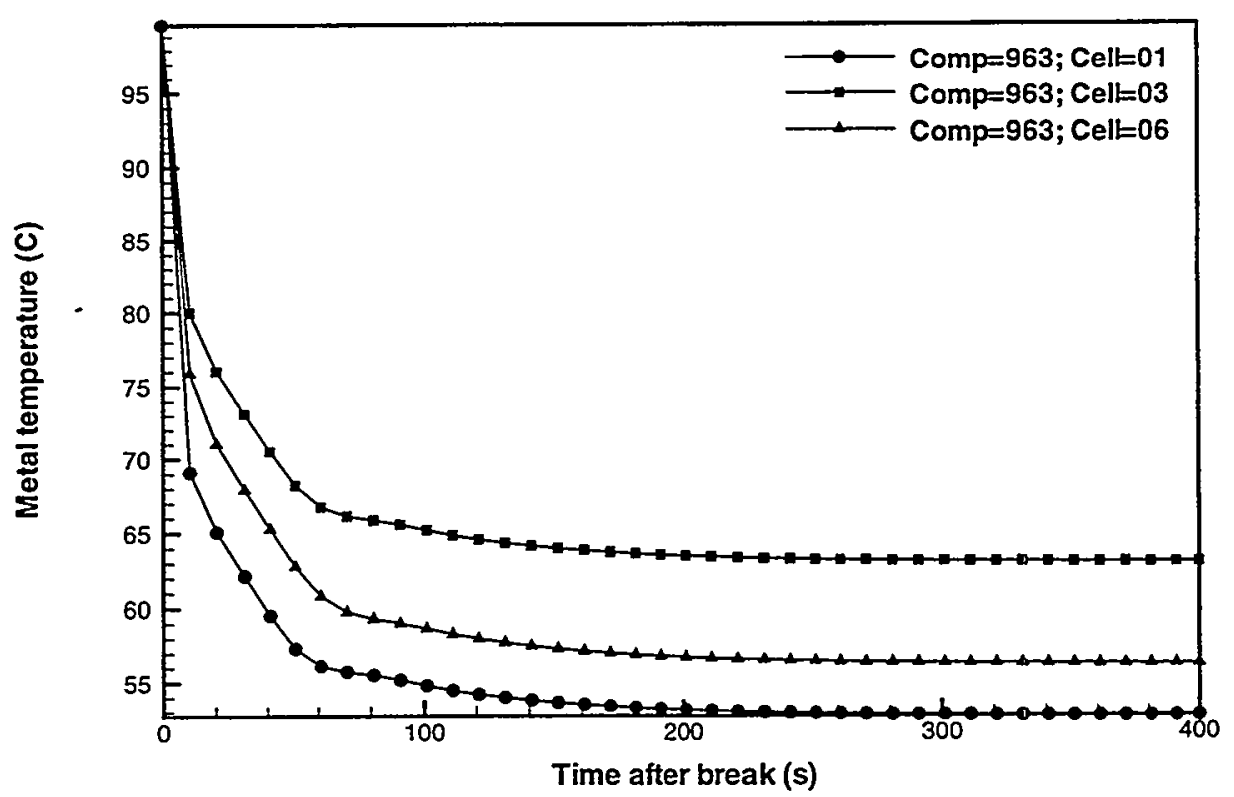

Figure B-35 Module 5 upflow section bottom, mid-plane, and top maximum lead metal temperatures for NO (False transient to establish steady-state). 


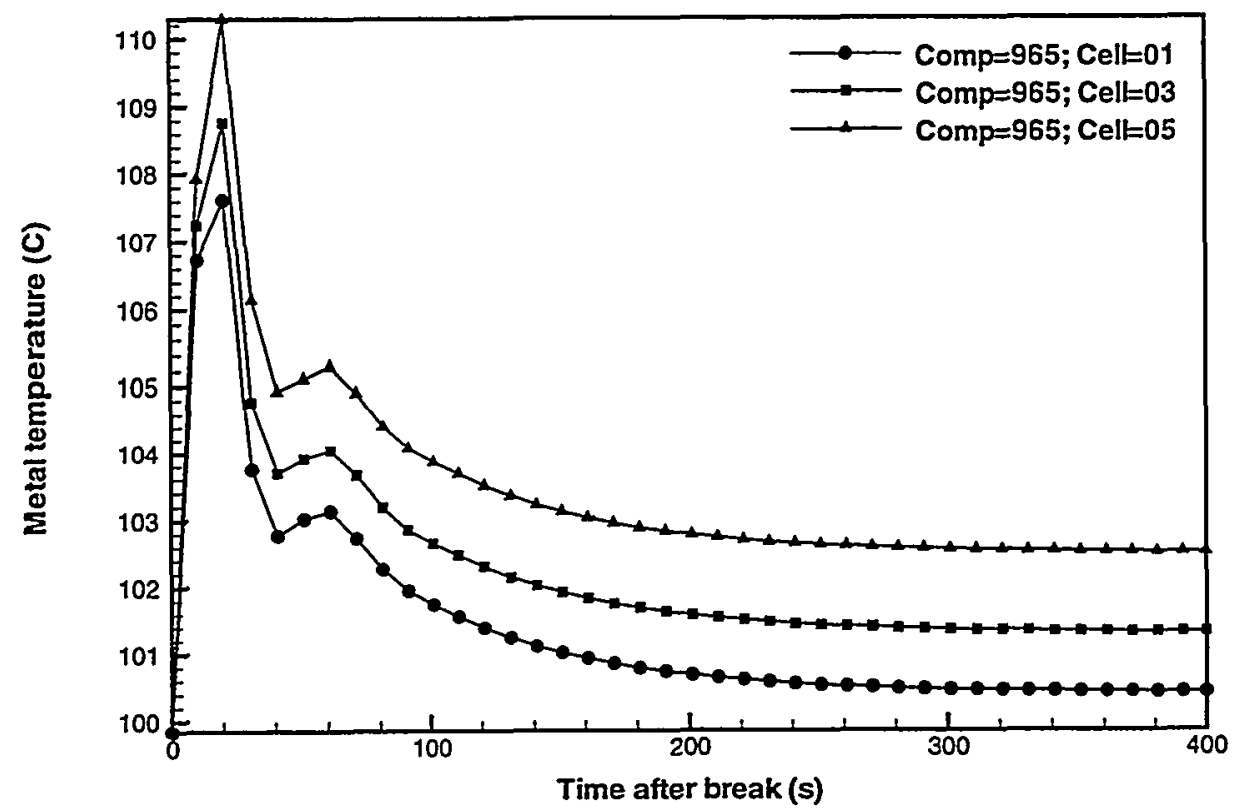

Figure B-36 Module 6 down-stream section bottom, mid-plane, and top maximum lead metal temperatures for NO (False transient to establish steady-state).

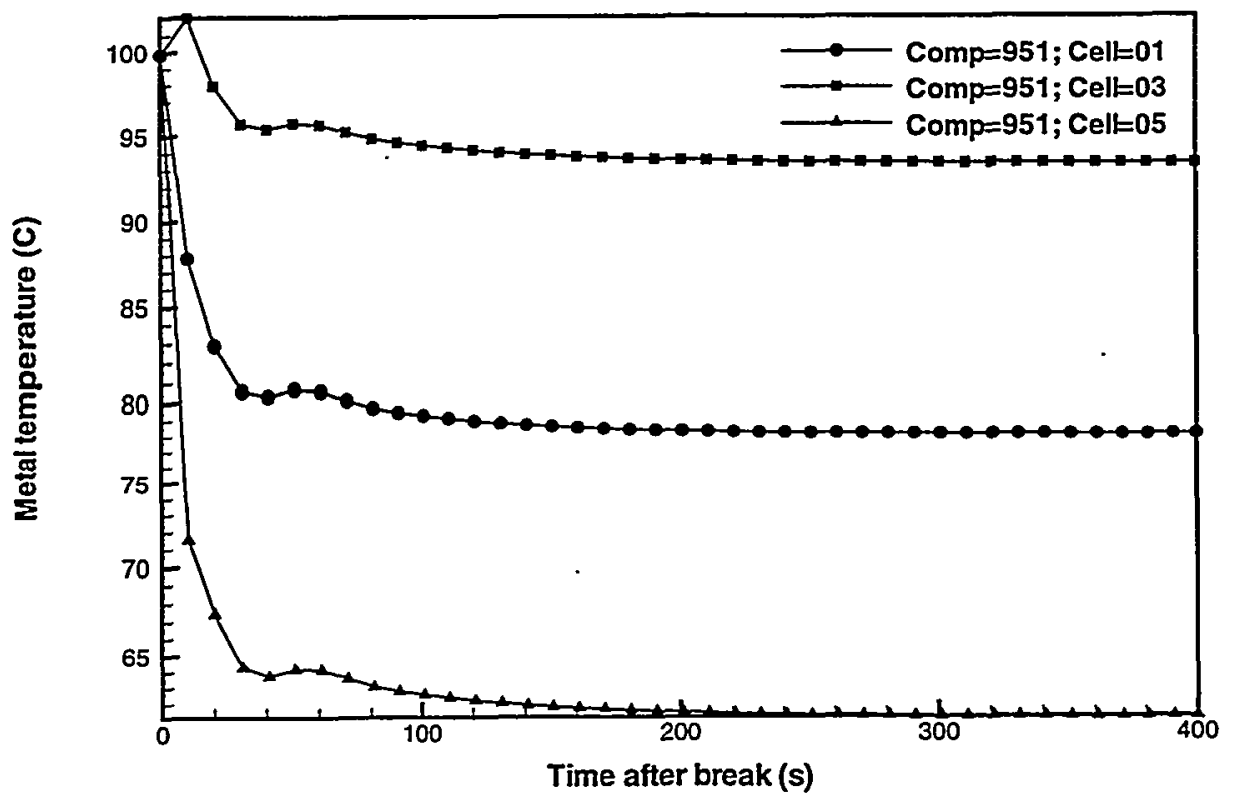

Figure B-37 Module 1 upflow section bottom, mid-plane, and top maximum aluminum metal temperatures for NO (False transient to establish steady-state). 


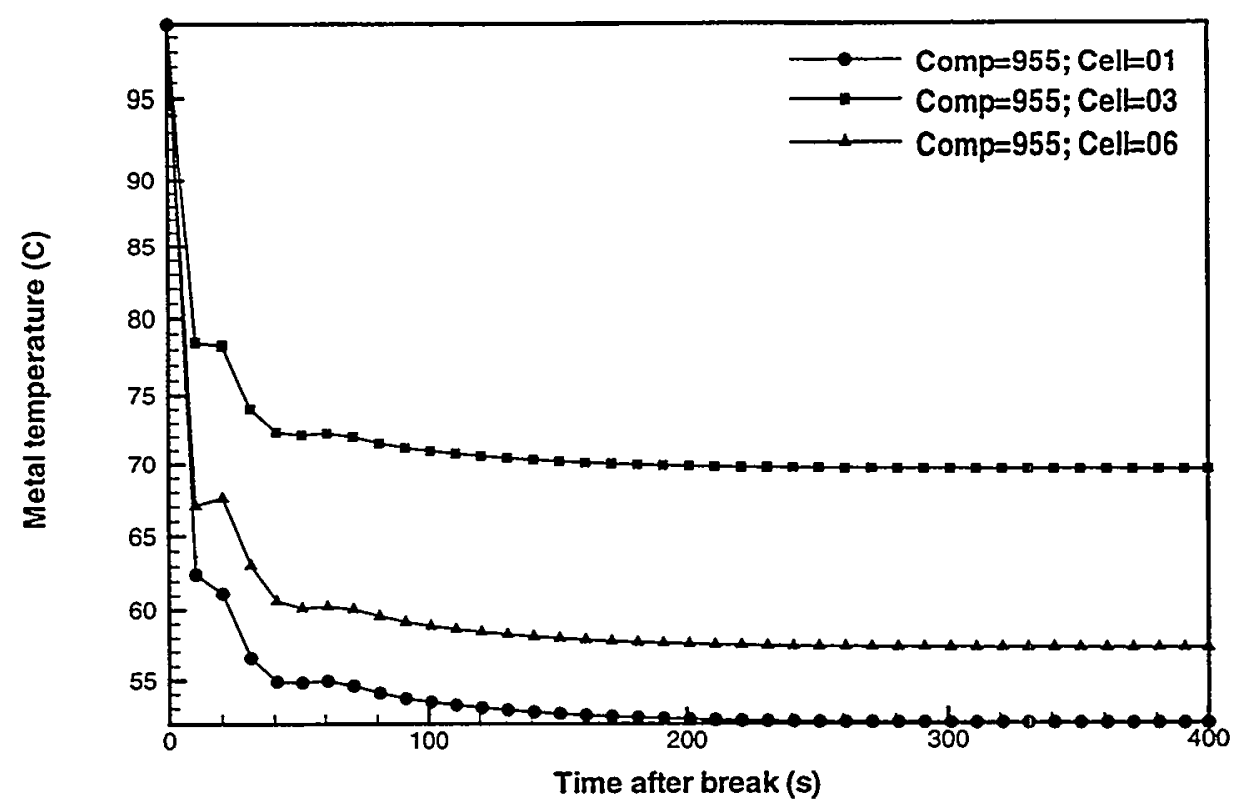

Figure B-38 Module 2 upflow section bottom, mid-plane, and top maximum aluminum metal temperatures for NO (False transient to establish steady-state).

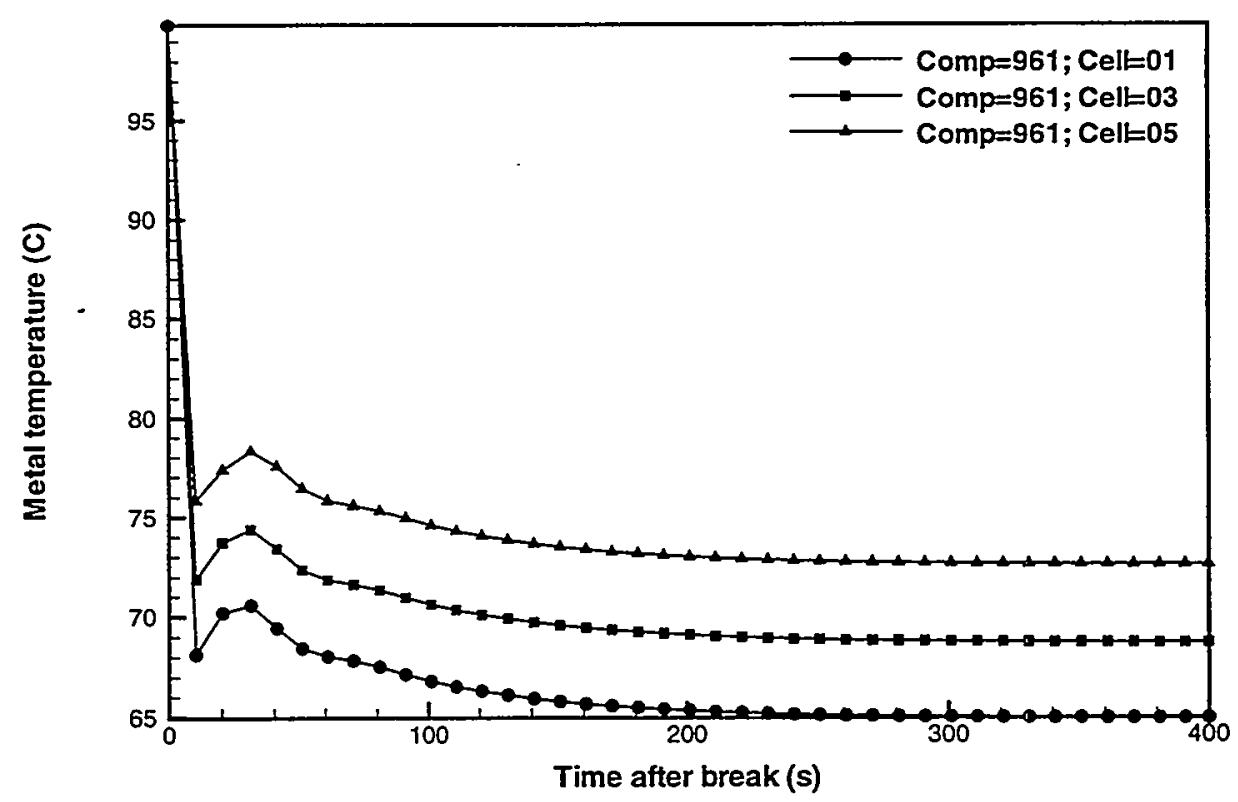

Figure B-39 Module 3 upflow section bottom, mid-plane, and top maximum aluminum metal temperatures for NO (False transient to establish steady-state). 


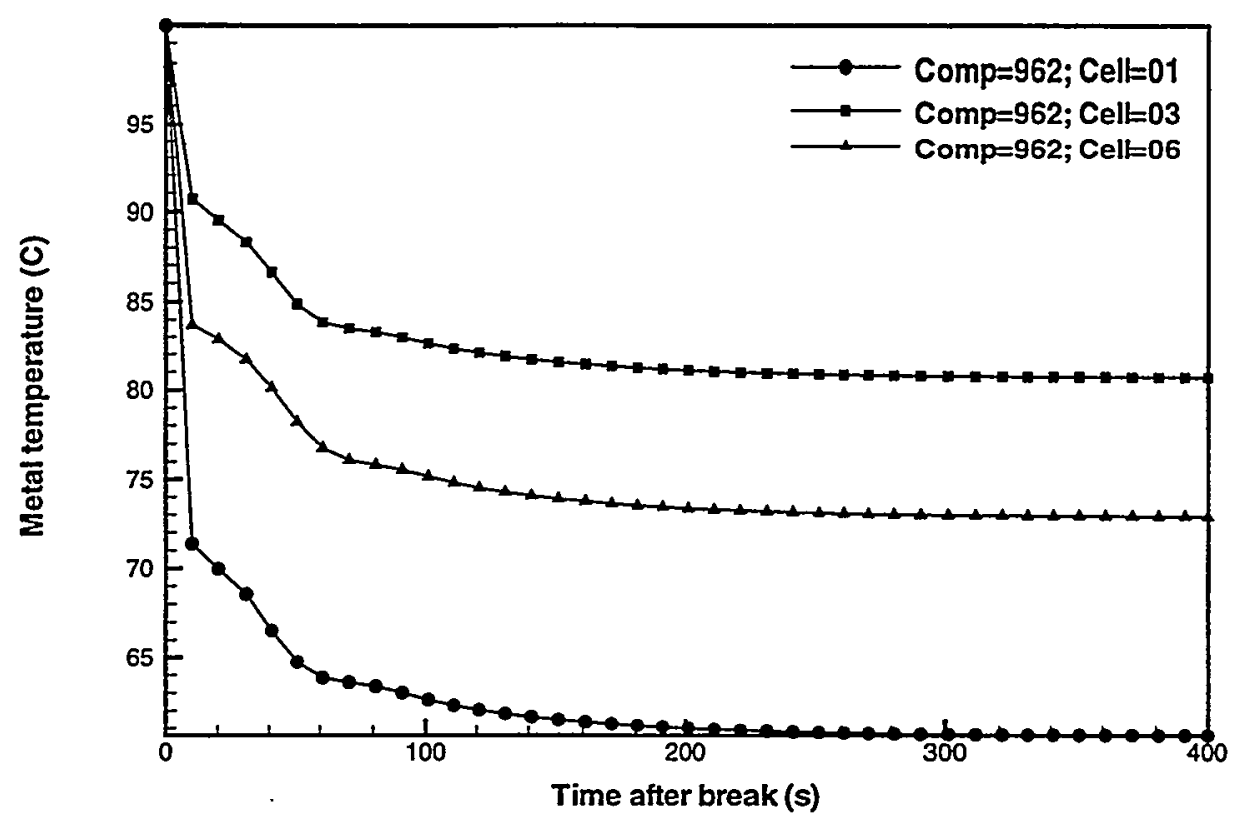

Figure B-40 Module 4 upflow section bottom, mid-plane, and-top maximum aluminum metal temperatures for NO (False transient to establish steady-state).

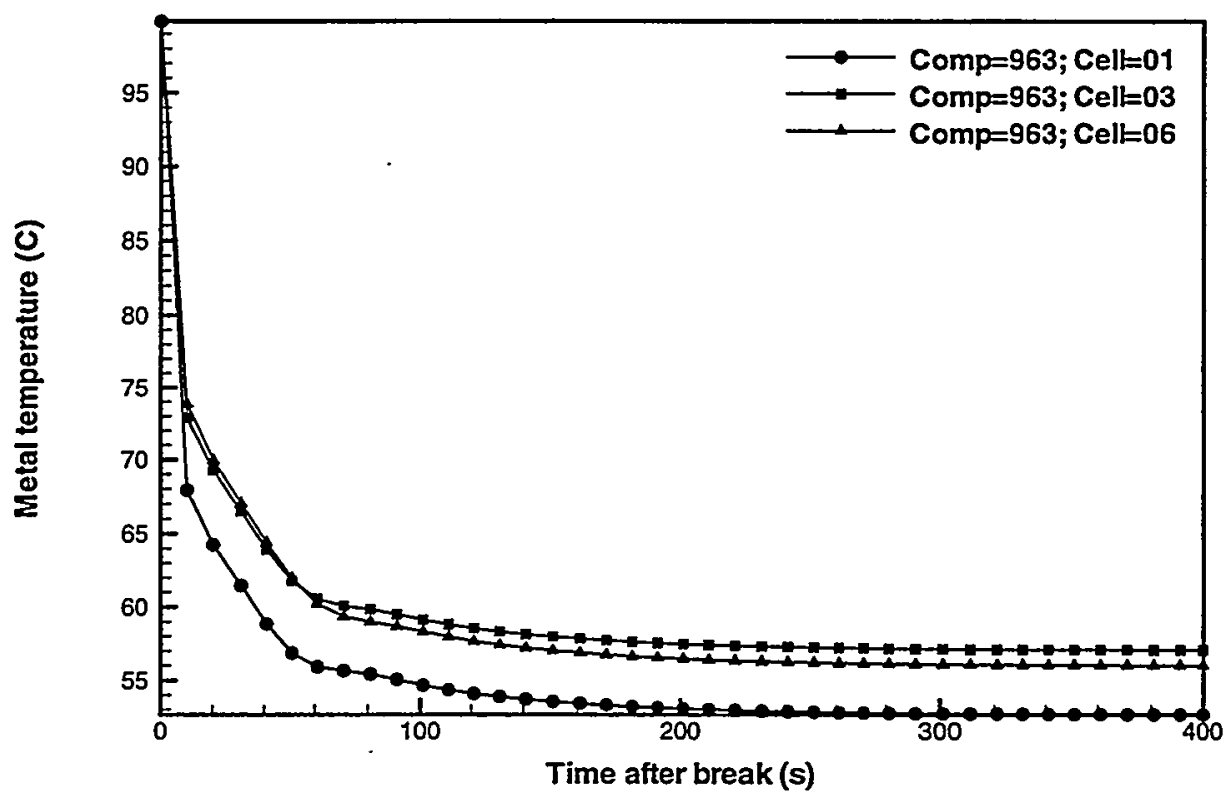

Figure B-41 Module 5 upflow section bottom, mid-plane, and top maximum aluminum metal temperatures for NO (False transient to establish steady-state). 


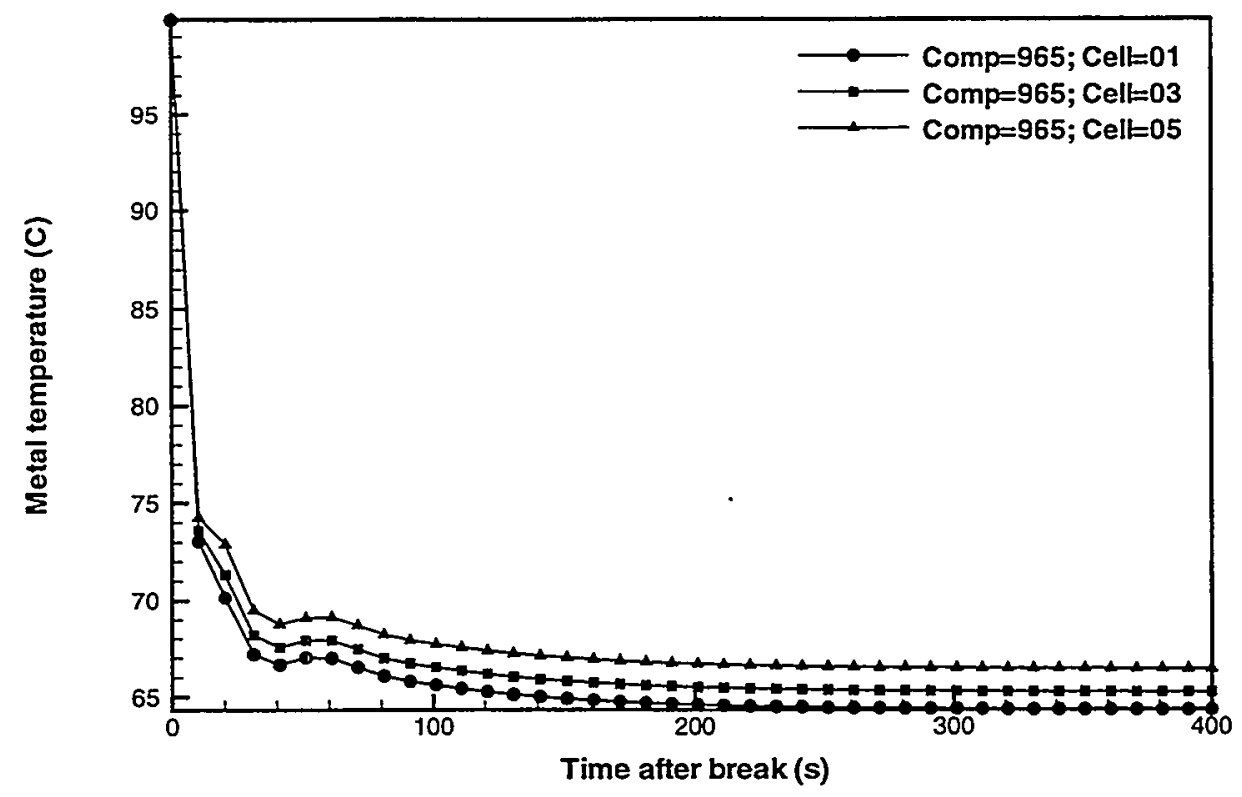

Figure B-42 Module 6 down-stream section bottom, mid-plane, and top maximum aluminum metal temperatures for NO (False transient to establish steady-state).

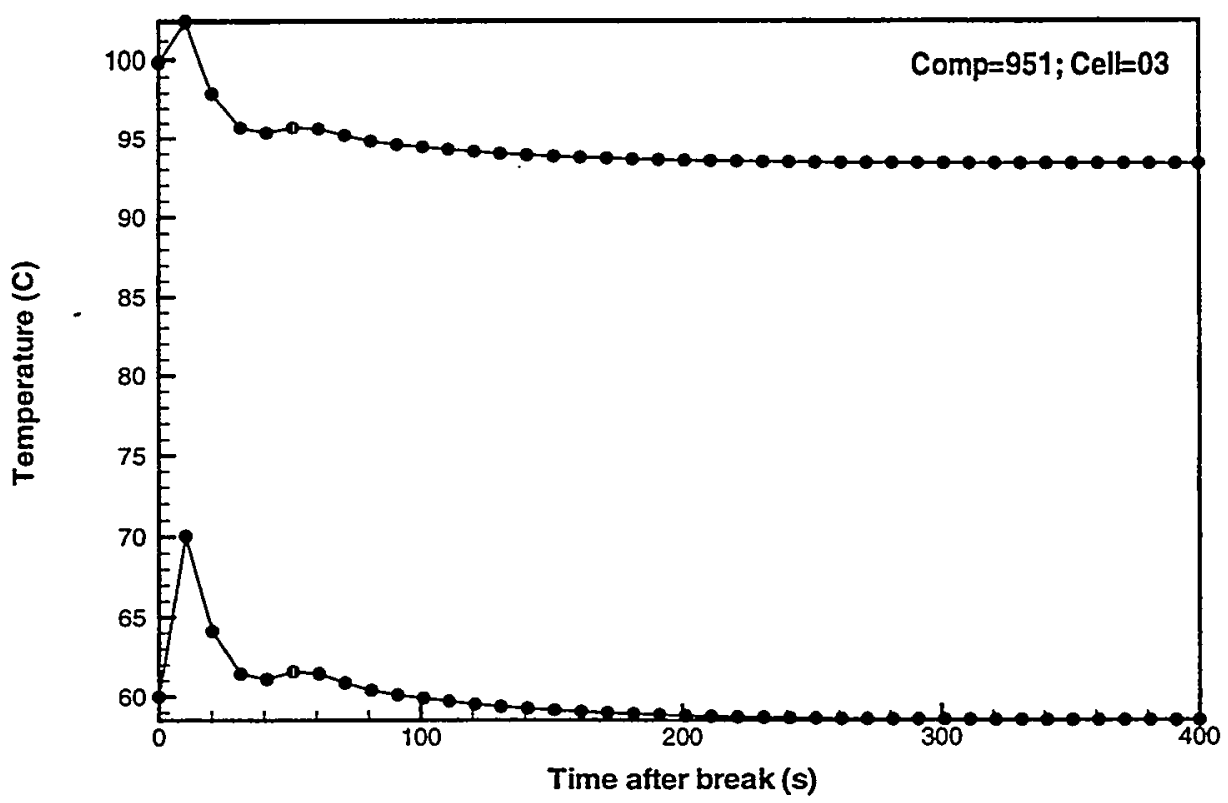

Figure B-43 Module 1 upflow section mid-plane surface and fluid temperatures for NO (False transient to establish steady-state). 


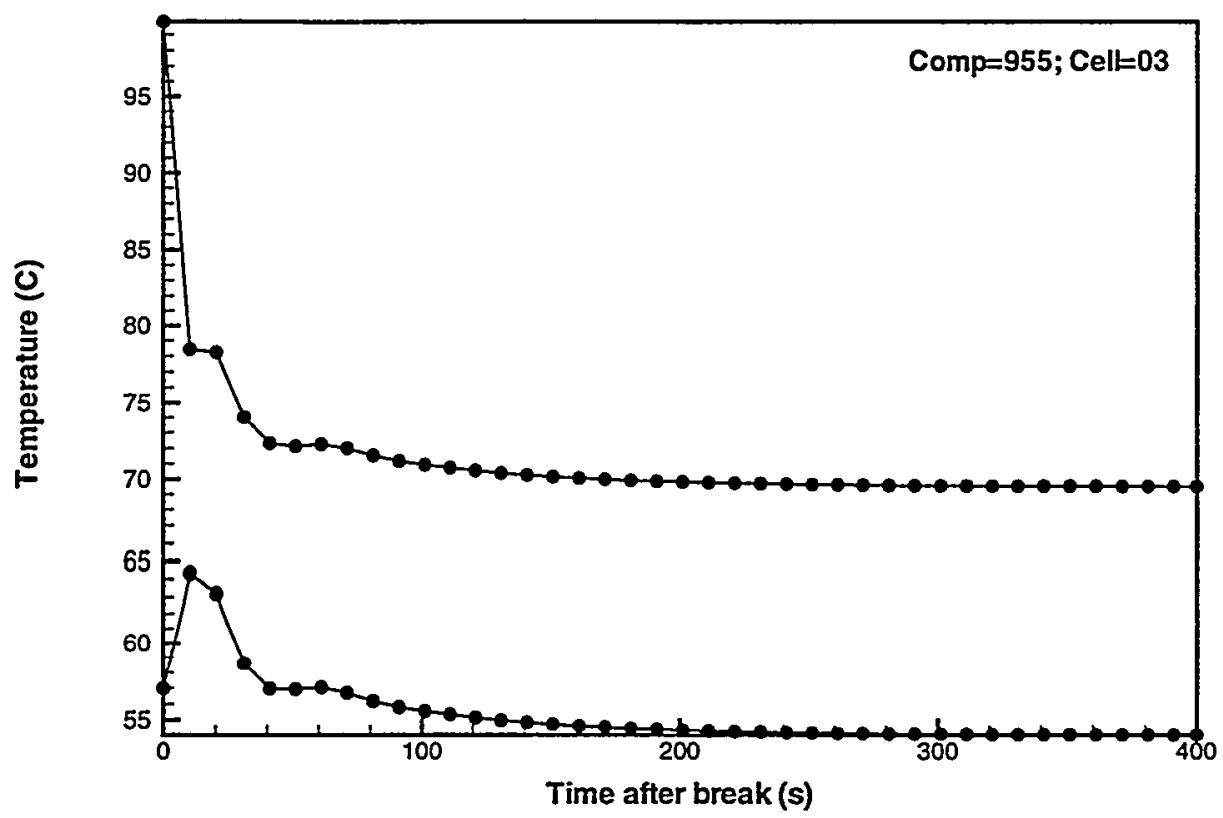

Figure B-44 Module 2 upflow section mid-plane surface and fluid temperatures for NO (False transient to establish steady-state).

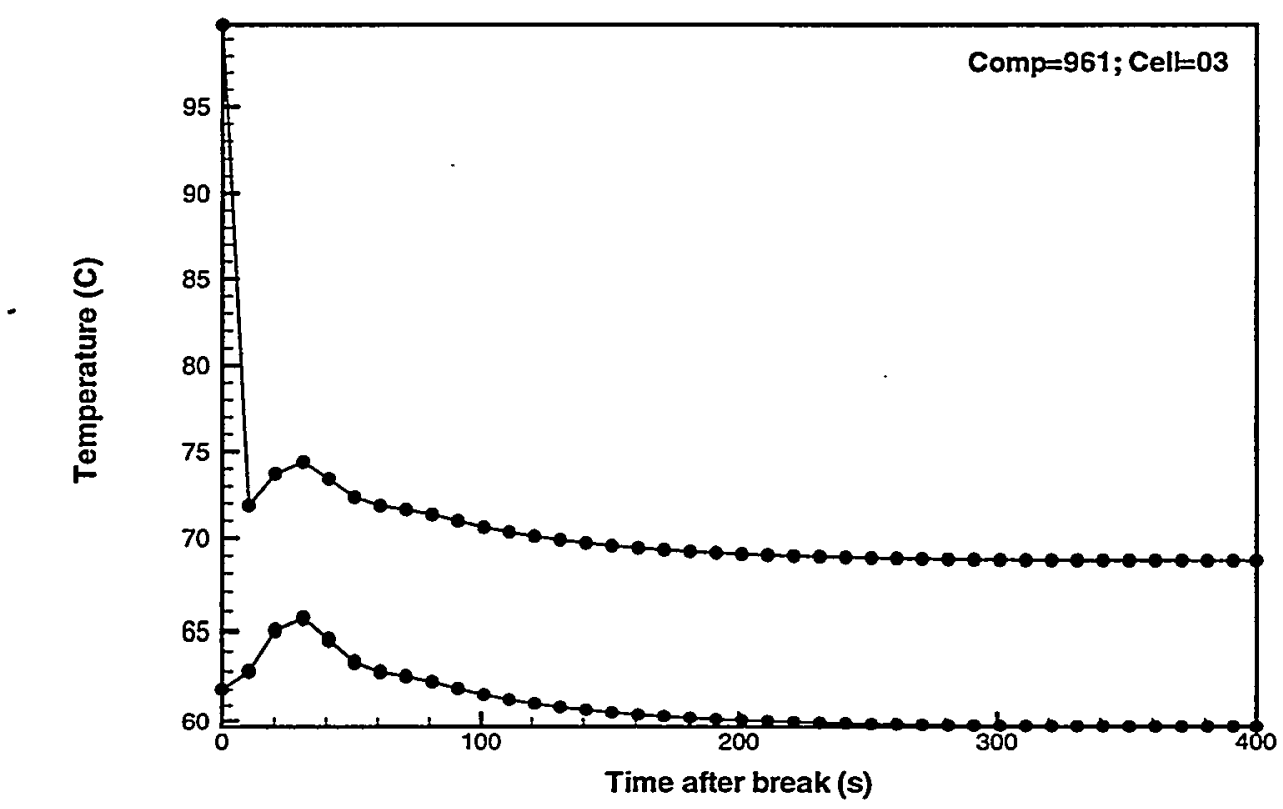

Figure B-45 Module 3 upflow section mid-plane surface and fluid temperatures for NO (False transient to establish steady-state). 


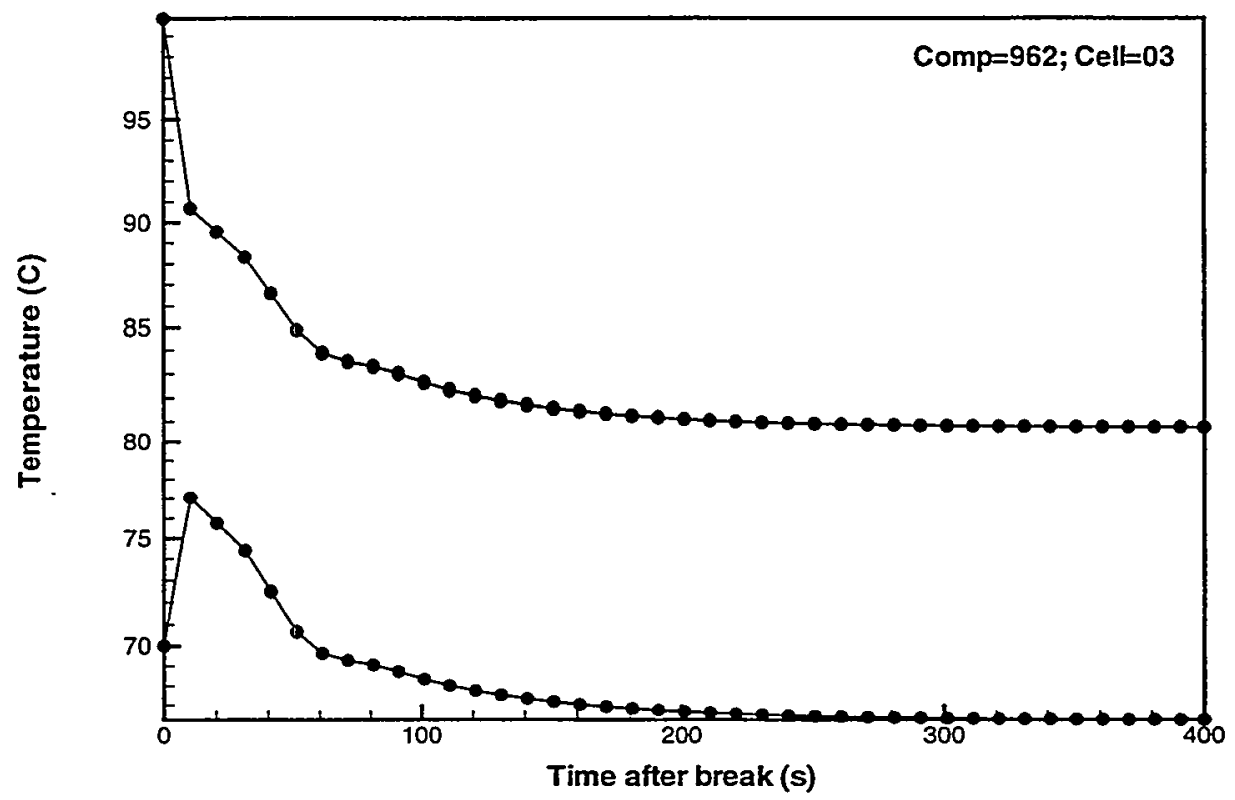

Figure B-46 Module 4 upflow section mid-plane surface and fluid temperatures for NO (False transient to establish steady-state).

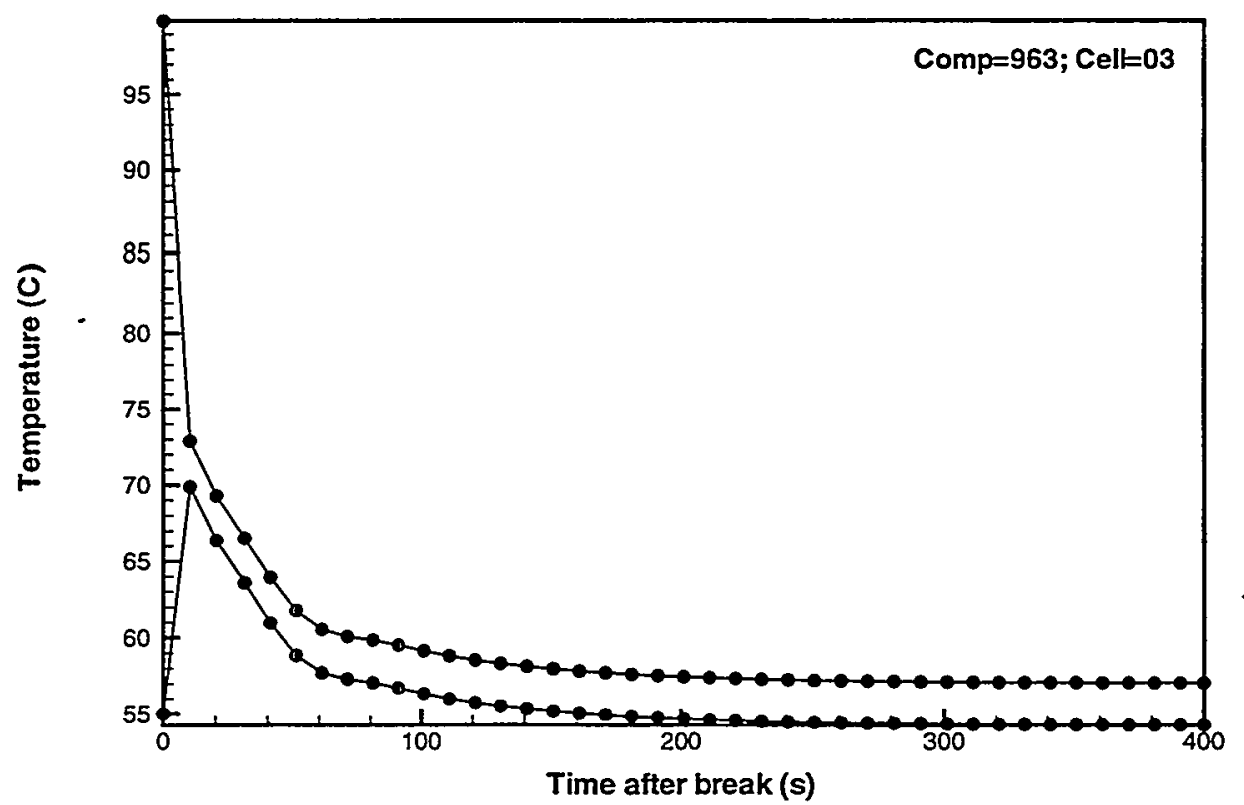

Figure B-47 Module 5 upflow section mid-plane surface and fluid temperatures for NO (False transient to establish steady-state). 


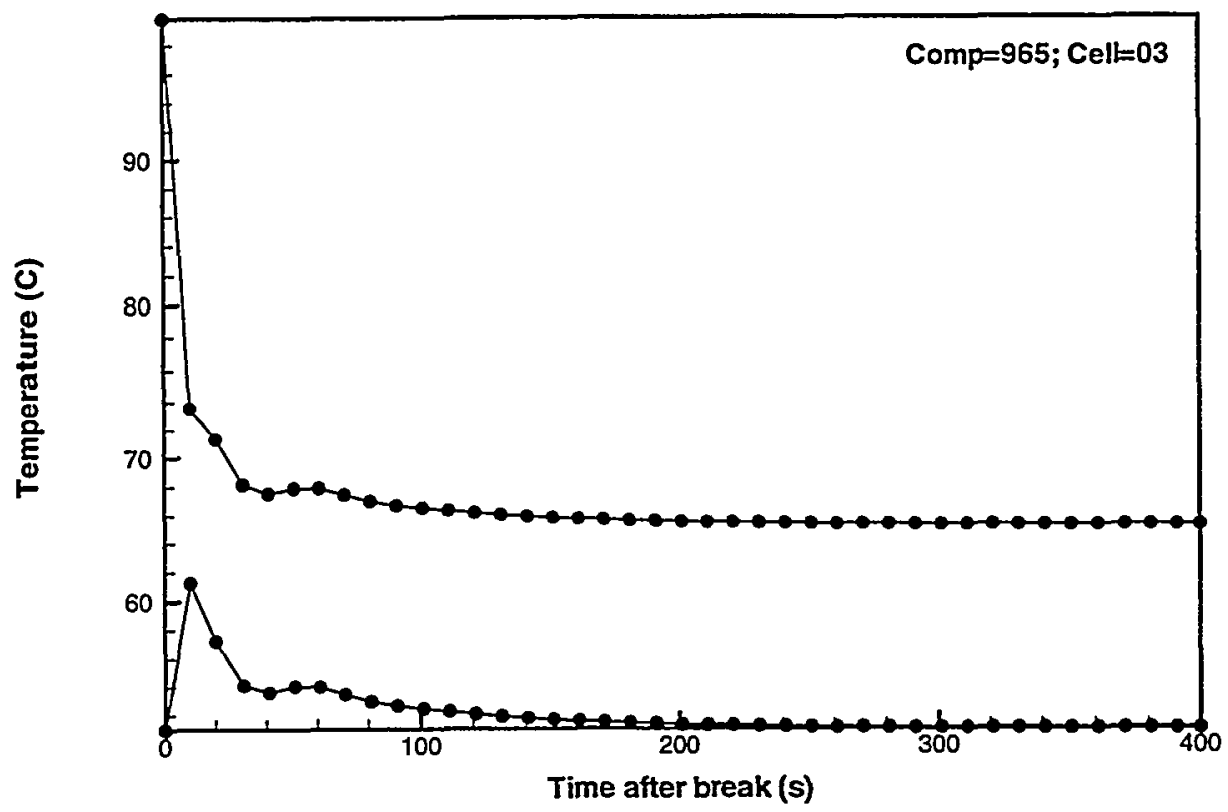

Figure B-48 Module 6 upflow section mid-plane surface and fluid temperatures for NO (False transient to establish steady-state).

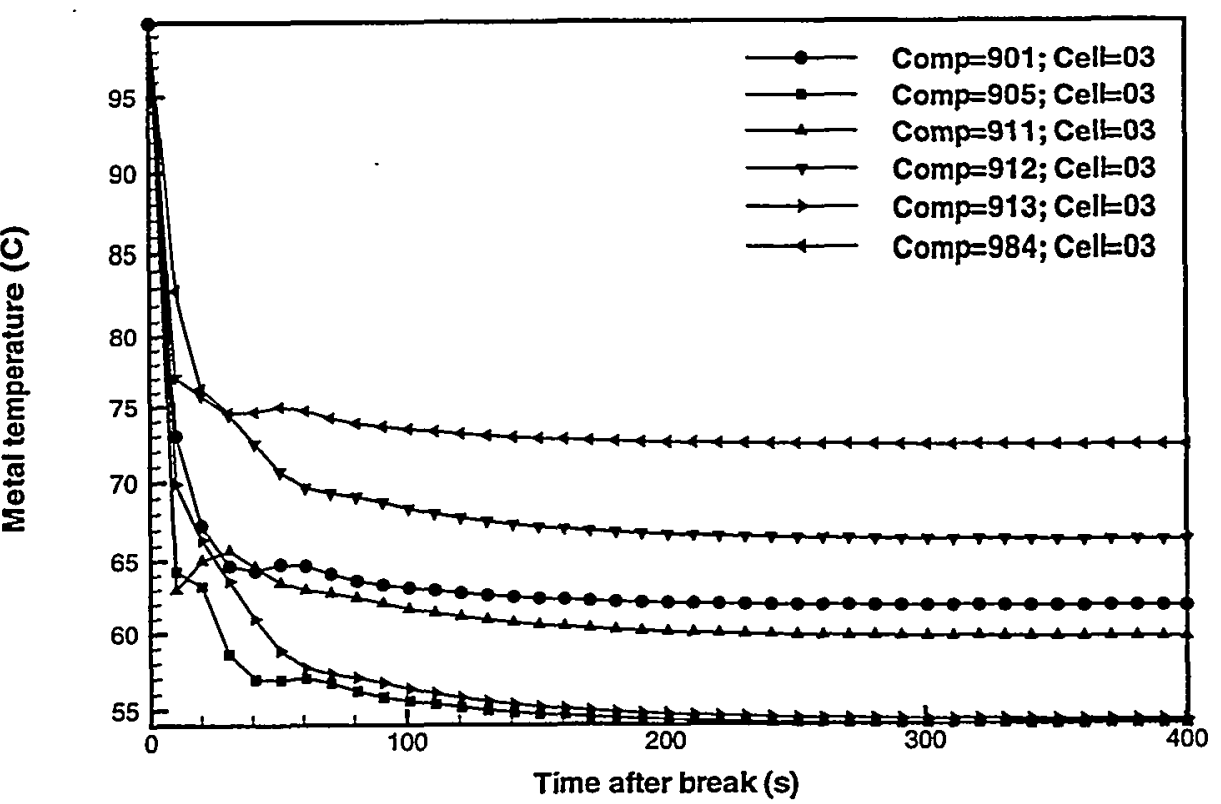

Figure B-49a Metal temperatures for various module outer aluminum surfaces at their mid-plane for NO (False transient to establish steady-state). 


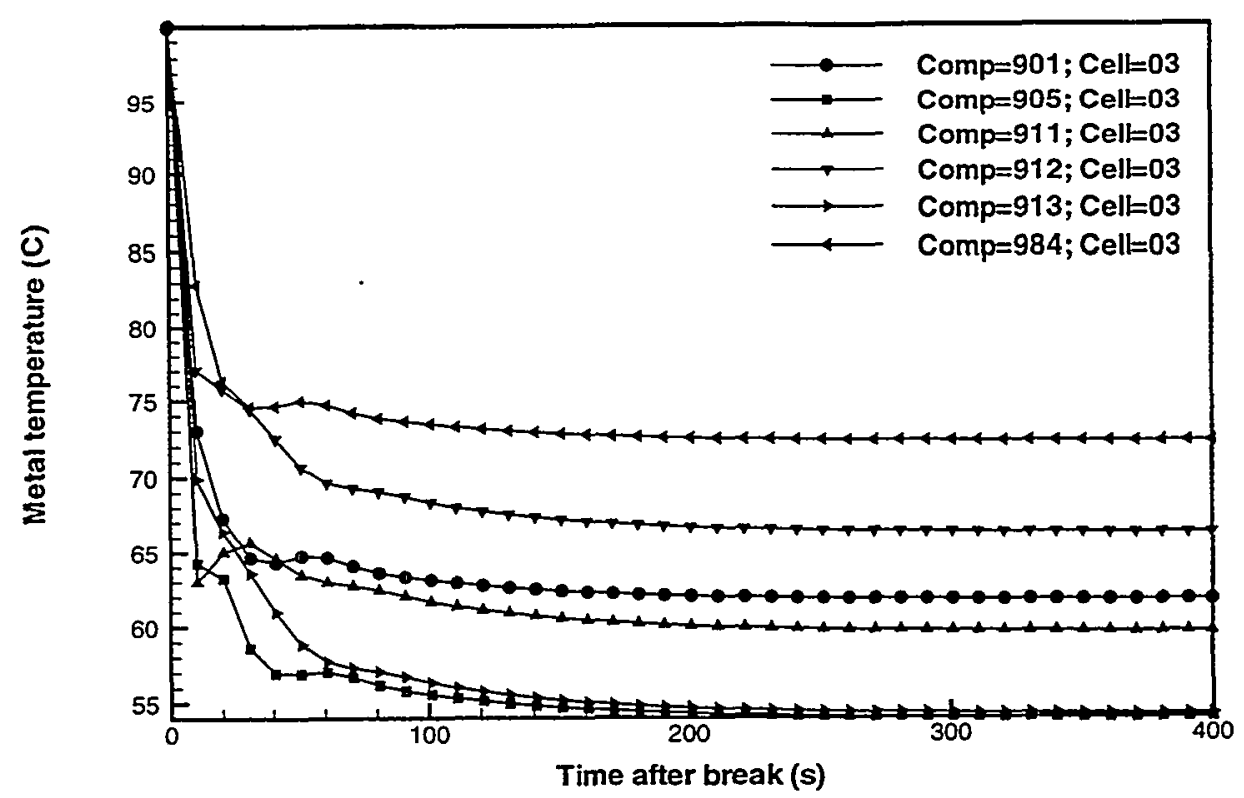

Figure B-49b Metal temperatures for various module outer aluminum surfaces at their mid-plane for NO (False transient to establish steady-state). 


\section{Appendix C: TRAC Standard Input File for Normal Operation Case}

The file listed below represents the entire TRAC code "tracin" file that corresponds to the normal operation case for the blanket system, all of its primary heat removal (HR) and residual heat removal (RHR) piping components, its six lumped modules, the cavity vessel, and the cavity flood system. This input deck provides the nominal design basis case for normal operation (NO) and the TRAC restart file ("trcrst") for all design basis accidents (DBAs) considered.

Input file tracin:

- See Ref. [1] for complete listing of input deck - 


\section{Appendix D: TRAC Graphics Input File for Normal Operation Case}

The file listed below represents the TRAC code "graphin" file that contains the various graphics points selected for output to the "tecsum.grf" file. Modifications were made to the TRAC code standard output routines in order to generate an ASCII output file called "tecsum.grf". This output file contains results at each requested graphic point (i.e., TRAC component and specified cell number) written out at a specified time frequency.

Input file graphin:

- See Ref. [1] for complete listing of input deck - 
WESTINGHOUSE SAVANNAH RIVER COMPANY

BLANKET SYSTEM NORMAL OPERATION
Report: WSRC-TR-98-0057

Section:

Date:

Page:
Appendix D

07/13/98

(This Page Intentionally Left Blank) 


\section{Appendix E: FLOWTRAN-TF Standard Input File for Normal Operation Case}

The file listed below represents an annotated FLOWTRAN-TF code input file that corresponds to the normal operation case for the module 1 plate-type bin (i.e., reference 1 lateral Row 1 module). The solid and fluid geometric input has been deleted and can be seen in Ref. [10].

\section{Input file apt.in:}

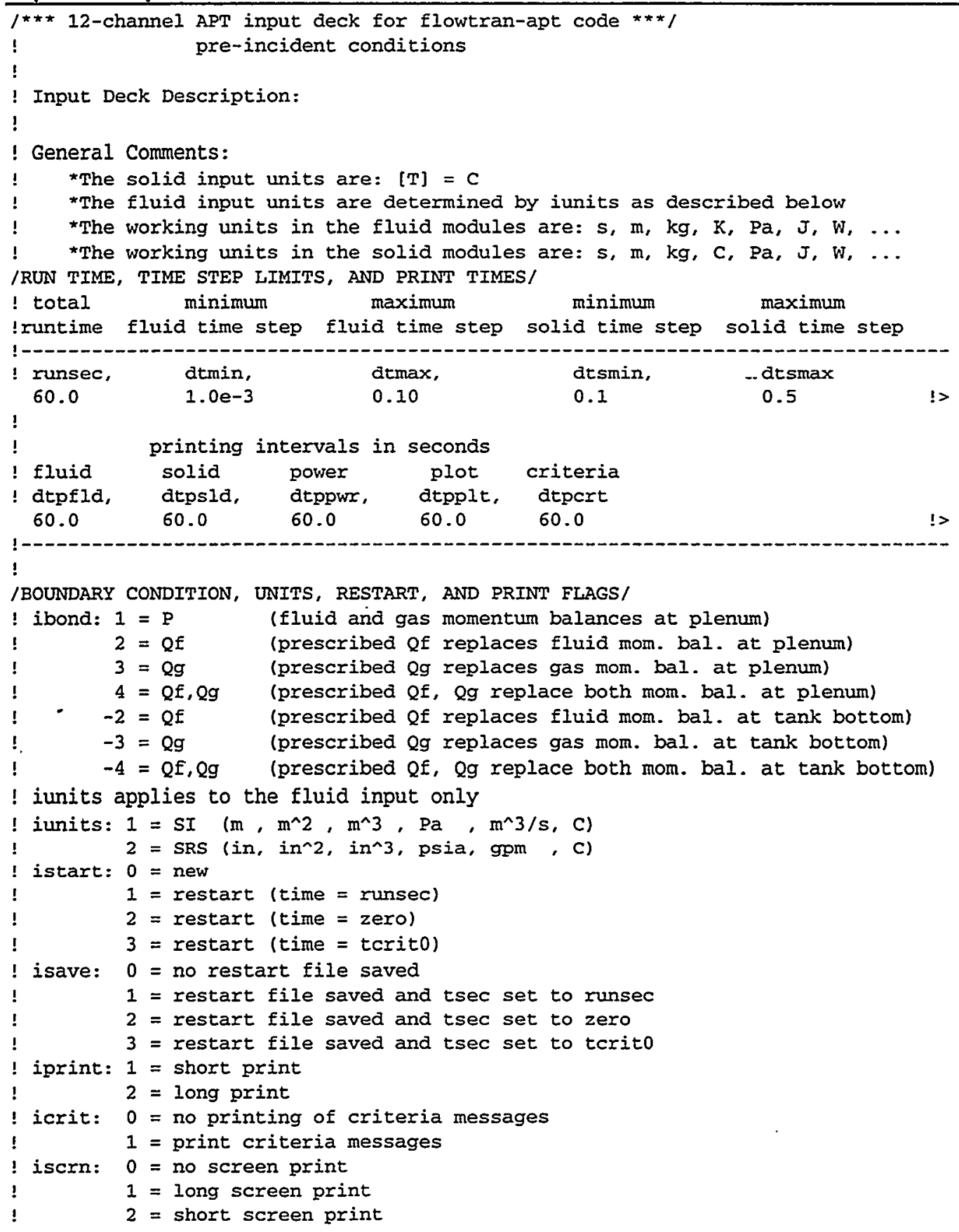




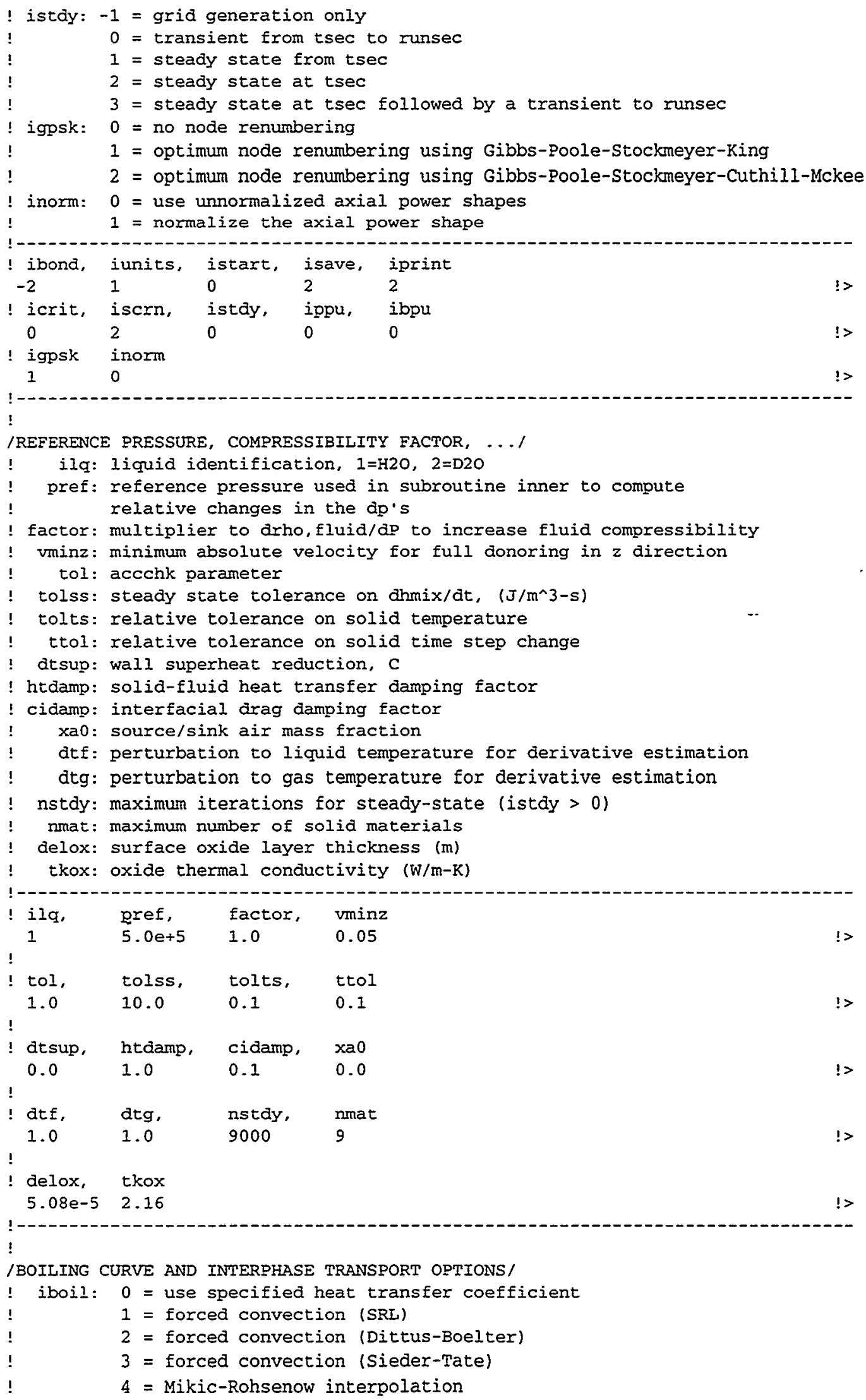




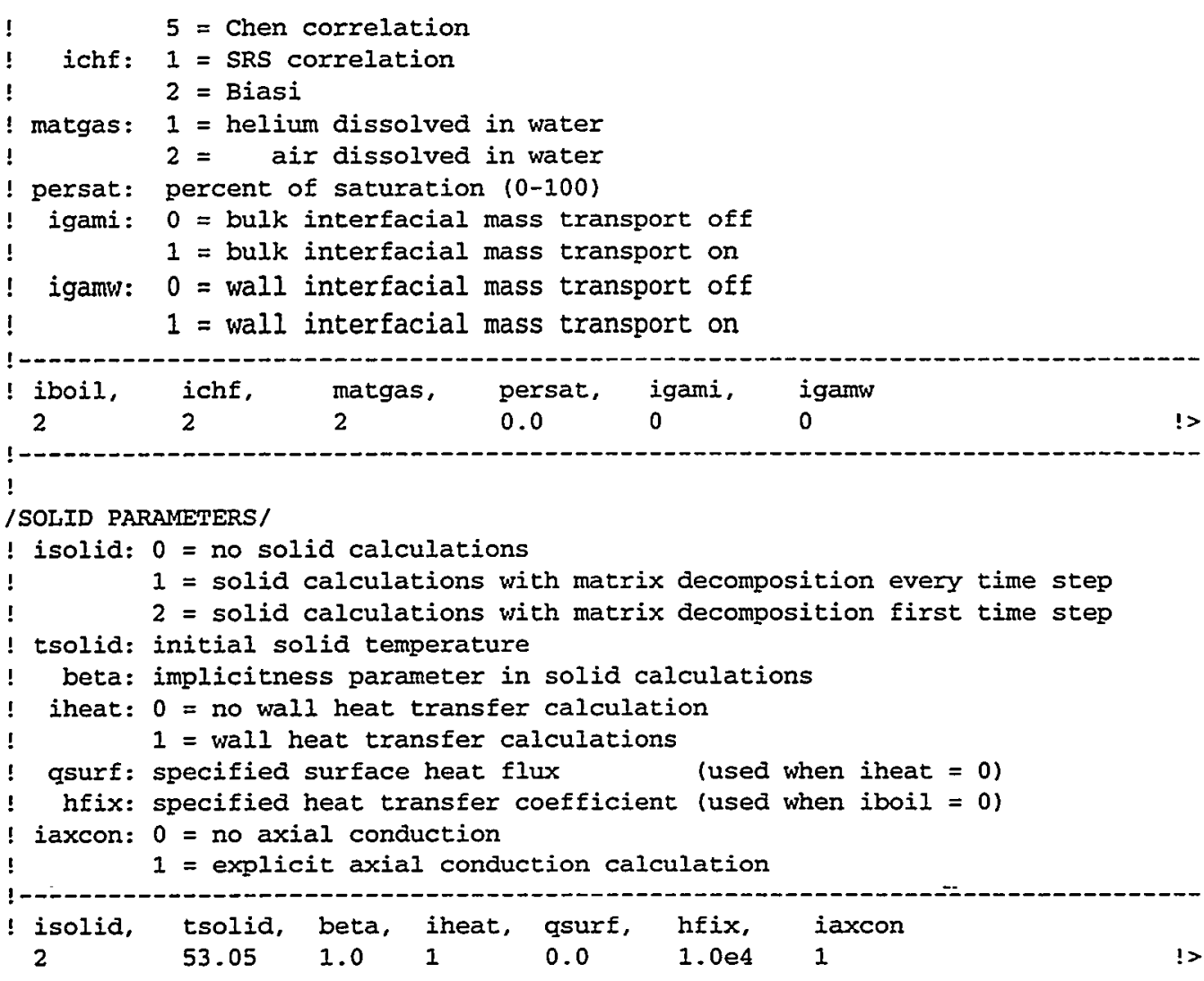

!

/INNER ITERATION OPTIONS \& NEWTON ITERATION PARAMETERS/

! irebal: $0=$ no coarse mesh rebalance

1 = coarse mesh rebalance on first pass

2 = coarse mesh rebalance on each pass

ncmr: number of coarse mesh rebalances when irebal $=1$ or 2

epsin: inner iteration convergence criterion for relative dp error

! initmx: max. number of inner iterations allowed

epsp: newton iteration convergence criterion for absolute $\mathrm{p}$ error in $\mathrm{Pa}$

! epsalp: newton iteration convergence criterion for absolute alp error epstg: newton iteration convergence criterion for absolute tg error in $\mathrm{k}$ epstf: newton iteration convergence criterion for absolute tf error in $k$ epsxa: newton iteration convergence criterion for absolute xa error

nitmax: |nitmax| = max. number of newton iterations allowed

! If nitmax is positive and $\mid$ nitmax| iterations are reached, then then computations continue using the mth iterate values from the |nitmax| iteration.

If nitmax is negative and |nitmax| iterations are reached, then a new time step with a time step reduction is requested.

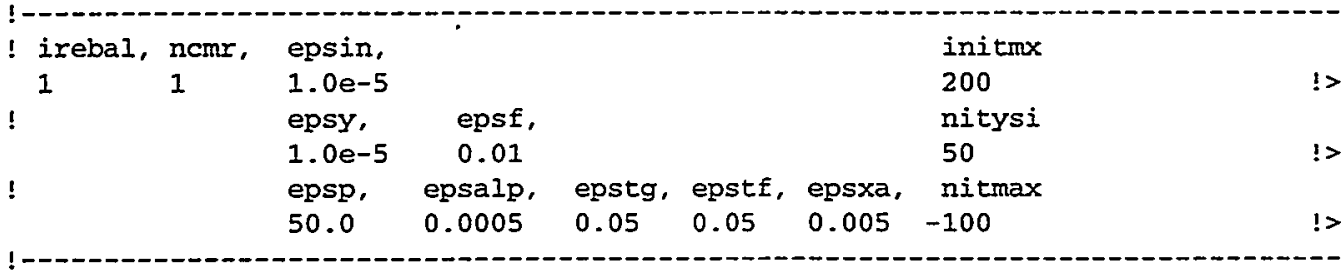

/NUMBER OF SPLINE PROFILES AND DATA POINTS/

! ndata: number of data groups

! itime: number of time snapshots for axial power profiles 
Solid mesh input for finite element regions, nodes and side boundary conditions is identical to that shown in Ref. [10] 
Fluid geometry input is identical to that shown in Ref. [10]

FLUID GEOMETRY AND MOMENTUM CLOSURE INPUT SECTION

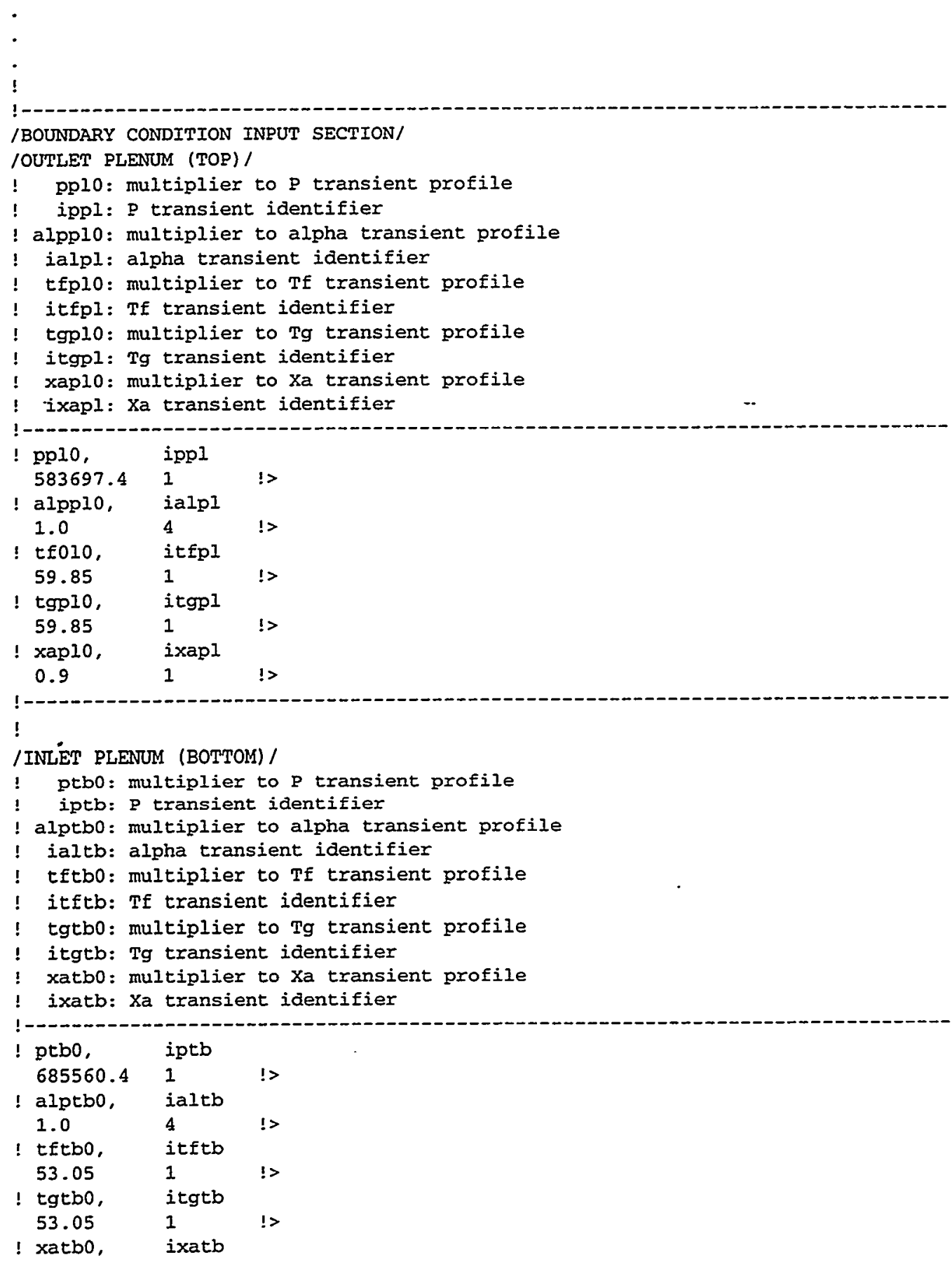




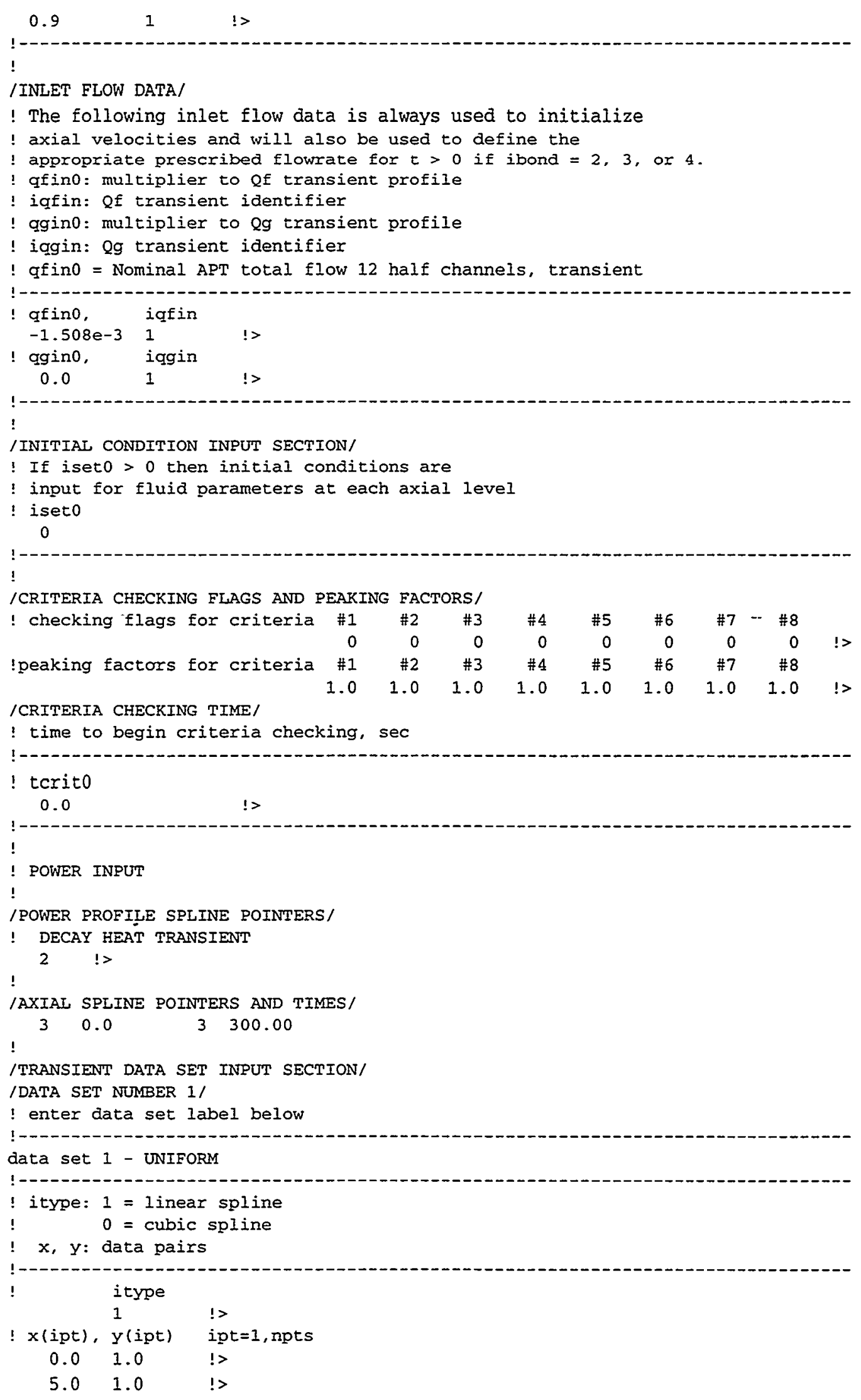


WESTINGHOUSE SAVANNAH RIVER COMPANY

BLANKET SYSTEM NORMAL OPERATION
Report: WSRC-TR-98-0057

Section: Appendix E

Date:

$07 / 13 / 98$

Page:

7 of 8

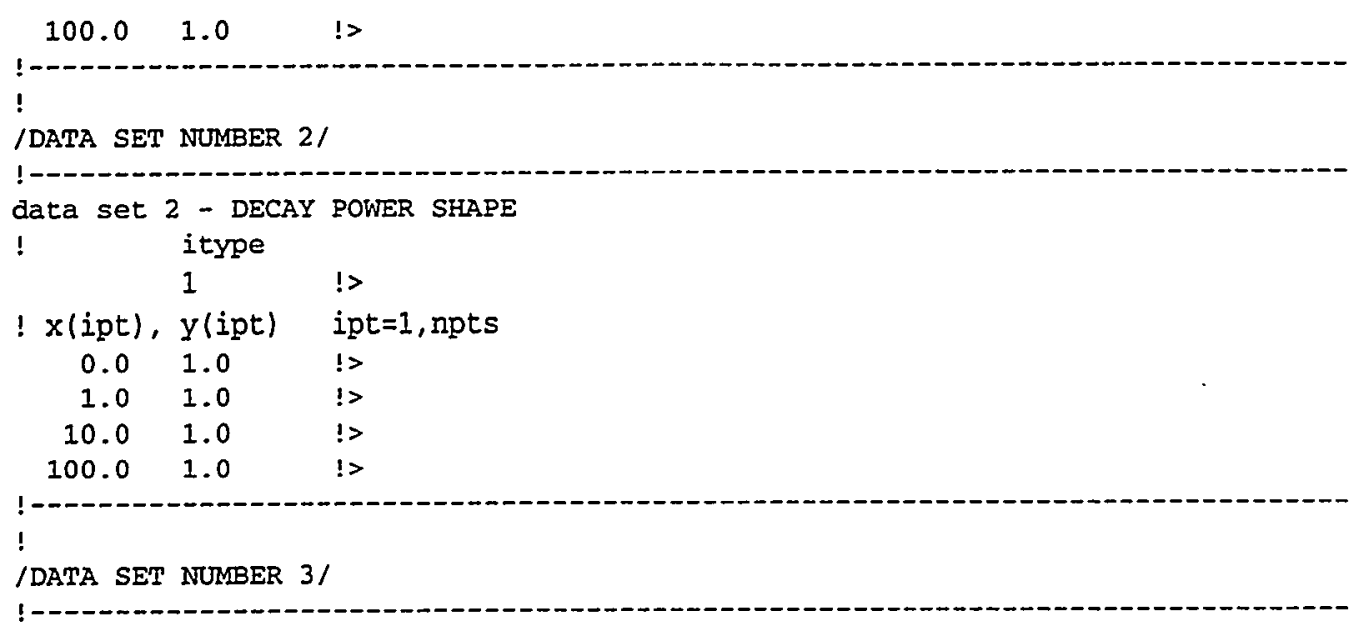

data set 3 - NON-UNIFORM AXIAL POWER PROFILE

!

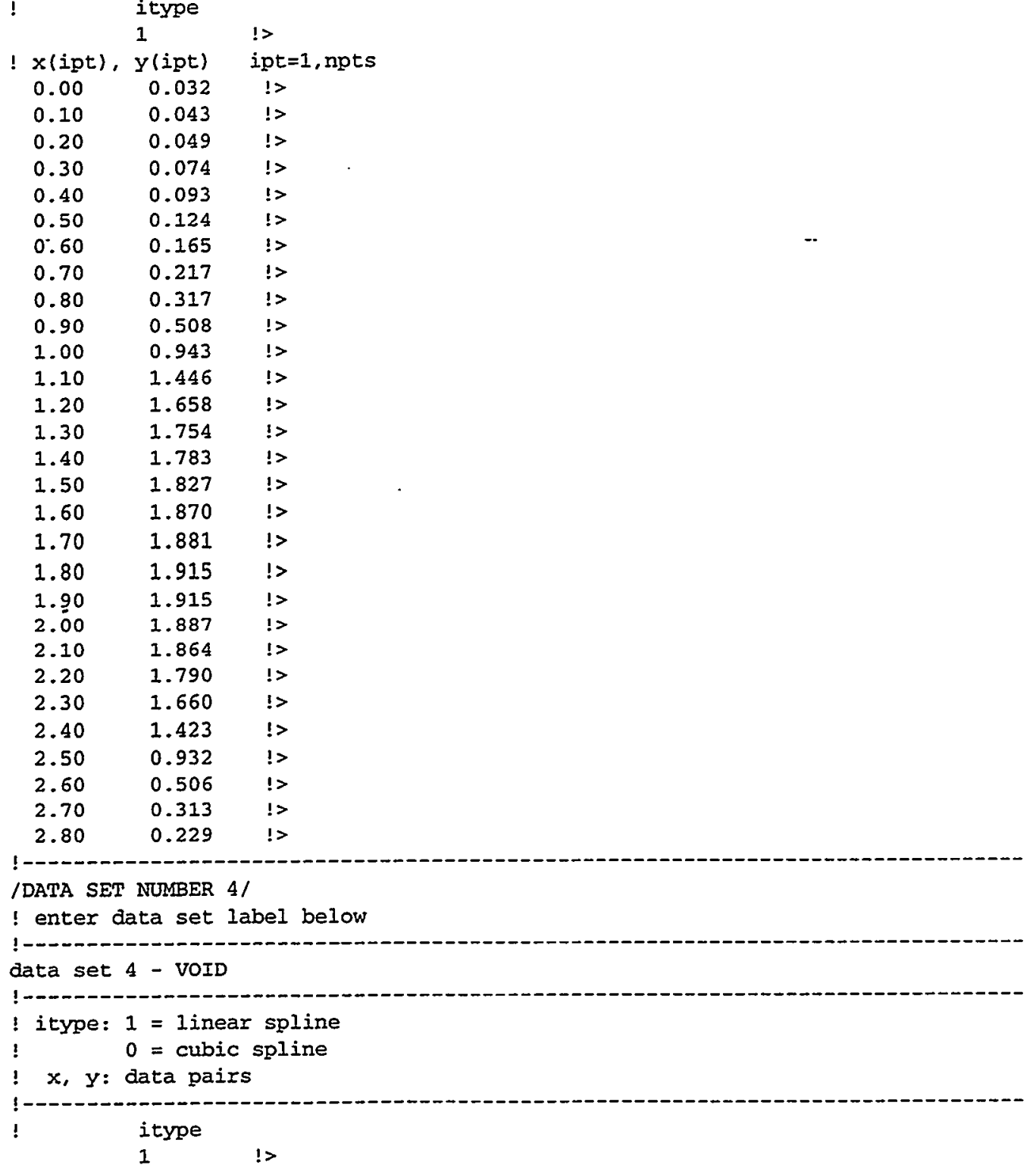


! x(ipt), y(ipt) ipt $=1$, npts

$0.0 \quad 0.0$

!>

$\begin{array}{ll}5.0 & 0.0\end{array}$

!>

$100.0 \quad 0.0$

!> 